Portland State University

PDXScholar

Spring 5-9-2014

\title{
Adult Returning Students and Proportional Reasoning: Rich Experience and Emerging Mathematical Proficiency
}

Ann Sitomer

Portland State University

Follow this and additional works at: https://pdxscholar.library.pdx.edu/open_access_etds

Part of the Higher Education Commons

Let us know how access to this document benefits you.

\section{Recommended Citation}

Sitomer, Ann, "Adult Returning Students and Proportional Reasoning: Rich Experience and Emerging Mathematical Proficiency" (2014). Dissertations and Theses. Paper 1794.

https://doi.org/10.15760/etd.1793

This Dissertation is brought to you for free and open access. It has been accepted for inclusion in Dissertations and Theses by an authorized administrator of PDXScholar. Please contact us if we can make this document more accessible: pdxscholar@pdx.edu. 
Adult Returning Students and Proportional Reasoning:

Rich Experience and Emerging Mathematical Proficiency

by

\section{Ann Sitomer}

A dissertation submitted in partial fulfillment of the requirements for the degree of

\section{Doctor of Philosophy}

in

Mathematics Education

Dissertation Committee:

Karen Marrongelle, Chair

Gary Brodowicz

Helen Burn

Swapna Mukhophadthay

Jennifer Noll

Eva Thanheiser

Portland State University 2014 


\begin{abstract}
This study explores adult returning students' mathematical experience and ways of thinking prior to enrolling in a community college arithmetic review course. It further examines one student's experience of the course. The first part of the study documents everyday activities adult students perceive as mathematical using Bishop's pan-cultural mathematical activities (Bishop, 1994), and queries students' prior experience with mathematics in school. The second part examines students' ways of thinking about proportion prior to instruction, using a framework developed from previous research (e.g., Lamon, 1993). The third part of the study examines the interaction between informal ways of thinking about mathematics that adult students bring to school and the mathematics they encounter in the classroom. Findings include: (1) Adult students view a variety of activities from their everyday lives as mathematical, (2) adult students' reasoning about proportional situations varies along a developmental trajectory described in previous research on proportional reasoning conducted with younger students, and (3) one student's experience in the arithmetic review course illustrates that she typically suppressed contextual ways of reasoning about problems she brought to the course and, when she did share prior experience, it was not leveraged to support the development of her and other students' mathematical understanding. These findings suggest that adult students' experience of everyday mathematics and ways of thinking about proportion should be the foundation that support students as they build upon informal ways of thinking toward the more formal ways of reasoning expected in school.
\end{abstract}




\section{Table of Contents}

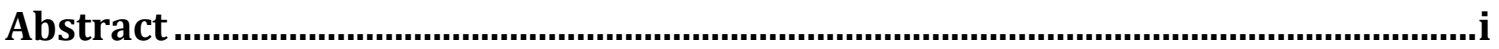

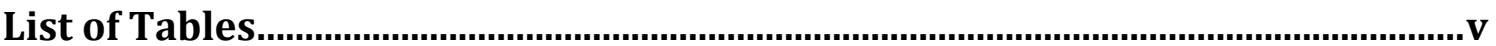

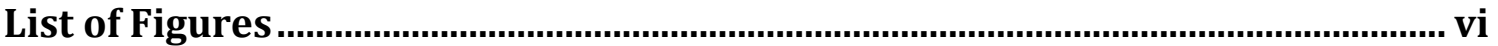

Chapter 1: Introduction and Rationale for the Study........................................... 1

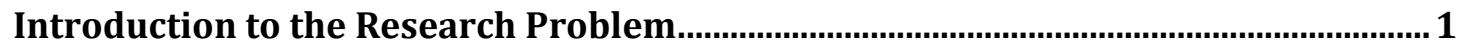

Developmental Mathematics at Community Colleges ….............................................. 2

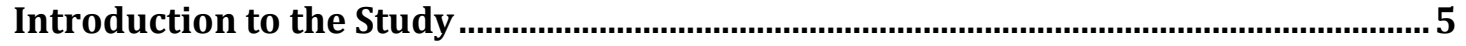

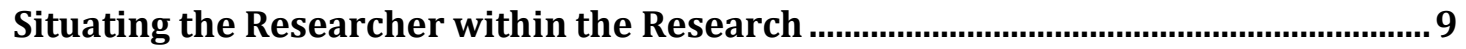

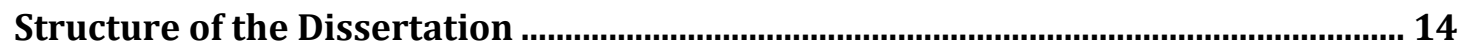

Chapter 2: Conceptual Framework and Literature Review ...............................15

Out-of-School Mathematical Practices ……......................................................................... 17

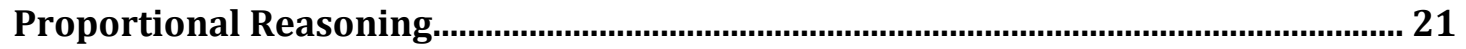

Differences between Mathematical Activity in School and Outside of School ......... 34

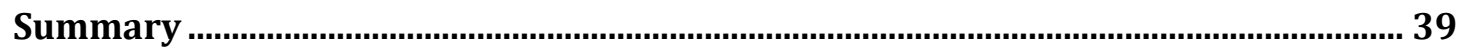

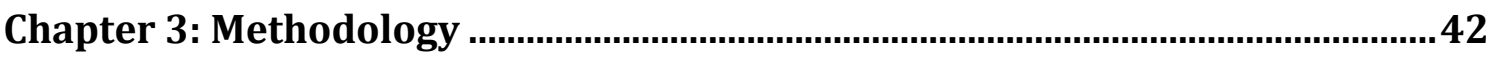

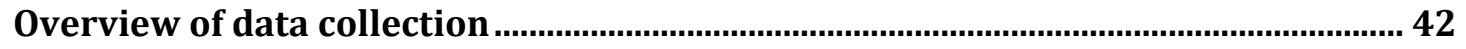

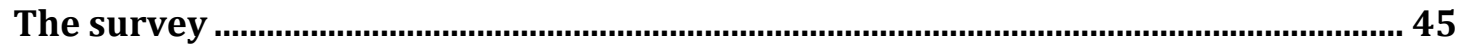

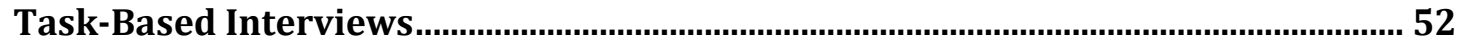

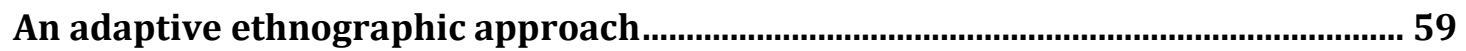

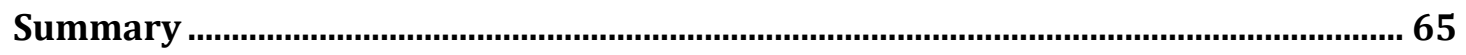

Chapter 4: The Students and Their Mathematical Experience ...........................66 


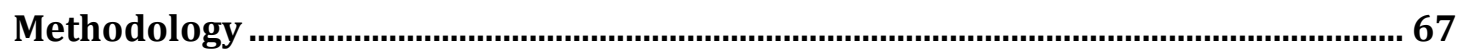

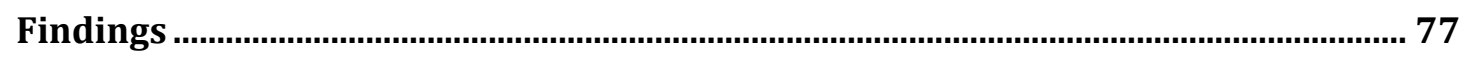

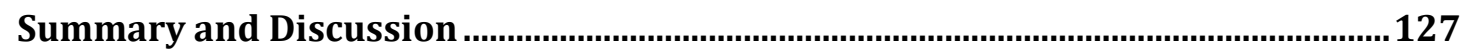

Chapter 5: Proportional Reasoning..................................................................... 134

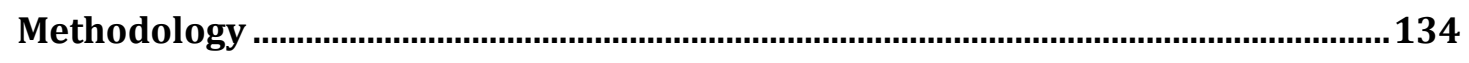

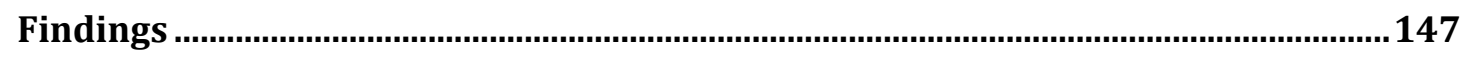

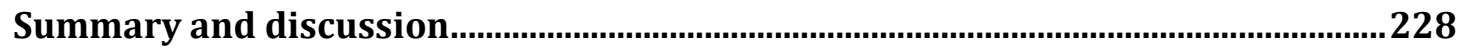

Chapter 6: Sasha's Story ……............................................................................ 236

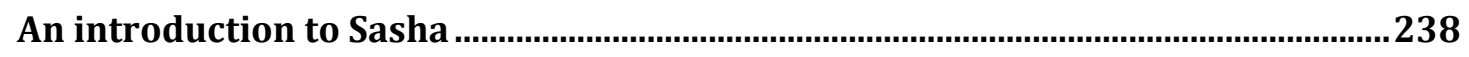

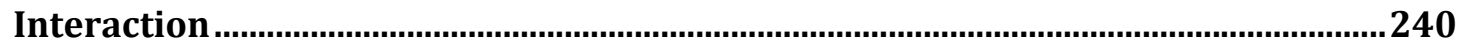

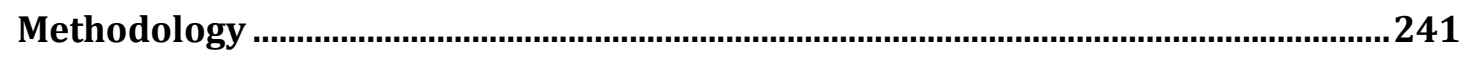

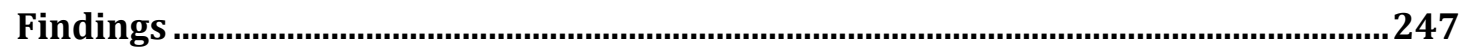

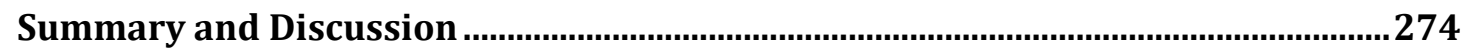

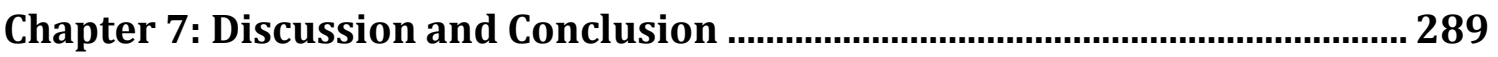

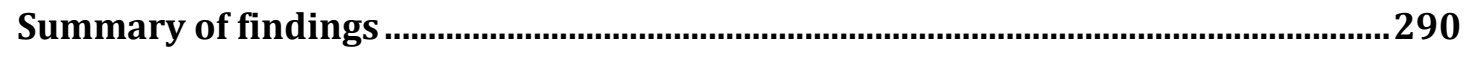

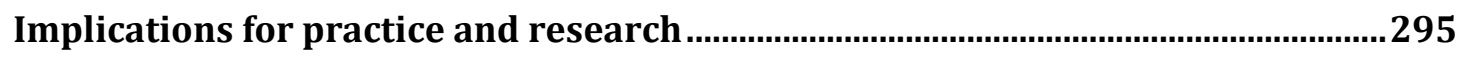

Advancing a research agenda in community college mathematics education .......298

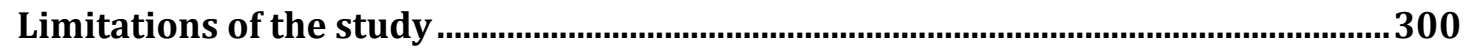

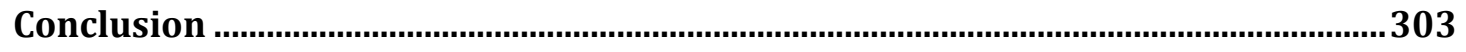

References......................................................................................................... 304

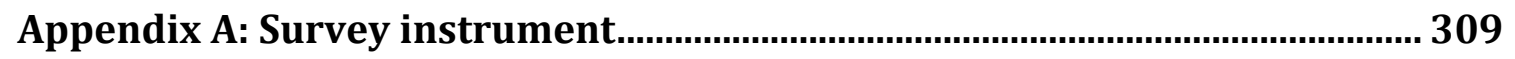

Appendix B: Interview protocol .................................................................... 313 
Appendix C: Mathematical tasks from the survey and interview ...................... 320

Appendix D: Preliminary findings from the survey data ................................. 322 


\section{List of Tables}

Table 1: Relationship between research questions and collected data..................9

Table 2: $\quad$ Ways of reasoning or understanding proportions..........................28

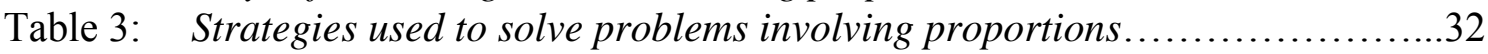

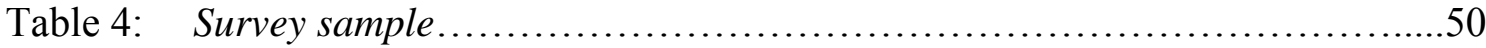

Table 5: Survey sample......................................................68

Table 6: Activities adult students perceive as mathematical categorized using Bishop's pan-cultural mathematical activities.....................................87

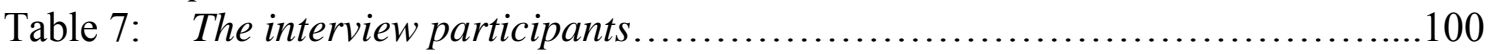

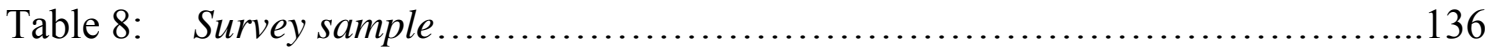

Table 9: Examples each strategy in the four-strategies framework.................142

Table 10: Examples of Correct, Valid and Invalid solutions from Flower Stem problem.............................................................145

Table 11: Surveyed students' overall performance on the four mathematical tasks on the survey..................................................148

Table 12: Students' strategies on the Flower Stem problem........................150

Table 13: Students' strategies on the Percent Discount problem .......................150

Table 14: Students' strategies on the Bread Flour problem.........................151

Table 15: Students'strategies on the Comparing Speeds problem...................152

Table 16: Adaptation of the framework from Lembke and Reys......................203

Table 17: Surveyed students' correct primary strategies on the Percent Discount problem......................................................205

Table 18: Surveyed students' incorrect primary strategies on the Percent Discount problem........................................................205

Table 19: Interview participants' understanding of an 18\% tip................................208

Table 20: The variety of interview participants' strategies and understandings of percent...............................................................215 


\section{List of Figures}

Figure 1: Schematic of conceptual framework....................................16

Figure 2: Comparison of learners' ages between sample of Basic Math students surveyed and the population of students enrolled through fourth week of quarter........................................................... 79

Figure 3: Time away from school mathematics................................... 80

Figure 4: Experiences prior to attending the community college.....................81

Figure 5: An iterated-composed-unit strategy on the Flower Stem problem............153

Figure 6: An iterated-composed-unit strategy on the Bread Flour problem............154

Figure 7: A student builds up the unit 8 miles in 10 minutes in order to compare Victor's speed to Sharon's...........................................156

Figure 8: A student partitions the unit representing Sharon's speed and then builds up this new unit to compare Sharon's speed to Victor's.......................156

Figure 9: A student interprets the factor of five in the Flower Stem problem...........159

Figure 10: A student interprets the scalars in the Bread Flour problem.................159

Figure 11: Scalar reasoning on the Comparing Speeds problem.....................160

Figure 12: An example of one student's difficulty with reasoning using unit rates on the

Comparing Speeds problem....

Figure 13: A student uses an emerging understanding of percent as rate and a buildingup strategy on the Percent Discount problem............................ 163

Figure 14: A student uses an emerging understanding of percent as rate along with scalar reasoning..................................................163

Figure 15: Ruby's written work on the Bread Flour problem prior to the interview....171

Figure 16: Ruby's ICU and scalar strategies on the Bread Flour problem..............172

Figure 17: Sample BU strategy considered by interview participants..................175

Figure 18: Sasha's written work on the first variation of the Bread Flour problem.....175

Figure 19: Written record of Ruby's reasoning on the Better Buy problem..............178

Figure 20: Written record of Sasha's thinking on the first variation of the Flower Stem problem.........................................................181

Figure 21: Andrea's written work on the Comparing Speeds problem..................191

Figure 22: Ms. Rose's first percentage table....................................210

Figure 23: Two types of multiplicative relationships between quantities in a proportion......................................................230

Figure 24: Unpacking the formula $A=R B$ by building on students' understanding $\ldots 231$

Figure 25: Configuration of Sasha's classroom..................................257

Figure 26: Table used to write a proportion equation.............................261

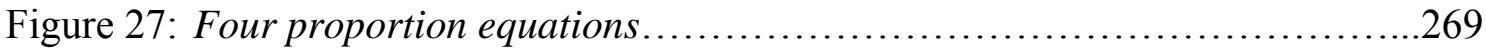

Figure 28: Sasha's solution...................................................269

Figure 29: My mathematization of a problem from photography posed by Sasha.......274 


\section{Chapter 1: Introduction and Rationale for the Study}

"As far back as I can remember I have struggled with math and because of these struggles I just give up. I think it is because I have a strange way of figuring things out. For example, it seems easier for me to do things the long way like percentages. I know what ten percent of most numbers are, so what I do is figure that out, then I do ten percent of ten percent which of course is one percent of the original number."

(A statement written for a class assignment by Jerome, a community college student repeating a developmental mathematics class.)

\section{Introduction to the Research Problem}

Adult students return to school with diverse life experiences that influence their academic work in a variety of ways. In some academic disciplines students are asked to reflect upon these experiences and to use these reflections as a source of new learning. But when entering a mathematics class for the first time in several years many students leave their life experience at the door; often the only experience that comes to bear on a student's work in a mathematics classroom is a distant and often unpleasant memory of school mathematics.

On the other hand, the mathematical knowledge embedded in the activities that constitute adults' lives has been researched in a variety of contexts, revealing the prevalence of situated ways of mathematical knowing. Typically, mathematical activity outside of school bears little resemblance to the mathematics encountered in classrooms. Yet when adult students return to school they take placement tests that measure what they do or do not remember about school mathematics. These tests place many returning students in developmental mathematics classes. According to the Intuitional Research office at the community college where the study was conducted, one-third of the 
students taking the placement test place into a Basic Math ${ }^{1}$ course (L. Massey, personal communication, February 2014) $)^{2}$. However, evidence from the research on adults' mathematical activities outside of school (discussed in detail in Chapter 2) suggests that adult students return to school with mathematical abilities that may not be measured by current placement tests. If this is the case, two initial questions emerge:

- How can adult students' mathematical abilities be identified and utilized in the classroom?

- How can developmental mathematics courses be adapted to the needs and mathematical abilities of adult returning students?

In the remainder of this chapter, I examine some of the current discussion about developmental mathematics education at community colleges, introduce my study and my own positionality with respect to this study, and conclude with a discussion of the rationale for this work.

\section{Developmental Mathematics at Community Colleges}

It is an exciting time for developmental mathematics and mathematics education in general at community colleges. A few years ago the discourse about developmental mathematics education was discouraging. Treisman (2011) characterized developmental mathematics at community colleges as an "academic graveyard" for many students. For example, Bailey (2009) documented that only $31 \%$ of students who are referred to developmental mathematics complete the sequence of courses. The statistics about

\footnotetext{
${ }^{1}$ Basic Math is a course that reviews a variety of arithmetic topics, including fractions, decimals and percentages. The course is a prerequisite for introductory algebra and is consistent with the level of mathematics studied in middle school.

${ }^{2}$ Institutional data is used instead of national data on placement into developmental mathematics, because that national data does not distinguish placement into an arithmetic review course from placement into a mathematics course one level below college level mathematics.
} 
retention remain bleak, but substantial changes are beginning to take place in the developmental mathematics curriculum. Traditionally, the developmental mathematics curriculum was aligned with the curriculum from middle school through a second course in algebra with the year of geometry excluded; the topics in this curriculum would typically be covered over three semesters rather than three years or more. The developmental mathematics curriculum prepared students for college algebra, precalculus and calculus. However, recent developments focus on providing alternative to the STEM pathway by developing curricula for courses in quantitative and statistical literacy (e.g., the work being done by the Carnegie Foundation for the Advancement of Teaching ${ }^{3}$ and the Dana Center at the University of Texas Austin ${ }^{4}$ ). The Developmental Mathematics committee the American Mathematics Association of Two-Year Colleges (AMATYC) is rethinking the traditional developmental mathematics sequence by developing courses that focus on algebraic literacy rather focusing on procedures ${ }^{5}$. These curriculum projects are also transforming the ways community college mathematics faculty members approach their work. For example, the focus of the recently completed project, Rethinking Pre-College Mathematics ${ }^{6}$, was faculty learning around student learning, curricular innovations and changes in instructional practice. In addition, the Scaling Innovation project at the Community College Research Center at Columbia University ${ }^{7}$, is undertaking research on faculty learning around innovations in developmental education. These initiatives in developmental mathematics education

${ }^{3} \mathrm{http}: / /$ www.carnegiefoundation.org/developmental-math

${ }^{4} \mathrm{http}: / / \mathrm{www} \cdot$ utdanacenter.org/higher-education/new-mathways-project/new-mathways-projectcurricular-materials/

5 https://sites.google.com/site/amatycdmc/

${ }^{6}$ http://transitionmathproject.org/index.php/projects/detail/rethinking-pre-college-math-in-washingtoncolleges 1

${ }^{7} \mathrm{http} / / / \mathrm{ccrc} . t c . c o l u m b i a . e d u /$ research-project/scaling-innovation.html 
were the focus of the recent National Summit on Developmental Mathematics held October 2013 prior to the annual meeting of AMATYC.

Research on teaching and learning mathematics at community colleges is an emerging domain within mathematics education research (Mesa, Wladis, \& Watkins, 2014; Sitomer et al., 2012). Members of AMATYC's Research Committee and other community college researchers and practitioners formed a working group, which has convened at the 2011-2014 annual conferences of a special interest group of the Mathematical Association of America, Research in Undergraduate Mathematics Education (RUME). The initial goal of the group was to establish a research agenda in community college mathematics education. This work required that community college researchers and practitioners make the case that mathematics teaching and learning at community colleges is different from both K-12 mathematics education and research undertaken by members of the RUME community. This distinction is becoming well established (Mesa et al., 2014) and developmental mathematics at community colleges is one of these distinguishing factors: "Although developmental coursework is not the only feature of the community college environment that sets it apart from other institutions of higher learning, it is a key part of what must be studied if we are to understand the learning and educational trajectories of community college mathematics students" ( $p$. 175). In addition, Mesa and her colleagues observe that little is known about the learning trajectories of students in a community college mathematics classroom: "For example, do adults follow similar learning trajectories as children when learning about fractions (or other mathematical topics taught in school mathematics)? What are typical mathematical misconceptions that community college students (including adults who 
have had a gap in schooling) possess, how do these misconceptions manifest, and how do they change as students engage in learning remedial mathematics?" (p. 182).

Changing perspectives on the developmental mathematics curriculum and an emerging focus on research on teaching and learning mathematics at community colleges makes this an exciting time for developmental mathematics. The study that is introduced in the next section focuses on a particular population of community college students enrolled in developmental mathematics - students who enroll in an arithmetic review course. The study also aims to establish "research-based evidence about how mathematics teaching and learning occur in [the community college setting]" (Mesa et al., 2014, p. 185).

\section{Introduction to the Study}

This study is an exploration of a particular type of mathematical reasoning proportional reasoning ${ }^{8}$ - and the connections adult students make between their ways of reasoning about proportions and how topics involving proportional reasoning are presented in their mathematics classes. Uncovering and describing adult returning students' proportional reasoning addresses the first of the two initial questions posed, "How can adult students' mathematical abilities be identified and utilized in the classroom?" Students' ways of thinking need to be made visible if we want to leverage their ways of thinking in the classroom: "If [students'] initial understanding is not engaged, they may fail to grasp the new concepts and information that are taught, or they

\footnotetext{
8 The definition of proportional reasoning used in this study is described in detail in the next chapter, but the definition has been borrowed from the work of Susan Lamon: “... proportional reasoning means supplying reasons in support of claims made about the structural relationship among four quantities (say $a, b, c, d$ ) in a context simultaneously involving covariance of quantities and invariance of ratios or products; this would consist of the ability to discern a multiplicative relationship between two quantities as well as the ability to extend the same relationship to other pairs of quantities" (Lamon, 2007).
} 
may learn them for purposes of a test but revert to their preconceptions outside the classroom" (Donovan, Bransford, \& Pellegrino, 1999). Understanding the connections adult students make between their own experiences, ways of thinking, and the mathematics they encounter in a Basic Math classroom addresses the second initial question, "How can developmental mathematics courses be adapted to the needs and mathematical abilities of adult returning students?" This study seeks to better understand students' experience with mathematics and one type of mathematics ability proportional reasoning - in order to begin a discussion of how courses might be better adapted to our students.

The study consists of three phases that together paint a portrait of the student who returns to school and, as part of this experience, is required to return to school mathematics. The three parts of this study address the following research questions:

(i) What are the backgrounds of students who enroll in a Basic Math course and what are their experiences of mathematics in their lives and in school?

(ii) What proportional reasoning abilities do students placing into Basic Math demonstrate prior to returning to school mathematics? and

(iii) How do a student's proportional reasoning abilities interact with the mathematics he or she encounters in a Basic Math class?

The choice to document students' proportional reasoning abilities was made for two reasons. First, proportional reasoning abilities have been researched in several communities of practice, for example, among fisherman, cooks, and construction foremen (Carraher, 1986; Schliemann \& Carraher, 1993). Second, proportional reasoning has been described as "both the capstone of elementary arithmetic and the 
cornerstone of all that is to follow" (Lesh, Post, \& Behr, 1988, p. 95). In mathematics, proportional reasoning is foundational to developing a robust understanding of fractions, decimals and percentages (the primary focus of the Basic Math course), understanding linearity (introductory through college algebra), rate of change and accumulation (calculus), modeling dynamical systems (differential equations) and statistical inference (statistics).

Three sources of data were collected to address the research questions. Table 1 summarizes the relationship between the research questions and the three sources of data. In Chapters 3-6, the different analysis techniques that were used to address each research question are described.

(i) A survey was administered to participants from a random sample of sections of Basic Math (see Appendix A) at an urban, multi-campus community college. Some biographical data were collected (e.g., gender, age, prior college experience). Other survey questions were written by me and piloted prior to the study. The questions were designed to solicit information about participants' experiences with mathematics both in school and outside of school. In addition, four mathematics problems were included on the survey. Two of these four problems were adapted from prior research on proportional reasoning, another was from a national assessment of students' mathematical understanding and the fourth problem I wrote. Unlike the placement exam used at the college, students were asked to provide reasons for their solutions. The survey data are intended to develop a broad perspective on the 
proportional reasoning abilities of participants who place into a Basic Math course at a community college.

(ii) Task-based interviews were conducted with a sample ${ }^{9}$ of participants prior to the academic term. The tasks assessed participants' proportional reasoning abilities and were adapted from tasks used in other studies of proportional reasoning. The interview also queried participants about occasions for problem solving in their lives, exploring the extent to which the interview tasks resembled or did not resembled quantitative problems the participants encounter outside of school.

(iii) An adaptive ethnographic approach was used to describe of a participant's experience as he/she returned to school mathematics was undertaken during the term following the task-based interviews. One informant was chosen from the participants selected to take part in the task-based interviews described above. I attended most of the mathematics classes with the informant and interviewed the informant periodically throughout the term about her experience as a returning student in a mathematics class.

The data collected to answer each question were analyzed using different data analysis techniques. These techniques are introduced in Chapter 3 and discussed in detail in the Methodology sections Chapters 4-6.

\footnotetext{
${ }^{9}$ The sampling procedures will be described in detail in Chapter 3.
} 
Table 1

Relationship Between research questions and collected data

\begin{tabular}{|l|l|l|}
\hline \multicolumn{1}{|c|}{ Research Question } & \multicolumn{1}{|c|}{ Data source } & $\begin{array}{l}\text { Primary framework } \\
\text { for analysis }\end{array}$ \\
\hline $\begin{array}{l}\text { What is the background of students who } \\
\text { enroll in a Basic Math course and what is } \\
\text { their experience of mathematics in their } \\
\text { lives and in school? }\end{array}$ & $\begin{array}{l}\text { Survey } \\
\text { Task-based interview }\end{array}$ & $\begin{array}{l}\text { Bishop's (1984) pan- } \\
\text { cultural mathematical } \\
\text { activities }\end{array}$ \\
\hline $\begin{array}{l}\text { What proportional reasoning abilities do } \\
\text { students placing into Basic Math } \\
\text { demonstrate prior to returning to school } \\
\text { mathematics? }\end{array}$ & $\begin{array}{l}\text { Survey } \\
\text { Task-based interview }\end{array}$ & $\begin{array}{l}\text { Four-strategies } \\
\text { framework based on prior } \\
\text { research on proportional } \\
\text { reasoning (e.g. Lamon, } \\
\text { 1993, 2007) }\end{array}$ \\
\hline $\begin{array}{l}\text { How do a student's proportional reasoning } \\
\text { abilities interact with the mathematics he } \\
\text { or she encounters in a Basic Math class? }\end{array}$ & Ethnographic data & $\begin{array}{l}\text { Framework suggested by } \\
\text { initial interview with } \\
\text { informant }\end{array}$ \\
\hline
\end{tabular}

\section{Situating the Researcher within the Research}

The research questions posed in this study emerged from my 18-year-long career as a community college mathematics instructor. While I was working at the community college, I started taking one or two mathematics courses per year in order to determine whether I wanted to pursue a doctorate in mathematics. I came upon the field of mathematics education research by chance. The mathematics department where I was studying included a growing number of mathematics education researchers and a program that led to a $\mathrm{PhD}$ in mathematics education. I met the mathematics educators when a friend came to the mathematics department to give a talk. I started attending a weekly seminar in mathematics education and during Fall term 2004 took my first course in mathematics education. I officially began the $\mathrm{PhD}$ program in mathematics education in 2006 as I continued my professional work as a community college mathematics instructor.

During this time I identified myself primarily as a practitioner, and I often felt a tension between my professional work and my academic work. On the one hand, there 
seemed to be little consideration of theory or empirical research within during discussions of community college mathematics. On the other hand, within the field of mathematics education research, it appeared that there is little understanding of community college mathematics curriculum and some of the unique questions that emerge when working with a population of students that differ in significant ways from students in K-12 mathematics classroom or enrolled in university mathematics programs. This research study is an attempt to begin to resolve this tension.

The motivation for this study has emerged from both my own practice as a community college mathematics instructor and from the research literature on adults' out-of-school mathematical practices. As a teacher I typically ask students to work collaboratively on a mathematics problem on the first day of class. I provide this opportunity for two reasons: (a) to assess informally students' mathematical abilities and (b) to introduce students to the culture of the classroom and my expectations about their participation in this community. In the Basic Math course this first-day-of-class problem typically involved proportional reasoning, since I organized much of the course content around this form of reasoning. During this activity students are typically able to reason through to a solution, although many of these same students later claim they cannot solve problems presented in the textbook. This experience provided anecdotal evidence that students return to school with the ability to reason proportionally. Research studies on adults' out-of-school mathematical activity show that people often use strategies for solving problems that are different from strategies taught in school (for example, Carraher, Carraher, \& Schliemann, 2004; Lave, 1988). Some of this research focuses on problems that involve proportional reasoning (Carraher, 1986; Hoyles, Noss, \& Pozzi, 
2001; Schliemann \& Carraher, 1993), documenting that adults who may not have studied proportions in school are capable of this type of reasoning (I will discuss this research in detail in the next chapter), again suggesting that adult students return to school with proportional reasoning abilities that might be made visible and built upon in a Basic Math class. This study attempts to provide a scientific foundation to this claim.

The discourse of deficit thinking has been documented in a variety of contexts (Coben, FitzSimons, \& O'Donoghue, 2000; Duranczyk et al., 2004; Valencia, 2010) and students in developmental mathematics classes are frequently viewed as deficient with respect to the course content. In the course of my professional work, it felt as if placing the cause of failure on our perceptions of students' deficits halted any discussion of what we as teachers or as an institution might do to improve students' experiences and learning in our mathematics classrooms.

The knowledge deficit model is not a useful model. First and foremost, the deficit model does not distinguish between different ways of knowing mathematics. Are students competent with a procedure for multiplying fractions, for example, but fail to understand what it means to multiply a quantity by two-thirds? Or is it the case that a student never bothered to master computational procedures because these procedures appeared decontextualized and senseless when presented in school? These questions highlight that different teachers, researchers and policy makers might value different ways of knowing mathematics and would therefore have different definitions of deficient with respect to course content. Second, describing students as deficient tends to place blame elsewhere, for example, on a student's past schooling or on the characteristics of a particular student. This blame diverts attention from problems that might have a different 
source, for example, arising from the course content itself rather than the student's relation to this mathematical content or arising from the placement tests that measure deficiencies. Finally, viewing a student as deficient is pejorative and does not acknowledge that the mathematical experience of students might differ in significant ways from the mathematical experience of their teachers and textbook authors who define the content of developmental mathematics courses. Instead of focusing on perceived deficits, new mathematical knowledge needs to be built on a student's current mathematical understanding: "If [students'] initial understanding is not engaged, they may fail to grasp the new concepts and information that are taught, or they may learn them for purposes of a test but revert to their preconceptions outside the classroom" (Donovan et al., 1999). It is important to document what a student understands prior to instruction, and placement tests typically document what a student does not know.

I feel strongly about giving a voice to the students who are seen as the most deficient with respect to mathematics: students at the community college. It seemed to me that the discourse of deficit seemed appeared so prominent in my professional work because we tend to view our students through the lens of our own experience as mathematics students. My own educational experience is likely different from most of my students. I am a white, middle-class woman who had the privilege to attend both a private high school and a private liberal arts college. I never attended a community college. After a short time away from school after high school, I started a degree in classical liberal $\operatorname{arts}^{10}$ at the age of 20 , completing the degree in three years. At the age of 28 I returned to school to earn a second undergraduate degree in mathematics and then

\footnotetext{
${ }^{10}$ The liberal arts degree included four years of studying primary texts in mathematics. I took a course in differential equations at another college during the summer between my junior and senior year.
} 
continued on at another institution to earn a master's degree in mathematics. I was an adult returning student, but since I had a degree already I felt able to plan my own course; the institution never told me I needed to repeat mathematics courses I completed in the past. For example, I simply enrolled in multivariable calculus although I completed single variable calculus 10 years previously. Later, there was a seven-year gap between completing a MA in mathematics and enrolling in a differential geometry course in 2001. I recognized my own deficiencies with respect to course content after these intermissions from the formal study of mathematics and I worked hard to fill in the gaps in my knowledge on my own. However, I expect that my experience as an adult returning student in a mathematics classroom is likely quite different from the experience of many of my students. I had access to the resources to earn a variety of degrees. The degrees, the transcripts from these institutions, seemed to give me the ability to set my own course in an academic world. Yet, returning to mathematics after any break creates obstacles for most students, so in this respect I have empathy with my own students' efforts and struggles returning to school mathematics.

I believe that knowledge is situated and constructed in collaboration with others within the context of a particular situation (Wenger, 1998). Students whose recent life experiences have been far removed from the school setting have knowledge that is likely not situated in the kinds of knowledge that are valued in school. However, this perspective on knowledge construction creates difficulties in terms of designing a study about the mathematical ways of knowing that adult returning students bring from their lives to the mathematics classroom. Unlike researchers who have explored the mathematical knowledge of particular groups (e.g., bookies or fishermen; the next 
chapter discusses these studies) I cannot take a trip into the "wild" (Hutchins, 1995) and explore the situated mathematical knowledge in the diverse life experiences of adult students who come to the community college. I can only explore this knowledge in the intersection between their lives and school, thus trying to understand returning students' previous experience. I am looking at knowledge that is situated in a unique place - the territory between adults' everyday life and the mathematics classroom -the place from which adult returning students embark upon their college experience.

\section{Structure of the Dissertation}

Chapter 2 defines the conceptual framework on which this study is grounded, describing in detail the aspects of proportional reasoning salient to this study, what is understood about adults' out-of-school mathematical practices, and the ways mathematical activity outside school differs from school mathematics - in particular with respect to reasoning proportionally. Chapter 3 discusses the research methodology, although Chapters 4, 5 and 6 also include methodology sections. Chapter 4 presents findings from the first research question, presenting a portrait of the adult students who enroll in Basic Math and their experiences with mathematics in their lives and in school. Chapter 5 describes the ways of reasoning proportionally the research participants brought to their Basic Math class. Chapter 6 tells part of one student's story as she experienced her Basic Math class, addressing the final research question. Finally, Chapter 7 includes a discussion of the findings and a revised conceptual framework, implications, limitations and possibilities for future research. 


\section{Chapter 2: Conceptual Framework and Literature Review}

Frank Lester's definition of a conceptual framework is used in this chapter: "A conceptual framework is an argument that that the concepts chosen for investigation, and any anticipated relationships among them, will be useful given the research problem under investigation" (Lester, 2010). The particular concepts I am interested in are proportional reasoning, adults' out of school mathematical practices and the nature of the differences between mathematical activities outside school and in school. The literature review I include in this chapter focuses on these three concepts. I first discuss the expected relationships between these concepts in terms of the research problem and, in particular, the research questions.

This study was designed to investigate three questions: (i) What are the backgrounds of students who enroll in a Basic Math course and what are their experiences of mathematics in their lives and in school? (ii) What proportional reasoning abilities do students enrolling into Basic Math demonstrate prior to returning to school mathematics? and (iii) How do a student's proportional reasoning abilities interact with the mathematics he or she encounters in a Basic Math class? These questions emerged from three fundamental areas described in the research literature in mathematics education:

- out-of-school mathematical practices,

- proportional reasoning in general and within particular out-of-school practices, and

- the differences between mathematical activity outside school and in school. 
Figure 1 represents the conceptual framework for the study and how the research questions fit into this framework. At the center is the student enrolled in Basic Math. Question 1 considers the relationship between the student and her experience of mathematics outside of school. Question 2 examines the relationship between the Basic Math student and her proportional reasoning. Question 3 examines the relationship between the student and the Basic Math curriculum as enacted in his/her classroom. The difference between mathematical activity outside school and in school is represented in the connection between out-of-school mathematical practices and the Basic Math curriculum.

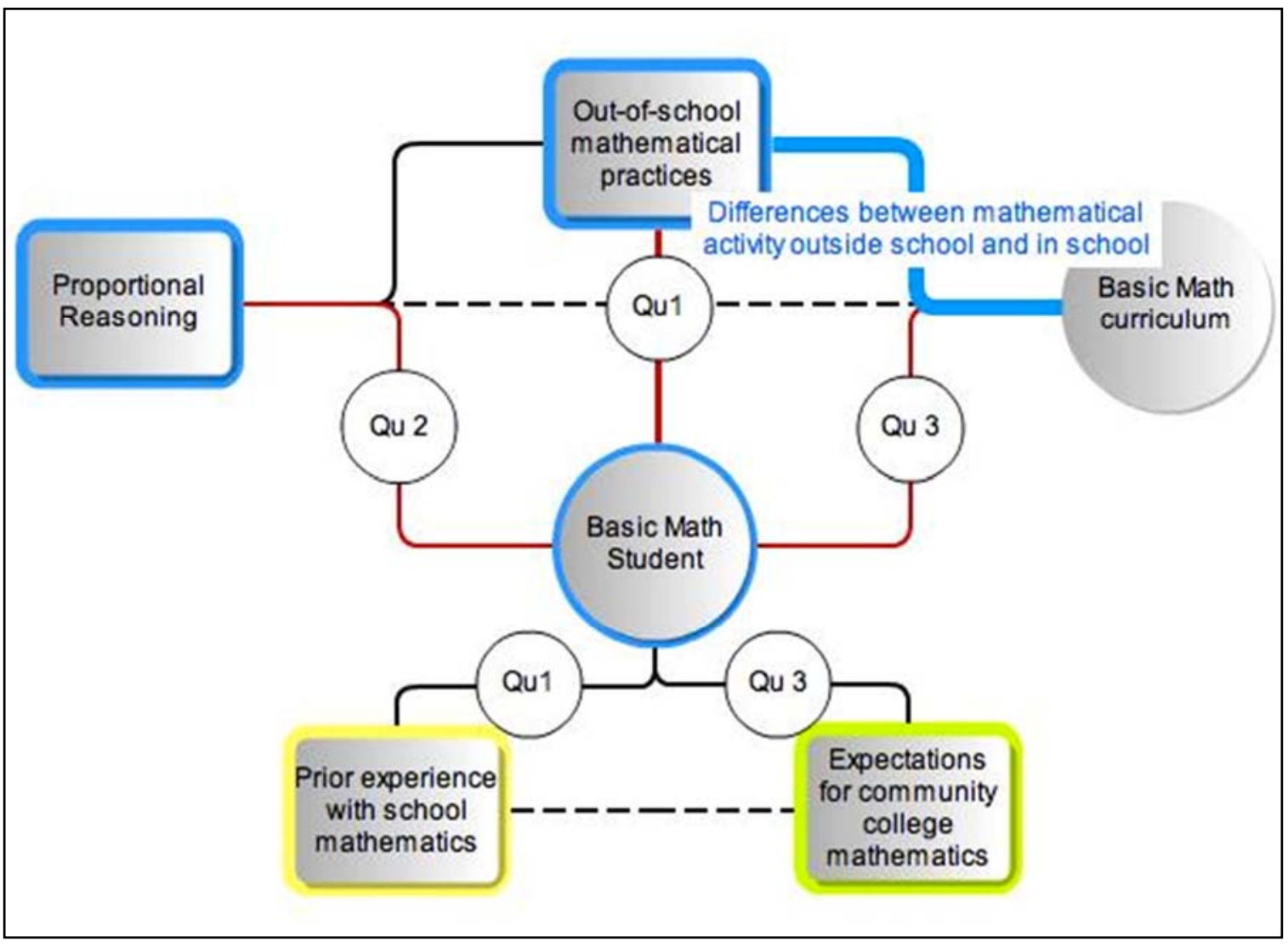

Figure 1. Schematic of conceptual framework 
A student's prior experience with school mathematics and his or her expectations for the Basic Math course are also related to the first and third research questions; these relationships are illustrated in Figure 1. For example, a student's expectation for the Basic Math course might shape the way a student's proportional reasoning interacts with the mathematics he or she encounters in the Basic Math class.

\section{Out-of-School Mathematical Practices}

"Problems in the real world are generally complicated, not in terms of their mathematical demand, but in the relative influence of subjectivity, experience, communication, process and content” (Boaler, 1993, p. 371).

The ways both children and adults reason about quantities has been explored in a variety of contexts. The mathematical practices of street vendors, shoppers, bookies, fishermen, cooks, construction foremen, carpet layers, warehouse workers and nurses have been explored (Carraher, 1986; Carraher et al., 2004; Hoyles et al., 2001; Lave, 1988; Masingila, Davidenko, \& Prus-Wisniowska, 1996; Schliemann \& Acioly, 1989; Schliemann \& Carraher, 1993; Schliemann \& Nunes, 1990; Scribner, 1984). These studies have led to a variety of findings, including a lack of reliance on school-based procedures in out-of-school mathematical practices and strategies developed using context rather than mathematical structure. For example, Carraher, Carraher and Schliemann (2004) studied the computational abilities of street vendors in Recife, Brazil and Lave (1988) studied the ways shoppers make quantitative decisions. Both studies found that people rarely use procedures learned in school in these contexts. For example, the street vendors used a variety of strategies, including using repeated addition to determine a product rather than relying on multiplication facts, to reason to an 
appropriate solution. The context suggests the strategy; the vendor is 'adding up' what is owed. Hoyles, Noss and Pozzi (2001) found that the procedure nurses use to determine drug dosages is context dependent, and again, rarely resembles the procedures taught to the nurses in their training. For example, one nurse described that the way she determined a dose was "associated with the drug itself rather than with the ratio between the mass and the volume: 'That's how it is with amakacine,' says Belinda, apparently seeing the allowable arithmetic operation and the drug itself as intimately connected" ( $\mathrm{p}$. 20). Again, the context suggests the strategy.

In a study with Brazilian bookies, Schliemann and Acioly (1989) found that the amount of schooling a bookie had did not influence the procedures he or she used to solve the quantitative problems posed, although the bookies did resort to written algorithms (as opposed to the mental computations they used on a daily basis) when a problem involved numbers not encountered in the bookies' daily work. However, when presented with an unfamiliar yet contextual problem (in this case, problems involving division), the bookies were able to reason towards a solution without relying on school procedures. This suggests that the bookies may have been reasoning using contextual clues from the problem. Other researchers (Masingila et al., 1996; Scribner, 1984) compared adults' out-of-school mathematical practices with school children's abilities with the same type of mathematical problems. In both cases, adults' out-of-school experiences informed their problem-solving strategies in ways not accessible to the younger students. Scriber (1984) observed that warehouse workers at a dairy often devised a problem solution that required less physical work. Dairy orders are written as a number of full cases plus or minus a number of units. The complexity of the task is 
compounded by the fact that different products are packed into cases with different quantities of units. The researcher observed that people filling orders often did not fill orders literally (for example, removing four units from a case), but might add two units to a partial case in order to fill the order if this solution involved less physical work. More importantly, the warehouse workers used the physical configuration of the cases of dairy products to count. In addition, Scribner gave order-filling tasks, like the tasks undertaken by the warehouse workers, to middle-school students. These students did not tend to find a laborsaving (in terms of moving dairy items into cases for filling orders) solution to these problems and did not reason using contextual clues. It is not surprising that the school children did not consider the actual work involved in their solutions, but it is interesting that the adults' strategies were closely aligned with their experience putting together orders at the dairy. Masingila et al. (1996) studied the mathematical reasoning of carpet layers and found that the carpet layers had a deeper understanding of the underlying concepts of their work (e.g., area) than high school students given tasks that the carpet layers executed as part of their work. Again, it is not surprising that the high school students did not have the same concept of area as the carpet layers, but rather that the carpet layers had a well-formed understanding of area developed on the job.

Strategies developed to solve problems in out-of-school contexts may be context dependent, but in a paper highlighting the distinction between everyday mathematics and school mathematics Schliemann (1995) observed that strategies developed in out-ofschool contexts may obscure mathematical structure. She cited the example of the street vendors in Recife who will find the cost of 100 candies by computing $100 \times 6$, perhaps 
using an abbreviated building up strategy (10 sixes are 60, 20 are 120, etc.) rather than computing the simpler (at least in terms of repeated addition) product $6 \times 100$; the commutative property of multiplication was not accessed by the street vendors. Also, in a study of fisherman Schliemann and Nunes (1990) note that fisherman rarely determine the price of a quantity of fish using a unit price. Rather, they reason about quantity and price as independent measures (more will be said about this form of reasoning in the section on proportional reasoning). Thus, building on adult students' everyday mathematics in the classroom would involve making the mathematical structure visible.

Bishop (1988) considered everyday mathematics from a cultural perspective, identifying six pan-cultural mathematical activities - counting, locating, measuring, designing, playing, and explaining - were used. These activities are not only universal, but also fundamental for the development of mathematical knowledge. Bishop claims that mathematics, in its foundations, has a cultural basis and notes that it is important that we ask whose cultural history we are referring to when we consider the cultural foundation of mathematical knowledge. Bishop also claims that these pan-cultural activities are related to the mathematics learned in school. For example, he lists the following mathematical ideas as related to counting: numbers; number patterns; number relationships; development of number systems; algebraic representation; infinitely large and small; events, probabilities, frequencies; numerical methods; iteration; combinatorics; limits (p. 183). This perspective is important to understanding the connection between everyday mathematics and school mathematics.

Summary. An adult returning student has likely relied little on school-taught procedures outside school and may use contextual clues and artifacts to reason. Even 
though the attempt may be made to situate school mathematics problems in contexts familiar to adults, there may be little connection to their ways of thinking mathematically outside school. It is not the contextual features of the problem that are most important, but rather it is the ways that adults - and others - may use contextual features to reason to a solution. I conjectured that an adult student's experience with problem solving and reasoning about quantity in out-of-school contexts shapes the experience the student has in the Basic Math course. The connection between the student and his or her out-of-school mathematical practices will be examined with the first research question, "What are the backgrounds of students who enroll in a Basic Math course and what are their experiences of mathematics in their lives and in school? (see Figure 1). Any discontinuity between these two roles was explored through an examination of the literature on the differences between mathematical activity in school and outside of school (see Section 2.4). In addition, several of the studies of adults' outof-school mathematical practices highlight the prevalence of proportional reasoning in these practices. For this reason, it is also conjectured that a student enrolled in a Basic Math class has the ability to reason proportionally in several contexts. A description of proportional reasoning is provided below.

\section{Proportional Reasoning}

Early research on proportional reasoning was influenced by Piaget's stage theory of cognitive development (Inhelder \& Piaget, 1958; Noelting, 1980a, 1980b; Suarez, 1977). However, the nature of the research on proportional reasoning changed after Vergnaud's seminal work on the multiplicative conceptual field (Vergnaud, 1983). Some research after Vergnaud (e.g., Behr, Harel, Post, \& Lesh, 1992) considered the 
multiplicative conceptual field, including ratio and proportion, from the perspective of mathematical structure. Other researchers (e.g., Confrey, 1994; Lamon, 1993; Mack, 1990) examined the multiplicative conceptual field from the perspective that understanding multiplicative concepts develop from children's informal reasoning. It is the latter body of research that frames this study, since the study queries adult students' proportional reasoning as they transition back to formal schooling and whether this proportional reasoning is informal, a conjecture based on the body of research that examined adults' proportional reasoning in everyday contexts (see Section 2.4).

The description of proportional reasoning that grounds this study is taken from Lamon (2007):

I propose that proportional reasoning means supplying reasons in support of claim s made about the structur al relationship am ong four quantities (say, $a, b, c, d$ ) in a context sim ultaneously involving covariance of quantities and invariance of ratios or products; this would consist of the ability to discern a $\mathrm{m}$ ultiplicative re lationship between two quantities a $\mathrm{s}$ well as the ability to extend the sa me relationship to other pairs of quantities. (p. 638, emphasis added)

This description highlights several salient features of proportional reasoning. First, it is a form of reasoning that is given in support of claims made about quantities related in a particular way. Second, one must recognize several features of the particular relationship: pairs of quantities covary, any two of these quantities are related multiplicatively, and further, there is a derived quantity that remains invariant as the 
other quantities vary. An example of reasoning about percentages is provided to illustrate the details of this description of proportional reasoning.

Suppose someone wants to compute $40 \%$ off a $\$ 35$ pair of jeans. There are two obvious quantities in this situation, the $\$ 35$ pair of jeans and the amount of savings, and two quantities that are implicit, the part and the whole represented by $40 \%$. There are several ways to think about $40 \%$, for example, 40 parts out of 100,4 parts out of 10 or 0.40 out of 1 . In this context, there is a correspondence between the $\$ 35$ pair of jeans and the whole implicit in $40 \%$ and another between the amount of savings and the 40 parts out of the 100. If the percent discount increased (the 40 parts out of 100), then the amount of savings would increase. This is an example of covariation. In addition, there are several ways of describing the multiplicative relationships between the quantities in this problem. For example, if the discount were storewide, the savings on a $\$ 70$ pair of jeans would be twice the savings on a $\$ 35$ pair of jeans. In the context of the task at hand, someone might reason using a multiplicative relationship in several ways. For example, if $20 \%$ off is a $\$ 7$ savings, then $40 \%$ off is a $\$ 14$ savings. Or alternatively, four times $10 \%$ is a $40 \%$ savings and $10 \%$ of $\$ 35$ is $\$ 3.50$. Therefore $40 \%$ off is a savings of $\$ 14$. Further, the derived quantity ${ }^{11}$ in this situation, $40 \%$, is the invariant ratio, which can be used to reason to a solution. For example, a shopper might reason that $40 \%$ off means she will save $\$ 0.40$ on every dollar, or $\$ 4$ on every $\$ 10$ and $\$ 2$ on every $\$ 5$. In this case she will save $\$ 4+\$ 4+\$ 4+\$ 2$ on a $\$ 35$ pair of jeans, using the correspondence between $\$ 4$ of savings for every $\$ 10$ that constitutes the price of the jeans. All of these ways of reasoning about the percent discount illustrate that there is

\footnotetext{
${ }^{11}$ This particular derived quantity is not as abstract as other derived quantities like average speed or torque.
} 
more to proportional reasoning than solving a problem involving a proportion. Rather one reasons using the structural relationship among four quantities. This example also illustrates the variety of ways of reasoning proportionally and the relative sophistication of strategies used.

Types of problems that involve proportional reasoning. Lamon (1993)

classifies four types of problems that elicit proportional reasoning: problems involving well-chunked or well-known rates, problems involving part-part-whole relationships, problems that relate associated sets, and scaling problems. Examples of well-chunked or well-known rates include hourly wages and average speed; a problem involving a wellknown rate would be to determine who earns more, a person who earns $\$ 75$ for five hours of work or a person who earns $\$ 480$ for a 40 -hour week? Problems involving partpart-whole relationships involve comparing one group made up of a certain number of women and men to another group with a different composition of men and women. Associated-sets problems involve relating a stated number of objects from one set with a number of objects from a second set, for example, three flower stems cost $\$ 2$. Finally, scaling problems are typically geometrical: "How does the width of a 5-inch by 8-inch photograph vary as its length is enlarged to 12 inches if its shape remains the same?" or "How does the area of a garden increase as its dimensions are doubled?"

Yet classifying problems that elicit proportional reasoning may be more nuanced than these four categories suggest. For example, several researchers (e.g., Lobato \& Thanheiser, 2002; Thompson, 1994) demonstrate that constructing speed is non-trivial. In fact, as mentioned above, reasoning with a unit rate is a cognitively sophisticated strategy. In these cases, one needs to understand a ratio as a measure of a quantity 
derived from two measurable quantities. For example, speed is derived from measured distances and the time needed to travel these distances and a percent rate is derived from the amount of savings for each dollar spent. In addition, as discussed above, a person could reason about the amount saved on a $\$ 35$ pair of jeans discounted $40 \%$ without constructing a percent rate; instead a person might reason as if this was a problem associated one set (percentage) to another set (dollars saved). Further, a percent discount problem might be interpreted as a part-part-whole problem in which a student reasons with three quantities: the original price of the jeans (the whole), the amount saved and the sale price of the jeans (the two parts). Finally, scaling problems involve both simple proportions and multiple proportions, a distinction made by Vergnaud (1983). For example, determining that the width of a enlarged photograph will double when its length is doubled is an example of a simple proportion, whereas determining that the amount of photo paper used to print the photograph quadruples when both dimensions double is an example of a multiple proportion since the area of the photograph varies jointly with both its length and width. Yet, problems that involve joint variation in nongeometrical contexts may appear qualitatively different. Vergnaud (2004) gives examples of multiple proportions in the context of consumption problems that involve continuous quantities like amount of sugar consumed, but also discrete quantities like number of people. Discrete quantities may be easier to pair with another quantity in a composed unit such as four pounds of sugar to 10 people; this composed unit can be iterated to generate a solution.

In the next section I discuss different ways of reasoning about problems involving proportions. It will be seen that some have argued that certain types of 
problems lend themselves to particular ways of reasoning, or that certain ways of reasoning are more prevalent among certain populations regardless of how the problem is structured.

Ways of reasoning about problems involving proportions. For this study, a hierarchy of ways of reasoning proportionally is adapted from both Lamon (1993) and Lobato and Ellis (2010). Lamon describes preproportional reasoning as "informal methods that resulted in correct solutions without understanding scalar and functional relationships" and proportional reasoning as "when a student could demonstrate understanding of the equivalence of appropriate scalar ratios and the invariance of the function ratio between two measure spaces" (p. 45). Demonstrating an understanding of a scalar relationship in the context of the percent discount problem discussed above might involve multiplying the correspondence between $10 \%$ and $\$ 3.50$ by four to determine that $40 \%$ corresponds to $\$ 14$. (Lobato and Ellis refer to the correspondence between $10 \%$ and $\$ 3.50$ a composed unit constructed from the $10 \%$ and $\$ 3.50$.) On the other hand, understanding a functional relationship would imply that a shopper understands that any price could be multiplied by the percent rate to obtain the discount (that is, multiply the price of the item by 0.40 to find the amount of savings). In this context, the percent rate can be understood as a unit rate partitioned down from $\$ 40$ off every $\$ 100$ to $\$ 0.40$ off every $\$ 1$.

Lamon (1993) distinguishes scalar from functional ways of reasoning, a distinction originally described in Vergnaud (2004). Yet Lobato and Ellis (2010) assert that making the connection between iterating composed units like $10 \%$ to $\$ 3.50$ (a scalar 
strategy) and understanding the percent rate as relating two quantities multiplicatively via a unit rate (a functional strategy) is cognitively more complex than either of these understandings taken individually: "Forming a composed unit is a rudimentary, yet foundational concept, which can be used in conjunction with other essential understandings ... to develop the big idea of proportional reasoning" (pp. 19-20). Yet studies of adults' proportional reasoning abilities in out-of-school contexts reveal that there is a tendency to iterate a composed unit rather than using a unit rate, even in situations posed to make the unit rate easier to compute. For example, Schliemann and Nunes (1990) note that fishermen do not use a unit price strategy, writing "This scalar approach is both terribly clever and awkward. It is this contradiction between clear ability with number and apparent difficulty with a simple problem [if worked using a unit rate], which strengthens the notion that the isomorphism of measures schema is used by subjects to conceive proportions situations and blocks other routes to solution" (p. 263). This suggests that the understanding that connects reasoning with a composed unit to reasoning using multiplicative relationship between two measure spaces may be more challenging for adult students to develop than is currently assumed by those who develop mathematics curricula.

Finally, the "pull" of incorrect additive reasoning typically occurs in two particular types of problems (Kaput \& West, 1994). First, incorrect additive reasoning may be invoked when solving a problem in which the numbers do not involve integer ratios and the difference between the numbers in the given ratio is small, as in one problem used in Kaput and West's study: “Joan used exactly 15 cans of paint to paint 18 chairs. How many chair can she paint with 25 cans?” (p. 251). Second, problems 
involving similar geometric figures exert a strong additive pull. Kaput and West observe that in many contexts it is natural to ask, "Which length is longer?" or "What is the difference in lengths?" They conjecture that the fact that length is a continuous quantity also presents a difficulty. The ability to reason proportionally involves the ability to distinguish problems that require additive reasoning from problems that involve multiplicative reasoning (Lamon, 2007). For this reason, incorrect additive strategies come before other forms of reasoning in a hierarchy. A hierarchy of ways of reasoning about proportion is illustrated in Table 2 .

Table 2

Ways of reasoning or understanding proportions

\begin{tabular}{|c|c|}
\hline Ways of reasoning/understanding & Examples \\
\hline Invalid reasoning & $\begin{array}{l}\text { Using an apparently random procedure or an } \\
\text { incorrect additive strategy }\end{array}$ \\
\hline $\begin{array}{l}\text { Pre-proportional reasoning } \\
\text { Proportional reasoning }\end{array}$ & $\begin{array}{l}\text { Estimating or noticing that one quantity increases } \\
\text { (for example) as another quantity increases }\end{array}$ \\
\hline Scalar understanding & $\begin{array}{l}\text { Doubling one quantity increases the other quantity } \\
\text { by a factor of two. }\end{array}$ \\
\hline Functional understanding & One quantity is always 1.5 times the other. \\
\hline $\begin{array}{l}\text { Connection between scalar and functional } \\
\text { understandings }\end{array}$ & The two understandings described above are related \\
\hline
\end{tabular}

\section{Strategies used to solve problems involving proportions. Lamon (1993)}

distinguishes quantitative from qualitative strategies. Quantitative strategies are distinguished from qualitative strategies by the symbolic representations used. One example of a quantitative strategy is writing an equation describing the equivalence of two ratios in a missing-value problem. Although Lamon appears to privilege quantitative 
over qualitative strategies among the strategies she describes, in some situations it may be the case that a symbolic representation of a proportion problem may not represent reasoning at all. Lobato and Ellis observe that, “...students who have not yet mentally formed ratios, either as composed units or multiplicative comparisons, may interpret the proportion [the equivalence of two ratios represented as fractions] simply as a template for inserting whole numbers into boxes" (p. 33). In addition, symbolic procedures may be conjured up in a random attempt to solve a problem (e.g., cross multiply and divide without attending to the quantities involved in a problem) or an appropriate procedure may be invoked to solve a problem only because the problem has a particular form (e.g., to find a percent multiply the quantity by the percent after moving the decimal point to the left two places). In this study, it is expected that qualitative strategies will be more prevalent and that symbolic representations of problems may or may not represent a more developed way of reasoning.

People with a scalar way of reasoning about proportional situations frequently use building-up or building-down strategies, either working with a composed unit (for example quadrupling a unit such 5 pounds of unprocessed fish to 3 pounds of processed seafood to solve a problem) or by working with the two quantities independently (in this case, quadrupling both the quantity of unprocessed fish and the quantity of processed seafood without explicit reference to a composed unit ${ }^{12}$ ). Although both Lamon (1993) and Lobato and Ellis (2010) categorize building-up or building-down a composed unit as multiplicative, Kaput and West (1994) refer to these strategies as a form of additive reasoning. This apparent disagreement may be more a function of what types of

\footnotetext{
${ }^{12}$ This is a distinction I am suggesting based on pilot data collected to inform this study. It is not always clear whether people with a scalar way of reasoning make use of a composed unit explicitly.
} 
reasoning are referred to as building-up strategies than a disagreement about what constitutes multiplicative reasoning. Another example of reasoning with percentages will be used to illustrate this distinction. Consider the following problem:

Susheela earns a $6 \%$ raise. The raise adds $\$ 1.26$ to her hourly rate. What was her hourly rate before the raise?

One strategy for solving this problem involves the following steps: adding $\$ 1.26$ to itself five times to figure out that $30 \%$ of the hourly rate before the raise is $\$ 6.30$. Then adding $\$ 6.30$ to itself three times to determine that $90 \%$ of the hourly rate before the raise is $\$ 18.90$. Finally, a student would add to $90 \%, 6 \%, 3 \%$ (one-half of $6 \%$ ) and $1 \%$ (onethird of $3 \%$ ) to obtain $100 \%$ or the hourly rate before the raise. Although this strategy uses some multiplicative reasoning (e.g., $3 \%$ is one-half of $6 \%$ ), it demonstrates how a student builds $100 \%$ by adding up $6 \%$ and multiples of $6 \%$. I call this strategy, iterating a composed unit, which Lamon describes as a strategy that bridges additive and scalar reasoning (1994). Compare this strategy to the following: If $6 \%$ of the hourly rate before the raise is $\$ 1.26$, then $1 \%$ is one-sixth of this or $\$ 0.21$ and $100 \%$ is $\$ 21$. I would classify this second type of building-up/down strategy as a scalar strategy. The distinction between these two ways of reasoning points at the relationship between addition and multiplication, but also suggests that the second, scalar strategy is more efficient way of reasoning.

Another problem solving strategy involves computing a unit rate either by partitioning a composed unit down to the unit rate or simply dividing one quantity by another to find this rate. As mentioned previously, Thompson (1994) argues that dividing a distance by the time it takes to travel that distance does not necessarily 
indicate understanding of the derived quantity speed. Lobato and her colleagues (Lobato \& Ellis, 2010; Lobato \& Thanheiser, 2002) argue that using a ratio as a measure is nontrivial. Unit rate strategies are frequently used in comparison problems (e.g. which of two cars is traveling faster?), but the use of a unit rate in these types of problems may be an instance of applying a memorized procedure rather than an indication of a functional way of reasoning. People with a functional way of reasoning about proportional situations use a unit rate as the multiplicative unit (constant of proportionality) between two quantities. For example, the distance traveled by a bicycle traveling at a constant speed can by found by multiplying the constant speed by the amount of time the cyclist has been traveling at this speed.

For the purposes of this study, informal proportional reasoning strategies are understood to be strategies that involve iterating or partitioning a composed unit like 5 pounds of unprocessed fish to 3 pounds of processed seafood, although not necessarily partitioning the composed unit down to a unit rate (in this example, $12 / 3$ pounds of unprocessed fist to one pound of processed seafood). The recognition of the invariance of a ratio as a unit rate in order to make a multiplicative comparison will represent a cognitively more sophisticated and more generalizable way of reasoning. These strategies are summarized in Table 3, which represents my interpretation of the strategies and related understandings described by both Lamon (1994) and Lobato and Ellis (2010). 
Table 3

Strategies used to solve problems involving proportions

\begin{tabular}{|c|c|c|c|}
\hline Strategy & $\begin{array}{c}\text { Example } \\
\text { Qualitative strategy }\end{array}$ & $\begin{array}{c}\text { Example } \\
\text { Quantitative strategy }\end{array}$ & $\begin{array}{l}\text { Corresponding way of } \\
\text { reasoning/understanding }\end{array}$ \\
\hline Additive strategy & $\begin{array}{l}\text { If the length of the } \\
\text { photograph is increased } \\
\text { by three centimeters, so } \\
\text { is the width. }\end{array}$ & Inv & alid \\
\hline Random procedure & & $\begin{array}{l}\$ 35 / 0.40 \text { in order to find } \\
40 \% \text { of } \$ 35\end{array}$ & Invalid \\
\hline $\begin{array}{c}\text { Elementary } \\
\text { covariational strategy }\end{array}$ & $\begin{array}{l}\text { If the length increases, } \\
\text { so does the width. }\end{array}$ & $\operatorname{Pr}$ & e-proportional \\
\hline Estimation strategy & $\begin{array}{l}40 \% \text { off } \$ 35 \text { is a little } \\
\text { more than } 50 \% \text {, so the } \\
\text { jeans cost about } \$ 20 \text { on } \\
\text { sale. }\end{array}$ & $\operatorname{Pr}$ & e-proportional \\
\hline $\begin{array}{c}\text { Iterated-composed-unit } \\
\text { strategy }\end{array}$ & $\begin{array}{l}10 \% \text { to } \$ 3.50 \\
10 \% \text { to } \$ 3.50 \\
10 \% \text { to } \$ 3.50 \\
10 \% \text { to } \$ 3.50 \\
\end{array}$ & & Transition to scalar \\
\hline $\begin{array}{l}\text { Building-up/down } \\
\text { strategy }\end{array}$ & $\begin{array}{l}\text { If } 10 \% \text { off a } \$ 35 \text { pair of } \\
\text { jeans is } \$ 3.50 \text {, then } 40 \% \\
\text { off is } 4 \times \$ 3.50=\$ 14\end{array}$ & $\frac{40 \%}{10 \%}=\frac{x}{\$ 3.50}$ & $\begin{array}{c}\text { Scalar } \\
\text { (A quantitative strategy may or } \\
\text { may not indicate a } \\
\text { multiplicative way of } \\
\text { reasoning.) } \\
\end{array}$ \\
\hline Unit-rate strategy & & $0.40 \times \$ 35$ & Unclear \\
\hline Unit-rate strategy & $\begin{array}{l}40 \% \text { means } \$ 0.40 \text { off } \\
\text { every dollar. } \\
\text { So } 35 \times \text { x } \$ 0.40=\$ 14 \text { is } \\
\text { the discount. }\end{array}$ & $\begin{array}{l}\frac{40}{100}=\frac{x}{\$ 35} \text { or } \\
0.40 \times \$ 35\end{array}$ & $\begin{array}{c}\text { Functional } \\
\text { (A quantitative strategy may or } \\
\text { may not indicate a functional } \\
\text { way of reasoning.) }\end{array}$ \\
\hline
\end{tabular}

In conclusion, students who have been away from school may come to their mathematics classes with robust ways of thinking about quantitative problems, but ways of thinking that may be in conflict with what they are asked to do in their mathematics classrooms. For example, it is typical that problems that might elicit proportional reasoning are solved, in both textbook examples and by teachers, by setting up the equivalence of two ratios, cross-multiplying and dividing, a technique that has been described as "quantitatively vacuous" (Kaput \& West, 1994, p. 254). In fact, a common 
feature of the studies that document proportional reasoning in out-of-school practices is that adults do not use the cross-multiply-and divide algorithm outside of school. This has implications for instruction: "When school instruction, without considering students' everyday schema of proportionality, introduces the proportion algorithm from the outset, the schema of isomorphism of measures may compete with school-taught procedures" (Schliemann \& Nunes, 1990, p. 265).

Strategies for reasoning about percent. Although proportional reasoning may be used to solve problems involving percent, proportional reasoning strategies are not the only strategies that might be brought to bear. In a study that queried both school children's reasoning about percent before instruction and the ways instruction influenced this reasoning, Lembke and Reys (1994) classified eight strategy types students used on questions about percent: (1) reasoning with benchmarks, (2) transforming a percent to a fraction, (3) reasoning with a ratio, (4) using an equation, (5) computing and checking, (6) using trial and error, (7) reasoning with a picture, and (8) unclassified or no justification. Reasoning with benchmarks involves reasoning with 50\%, 25\% and/or $10 \%$; these strategies may lead to an exact computation or be used to make a reasonable estimate; Reasoning with a ratio is described as follows: "Sets up a comparison or a proportion to solve the problem or finds a proportionality constant" (p. 243). This is not necessarily writing and solving a proportion equation. For example, a student may argue that $21 \%$ of 400 is four times $21 \%$ of 100 or four times 21 . Computing and checking involves performing an operation (in the case of reasoning with percent, either multiplication or division) and determining which result is reasonable, whereas using trial and error involves making a guess, checking that value and then revising the guess. 


\section{Differences between Mathematical Activity in School and Outside of School}

"More generally, our data on the mathematics used in nursing confirm the disjunction

between visible mathematics—whether it is school mathematics or the mathematics introduced in training programs - and what happens in practice"

(Hoyles et al., 2001, p. 23).

Nurses do not rely on the nursing rule that is taught in many training programs as a way to bypass proportional reasoning when solving problems about medicine dosages. This rule is stated in nursing textbooks as follows:

$$
\frac{\text { Dose presrcibed }}{\text { Dose per 'measure' }} \times \text { number of measures }
$$

This rule was often invoked by the nurses in a more informal form:

$$
\frac{\text { What you want }}{\text { What you've got }} \times \text { The amount it comes in }
$$

But Hoyles and her colleagues observe that nurses compute dosages using both scalar and functional ways of reasoning. The authors offer an example of a building-down strategy use by a nurse to determine how to administer $1.5 \mathrm{mg}$ of morphine packaged in 20-mg ampules diluted to $10 \mathrm{ml}$ (Hoyles et al., 2001, p. 18): "I did it in my head. [Joe] worked it out, then I went, “Twenty mg in ten mils, that's ten mg in five mils, so that's five $\mathrm{mgs}$ in two poi' ... no wait, twenty $\mathrm{mg}$ in ten, ten in five, five in two point five, one in point five, and then one point five in point seven five." Another nurse uses what might be described mathematically as a functional way of reasoning, but this nurse understands the computation in terms of the particular drug: “'That's how it is with amakacine,' says Belinda, apparently seeing the allowable arithmetic operation and the drug itself as 
intimately connected" (p. 20). Context exerts a strong pull on the way nurses determine how to administer a prescribe dosage.

Hoyles, Noss and Pozzi (2001) describe the "disjunction between visible mathematics and what happened in practice" ( $\mathrm{p} 23$ ), and although Hoyles et al. consider the influence - or lack thereof - of school mathematics on practice, this disjunction may be just as evident to students who return to school after years of work, raising a family, and/or managing a household. In the following, I discuss three authors' perspective on the differences between mathematics in school and outside school, noting ideas that provide a perspective on examining how a student's proportional reasoning abilities may or may not interact with what she encounters in the Basic Math classroom. I conclude this discussion with a summary of some of the literature on adults' experiences in school mathematics.

Lauren Resnick (1987) describes four "discontinuities" between learning in school and learning outside of school: (i) individual cognition in school versus shared cognition outside, (ii) pure mentation in school versus tool manipulation outside school, (iii) symbol manipulation in school versus contextualized reasoning outside school, and (iv) generalized learning in school versus situation-specific competencies outside. The last two of the discontinuities described by Resnick are the most salient to this study. As discussed in the section on out-of-school mathematical practices, it has been observed that people reason within a particular context - and may use artifacts from a particular context as tools. Also, as discussed by Schliemann (1995), situation-specific competencies can be inadequate for revealing the mathematical structure that becomes the foundation for much of the generalized structure in school. Bridging this last 
discontinuity could be a primary goal of mathematics curricula for adult returning students.

Abreu (2002) also describes differences between mathematics outside school and in school. She notes that one primary difference is that outside school the focus is on developing a strategy for solving a problem rather than understanding mathematical structure. An example of this difference was discussed in Section 2.2 in the context of the street vendors who compute the sum of 100 sixes rather than six 100 s because the first strategy models the problem they are solving, How much does it cost for 100 candies at 6 cents each? In addition, Abreu explains transfer between contexts as (re)contextualizing: “(re-)contextualizing was suggested ... to encapsulate the idea that intellectual activity is embedded in sociocultural activities. The advantage of this concept over transfer is that contextualizing takes into account the social structuring of practice" (p. 335). Although researchers have considered how people use school mathematical knowledge in contexts beyond school (e.g., Boaler, 1993; Noss, Hoyles, \& Pozzi, 2000; Schliemann \& Acioly, 1989), there is a little research on how adults may re-contextualize their out-of-school experience when returning to a mathematics classroom.

In addition, Masingila and her colleagues (Masingila et al., 1996) describes three key differences between in-school and out-of-school mathematics practice: (i) the goals of the activity, (ii) the conceptual understanding of the person engaged in the activity, and (iii) flexibility in dealing with constraints. Within out-of school contexts mathematics is a tool for problem solving, whereas in school, learning mathematics is the goal of the problem. The authors suggest that the goal structure of school activities 
should model the goal structure of out-of school activities. For students in school, the procedure to be used is not dependent on context, but upon what chapter in the book a problem is posed. For this reason, the authors claim that choosing a strategy that depends on the context demonstrates more conceptual understanding. Finally, students have difficulty dealing with the types of constraints that are often present in problems encountered outside of school; the authors conjecture that this is due to a lack of constraints in the applied problems found in mathematics texts. In their concluding remarks, the authors note that they have not addressed the implications of their suggestions for curricula, teacher education or assessment, and they admit struggling with the following question: "Can all mathematics that should be taught in schools be taught by building on and formalizing out-of-school mathematics practice and learning?" (p. 198).

These distinctions between mathematical activity in school and outside of school suggest that adult students who have been away from school and from school mathematics bring different ways of thinking and problem solving to the classroom. As Jerome observed in the quote presented at the beginning of this proposal, he describes his way of thinking as "a strange way of figuring things out," 13 because his way of thinking did not conform to what was expected of him in the classroom. In addition, previous experience of school mathematics may suggest to returning students that in the mathematics classroom they cannot rely on familiar ways of thinking - for example, using tools or contextual clues to support reasoning (Resnick, 1987), or by reformulating or dissolving a problem (Lave, 1988) - they relied upon outside of school. Although

\footnotetext{
${ }^{13}$ A student who participated in a pilot interview also expressed this sentiment.
} 
children may have similar experiences in school, adults' out-of-school experience might present more of an obstacle to their experiences in school. Wedege (2000) writes, “... teaching which conflicts with the hidden mathematical competencies of the participants, e.g., their craft skills, can result in severe obstacles to learning" (p. 110).

Adults draw on their out-of-school experience when they return to school (Evans, 2000; Illeris, 2002; Wedege, 1999). This involves a transfer (or translation or recontextualization) of their knowledge across contexts (Abreu, 2002; Benn, 1997; Evans, 2000). In addition, learning mathematics as an adult involves overcoming one's previous experience of mathematics (Wedege \& Evans, 2006). Often teachers address adults students' previous experience of school mathematics by building their confidence (Benn, 1997; Mesa, 2010), but teachers often do this by supporting students' mastery of routine problems. Some argue that adults' learning in general and mathematics learning in particular must be transformative rather than formative (Mezirow, 1991; Wedege \& Evans, 2006), that is, an adult's perspective on what it means to learn mathematics in school may need to shift in a significant way. But Mezirow notes that, "Viewpoints that call our frame of reference into question may be dismissed as distorting, deceptive, illintentioned or crazy" (p. 18). In fact, in a recent book, Cox (2009) notes that community college student often resist pedagogies that do not conform to their expectations about teaching and learning. Transformative learning may be a significant characteristic of adults learning mathematics, but one that may or may not be supported by the mathematics courses students enroll in at a community college.

Lastly, the third research questions that guides this study queries how an adult student's mathematical ways of thinking developed outside school interact with the 
mathematics he or she encounters in Basic Math. I conceive of interaction in terms of a student's participation in several communities of practice (Wenger, 1998). The student's Basic Math classroom - the students, the instructor, the physical layout of the space and the curriculum materials - constitute one community of practice where mathematics learning occurred. However, the student's family, his or her social activities or job may also be communities of practice in which the student participates mathematically.

Participation is primary within this theoretical perspective. Understanding the ways a student's mathematics interact with the mathematics she or he encounters in Basic Math might query the extant that the student's participation in the Basic Math community provided her opportunities for "mutual engagement with other members, to their actions and their negotiation of expertise, and to the repertoire in use" (Wenger, 1998, p. 100). For example, what are the opportunities for mutual engagement for members of the classroom community, for participation in classroom activities and to collaborate with each other as they engaged in these activities? Members of the classroom community also negotiate the activities and forms of participation that are normative. In any community, the members negotiate what it means to be an expert participant, but in a mathematics classroom these negotiations might occur on different levels. For example, expert practice may be judged by where a student sits in the classroom or the questions she asks. Finally, the participants adapt the intended curriculum, the curriculum materials and ways of thinking that emerge within the community to develop a repertoire of tools for participation.

\section{Summary}

The conceptual framework that supports this study is grounded on three areas of 
research: adults' everyday mathematical practices and ways of reasoning within these practices; proportional reasoning; and the differences between problem solving within school and outside school. Relationships between these areas of research have also been discussed. The ways of thinking that a Basic Math student brings to the course is at the center of this study that examines a student's relationship with everyday mathematical practices, her proportional reasoning and how she connects her ways of thinking within the context of her Basic Math class. This study extends previous research on the development of proportional reasoning with its focus on adult returning students. In addition, research on adults' everyday activities revealed informal proportional reasoning in many of these activities and noted adults' lack of reliance on school-based procedures. This study seeks to examine whether adult returning students, who come from a wide variety of backgrounds and practical experiences, bring informal proportional reasoning strategies back into the Basic Math classroom; the research questions query whether informal strategies might be leveraged to support the understanding of more formal ways of reasoning about proportion. Finally, research in community college mathematics education is an emerging domain (Mesa et al., 2014; Sitomer et al., 2012). One characteristic that distinguishes community college mathematics education from mathematics education research conducted with K-12 students is the likelihood that community college students have been away from formal schooling and often need to "unlearn deep-rooted misconceptions about mathematics built from previous (mostly negative) experiences and reconcile their 'real world' experiences with their concepts, as they may clash with the academic presentation done in the classroom" (Mesa et al., 2014, pp. 175-176). This study seeks to understand one 
instructional context - teaching proportion in a Basic Math course - in which the 'clash' between everyday and school mathematic may emerge. Finally, practitioners and researchers interested in community college mathematics education have noticed a lack of attention to community college students' mathematical understandings in the discussion of the challenges of developmental mathematics education:

Research is needed to augment our knowledge base on community college students' understanding of mathematical notions, their attitudes and motivations, and their expectations of and dispositions toward mathematical work in a community college classroom. Rather than proposing general characterizations of community college mathematics students, like most studies available today, we seek to understand better their mathematics learning trajectories. For example, do adults follow similar learning trajectories as children when learning about fractions (or other topics taught in school mathematics)? (Mesa et al., 2014, p. 182).

This study seeks to advance our understanding of the type of questions outlined in the research agenda on community college mathematics, that is, what do adult students understand about solving problems involving proportion and how do their informal ways of reasoning interact with the mathematics they include in Basic Math? 


\section{Chapter 3: Methodology}

\section{Overview of data collection}

Three sources of data will be used to address the research questions.

- A survey was administered to participants from a random sample of sections of Basic Math. Survey questions were written to solicit information about participants' experiences with mathematics both in school and outside of school, as well as to query the strategies use to solve problems involving proportions. The intent of the survey is to develop a broad perspective on the proportional reasoning abilities of students who place into a Basic Math course at a community college.

- Task-based interviews were conducted with seven participants prior to the academic term. The tasks assessed the participants' proportional reasoning abilities and have been adapted from tasks used in other studies of proportional reasoning. The interview also queried participants about the occasions for problem solving in their lives, exploring the extent to which the interview tasks resemble or do not resemble quantitative problems the participants encounter outside of school. Finally, the interview included questions to help me understand the participants' prior experience with school mathematics, as well as their expectations for Basic Math.

- Ethnographic data documenting one student's experience as she returns to school mathematics were collected during the Winter term 2012. One informant was chosen from the participants in the task-based interviews described above. The ethnographic data included my field notes as I attended Basic Math classes with the participant, 
interview data from regular conversations with the informant held during the term, and artifacts from the informant's class.

There were two principal reasons for the decision to use three data sources for this study. First, too little is known about the students who place into the Basic Math course beyond the scores they receive on mathematics placement exams and the grades they receive in the course. The survey data provides information about this population of students in general ${ }^{14}$. The task-based interviews allowed me to understand a participant's mathematical ways of thinking in way not possible using only students' written mathematical work. Finally, the ethnographic data provided one student the opportunity to speak in her own voice about the experience returning to school mathematics, and in particular about her experience in the Basic Math course. The cultural and mathematical experience of teachers may be entirely different from the experience of students in our classes. The ethnographic data helps us understand the third question: "How do a student's proportional reasoning abilities interact with the mathematics he or she encounters in a Basic Math class?" The question should not be addressed from the perspective of expertise of the teacher, but rather from the perspective of the students whose experiences with school mathematics likely bear little resemblance to the experience of their teacher. Instead, what can be learned from the students themselves? All three data sources tackle this question from different perspectives.

\footnotetext{
${ }^{14}$ These data will be gathered across the several campuses of one community college and for this reason, would not tell us about this population of community college students taking courses like Basic Math as a whole. However, later studies might use the survey at other community colleges and results could be compared, revealing similarities and differences between different parts of the country or different settings (for example, urban, suburban or rural).
} 
The three sources of data also allowed me to consider the research questions from different perspectives. The survey data provides a broad perspective on the students who enroll in Basic Math and the extent of proportional reasoning among this particular group of community college students. The interviews that follow allowed me to explore further findings from the survey and to learn more about the students' ways of reasoning mathematically. The final part of the study followed the interviews in order to focus on the way one student's way of thinking interacts with the mathematics curriculum she encountered in Basic Math.

When a participant presents a written solution to a mathematics problem on a survey, there is something that can be learned, but we cannot know whether the strategy used is the first strategy a participant might choose if he or she was not being surveyed in a mathematics classroom. The literature on the differences between everyday mathematics and school mathematics suggests that students may expect the teacher (or researcher) will anticipate that a student recalls a particular strategy. In addition, a student's written annotations of a problem solution will allow the strategy to be classified as a particular type, but these annotations only give a partial picture of the student's mathematical thinking. In addition, we cannot conclude that no response to a problem indicates a participant is unable to solve the problem. For these reasons, the interview setting revealed more about the extent of the participant's mathematical ways of reasoning (Goldin, 1998). Finally, although the mathematical tasks used on both the survey and in the interviews are set in contexts that would be familiar to many, these problems might resemble school mathematics problems more than the types of problems returning students typically encounter in their lives outside school. For this reason, 
participants' thinking about the problems might provide a limited view of the participants' mathematical abilities. To remedy this difficulty, asking a participant to talk about the mathematics in his or her life and how the mathematics s/he know interacts with the mathematics encountered in class provided a broader perspective on a student's mathematical abilities.

The findings from the interviews and the ethnographic data may not be generalizable, but these findings provided a perspective on what was learned from the survey data. In addition, these findings suggested questions that could be further explored in subsequent studies. The three different data sources presented opportunities to understand different perspectives on the question of adult returning students' mathematics and, in particular their proportional reasoning to triangulate findings from the different data sources, leading to greater confidence in the conclusions from the study (Firestone, 1987; Miles \& Huberman, 1994).

\section{The survey ${ }^{15}$}

The survey data addresses two of the research questions: What is the background of students who enroll in a Basic Math course and what is their experience of mathematics in their lives and in school? and What proportional reasoning abilities do students placing into Basic Math demonstrate prior to returning to school mathematics?

The survey was developed and piloted twice prior to data collection for this study.

During the development of the survey, a draft of the survey was shared with instructors who teach both developmental reading and developmental mathematics. The draft was also shared with researchers with expertise surveying community college students and

${ }^{15}$ The survey is included in Appendix A. 
faculty. The survey was refined based on the suggestions from these colleagues and then shared with instructors who teach Basic Math for further input. After several revisions, the survey instrument was first piloted with 25 students in my own Basic Math class on the first day of class Fall Term 2010. The survey was piloted again on the first day of Winter Term 2011 in four sections of Basic Math taught by two other instructors; 111 surveys were completed during the second pilot. These pilots were used to revise and refine questions, to discover which mathematical questions revealed participants' reasoning and, finally, to determine the amount of time needed for participants to complete the survey and adjust the survey so that most participants would finish in 15 minutes. The second pilot was also used to assess whether the directions given to the instructor were adequate. These pilots led to the development of the survey used in this study. This survey is included in Appendix A.

The survey was used to gather biographical data about the participants, including how long participants have been away from school mathematics, what occupations participants have undertaken in the interim (e.g., work, military service, raising a family, unemployed or under-employed) and information about a participant's academic plans. In addition, the survey queries participants' previous experience with school mathematics and the situations in which participants use mathematics outside of school.

The survey also included four mathematics problems and a question about which of these problems were easy or difficult for the participants and why. Two of the mathematics problems were adapted from problems used to study school children's proportional reasoning ability. The first of these was adapted from a problem used by Susan Lamon (1993): 
Valentine's Day is approaching, and you want to buy flowers for someone special.

Three flower stems cost \$2. How much will 15 stems cost?

This is an example of an associated set problem: a number of flowers is associated with an amount of money. This problem was included because of its simplicity; it could be used to establish a floor for students' proportional reasoning strategies. The second problem adapted from the research literature comes from the work of Gerard Vergnaud (2004):

A cook is planning for a group of 50 people who will spend 28 days at a summer camp. He needs to buy enough flour for baking bread and the cook knows that the average consumption of flour is 4 pounds per week for 10 persons. How much flour does he need to buy?

This problem was chosen because of its complex structure and its structural similarity to the scaling problems that have been documented as difficult in prior research. Vergnaud described this problem as a multiple proportion because the amount of flour needed varies with both the number of people and the duration of the stay.

The third problem is taken from the released NAEP items from $1996^{16}$ :

Victor's van travels at a rate of 8 miles every 10 minutes. Sharon's sedan travels at a rate of 20 miles every 25 minutes.

\footnotetext{
${ }^{16}$ Every two years the National Assessment of Education Progress (NAEP) exam collects data nationwide on the mathematical abilities of students in Grades 4, 8 and 12. Some of the test items have been released and are available online: http://nces.ed.gov/nationsreportcard/. Students' performance on each item is also available.
} 
If both cars start at the same time, will Sharon's sedan reach point A, 8 miles away, before, at the same time, or after Victor's van? Explain your reasoning.

If both cars start at the same time, will Sharon's sedan reach point B (at a distance further down the road) before, at the same time, or after Victor's van? Explain your reasoning.

A NAEP problem was selected so that the surveyed participants' performance on the problem could be compared to the performance of the students who were presented with this problem on the NAEP exam. This particular problem was chosen for three reasons: (i) The problem was used on the $8^{\text {th }}$ grade NAEP exam and the mathematical content students encounter in Basic Math is consistent with the mathematics studied in middle school; (ii) The $8^{\text {th }}$ grade students had difficulty with this problem (only $14 \%$ presented a correct solution); and (iii) Reasoning about rates is a significant mathematical skill. This problem presented an opportunity to explore whether or not adult participants fare better than the $8^{\text {th }}$ grade students who took the NAEP exam, querying whether adult students' life experiences contribute to their abilities to reason proportionally.

The final mathematics problem is a problem involving percent discount:

Fred Meyer is having a sale. A \$35 pair of jeans is marked $40 \%$ off. Can you buy the jeans for $\$ 20$ or less? How do you know?

This problem was chosen because solving problems involving percentages is an explicit topic in the Basic Math curriculum and the context of shopping is likely a familiar one for adult students. 
Other data about a participant's experience with mathematics was collected using the survey. Participants were asked to reflect on the mathematics they use in their daily activities and how frequently they use mathematics outside of school. Participants were asked to describe their previous experience with the topics explored in the Basic Math course; responses to this question allowed me to determine how many participants in the sample only need a review of these topics versus how many needed to learn these topics. In addition, Bailey and Cho (2010) suggest that there are students enrolled in developmental mathematics courses due to difficulties with English. This option is provided in order to query whether or not this is the case at the community college at which the study is being conducted.

Survey Participants and Data Collection. Cluster sampling was used to survey students in their mathematics classrooms during the first week of fall term 2011. Sections of Basic Math throughout the community college district were selected at random by a staff member in the college's institutional research office. The number of sections sampled at each campus was proportional to the total number of sections offered at the campus. The instructors of the selected sections were not required to administer the survey, but the instructors of 13 of 21 sections sampled were willing to administer the survey. (The number of sections sampled was more than necessary to obtain a representative sample since not all instructors were expected to participate.) In all, 340 student surveys were collected in 13 sections of Basic Math, approximately $21 \%$ of the total number of sections offered that term. Table 4 describes the sample in terms of each of the four campuses of the college. 
Table 4

Survey sample

\begin{tabular}{|lccc|}
\hline & Number of & Percentage & sections \\
Campus & sections $^{\mathrm{a}}$ & of total & surveyed \\
Northside 15 & & $26 \%$ & 4 \\
Westside 17 & $24 \%$ & 4 \\
Eastside 9 & $0 \%$ & 0 \\
Southside 16 & & $25 \%$ & 4 \\
Extended 4 & & $25 \%$ & 1 \\
& & & \\
Total 5 & 0 & & 13 \\
& & & \\
\hline
\end{tabular}

a This was the number of sections being offered when the sample was selected. Occasionally some sections are canceled while others added prior to the term.

Analysis of survey data. The biographical data from the survey situates both the setting of the research and the participants, in particular, the background of the students who enroll in Basic Math. This particular population of students is under-represented in the mathematics education literature and may be unfamiliar to researchers in mathematics education, since there is no analogue to this population of students or to the Basic Math course in K-12 or university mathematics. A summary of the surveyed students' demographics is presented at the beginning of Chapter 4, providing a partial answer to the first part of the first research question, "What is the background of students who enroll in Basic Math and what is their experience of mathematics in their lives and in school?

The survey data was used to address the first two research questions and the analyses conducted using these data were different for each question. More details of the 
particulars of analysis of the survey data for the first research question are presented in Chapter 4 and for the second question in Chapter 5. However, an overview is provided here.

The data from the survey provided a list of activities that students enrolled in Basic Math perceived as mathematical. Bishop's six pan-cultural mathematical activities - counting, locating, measuring, designing, playing, and explaining (Bishop, 1988) were used to organize these activities and to understand better students' experience of mathematics outside school.

In order to answer the second research question, and "What proportional reasoning abilities do students placing into Basic Math demonstrate prior to returning to school mathematics?", participants' reasoning on four mathematics problems was initially analyzed using a priori categories described in the research literature on proportional reasoning ${ }^{17}$ (Miles \& Huberman, 1994). These data were also mined for ways of thinking not previously described in the research literature, but adults' strategies on these four problems were aligned with strategies described in previous research. This preliminary analysis of students' work on the four mathematical tasks from the survey raised several questions as well, which were used to develop mathematical tasks for the interview. This preliminary analysis was shared with other researchers in order to determine next steps for analysis and the development of tasks for the interviews. (Findings from this preliminary analysis are included in Appendix D.)

The preliminary analysis of students' work on the mathematical tasks from the survey led to a refinement of the a priori categories used to consider the data initially. A

17 The strategies provided in Table 3 were be the starting point for a list of a priori categories used to code both the from students' work on the mathematical problems on the survey. 
four-strategies framework was developed for the final analysis of these data. The framework is described in detail in Chapter 5, but it was developed from strategies previously described in the research literature (an iterated-composed-unit strategy, a building-up strategy, a scalar strategy and a unit-rate strategy) and was useful in understanding the way students were using these strategies on different types of problems.

The survey instrument as a recruitment tool. The survey was also used to recruit participants for the task-based interviews. The 600 students, who had registered for Basic Math six weeks prior to the start of winter term 2012 and were not repeating Basic Math at the college, were contacted by email and asked to complete and return the survey to indicate their willingness to participate in the task-based interviews.

\section{Task-Based Interviews}

The second phase of the study consisted of task-based interviews conducted with seven students during the break between Fall quarter 2011 and Winter quarter 2012. Like the survey data, the interview data addresses the first two research questions. The task-based interviews were designed to uncover participants' proportional reasoning abilities in more detail than students' written work on the surveyed allowed. The interview was also used to understand participants' experiences of mathematics in school and outside school.

Interview participants and data collection. Participants in this phase of the study were community college students who had enrolled in Basic Math, but had not started the course. Prior to the study, it was proposed to select a purposeful sample of students from among those who responded to the recruitment email. It was proposed that 
the purposeful sample would be compared to the population as a whole using dimensions that would be determined using results from the survey. However, out of the 600 students contacted by email, only seven expressed willingness and were able to participate. I introduce the interview participants in Chapter 4 and discuss possible reasons why each self-selected for the study. Subjects were interviewed prior to the start of the Winter Term 2012 in order to assess students' proportional reasoning abilities before their first mathematics class at the community college. Each participant was interviewed once and individually. The interviews ranged in length from 65 to 100 minutes.

There are two implicit assumptions when using task-based interviews to learn about participants' mathematical thinking (Schoenfeld, 1985): (i) problem solving in the context of the interview bears some relation to the participant's problem solving on other contexts, and (ii) thinking aloud while problem solving provides a record of the participant's thinking. Both of these assumptions are problematic, but task-based interviews are considered a viable tool for understanding a subject's mathematical thinking (Goldin, 1998, 2000). The participants in the interview were asked how the interview tasks either resemble or do not resemble the types of quantitative problems they encounter in their lives. The interviews were video recorded and transcribed verbatim.

The interview tasks. Some of the mathematical tasks used during the interview were selected or adapted from the research literature on proportional reasoning. Other tasks were written based on the preliminary analysis of the survey data. The interview tasks were structured around the four mathematical tasks included on the survey: the 
Flower Stem, the Percent Discount, the Bread Flour and the Comparing Speeds problems ${ }^{18}$. Each participant had submitted written work on the mathematical tasks from the survey prior to the interview. First, a participant was asked to explain his or her reasoning on the written work on the particular survey problem under consideration. Next, the participant considered other strategies students had used to solve the problem (this was not done for the Bread Flour problem). The sample strategies were from the survey data and were shared with participants in order to query whether or not their were other strategies the participant might use if thinking about a similar problem in another context. Finally, the student considered either variations of the survey problem or similar problems in order to query questions that emerged during the preliminary analysis of the survey data. I summarize the variations of each survey problem and my rationale for selecting each problem.

Flower Stem problem variations. Two variations of the flower stem problem were included in the interview:

The first variation of the Flower Stem problem

Suppose 18 flower stems cost \$15. How much would you pay for 6 flower stems? The second variation of the Flower Stem problem

Suppose 18 flower stems cost \$15. How much would you pay for 21 flower stems?

The preliminary analysis of the survey data revealed that more students than expected used building-up strategies to solve this problem, but it was unclear whether students were using building-up strategies to explain scalar reasoning or if these strategies were

${ }^{18}$ The text of all problems used in the study is included in Appendix C. 
tools for reasoning about the problem. For example, a student may have recognized that 15 flower stems is five times three stems, but iterated the composed unit 3 flower stems to $\$ 2$ to illustrate how she knew 15 is five times three, but the only tool another student had to solve the problem was iterating the composed unit. To use scalar reasoning on the first variation would require recognizing that six stems is one-third of 18 stems and this would not be as easy to represent using a building-up (or in this case, as partitioning strategy).

The survey data also revealed that shopping was a frequently cited activity perceived as mathematical by students. The next problem included on the survey built on the shopping context, a problem that was not a variation of one of the survey tasks.

\section{The Better Buy problem}

Which is the better buy? An 8-ounce stick of deodorant priced at $\$ 4.50$ or a 12ounce stick priced at $\$ 6.50$ ?

The Better Buy problem was adapted in two ways from a problem used by Capon and Kuhn (1979) in a study of adults' proportional reasoning. The problem was adapted in two ways. First, the prices were updated to represent more accurately the current cost of deodorant. Second, the numbers used by Capon and Kuhn required pencil-and-paperstrategies to compute a unit cost. I chose numbers so that there was an alternative to a unit-cost strategy; a 12-ounce stick of deodorant is 1.5 times the size of an 8-ounce stick. This problem was included because it is possible to reason to a conclusion without computing a unit cost, querying whether students might reason using a multiplicative comparison. 
Percent discount problem. The preliminary analysis of the survey data revealed that students used a variety of strategies to reason about percent, including working with estimates, using benchmarks such as $50 \%$ and $10 \%$ to determine a $40 \%$ discount, and reasoning contextually (a $40 \%$ discount means $\$ 4$ each $\$ 10$ ). I was interested in knowing whether or not students would draw on a similar variety of strategies when reasoning about a problem in which the whole (base amount) is unknown, a type of percent problem that is typically difficult for students (Parker \& Leinhardt, 1995). The Ticket Sales problem was included to address this question:

The Ticket Sales problem

The number of people buying season tickets for Blazer games decreased $40 \%$ from last year's numbers, leaving only 1200 season ticket holders this year. How many season ticket holders were there last year?

A student reasoning contextually might recognize that a decrease of $40 \%$ from last year means that the 1200 season tickets sold this year represent $60 \%$ of last year's sales. A partitioning or scalar strategy might be used to determine, for example, that $10 \%$ of last year's sales is 120 season tickets, a composed unit that could be built up again to determine that $100 \%$ of last year's sales is 1200 season tickets.

The Bread Flour problem. The preliminary analysis of the survey data indicated that more than one-third of the students surveyed were able to solve the Bread Flour problem, but students written responses were insufficient for making conjectures about what students understand about joint variation. The following three variations of the Bread Flour problem were included in the interview protocol. The first varied the number of people who would be coming to the camp, the second varied the duration of 
the stay, and the third variation varied both quantities. The problems were included in order to query whether or not a participant's words suggested an understanding that two quantities were varying jointly.

$\underline{\text { The first variation of the Bread Flour problem }}$

The cook needs 80 pounds of flour for the 50 people who are coming to the camp for 4 weeks. How much flour will he need if 250 people show up instead? The second variation of the Bread Flour problem

The cook needs 80 pounds of flour for the 50 people who are coming to the camp for 4 weeks. How much flour will he need if 50 people come to the camp for only 2 weeks?

The third variation of the Bread Flour problem The cook needs 80 pounds of flour for the 50 people who are coming to the camp for $\mathbf{4}$ weeks. How much flour will he need if $\mathbf{1 5 0}$ people show up for $\mathbf{2}$ weeks?

Comparing speeds problem. The preliminary analysis of the survey data revealed that the second part of the Comparing Speeds problem was problematic without the picture that was included in the NAEP assessment item. For this reason, only the first part of the problem was used for analysis. An alternate speed-comparison problem was discussed with the interview participants.

The Two Joggers problem

Who is the faster jogger? A women who runs 2 miles in 25 minutes or her partner who runs 3 miles in 39 minutes? 
This problem shares some structural similarities with the Comparing Speeds problems; the units of measurement for distance and time are the same and it is a comparison problem. Yet this variation suggests comparing speeds not in miles per minute, but in minutes per mile, a unit familiar to runners, but not necessarily to non-runners. In addition, the numbers used in this alternative problem could lead to a building-up strategy using both composed units in order to compare the two rather than building up just one composed unit in order to compare it to the second. One last problem about speed was included in the interview protocol:

The Speed as Proportional Reasoning problem A person travels 125 miles in 21/2 hours at a constant speed, how far does she travel in $1 / 2$ hour?

This problem was adapted from Carlson and Oehrtman (2009). The context of this problem is the same as the Comparing Speeds problem, but the structure is different. A student might use a unit rate strategy, but may also recognize that the person travels onefifth of 125 miles in 0.5 hour, suggesting an understanding speed in terms of proportional reasoning (Thompson, 1994).

Analysis of interview data. Participants' proportional reasoning In order to address the question, What proportional reasoning abilities do students placing into Basic Math demonstrate prior to returning to school mathematics? the interview transcripts and the participants' written work on the mathematical tasks were analyzed using a four-strategies framework, based on strategies described in previous researched, which was summarized in Table 3 . The framework and how it was to analyze the interview transcripts is described in detail in Chapter 5. Finally, the interview transcripts 
were used to identify relevant text, repeating ideas and themes (Auerbach \& Silverstein, 2003) with respect to the participants' experience of mathematics in their lives and in school. Analytic memos (Strauss \& Corbin, 1998) were written to describe and unpack the emerging themes. Further details about this phase of the analysis are discussed in Chapter 4.

\section{An adaptive ethnographic approach}

Ethnographic data, including interviews with a Basic Math student and field note data from her classroom, were collected to address the third research question, How do a student's proportional reasoning abilities interact with the mathematics he or she encounters in a Basic Math class?

Schliemann and Nunes (1990) conjectured that everyday ways of reasoning proportionally conflict with school-taught procedures for solving proportion problems. In Chapter 5 I document that prior to Basic Math, students do not use school-taught procedures, such as writing and solving a proportion equation, to solve proportion problems. The data collected to answer the third research question allowed me to query whether or not the conflict between informal and school-taught procedures was salient for one student. If not, then I wanted to know what is the nature of the interaction between one student's proportional reasoning and the mathematics she encountered in her mathematics course.

However, this part of the study was not ethnography in the sense that it is not my primary purpose is to discover both questions and answers from the student-informant (Spradley, 1979). Although I expect several interesting questions might emerge from the analysis of these data, the primary purpose of the ethnographic data was to provide 
plausible answers to the research questions.

Ethnographic participant and data collection. One informant was chosen from the participants in the task-based interviews, Sasha ${ }^{19}$. All the interview participants were willing to participate in the third part of the study and Sasha was selected for convenience. It was possible for me to attend classes with Sasha and her instructor, Ms. Rose, was willing to allow me to be participant-observer in the classroom. In addition, Sasha had time after class to meet for a weekly interview.

Several forms of data were collected: (i) my field notes from Sasha's Basic Math class; (ii) artifacts from Sasha's Basic Math class, such as activities, quizzes and exams; (iii) six interviews with Sasha; and (iv) an auto-ethnography to record how I am affected by what I learn about adult returning students and "to account for the sources of emergent interpretations, insights, feelings, and the reactive effects that occur as the work proceeds" (Eisenhart, 1988, p. 106).

Field notes were taken as I observed the Basic Math class. The field notes contained more than one type of record. The notes contained a record of the classroom geography. For example, during each class meeting I recorded where students were seated in the classroom, the gender of these students, where my ethnographic informant sat and where I sat. Other features of the geography were not as flexible, but occasions when students left their seats to go to the board, to collaborate with others or to participate in an activity were also noted. The field notes also contained a record of the problems discussed during class. For example, I identified the problems from the text about which students had questions, described the examples that the instructor presented

${ }^{19} \mathrm{JR}$ and Roo were also informants during the early part of the term, but they did not persist in their Basic Math course. 
to the class and the way she presented the mathematics present in each example. The field notes contained a record of occasions when either the instructor or a student brought up an example of everyday activities or related the mathematics under discussion to an everyday activity. I wanted to be able to use the field notes to provide a rich description of the classroom, and in particular, occasions for proportional reasoning that occurred. As each class progressed and over the course of the term, I included in the field notes answers to questions I asked to obtain a better understanding of what was happening.

Questions I posed included the following: Was proportional reasoning explicit in the teacher's enactment of the curriculum and if so, in what ways? What were the teacher's expectations for mathematical activity in the classroom? What were the students' expectations of their role in the classroom? How did the students interact with the teacher, other students and the mathematical activities in which they engaged during class? Did students ask questions, and if so, who asked questions and what types of questions did they ask? Did students ever challenge the mathematics presented by the teacher?

In the classroom I was a participant-observer. During class activities, I sometimes participated as a fellow student and at other times I observed and asked questions. The students knew I was both a graduate student and an instructor at the college and not a student, so I chose to participate selectively. For example, when students were asked to collaborate with neighbors to solve a problem, I observed 
students at work ${ }^{20}$ and asked questions. However, when the activity involved inquiry or engaging in 'play,' I would participate. During lecture, I took notes and did not participate in whole-class discussion. I took quizzes and exams with students, and about halfway through the term, I started completing the out-of-class assignments.

The informant's Basic Math class met one day per week for four hour over a 10week term. The informant and I met for about one hour after class to talk about her experiences in Basic Math, although our schedules did not allow us to meet every week. Our interviews were conducted the first, second, fourth through sixth and ninth weeks of the term. We met one last time the first week of the following term. Interview questions ranged from grand tour questions to learn about the role of mathematics in the student's life to more structural questions to unpack meanings and discriminate between concepts relevant to the informant's experience (Spradley, 1979). In particular, I wanted to understand the ways the informant perceived the expectations for mathematical activity and learning in her classroom and how this related to her prior experience with mathematical tasks both out-of-school and within school. However, I did not always stay in my researcher's role during the interview. For example, I felt an ethical obligation to answer informant's mathematics questions.

Finally, the auto-ethnography helped me understand my role as a participantobserver in the classroom, my role in my relationship with Sasha and helped me articulate and interpret what I was learning from Sasha and her experience in Basic Math.

\footnotetext{
${ }^{20}$ I obtained informed consent from all but two students in Sasha's Basic Math class for making notes of their participation in class and allowing me to observe their work and ask questions.
} 
Analysis of ethnographic data. The analysis of the ethnographic data is described in detail in Chapter 6. In this chapter, I outline the perspective on ethnography in mathematics education that informed this part of the study. In the late 80s, Eisenhart wrote a seminal article on ethnography and educational research (1988). In this article, she argued that findings from ethnography can and should be made replicable if the researcher carefully describes "(a) the choice and use of settings and people in the study, (b) the social conditions under which the study took place, (c) the role and status of the researcher in the study, (d) the theoretical and analytic constructs used to guide data collection or analysis, and (e) the data collection and analysis procedures used" (Eisenhart, 1988, p. 108). In the following, I address each of these claims with respect to this study.

- Choice and use of settings and people in the study. The rationale for the decision to research community college mathematics education, and in particular, Basic Math, was made in Chapter 1. The question, "Why Sasha as an ethnographic informant?" is addressed in Chapter 6.

- The social conditions under which the study took place. The social conditions under which the study took place include the following: the context of community college mathematics education (described in Chapter 1), the Basic Math classroom (described in Chapter 6) and the background of the ethnographic informant (described in Chapter 6).

- Role and status of the researcher in the study. My relationship with the ethnographic informant and the students in her Basic Math classroom is described in detail in Chapter 6. 
- Theoretical and analytic constructs used to guide data collection or analysis.

In Chapter 2, I discussed the three areas of research that inform this study, and in particular, the adaptive ethnographic approach that was used for this part of the study: adults everyday mathematics, which encompasses informal proportional reasoning; the proportional reasoning research; and research on difference between everyday mathematics and school mathematics.

- Data collection and analysis procedures used. The data collection and analysis procedures used are described in detail in Chapter 6, but these analytic procedures are introduced here.

Ethnography is a complex analytic tool. Eisenhart (1988) describes tracing all possible relationships and explanations in the data until convinced of the validity of the findings and looking for events or data that either disconfirm findings or present alternative explanations of what is going on and why. Spradley (1979) writes, "Ethnographic analysis is the search for the parts of a culture and their relationships as conceptualized by the informants" (p.93, emphasis in the original). In the context of this study, I was interested in particular aspects of the informant's experience. For example, how will the mathematical understandings and ways of reasoning the informant brought to Basic Math relate to her mathematical work in Basic Math? How are events like negotiating the expectations for mathematical activity in the classroom experienced by Sasha? Finally, the analysis focused primarily on Sasha's mathematical ways of thinking, and in particular, her ways of reasoning proportionally both within and beyond the classroom. Wolcott (1994) distinguishes analysis of ethnographic data from description and interpretation: "Description addresses the question, 'What is going on 
here?' Data consists of observations made by the researcher and/or reported to the researcher by others. Analysis addresses the identification of essential features and the systematic description of interrelationships among them - in short, how things work. Interpretation addresses questions of meaning and contexts: 'How does it all mean?' 'What is to be made of it all?'” (p. 12). The analysis presented in Chapter 6 includes description and analysis, as described by Wolcott. The interpretive phase is left for further inquiry.

\section{Summary}

This chapter outlines the methodology used to address the three research questions: (1) What is the background of students who enroll in a Basic Math course and what is their experience of mathematics in their lives and in school? (2) What proportional reasoning abilities do students placing into Basic Math demonstrate prior to returning to school mathematics? and (3) How do a student's proportional reasoning abilities interact with the mathematics he or she encounters in a Basic Math class? In Chapters 4 through 6, I describe in detail the data sourced and analytic techniques used to address each question, as well as the findings from this analysis: Chapter 4 focuses on Research Question 1, Chapter 5 on Research Question 2, and Chapter 6 focuses on Research Question 3. 


\section{Chapter 4: The Students and Their Mathematical Experience}

In this chapter I present findings related to my first research question, "What is the background of students who enroll in a Basic Math course and what is their experience of mathematics in their lives and in school?" This question is asked because little is known about adult learners who return to study developmental mathematics at a community college beyond institutional data such as students' pass rates and their persistence - or lack of it -- within the development mathematics curriculum. For this reason, I chose to learn more about the adult learners who enroll in Basic Math. For example, based upon distinctions between mathematics learning in school and outside school, I wanted to understand these learners' past experiences with school, and more importantly, the ways adult learners position themselves with respect to mathematics both within school and outside school. Based upon previous research on adults' everyday mathematical practices, I wanted to learn about the everyday activities adult learners perceive as mathematical and how they perceive their own competence with respect to these activities. Bishop's discussion of pan-cultural mathematical activities (1994) led me to wonder whether there culturally situated activities that adult learners view as mathematical that we, as their teachers, may not be familiar.

The conceptual framework for this study is grounded on three areas of inquiry the development of proportional reasoning, adults' out-of-school mathematical practices and the distinction between mathematical activity in school and outside school - as well as the relationships between these areas of inquiry. In this chapter I focus primarily on the latter two areas of inquiry, which I summarize briefly here. 
Adults do not typically use procedures they learned in school when performing computations in their everyday lives (e.g., Lave, 1988; Schliemann \& Nunes, 1990). In addition, problem solving is frequently context dependent. For example, a vendor computes $100 \times 6$ rather than $6 \times 100$ because the first product has contextual meaning (Schliemann, 1995). Context can also be used as a tool for reasoning, as when a dieter determines three quarters of two-third cup of cottage cheese by putting the cottage cheese on a plate, marking it in quarters and removing one quadrant (Lave, 1988). This last example highlights one of the differences between mathematics in school and everyday mathematics. School mathematics is symbolized and the goal of mathematical activities is to describe and use mathematical structure. The goal of everyday mathematics is different; the goal is to solve the problem using strategies and ways of reasoning that are often context dependent (Masingila, 1993; Resnick, 1987).

\section{Methodology}

Two forms of data are used to address the first research question: survey data and data from task-based interviews with students.

Survey data collection and analysis. Cluster sampling was used to survey students in their mathematics classrooms during the first week of fall term 2011. Sections of Basic Math throughout the community college district were selected at random by a staff member in the college's institutional research office. The number of sections sampled at each campus was proportional to the total number of sections offered at the campus. The instructors of the selected sections were not required to administer the survey, but the instructors of 13 of 21 sections sampled were willing to administer 
the survey. (The number of sections sampled was more than necessary for a representative sample since not all instructors were expected to participate.) In all, 340 student surveys were collected in 13 sections of Basic Math, approximately $21 \%$ of the total number of sections offered that term. Table 5 describes the sample in terms of each of the four campuses of the college.

Table 5

Survey sample

\begin{tabular}{|c|c|c|c|}
\hline Campus & $\begin{array}{c}\text { Number of } \\
\text { sections }^{\mathrm{a}}\end{array}$ & $\begin{array}{c}\text { Percentage } \\
\text { of total }\end{array}$ & $\begin{array}{c}\text { Number of } \\
\text { sections } \\
\text { surveyed }\end{array}$ \\
\hline Northside 15 & & $26 \%$ & 4 \\
\hline Westside 17 & & $24 \%$ & 4 \\
\hline Eastside 9 & & $0 \%$ & 0 \\
\hline Southside 16 & & $25 \%$ & 4 \\
\hline Extended 4 & & $25 \%$ & 1 \\
\hline Total 5 & 0 & & 13 \\
\hline
\end{tabular}

a This was the number of sections being offered when the sample was selected. Occasionally some sections are canceled while others added prior to the term.

The survey included 10 demographic questions, three questions that queried students' experience with mathematics in their everyday life and in school, and four mathematical tasks. The survey instrument is included in Appendix A.

Three questions from the survey addressed students' experience with mathematics in their lives and in school:

1. List all your activities from yesterday. Put an M next to any activity that involved math. 
2. I use math outside school

all the time frequently occasionally never

3. In Basic Math, you will study ratios, proportions, fractions, decimals and percentages. Choose the category (or categories) that best describes your experience with these topics.

I felt good about these topics when I was in school, but I need a review.

I struggled with these topics in school.

I feel my math skills are good, but I am still learning English.

I am still learning English, but I also struggle with these topics.

None of the above

If none of the above, please explain.

The first two of these questions were included to learn how adult students perceive themselves as people who use mathematics and what activities from their everyday life they perceive as mathematical. I was interested in understanding students' quantitative worlds from their own perspective, which is why the first question was framed in terms of students' own everyday activities. The third question queried whether a student perceived that the Basic Math course would be a review or whether the topics explored in the course were topics that the student still needs to learn, two categories of students served by developmental mathematics education. It has been conjectured (Bailey \& Cho, 2010) that non-native English speakers are frequently misplaced into developmental 
mathematics, so this item also queried whether this was the case for this sample of students enrolled in Basic Math.

In order to examine the activities adult students perceive as mathematical in more detail, Bishop's (1988) six pan-cultural mathematical activities - counting, locating, measuring, designing, playing, and explaining - were used. These activities are not only universal, but, as Bishop claims, also necessary for the development of mathematical knowledge. I had two reasons for choosing these categories to describe learners' mathematical activities. First, mathematics, in its foundations, has a cultural basis and, as Bishop notes, it is important that we ask whose cultural history we are referring to when we consider the cultural foundation of mathematical knowledge. Since many researchers and teachers, including myself, are enculturated in Western mathematical knowledge, it is important to try to understand what the learners in our classrooms perceive as mathematical. Bishop claims that, "mathematics must now be understood as a kind of cultural knowledge, which all cultures generate but which need not necessarily 'look' the same from one cultural group to another" (p. 180). Second, Bishop also claims that these pan-cultural activities are related to the mathematics we learn in school. For example, he lists the following mathematical ideas as related to counting: numbers; number patterns; number relationships; development of number systems; algebraic representation; infinitely large and small; events, probabilities, frequencies; numerical methods; iteration; combinatorics; limits (p. 183). Situating adult learners' mathematical activities within these pan-cultural activities provides an opportunity to consider ways that adult students' experiences might be connected to the mathematical ideas they will explore in school. 
The activities that a student marked as involving mathematics were recorded, and sorted according to whether the activity was general, for example, 'work' or particular, for example, 'playing Sudoku.' The particular activities were then sorted using Bishop's categories. For example, 'shopping' was classified as a counting (or computing) activity. There were some activities, such as 'working on my car,' that were difficult to classify. This first classification of the activities was discussed with another researcher. Difficult to categorize activities were discussed, the classification of the activities refined, and the activities were further sorted into two types: work-related activities and non-work related activities.

Interview data collection and analysis. Seven interview subjects were selected from among the 600 students who had registered for Basic Math six weeks prior to the start of winter term 2012 and who were also not repeating Basic Math at the college. These students were contacted by email and asked to complete and return the survey used in the first stage of the study to indicate their willingness to participate in the taskbased interviews. The students who responded were eligible to win a $\$ 100$ gift card from the college bookstore. A purposeful sample was to be selected from the students willing to participate in the interviews, but only seven students were willing and able to participate in the interview, creating a self-selected sample. The interview participants' motivation for participating in the interviews was varied. Two of the interview participants, Lily and Ruby, made comments that suggested that the opportunity to win the bookstore gift card motivated them to participate. (All interview participants were provided a $\$ 25$ gift card from the college bookstore, except Lily who was selected at random as the winner of the $\$ 100$ gift card.) One participant, JR, was trying to decide 
whether he should retake Basic Math (he had completed Basic Math at another community college three years prior to the study) or whether he should attempt Introductory Algebra again, a course he had started but never successfully completed. Roo, another participant, was JR's partner, and his interest in the interview may have influenced her decision to participate. The other participants, Andrea, Jesse, and Sasha were all excited to return to school and made comments that suggested that the interview was an opportunity to get a head start on their upcoming mathematics course.

The interview protocol used for the interview is included in Appendix B. The interview protocol included questions written to learn about each participant's background, including their labor history, past education, and experience managing a household. Participants were asked whether they used mathematics any of their jobs or outside work, and if so, what activities they perceived to be mathematical and in what way. Particular questions were included to understand each participant's previous experience of mathematics in school and their expectation of the Basic Math course. The interviews were semi-structured in that the protocol was used as a guide to my conversation with each participant. The interviews ranged in length from 65 to 100 minutes, were video-recorded and the recordings transcribed verbatim.

The interview transcripts were used to identify relevant text, repeating ideas and themes (Auerbach \& Silverstein, 2003) with respect to the participants' experience of mathematics in their lives and in school. The goal of this particular analysis was to answer the second part of the first research question, "what is [students'] experience of mathematics in their lives and in school?" 
The first step of the analysis involved identifying relevant text regarding mathematics in participants' everyday life and their experience of school mathematics was identified in the interview transcripts. The purpose of this step was to focus subsequent analysis on particular portions of the transcript. Relevant text included episodes during which the participant described or the participant and I discussed either mathematics in their everyday life or their experience with mathematics in school. In some cases, relevant text addressed a participant's experience both with mathematics in life and school as was the case when a participant was, for example, describing a perceived difference between the two types of mathematical experience. However, not every mention of mathematics was tagged as relevant. I looked for text in which a participant described how and why she or he perceived a particular activity to be mathematical.

The following excerpt is an example of what was identified as relevant text for this analysis:

Ann: Can you say a little bit more about how you might use math at work?

Andrea: Not my current job, but before... I used to help with inventory at one of my recent retail jobs... the doing the ordering for products for our cold case like milk and eggs... that sort of thing.

Ann: So, what does that involve?

Andrea: That involves looking at previous sales, how much we sold versus what's on sale that I might need to order more of. What we wasted last 
time I had ordered versus... to try to bring down the money lost due to waste. But I still need to order enough to... Pretty much it's just addition, subtraction and multiplication. (Andrea, 4 January 2012)

This excerpt was identified as relevant text with respect to the question under consideration because Andrea did more than list an activity she perceived as mathematical, but also said why she perceived it this way. She highlighted several of the important quantities she worked as she managed inventory, such as previous sales and potential sales based on the sale price. Andrea also suggested that it is the relationships between these quantities that supported her decisions with respect to managing inventory. The next excerpt is an example of text that was not identified relevant even though Lily was responding to a question posed to learn more about how she perceived cooking as a mathematical activity.

Ann: And how do you use... just the measurements?

Lily: You just follow the recipe more then anything.

Ann: Do you ever change the recipes?

Lily: A little bit, but not really because it scares the crap out of me when baking. More with like the smoothie blended stuff, or making drinks. (Lily, 21 December 2011)

Unlike the previous excerpt, Lily did not mathematize the activity of changing recipes Unlike Andrea Lily did not identify particular quantities might be involved in the task of scaling up or scaling down a recipe. In general, transcripts excerpts, which ranged in 
length from one line to several pages, were identified as relevant text if a student was talking about his or her particular experiences with mathematics either in school, in their everyday lives or the experience of the differences between the two contexts. Andrea described an activity from a previous job she perceived as mathematical and which was noted as an example of a counting activity using Bishop's categories. Similarly, I noted that Lily perceived several everyday activities that involved measurement, but unlike Andrea who explained the way managing inventory was a mathematical activity, Lily did not provide a mathematical response to my question about changing recipes.

Next, the relevant text was reviewed several times in order to start the process of identifying repeating ideas. During this review analytic notes were written within the transcript. I used these notes to translate a participant's utterance into mathematical language that I am able to access due to my own expertise with formal mathematics, but language that I would not expect adult returning students to be able to access. For example, when Andrea and I were discussing managing inventory, she shared that part of her work involved, "to try to bring down the money due to waste." Here I noted that when Andrea was managing inventory that the decisions she made based on the quantities with which she was reasoning- previous sales, previous waste and projected sales - had consequences; wasted inventory is lost money.

The next step in the analysis involved identifying repeating ideas within the relevant text, using the analytic notes I had previously added to the transcript. A repeating idea is defined either as an idea mentioned more than once by one participant or an idea mentioned by more than one participant. One episode of relevant text may 
contain several different repeating ideas. An example of the first type of repeating idea within the relevant text about a participant's experience of school mathematics was Jesse's recurring references to looking for a formula as he engaged in the mathematical tasks during the interview. An example of the second type of repeating idea was a reliance on estimates noted within the relevant text about everyday mathematical activities from the transcripts from the interviews with most of the participants. A list of these repeating ideas included the following:

- I use math all the time

- Math in one's head

- Math on paper

- The long way

- Calculator use in everyday activities

- Estimation

- Rule of thumb

- School math is rigid; exact answers are expected

- School math is rigid; it involves formulas and equations

- Privileging school mathematics

- Relying on strategies learned in school

- Distancing from school mathematics

- I hated word problems in school

Finally, the relationships between repeating ideas like those listed above noted in the transcript were explored, using analytic memos that were written to reflect upon the 
data (Strauss \& Corbin, 1998). These memos provided the opportunity to explore conjectured relationships and to consider the meaning of preliminary findings. Most importantly, the memos put emerging findings on to paper so that they could be shared with other researchers and other possible interpretations of the relationships between repeating ideas discussed.

Themes emerged from the relationship between repeating ideas. For example, one repeating ideas was the use of estimates in the participants' everyday mathematics. Another was the use of rules of thumb developed on the job for performing computations. In this case, these two repeating ideas suggested a theme: in many everyday contexts, exact answers are not necessary and making use of estimates and rules of thumb is acceptable. In other instances, a repeating idea was so prevalent across the data that it became a theme. For example, all participants told me they used mathematics in their everyday lives and were able to provide examples. Although one participant, Jesse, downplayed these examples, the other participants provided many examples of their everyday mathematics. The repeating idea, "I use math all the time" was transformed into the theme "Mathematics in everyday life is ubiquitous and reasonable." Finally, not all repeating ideas could be merged with others into themes (for example, calculator use in everyday activities); these orphan ideas did not become part of the findings.

\section{Findings}

Survey sample: Demographic data. Nationally, the mean age of a community college student is 28 years old and more women (57\%) than men attend community 
colleges. In addition, $40 \%$ of community college students are first-generation college students. (American Association of Community Colleges, 2013). These data serve as a backdrop to the learning about a particular population of community college mathematics students: students attending an urban multi-campus community college, who enroll in an arithmetic review course, Basic Math. At this particular community college, this course is the first in a four-term developmental mathematics sequence.

The college where this study was conducted provided demographic data on the students who were enrolled in Basic Math at the end of the fourth week of Fall quarter 2011 (the quarter the survey data were collected). The mean age of these students was 26 years old $(n=2036)$ and $59 \%$ of the students who reported gender to the college $(n=$ 2015) were female. The mean age of the sample and the population cannot be compared directly, because the students were surveyed during the first week of the term and the data from the college was from later in the term, which is significant because not all students persist in the course. However, a comparison between these two data sets suggests that the sample of students surveyed is representative of the population as a whole. Figure 2 compares the age ranges reported by the students in the survey sample with ages of students in the population of Basic Math students that term. The percentage of female students in the survey sample was identical to the population as a whole. However, as reported to the college, there was a higher percentage of first generation college students in the population as a whole, $71 \%$, than in the sample, $41 \%$, which is close to the national statistic. The significantly higher percentage of first-generation college students enrolled in Basic Math might be due to the fact that the college only had 
data on this statistic for 1445 of the 2036 students enrolled in Basic Math through the fourth week of the quarter.

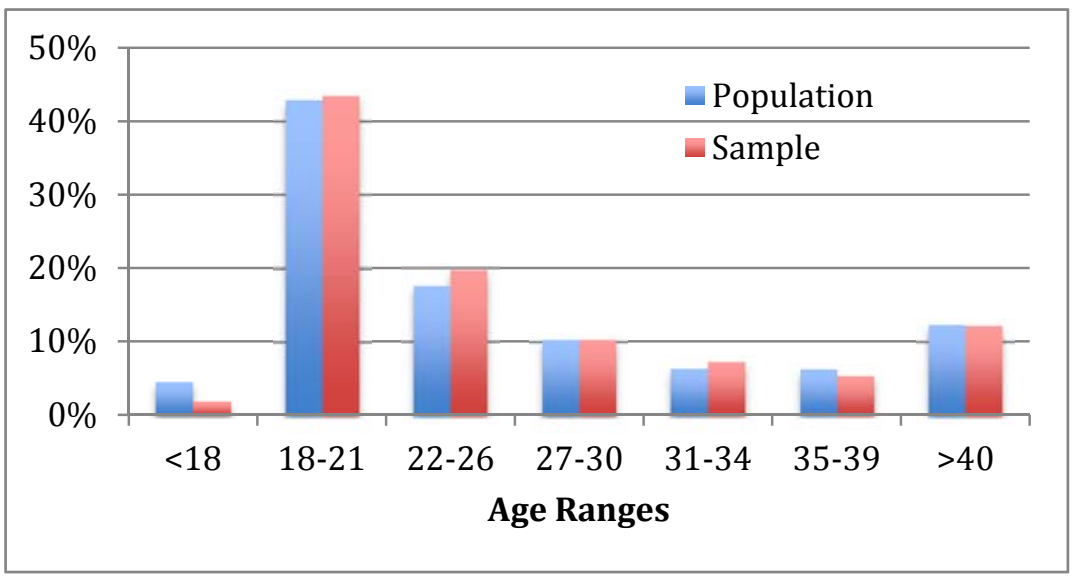

Figure 2. Comparison of learners' ages between sample of Basic Math students surveyed $(n=319)$ and the population of students enrolled through fourth week of quarter $(n=$ 2036)

In summary, the sample of students surveyed for this sample is representative in terms of the demographics of the sample.

The survey data reveal that there are students who enrolled in Basic Math Fall quarter 2011 that had not taken a mathematics class for a substantial amount of time. Figure 3 shows that $38 \%$ of the surveyed students who responded to this question (314 out of 340) had not taken a mathematic class for more than 5 years and $22 \%$ for more than 10 years. One implication of this finding is that it may not be the case that a Basic Math student's mathematical understanding at the time she enrolls in Basic Math is related to her high school mathematics education. For example, a study of the mathematical understanding of community college students enrolled in developmental mathematics analyzed students' responses to questions on a placement test. The researchers concluded that, "The picture we paint is disturbing, and shows the long-term consequences of an almost exclusive focus on teaching mathematics as a large number 
of procedures that must be remembered, step-by-step, over time" (Stigler, Givvin, \& Thompson, 2010). Yet they also acknowledge that, "Perhaps the longer students have been away from formal mathematics classes, the less likely they are to remember what they are supposed to do, and the more they must rely on their own understanding to figure out how to answer a question" (p. 12). This suggests that referring back to mathematical ideas that students previously learned in school in a Basic Math classroom would be less effective than referencing the strategies they may have developed outside of school.

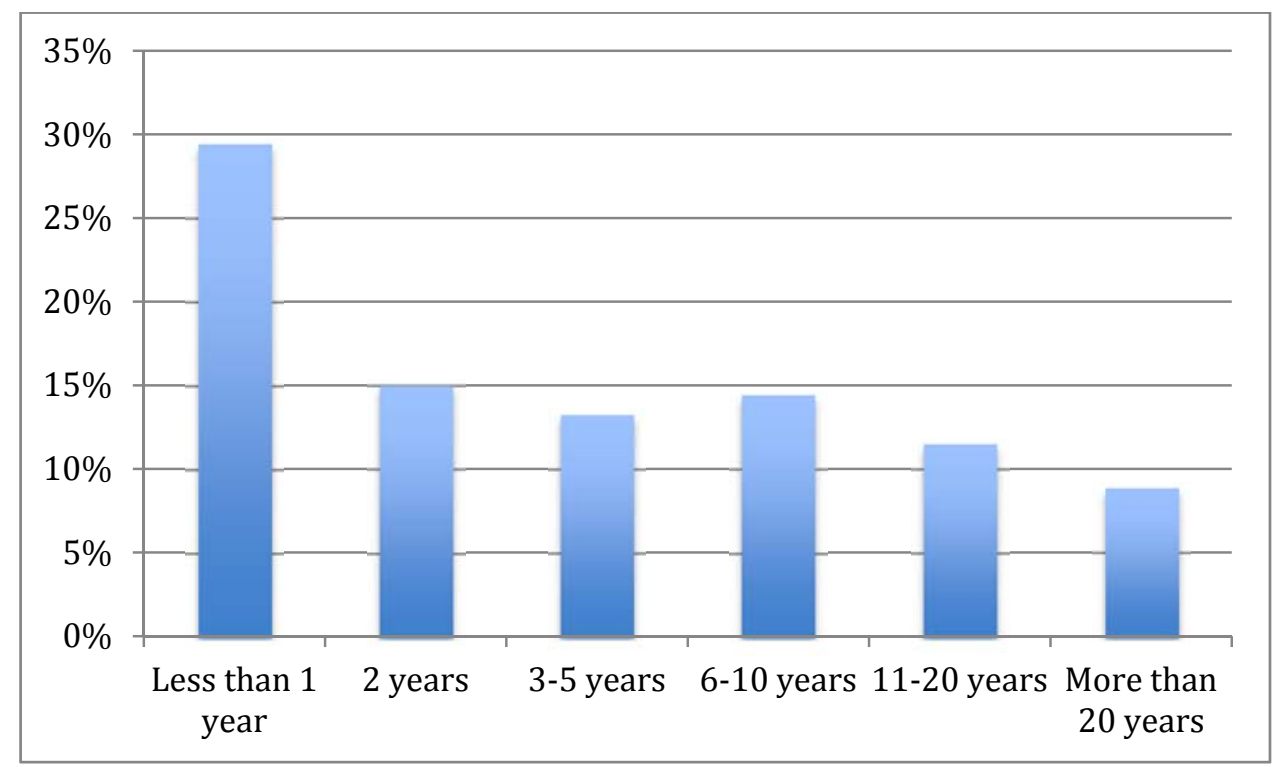

Figure 3. Time away from school mathematics $(n=314)$

The survey also queried what each student had been doing prior to enrolling in Basic Math. Students were able to select as many choices as applicable. Many students selected attending school in response to this question, but it is not possible to tease out whether these responses indicated that the student is a recent high school graduate or had attended another post-secondary institution. These data are presented in Figure 4. 


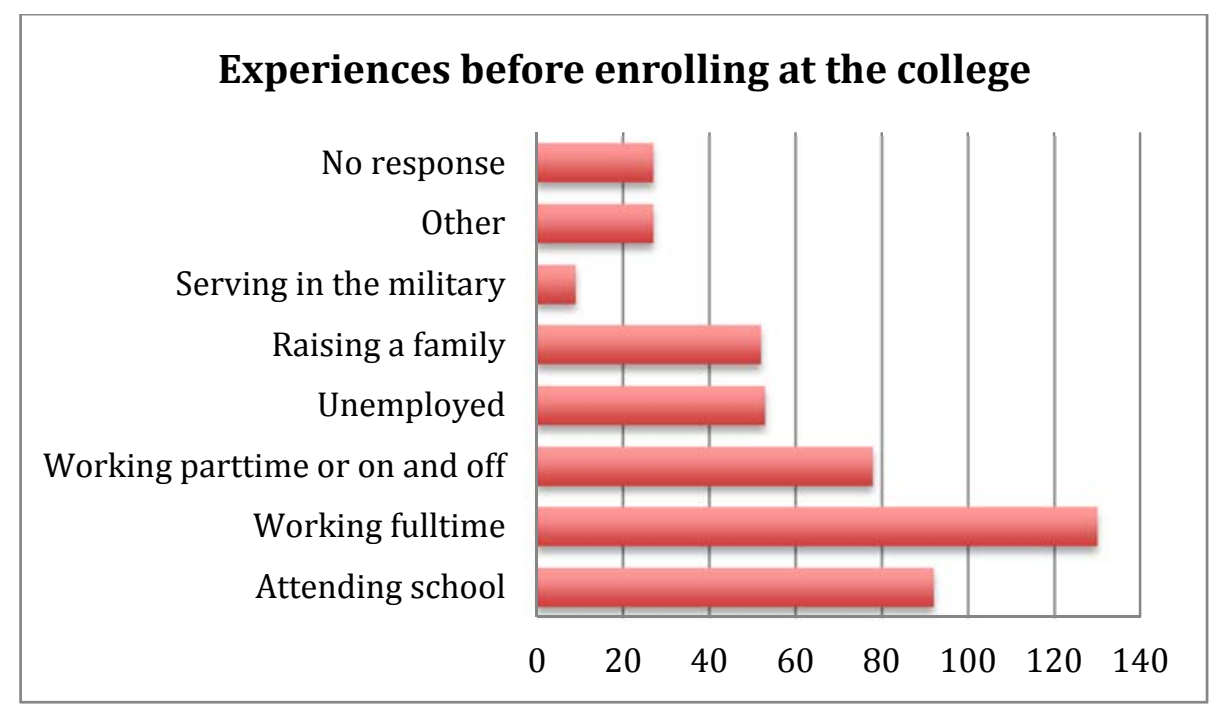

Figure 4. Experiences prior to attending the community college $(n=340)$

The majority of students in a Basic Math course have work experience, which both distinguishes these mathematics learners from younger students and provides likely contexts for everyday mathematics. In addition, the activities listed under the Other category illustrate that adult students' experiences before returning to school include experiences that are not typical for college students. Activities that constituted the Other category $^{21}$ include being incarcerated (4), traveling ${ }^{22}$ and/or being homeless (6), being a caregiver (2), starting a small business (2), participating in the Job Corps or missionary work (2), engaging in an internship or vocational training (4), and being ill or disabled (2). Collectively, these data suggest that students who enroll in Basic Math bring a variety of past experiences to the classroom, and as we will see in the next section, these students perceive many of the activities in which they engage as mathematical.

\footnotetext{
21 Not all respondents who selected Other $(n=27)$ indicated an activity.

22 "Travelers," homeless young people who travel from city to city, are common in the city where the study was conducted. Some of the students who indicated that they had been traveling may be homeless.
} 
The first part of the first research question queries the background of students who enroll in Basic Math. These demographic data indicate that this population has the following characteristics: It is a population of students that is almost equally divided between traditional age college students and older returning students (Figure 2) and more than one-third of the students have not taken a mathematics class for five years or more and nearly one-quarter for 10 years or more (Figure 3). Both of these statistics are significant in light of knowledge resources, such as students' recall of procedures or concepts from school mathematics, which students may be expected at access in a Basic Math classroom. Students' life experiences prior to returning to the community college (Figure 4), such as work or raising a family, might be better knowledge resources for students to access as they transition back to school.

Survey data: Students' experience of mathematics. Students were asked two questions on the survey to query the role of mathematics in their lives:

1. List all your activities from yesterday. Put an M next to any activity that involved math.

2. I use math outside school all the time frequently occasionally never About 48\% (164 out of 340) of the students surveyed reported that they use mathematics outside school "All the time" or "Frequently" and only $2 \%$ ( 8 out of 340 ) of the students reported that they "Never" use mathematics outside school. It is surprising that nearly half of the students in the sample perceive themselves as people who use mathematics and so few report that they never use mathematics in their everyday life. For this reason, 
it is important to understand both what constitutes mathematical activity for students enrolling in Basic Math and the types of activities adults perceive as mathematical.

Activities adult learners perceive as mathematical. $90 \%$ of the students surveyed (305 out of 340) responded to the question above about the everyday activities they perceive as mathematical. ${ }^{23}$ Of these 305 , only $20 \%$ reported that none of the activities they engaged in on the previous day involved mathematics. Some students (12 out of $305)$ only highlighted 'doing math homework ${ }^{24}$ as involving mathematics. The average number of activities a student listed was five and the average number activities per response that was marked as involving mathematics was two.

Students listed other courses in which they are enrolled as involving mathematics, for example, photography, welding, keyboarding, writing, weight training, college success, and health and fitness. About one-fifth of the students who responded to the question (19\%) reported using mathematics at their jobs, although many of these students (42 out of 60) did not indicate what activities at work they perceived as mathematical. However, many students indicated that they work with money: cashiering, invoicing customers, and providing quotes. Other students' work involved measurement (e.g., the work of machinists, welders, construction workers). Other mathematics-related work activities included routing freight, managing inventory, and categorizing data. In addition, $72 \%$ of the students who responded to this question $(65 \%$ of all students surveyed) indicated a wide variety of non-work activities that they perceive as mathematical. The most frequently cited activities were shopping, cooking, commuting

\footnotetext{
${ }^{23}$ It is important to note that these data are self-reported and may reflect either the learners' perception of what is mathematical or what they expect the researcher would classify as mathematical.

${ }^{24}$ The survey was administered during the first week of the academic term. Some instructors waited until the second class meeting to administer the survey.
} 
and managing finances. However, not all students who listed a particular activity - for example, shopping or cooking - among their activities indicated that this activity involved mathematics.

In order to examine these activities in more detail, Bishop's (1988) six pancultural mathematical activities - counting, locating, measuring, designing, playing, and explaining - were used. These activities are not only universal, according to Bishop, but also fundamental for the development of mathematical knowledge.

Counting and the related activity of calculating was prevalent in many of the activities listed by the adult students. For example, shopping (About how much will these groceries cost?), commuting (What bus should I take to get to work on time?), exercising (How many more reps do I need to do?), managing finances (What is balance in my checking account?), and time management (When should I go to bed if I need to get up at 5 am and I want six hours of sleep?) are examples of counting activities. Measuring was also prevalent. As mentioned above, several occupations involve measurement, but cooking, preparing 'bottles' for infants, and administering medications ${ }^{25}$ were also listed as mathematical activities. Playing team sports, watching football, playing video games, chess, Uno and poker, and solving puzzles such as Sudoku were described as activities that involve mathematics. Designing emerged as a category of mathematical activity; students included gardening, rearranging furniture, styling hair, and photography ${ }^{26}$ as mathematical activities. Getting to and from work or school was frequently described as a mathematical activity, and, as mentioned above,

\footnotetext{
${ }^{25}$ Two students described monitoring blood sugar levels and administering insulin, likely a familiar activity for many students.

${ }^{26}$ One of the students who listed photography as a mathematical activity focused on determining camera settings, which may be described as either measurement or design.
} 
often involved calculation (Can I afford this trip? How long will this trip take? How good is my mileage?). However, although not mentioned explicitly, locating is also involved in many people's commute (Where is the campus and how do I get there?).

Explaining was not as prevalent in these data as the other pan-cultural mathematical activities, but this does not suggest that adult learners do not "find ways to account for the existence of phenomena," (Bishop, 1988, p. 183). Whereas adults might have experience making arguments and justifying their positions on certain issues, justification and argumentation may not be perceived as mathematical from the students' perspective. However, one student explicitly mentioned categorizing as a mathematical activity, an activity Bishop classifies under explaining. Several people described helping their children with mathematics homework, which certainly involves explanation. In addition, some activities involve several of these six pan-cultural activities. For example, working on cars (mentioned by several students) might involve counting, measuring, locating and explaining what the nature of a problem with a car is.

Table 6 organizes the activities learners listed as "involving math," using both Bishop's categories and whether or not these were activities the students engaged with in their jobs or outside of work. There is surprising variety among the tasks that adult students perceive as mathematical. The table illustrates how prevalent counting or calculating is in adult students' lives and also the assortment of activities - some quite sophisticated - that involve counting or calculating. For example, managing receipts for a small business, invoicing customers, computing retiree benefits and managing personal finances are all contexts that could be brought into the classroom to build students' experience and uncover students' strategies for performing computations in these 
contexts. Students' experiences with measuring and designing tasks might be leveraged to explore topics in geometry, to reason about proportional situations, and to examine units of measurement and unit conversion, all typical topics in a Basic Math course.

The demographic data about the population of students enrolled in Basic Math suggested that the knowledge resources of these students are broader than what a student remembers about mathematics from previous schooling. The data displayed in Table 6 suggests possible sources for these alternative knowledge resources. The connections Bishop made between these pan-cultural mathematical activities and formal mathematics (1988) suggest ways that the activities students perceive as mathematical might become knowledge resources for the development of mathematical understanding in the classroom. This endeavor is quite different from cloaking school mathematics in contexts based on the activities students perceive as mathematical. Instead, teachers and researchers might collaborate with adult students in order to understand the mathematics a student brings to bear on a particular activity and to develop ways to formalize the mathematics that emerges from the context of adult students' lives and everyday experience of mathematics. 


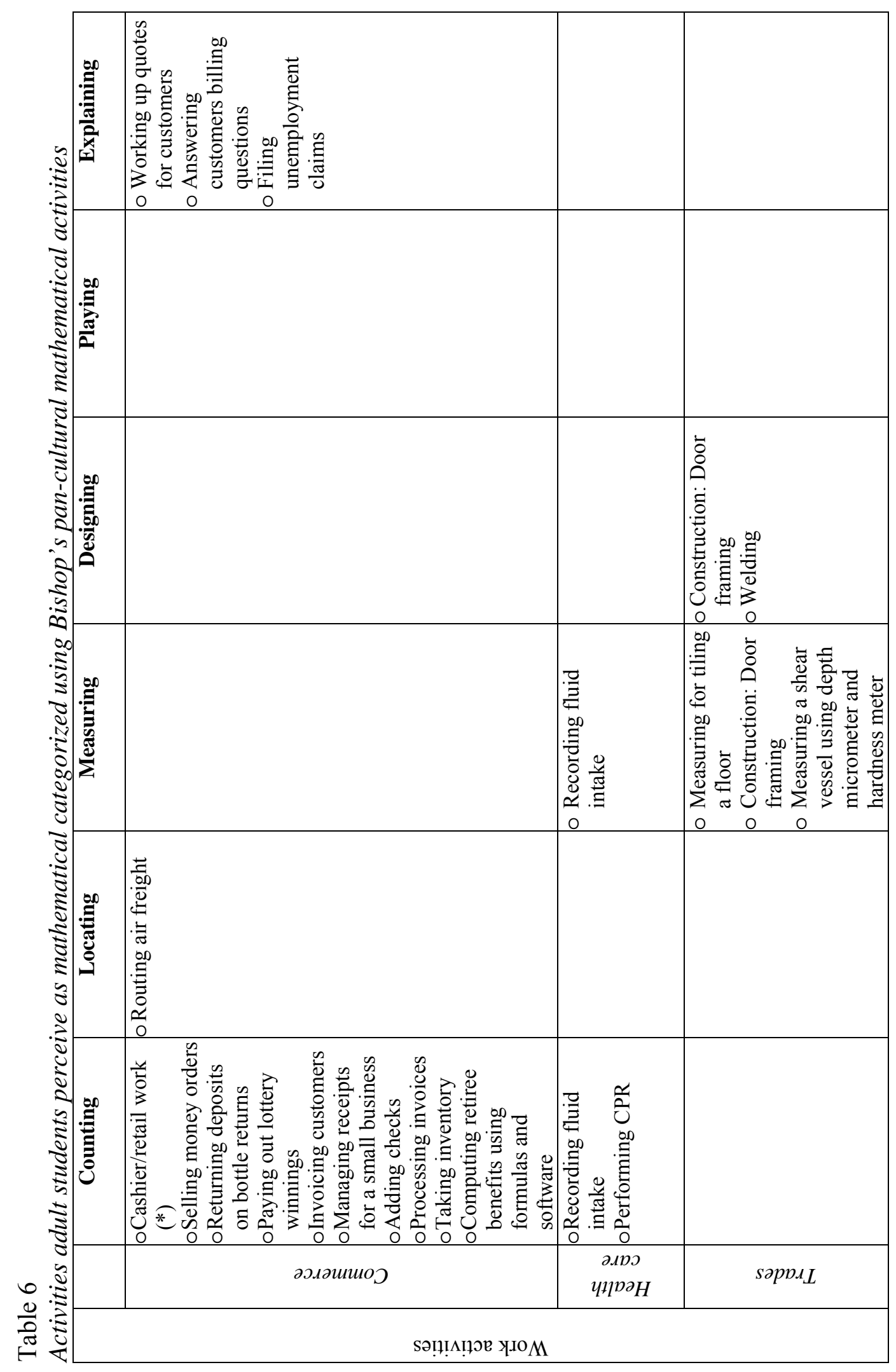




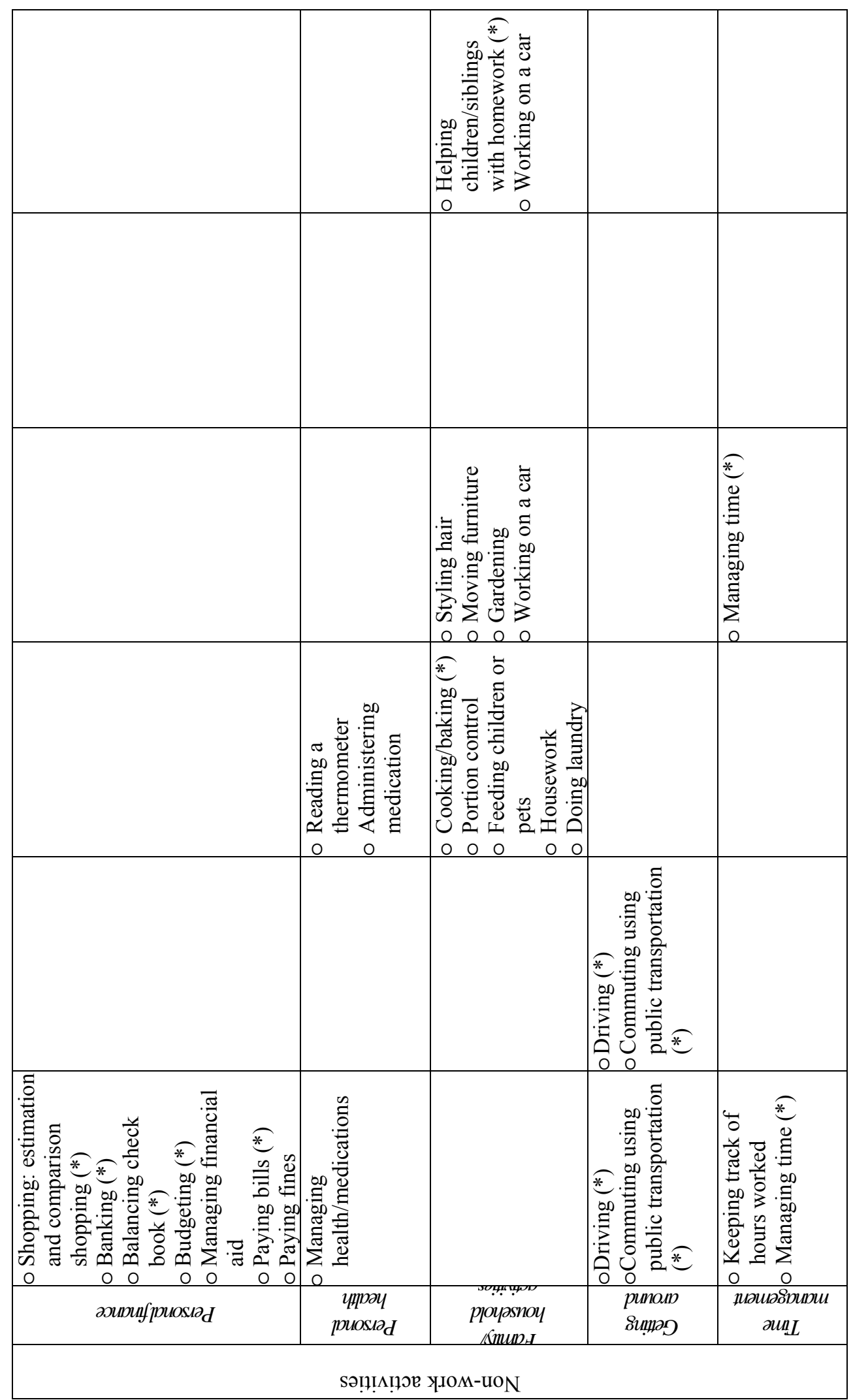




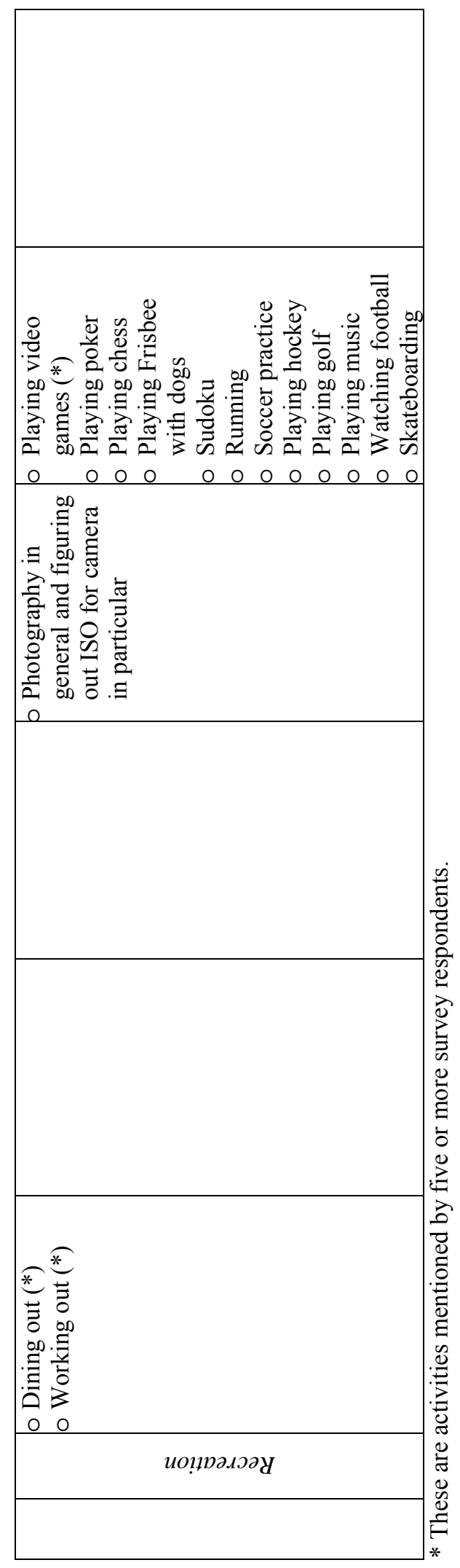


Students' previous experience with topics explored in Basic Math. In addition to querying the amount of time that had passed since a student had taken a mathematics course, one survey item was designed to determine whether or not the major topics in the Basic Math course were familiar to a student - topics a student just needs to review - or topics that a student needed to learn. The question also queried whether a student might have been placed in the course because he or she was a non-native speaker, a conjecture made by Bailey and Cho (2010).

In [Basic Math], you will study ratios, proportions, fractions, decimals and percentages. Choose the category (or categories) that best describes your experience with these topics.

I felt good about these topics when I was in school, but I need a review. I struggled with these topics in school.

I feel my math skills are good, but I am still learning English.

I am still learning English, but I also struggle with these topics.

None of the above

If none of the above, please explain.

300 of the 340 students surveyed responded to the question. Of these, $50 \%$ reported that they only needed a review and $46 \%$ claimed they had always struggled with these topics, suggesting that the Basic Math course serves two different populations. However, some students ( 11 of the 289 whose responses to the first two options were tallied) selected both options. It is possible that some of the topics on the list - and not all topics -- were review topics, indicating a flaw in the design of this question. In addition, the conjecture that students are placed into mathematics classes 
because they are non-native speakers was not supported by these data. Only 4 of the 300 respondents indicated that their math skills were good, but they are still learning English, and 5 of the 300 reported that they were still learning English, but still struggled with these topics in school. The fact that $46 \%$ of the respondents reported that they struggled with the topics they would be encountering in the course, in addition to the likelihood that more struggled with a subset of the topics, suggests that 'arithmetic review' is not the best characterization of this particular course in the developmental mathematics sequence.

Summary of findings from the survey data. The maturity of Basic Math students, the time they have been away from school and the statistic that nearly half of the students reported that they require more than a review of the central topics studied in Basic Math suggest that the expectation that students need to review particular topics and that they are accessing knowledge resources from prior schooling may not be reasonable. Instead, further inquiry into students' mathematical ways of thinking about the everyday activities they perceive as mathematical could support the development of curricular materials that draw upon the knowledge resources that Basic Math students are accessing.

The interview data provide an opportunity to explore students' experience of mathematics in their lives and in school from a different perspective than that provided by students' written responses to the survey items. In particular, the interviews provide an opportunity for the participants to explain the ways their ways of thinking about the everyday activities they perceive as mathematical. These findings are reported in the next section. However, these findings are not intended to confirm findings from the 
survey data. Rather the findings from the survey data suggested questions to be explored further using the interviews.

Interview participants: Biographical data. The seven interview participants ranged in age from their mid-20s to early 50s. Andrea, Lily and Jesse were all in their mid-20s with no children; each had moved to the city from out of state. Sasha, about 30 at the time of the study, and Ruby, in her early 40s, are both mothers with five children each. Sasha had moved to the city at 21 and Ruby grew up there. JR and Roo are partners, who traveled from a rural part of the state to attend the community college. Although JR did not discuss children, Roo did talk about raising children. The participants had a variety of work experience, which will be discussed in more detail in the next section.

Although JR and Roo were the oldest participants (around 50), they had been in school most recently. Each had attempted a Basic Math course at another community college several years prior to the study. JR successfully completed the course, but had been unable to complete the next course in the developmental mathematics sequence, an introductory algebra course. Roo had not successfully completed the Basic Math course. Andrea and Jesse had not attended school since high school (a period of about seven years), although Andrea had attended massage school. Lily attended a state university for two quarters after completing high school and also attended massage school briefly, but had not been in school since. Both Ruby and Sasha left high school to start a family. Sasha dropped out of high school at 15 and Ruby graduated from high school early. Three years prior to the study, Sasha had completed an adult high school diploma online. Sasha and JR were the only two participants who had dropped out of high school. These 
data are summarized in Table 7 along with other information about the participants that I

discuss later.

Table 7

The interview participants

\begin{tabular}{|c|c|c|c|c|c|}
\hline Participant Gender & Age & $\begin{array}{l}\text { Time away } \\
\text { from school }\end{array}$ & $\begin{array}{l}\text { High school } \\
\text { experience }\end{array}$ & $\begin{array}{l}\text { Selected work } \\
\text { experience }\end{array}$ & $\begin{array}{c}\text { Current } \\
\text { academic goal }\end{array}$ \\
\hline Andrea Female & 25 & 6 years & Completed & Retail & $\begin{array}{l}\text { Occupational } \\
\text { therapy }\end{array}$ \\
\hline Jesse Ma & 26 & 6 years & Completed & Glassblowing & Human biology \\
\hline Male & About 50 & 3 years & $\begin{array}{l}\text { Dropped out } \\
\text { (no information } \\
\text { about later } \\
\text { completion) }\end{array}$ & $\begin{array}{l}\text { Mill worker, } \\
\text { construction }\end{array}$ & $\begin{array}{l}\text { Construction } \\
\text { management or } \\
\text { addiction } \\
\text { counseling }\end{array}$ \\
\hline Lily Fem & 26 & 5 years & Completed & Retail, fashion & $\begin{array}{l}\text { Health and } \\
\text { biology }\end{array}$ \\
\hline Roo Female & About 50 & 3 years & Completed & Retail & $\begin{array}{c}\text { Retail } \\
\text { management }\end{array}$ \\
\hline Ruby Female & Late $40 \mathrm{~s}$ & \multicolumn{2}{|c|}{25 years Graduated } & $\begin{array}{l}\text { Nursing } \\
\text { assistant, small } \\
\text { business owner }\end{array}$ & $\begin{array}{c}\text { Business } \\
\text { management }\end{array}$ \\
\hline Sasha Female & 29 & 15 years & $\begin{array}{l}\text { Dropped out } \\
\text { (completed an } \\
\text { adult high } \\
\text { school diploma) }\end{array}$ & $\begin{array}{c}\text { Restaurant } \\
\text { management, } \\
\text { photography }\end{array}$ & $\begin{array}{l}\text { Ultrasound } \\
\text { technology }\end{array}$ \\
\hline
\end{tabular}

\section{Interview participants: Experience of mathematics in their everyday lives.}

According to JR, "Math is everywhere" [JR, 19 December 2011] and Sasha observed, "I think that almost everything I have done uses math at some point [Sasha, 22 December 2011]. On the survey, Sasha, Ruby and Roo reported they use mathematics outside of school "All the time," and JR, Andrea and Jesse reported "Frequently." Only one participant, Lily, reported "Occasionally." As I discuss in the following sections, not only did these students report a variety of activities they perceive as mathematical, but I was also able to learn something about how each participant approached his or her quantitative world.

As with the survey data, Bishop's categories were used to examine the participants' experience of mathematics outside school. Counting, and in particular, 
working with or managing money, was prevalent. Other activities that the participants perceived as mathematical fell under three other of Bishop's categories: measuring, locating and explaining.

Counting. All the interview participants remarked that working with money is a mathematical activity and a familiar context for these adult students:

Whenever I am doing math issues with my kids, I put it into a money perspective, since I have always worked with money in the restaurant businesses and stuff. So I can easily do, like, well, it takes so many nickels to make a dollar. It takes four quarters to make a dollar. So, that's pretty much the way I use the math in my head. I use it in a money perspective. [Sasha, 4 January 2012] In this excerpt, Sasha explains that she is comfortable working with money due to her experience working in a restaurant. (Sasha had experience as a restaurant manager.) She used this experience to help her perform mental computation, using facts such as the number of a particular value of coin in one dollar. Other participants also held jobs that involved handling money. Roo, Andrea and Lily had worked in retail. Andrea also worked as a barista and Lily as a bartender. Ruby had owned a janitorial services business and, as a small business owner, handled money on a different scale than the others. In fact, she reported that if she had been better at managing the business's money, the business might not have failed: "I realized that if I would have stayed in school and kept up with the tax laws, the accounting... I probably would have been able to budget, and manage and prepare better than I did. 'Cause what with the savings, what I thought I had and what sustained us... It lasted, but it didn't last long at all” [Ruby, 20 December 2011]. Keeping track of the accounts receivable and accounts payable is an 
important skill for a small business owner, a skill that involves computation and interpreting the results of computation in order to make informed decisions about the business.

All the participants, except Lily and Jesse, talked about managing household finances. Having little money and the constraints of a tight budget is a reality of these learners' lives. "I have been on a budget for a really long time, so as I am buying things, I am - in my head - I am tallying that" [Andrea, 4 January 2012]. Sasha described subtracting quantities from her budget as she shopped: "Well, we usually start with a certain budget, so then I have to... as soon as I put something in the cart, I have to subtract from my actual budget. And then, we usually use coupons, so I have to subtract the coupon price to get into where I am at... to see how much I am actually saving. That's pretty much the way I do it" [Sasha, 22 December 2011]. Overestimating the amount spent while shopping is a strategy Andrea, Sasha and Ruby described. Roo also talked about making estimates while shopping, but she and her partner JR both described how important it is to be accurate when living on a budget; they valued exact computations, even while shopping. Ruby provided examples of computations she used to make decisions about utility use: "Like you have a wattage usage of 2000 something, something and they times it by 0.153 something. So, then basically, you are paying 10 cents for every wattage that you use" [Ruby, 20 December 2011]. In the context of her utility bill the factor 0.153 had meaning, since she performed these computations in order keep her electricity bills reasonable.

However, many other activities perceived as mathematical by the participants were also classified as counting/calculation. Both Sasha and Andrea described placing 
orders at work as a mathematical activity: "For example, our gallons of milk. Normally they were like $\$ 3.50$, and sometimes they'd go on sale for $\$ 2$. For example, the whole milk, normally I would order 20 gallons. We'd go through, if it was on sale, we'd probably go through about twice that amount. Somewhere between half again and twice that. So we'd go through 30 to 40 gallons. So, I'd generally order 35 , just to be safe" [Andrea, 4 January 2012]. Both JR and Lily mentioned time management. Lily managed spa days at a salon and used this context to explain how she perceived time management to be mathematical: "Because there are like huge spa days at [the salon], so you have to organize a whole day and make sure the technicians are on time. That kind of thing... It's all numbers. It's all math and numbers. Scheduling time, like when your breaks are, when technicians are running late, if they're overlapping. You need to call your next clients and push them back, but they're not allowed to run behind" [Lily, 21 December 2011].

The prevalence of counting activities in adults' lives is not surprising, and the variety of activities that involve counting and computation described by the interview participants echo the variety of counting activities outlined in Table 6 . The variety of everyday activities the participants viewed as mathematical and computation was surprising, since developing accurate and efficient computational strategies is one of the primary goals of a Basic Math course. This suggests that the contexts and ways of reasoning adult students use in counting or computational activities might be used as the foundation for developing accurate and efficient strategies.

Measuring and locating. All the interview participants cited measurements in cooking or baking as a mathematical activity. Sasha regularly cooks for six or seven 
family members, adjusting recipes written for four servings. JR and Roo frequently gift baked goods to others and discussed scaling up the measurements in recipes: "The recipe, when it comes for single use recipe... Well, that's never enough if you're going to give some away. You just double your recipe to make it a little bit simpler. As long as you mix the dry ingredients the way they say you are supposed to do that so you don't have cream of tartar chunks everywhere in the biscuits, or whatever." [JR, 19 December 2011]. This is a basic example of measuring, but reflecting the activity of doubling measurements such as three-quarters or two-thirds of a cup could support the development of number sense with fractions.

Ruby, Lily, Jesse and JR described measuring as an important part of jobs they had held. Ruby worked as a Certified Nursing Assistant, measuring blood pressure and administering medications. Lily had worked in the fashion industry and described measuring models and adjusting the garments worn by the models in fashion shows: "You measure the fabric and then you are going to have to take the fabric out or in based on the model. So, you do fittings before the runway. Preferably, a designer will come in. They do it. I help. It's easy" [Lily, 22 December 2011]. The measured quantities of fabric with which Lily worked needed to be adapted to particular models, an activity that might lead to intuitions about the quantitative differences between different lengths. Lily also worked as a bartender, which involves measuring alcohol, but also gauging which glass to use for each cocktail:

Lily: I mean, measuring, I guess. Pouring is kinda math, but not really. It's like an ounce and a half, a half ounce.

Ann: Do you use three parts of this to one part of that? 
Lily: Kind of... but it's more like a gin and tonic is like half and half.

Ann: Right.

Lily: Not super complex... a little bit of fractions. There's not going to be more than three or four ounces of alcohol. Four ounces of alcohol is like an extreme amount... like a Long Island. An ounce is typical for a drink. So you can kinda gauge what glass you're grabbing... [Lily, 21 December 2011]

As with adapting a measured quantity of fabric to a particular model, Lily's work as a bartender provided experience with a particular measure, ounces, and being able to gauge the difference between an ounce and an ounce and a half of liquid.

Jesse worked for six years as a glass blower and described how he mixed different types of glass by weight in order to achieve a particular color: "So, when you're doing, when you're mixing colors. You kinda want to have a rough knowledge of how it's going to react in the flame before you do it. So you weigh one glass and you weigh the other glass, and there are ratio charts that you can just follow. So, then, after a while, you don't even have to do that. That was just in the beginning. You get a feel for it" [Jesse, 3 January 2011]. Jesse developed a sense of a quantity of a material based on its weight. JR had worked for a bricklayer and described measuring and cutting bricks according to given specifications. But he also worked in metal forging, which like Jesse glassblowing experienced, required measuring alloys, but also involved using a spectrometer: "When we change over from a ferrous metal to a stainless, we'd pour some reverted stainless alloy. That's where math was. We had to make our adds to make it come up to spec, depending on what the spectrometer said we needed" [JR, 19 
December 2011]. In this case, JR's sense of a quantity was not based on the way he perceived the quantity with his senses, as Lily and Jesse described, but on the way he interpreted measured quantities through reading a data display on a spectrometer.

Much of JR's labor history was in construction, a job that involves locating. For example, JR described using the Pythagorean theorem to determine where to place support cables for uprights and for setting dead mans, concrete used to anchor struts that temporarily hold up walls during construction:

You have to know where to set this dead man. Depending on how high up you go, how far out, what size of a strut you're going to be using. They only go out a certain... The fives go out 20 feet; the tens go out 30. [JR, 19 December 2011]. The stability of the structure depends on where the dead man at the base of the struts is located and this location depends on the size of the strut being used. In this case, geometry is used to determine the location.

The interview participants' experience with measuring and locating suggests that these students have a well-developed intuition about certain units of measure, such as Lily's sense of one ounce and Jesse's experience of the feel of certain weights. Only JR described an activity that could be classified as locating, but it is not unreasonable to imagine that other students in Basic Math have experience with construction - or other activities - that combine locating objects with practical geometry. Experiences like these could help students bridge their everyday mathematics to a more formal understanding of measurement, unit conversion and working with geometric formulas, which are common topics in a Basic Math course. 
Explaining. Roo, Ruby and Sasha - all mothers - described helping their children with their school mathematics. Roo described spending a summer with one of her daughters reviewing middle school mathematics together. Ruby admitted that it was easier to help her children with mathematics when she was still in school. (Ruby had her first child when she was in high school; her children ranged in age from four months to their mid-20s.) The further removed from school she was, the less efficient she felt her strategies were. For example, when working on multiplication facts with one of her younger children, Ruby listed multiplication facts: $1 \times 2=2,2 \times 2=4, \ldots$ Later, she realized that the multiplication table representation (with the factors along the first row and the first column and the products in appropriate cells) she used with her older children would have been a more efficient way of representing multiplication facts. Sasha values education and helps her children with their work, but her children were moving beyond what she could explain mathematically. This was painful to Sasha: "As a parent, you kinda feel like a failure at times, because you're supposed to have the answers for your kids" [Sasha, 22 December 2011]. Parents' experience explaining mathematics and other ideas to their children might serve as a first model of what constitutes a mathematical explanation in a Basic Math class.

Summary. Querying the everyday mathematical activities that the participants perceive to be mathematical and coming to understand in what way the activities are mathematical from the students' perspective provides one answer to the question about students' experience of mathematics in their lives. In addition, classifying these activities in terms of Bishop's pan-cultural mathematical activities allows us to understand students' experience as part of the human experience from which more formal 
mathematics emerges. The interview participants reported that they frequently use math in their everyday lives, engaging in a variety of activities - both in their jobs and outside work - they perceive as mathematical. These activities described by the participants involved counting or computing, measuring and locating, and explaining. As with the survey data, these data suggest that students' experience with these everyday activities might be used as a source of learning in the classroom. For example, computational strategies used while shopping or managing money could be linked to operations with decimals. Doubling the amount of measured ingredients in a recipe could be a way to ground a particular operation with fractions in a familiar context. Students' experience of the types of quantities they interact with in their jobs, measured using particular unit of measure, such as the fabric Lily worked with, the glass and metals that Jesse and JR worked with, might be shared in a classroom so that students might develop a quantitative understanding of unfamiliar units of measurement. In the next section, the participants descriptions of the differences between their everyday mathematics and mathematics in school are discussed. Perceptions like these might have come from the participants' prior experience with school, which appeared divorced from their lives. Students' experience in a Basic Math course could be different if the activities they perceive to be mathematical become a source for learning in the classroom.

\section{Interview participants: Experience of mathematics in their lives and in}

school. The interview participants reported that many of their everyday activities are mathematical, but over the course of the interview, several of the participants distanced their own mathematics from the mathematics they experienced in school. This section 
focuses on further findings from the interview data that address the interview participant's experience of mathematics in their lives and in school. This section starts with biographical sketches of each interview participant, since the interviews provided an opportunity for these students to share these stories with me. These sketches are my interpretation of the participants' stories, framed by my interest in their backgrounds and their experience of mathematics in their lives and in school. These sketches serve two purposes. First, the sketches help us understand the background of this particular group of students who would be enrolling in Basic Math in a different way than the more quantitative data from the surveys. The participants' stories also provide details about their background and experience, their prior experience of mathematics in school, and their expectations for Basic Math. Second, themes emerged from the analysis of the interview data that are illustrated in these sketches.

As I analyzed the interview data, several themes emerged that helped me to understand the participants' experience of mathematics in life and in school: (1) Mathematics in everyday life is ubiquitous and reasonable; (2) Everyday mathematics involves working with estimates and using rules of thumb; (3) School math is rigid and requires exact answers; and (4) the tension between everyday mathematics and school mathematics was apparent to several of the participants. I introduce these themes through biographical sketches of each participant, highlighting each participant's experience of mathematics in their life and in school and providing excerpts from the participants' stories that illustrate these themes. Table 7 illustrates the relationship between each participant's story and these themes. Sasha's story touches on all four themes and all students described estimation strategies or rules of thumb they use in their 
everyday mathematics. Some themes were noticeably missing from student's stories. For example, Jesse was focused on reviewing topics from arithmetic and algebra and he resisted talking about his everyday mathematics; his story does not touch on the theme that everyday mathematics is ubiquitous and reasonable. Although Andrea's experience with mathematics in school were not all positive, she finished high school mathematics with a teacher who helped her understand algebra and became so confident in her ability to understand mathematics that she tutored other students. Unlike the other participant's whose experience of mathematics in school was not positive, Andrea's story did not touch on the theme that school math is rigid.

Table 7

Participants' experience of mathematics in their lives and in school a

\begin{tabular}{|l|c|c|c|c|c|c|}
\hline Theme & Andrea & Jesse & JR & Lily & Ruby & Sasha \\
\hline $\begin{array}{l}\text { Mathematics is } \\
\text { ubiquitous and } \\
\text { reasonable in } \\
\text { daily life. }\end{array}$ & $\mathbf{X}$ & $\mathbf{X}$ & $\mathbf{X}$ & $\mathbf{X}$ \\
\hline $\begin{array}{l}\text { Everyday math } \\
\text { makes use of } \\
\text { estimates and } \\
\text { rules of thumbs. }\end{array}$ & $\mathbf{X}$ & $\mathbf{X}$ & $\mathbf{X}$ & $\mathbf{X}$ & $\mathbf{X}$ \\
$\begin{array}{l}\text { School math is } \\
\text { rigid and requires } \\
\text { exact answers. }\end{array}$ & & $\mathbf{X}$ & $\mathbf{X}$ & $\mathbf{X}$ & & $\mathbf{X}$ \\
\hline $\begin{array}{l}\text { There is a } \\
\text { tension between } \\
\text { everyday math } \\
\text { and school math. }\end{array}$ & & & $\mathbf{X}$ & $\mathbf{X}$ & $\mathbf{X}$ \\
\hline
\end{tabular}

a Roo's interview was not recorded, so data from her interview is not included in this analysis

$J R$. JR grew up in a rural part of the state and still lives there. Like his partner Roo, JR described learning within the family:

My father died just before I turned three. So, I was lucky to have some real good grandparents. One owned a construction company, a very large one. And the other one did janitorial and building maintenance. I worked for both from the 
time I was about six years old on. Papi, the building maintenance guy, he also commercial fished. So, we built our own dories in the garage and I took them to sea, jumped the rivers. So, I learned a lot of hand tools with him. We built dories with keels out of books. He was the smartest Indian I ever met in my life [JR, 19 December 2011].

This excerpt from JR's interview transcript was in response to one of the first questions posed during the interview, "Would you tell me a little bit about yourself, highlighting whatever you think is important to share?" JR first shares some of the things he learned from his grandfathers. This illustrates one repeating idea from JR's interview - learning takes place in the family and at work. Another important lesson JR learned within his was how to fix almost anything, "I learned to make anything we had laying around work for necessity. Necessity was the mother of all inventions. And we had a lot of necessity," again highlighting that living on a tight budget was a factor in how many of these participants encountered their quantitative worlds, another repeating idea from several of the participants' interview transcripts.

JR had a diverse labor history: "I've built everything but a dam and a bridge." In addition to construction, JR also worked as a boiler mechanic in paper and saw mills, and he worked forges in metal shops. As described in the previous section, JR used measurement and geometric concepts on these jobs. But this extensive job history also equipped JR with a practical knowledge of engineering, as well as a disdain for the educated engineers:

Do you want to know my reasoning behind simple? I have seen people try to reinvent the wheel. Mostly engineers. And it always looks good on paper until 
you got to put it together in the field. That's when I want them hanging right there next to me. Okay, now it doesn't work. I give you my word [JR, 19

December 2011].

This passage highlights that JR makes a distinction between the practical knowledge he learned from his grandfathers and through his varied work experience from what he perceived as the book knowledge of the engineers.

For JR, problem solving on the job is different than problem solving in school. While working on the mathematical tasks during the interview, JR described how he reads word problems, looking for the information that suggests what it is he needs to compute.

JR: But when I am reading a problem, I automatically will always jump to the good stuff.

Ann: How do you know what the good stuff is?

JR: Um... the end of it... Well, it's the end of it. It's the last words. This is a strategy for solving word problems in school. Consider first the last words of the problem, because it is here you will be told what to do. In contrast, JR describes that on the job, he is expected to know what to do to solve a problem. In response to my question about how he solves problems at work that are not presented in the same way as textbook problems are presented, JR replies,

JR: $\quad$ No. They say we want this, we want it now, we wanted it yesterday, and we want it ready. Don't make us show you how. You're a journeyman, making $\$ 30$ an hour.

Ann: So that strategy is good for school, textbook problems... 
JR: Yes....

Ann: ... and it is different than what you might do to problem solve outside of school?

JR: Well, you have a print, anyway. You are handed a print to go by and control lines to measure from.

Part of JR's competence on his job was his ability to read and interpret a print and turn the design into a product. However, when solving a school mathematics problem, JR avoided reading and interpreting. Interpreting a print in order to decide what to do in the field is a very different skill than deciphering a mathematics problem in a textbook.

JR - like other participants - described algebra as a stumbling block in school: "I dropped out of high school over algebra.” JR had successfully completed a course similar to Basic Math at another community college three years prior to the study, but he had been unable to complete the next course in the developmental mathematic sequence, Introductory Algebra, finding himself stuck once again at the transition from arithmetic to algebra. Whereas JR described his competence in several technical areas, he did not see himself as competence with respect to school mathematics, and his experience appeared to influence his beliefs about what constitutes an explanation in school mathematics:

JR: It's [referring to a building up strategy used on the flower stem problem] great except you couldn't use it in a math book. It doesn't look, it doesn't look [searching for a word] spiffy...

Ann: Mathy?

JR: Mathy. 
Ann: So, that's interesting. So, what doesn't look mathy about it?

JR: It doesn't have the 'and's and 'sums of'. It's not mathy. Mathy was your word. I called it spiffy.

Ann: You called it spiffy. It's not spiffy.

JR: It's not spiffy. But it's very simple. It could be in my math book. I'll hire him. I like the other one [iterated composed unit] best of all, so far. This one here. Straight to the point.

Textbooks use precise language likes 'sums of,' but JR valued examples that were meaningful and contextual, like illustrating a solution to the Flower Stem problem using a building-up strategy, and if he could write his own textbook, it might include examples like these.

Mathematics is ubiquitous in JR's daily life: "Math is everywhere." But while working on the mathematical tasks during the interview, he approached problems as school mathematics problems (which they were), and unlike some of the other participants, he did not rely on a belief that everyday mathematics is reasonable or has meaning when approaching the tasks in the interview. For example, when I asked JR, "Why divide 15 by 3 ?" while discussing the Flower Stem problem. JR focused on knowing his multiplication table rather than on the contextual meaning of the quotient, which Lily, Andrea and Sasha each referenced when asked the same question. JR's experience with contextual mathematics outside school and in school is very different. JR is confident about his ability to solve problems on the job, relying on computations, geometrical or mechanical understanding. However, in school contextual problems are 
word problems and JR does not focus on the context. It seemed to me that JR did not use the context is not used to make sense of an interview task; the context of the problem was just window dressing. This is not surprising; the context of school mathematics problems is secondary to the underlying mathematics. As I will discuss in Chapter 5, some of the interview participants did use the context of the interview tasks as a tool for reasoning about the solutions. Although JR's story touched on several experiences with contextual reasoning outside school, he did not bring this experience to bear on the interview tasks, highlighting a tension between his everyday problem solving and school problem solving.

JR's story touches on all four themes that emerged from the data about the participants' experience of mathematics in their lives and in school. Although the way JR described using mathematics in his everyday life was different from how approached the mathematical tasks on the survey and in the interview, the tension between everyday mathematics and school mathematics was not necessarily problematic for JR during the interview. It was difficult for JR to talk about his reasoning within the context of a problem, but he could reason to a solution to most of the tasks during the interview. Andrea. Andrea was 25 years old at the time of the study. She attended a trade school for massage therapy after high school, but did not finish due to problems with hand strength caused by working at shipping company. Andrea was returning to school to become an occupational therapist.

In addition to working for a shipping company, Andrea had worked in restaurants and in retail. When asked about mathematics at work, she described placing orders to maintain inventory: 
That involves looking at previous sales, how much we sold versus what's on sale that I might need to order more of. What we wasted last time I had ordered versus... to try to bring down the money lost due to waste. But I still need to order enough to... Pretty much it's just addition, subtraction and multiplication. Later in the interview Andrea provided a more detailed example:

Like, for example, our gallons of milk. Normally they were like $\$ 3.50$ and sometimes they'd do on sale for $\$ 2$. For example, the whole milk, normally I would order 20 gallons. We'd go through... If it was on sale, we'd probably go through about twice that amount. Somewhere between half again and twice that. So we'd go through 30 to 40 gallons. So, I'd generally order 35 , just to be safe [Andrea, 4 January 2012].

The computation Andrea describes here, ordering $150 \%$ to $200 \%$ of the amount of milk she typically ordered, is one of several examples of the types of computations Andrea performed effortlessly.

Like other interview participants, Andrea had also developed powerful computational strategies while away from school. For example, for most computations involving percentages, Andrea reasoned with $10 \%$. On the Percent Discount problem, Andrea computed the discount by multiplying $10 \%-$-- $\$ 3.50$-- by 4 . She reported that this is a strategy she frequently used:

Ann: So, this strategy of finding $10 \%$ and then multiplying it by 4 , is this something that you typically do? 
Andrea: Yeah. For an odd thing like that... if it was $40 \%$ or $60 \% \ldots$ something like that. Where if it were like 30\%, I'd just divide it by 3, 'cause, technically it's 33.33333 is $30 \%$.

Ann: Yeah, 30\% is about a third off. You're estimating there. So you wouldn't do $10 \%$ and multiply it by 3 ?

Andrea: No.

Ann: Why not?

Andrea: Just because it is easier to divide something by three. Whereas $40 \% \ldots$ well, $40 \% \ldots$ that's two-fifths. So, you could technically divide it by five I suppose [Andrea, 4 January 2012].

Andrea started by describing a strategy of working with one-tenth or $10 \%$, but then recognized that she could have also solved the Percent Discount problem by working with one-fifth or $20 \%$. She had developed a flexible and powerful way of determining percentages.

During the interview, Andrea was asked to consider the computation $0.40 \times \$ 35=\$ 14$, a computation many of the students who completed the survey used to solve the percent discount problem. She quickly recognized this as a strategy she had learned in school that is more efficient than her the strategies she had developed for computing percentages: the strategy is "a lot more simple than what I did" and "it cuts out a step of the process that would save me time." Andrea's strategy for computing $40 \%$ of $\$ 35$ was to determine $10 \%$ and multiply that by four, a two-step strategy. 
Computing $0.40 \times 35$ is a one-step strategy, which is more efficient when the computation is easy.

When reasoning about the Ticket Sales problem, Andrea used the formula rather than the computational strategies she brought to the interview. But the formula was more than a computation tool. In the context of the Percent Discount problem, parts of the formula had contextual meaning. When I asked Andrea why multiply 35 by 0.40 , she gave a partial response, "40 cents per dollar," that at least contextualized one of the two factors in a way that might be leveraged to develop the understanding of a percent as a rate that is necessary to make sense of this formula. Andrea recognized that using a formula to compute a percent as an efficient strategy she had forgotten from school, but she - like Ruby and Sasha - had developed computational strategies that were contextual and meaningful.

Like JR, Andrea had struggled with algebra in high school, repeating Freshman Math three times before finding a teacher who made the subject clear to her. But for Andrea, the experience of finally understanding the mathematics to the extent that she could tutor others was a positive one. In fact, Andrea was the only interview participant to report a positive experience with mathematics in high school. She was looking forward to taking Basic Math, believing it to be an accurate placement:

And I have never been so excited for a math class, just because I am happy to be going back to school. And I have been looking through my textbook and a lot of the stuff in the beginning of the book is going to be review. And at the end of the book it starts getting into algebra and all that. So, I feel really comfortable going 
into it, because I am starting with a base that I kinda know. [Andrea, 4 January 2012]

Andrea's story touches on the first two themes. In fact, mathematics was ubiquitous, but also very reasonable in her everyday life. She reasoned with tenths, fifths and thirds flexibly while reasoning about percentages. She was able to think about 1.5 times a quantity of milk that needed to be ordered. Like the other participants, Andrea also used estimates, such as one-third for $30 \%$ or an overestimate of $10 \%$ for an $8 \%$ sales tax. Unlike some of the other participants, Andrea did not express a tension between everyday mathematics and school mathematics, perhaps because she had success with mathematics in school. Andrea recognized that a formula for computing percentages others recalled from school as being more efficient than her strategy, but she did not seem to see school mathematics as rigid.

Ruby. Although not the oldest of the interview participants, Ruby had been away from school and school mathematics the longest - more than 20 years. Ruby had worked as a certified nursing assistant, a medical receptionist, had run a daycare in her home, and with her partner, Ruby owned a janitorial company that remained in business for 11 years prior to the recession. Ruby had taken some accounting classes so she would not need to depend on others to manage the books of her business, but she also believed that her business would have been successful if she had remained in school and had more experience with budgeting. Ruby was returning to school to study business. Her goal is to open a non-profit center to help members of the community apply for grants to start and maintain small businesses. 
Like Andrea, Ruby had developed computational strategies, which might not be efficient like algorithms used in school, but strategies that were accurate and the operations used meaningful in the context. For example, Ruby described how she illustrated for one of her children dividing by three. As a context, she used dividing a $\$ 1000$ grant for school into three parts, so it would last over the three months of the quarter. Ruby wrote the three months in a column and then divided up the $\$ 1000$, starting by distributing $\$ 300$ to each month. With the remaining $\$ 100$, she distributed \$25 to each month. This strategy is both an estimate, but also illustrates Ruby's understanding of what it means to divide $\$ 1000$ by three.

Although Ruby did not have an efficient or accurate unit-cost strategy for solving the first variation of the Flower Stem problem, she recognized that each stem was less than $\$ 1$, and used this meaning to solve the problem. Ruby performed operations on 18 and 15 until she found one that gave a reasonable result - the quotient of 15 and 18. Ruby's strategy for solving the variation of the Flower Stem problem may not have led to an accurate solution if Ruby has stumbled upon another quantity less than one, but unlike other participants who misused a unit-cost strategy, Ruby recognized that the stems could not cost $\$ 1.20$ each: "If you have 18 stems and they cost a total of $\$ 15 \ldots$ For one, they are not a dollar a piece, because if they were a dollar a piece that would be \$18." Ruby used her common sense about the cost of the flowers as she performed computation to solve the problem.

Ruby did not have a good experience with mathematics in high school. She described math classes as having too much content and too many students: "It was confusing and I didn't get anything out of it and there was never enough time." But 
when I asked Ruby what she expected from Basic Math, Ruby replied, "To be a recap... To brush up... To be able to have a better understanding... To be able to - whatever I am missing or don't quite get or quite understand - to be able to resolve that and to be able to move forward with confidence." Although her prior experience with mathematics in school was not positive, she was looking forward to studying mathematics at the community college. Unlike some of the other participants - JR, Sasha, Jesse and Lily Ruby did not seem to feel a tension between everyday mathematics and the mathematics she would be encountering in school.

Sasha. Like Ruby, Sasha was a mother of five children with experiences managing a household and finances. Sasha had worked as a restaurant manager and as a photographer and described both of these jobs as involving mathematics: "Well, I think money handling... you have to be good with math, because you got to be able to take the money and give the money back - change. Ordering, you have to be able to know how much you need to order. That takes math concepts. In photography, I would say just resize measurements are math based, timing. It's all math.” Sasha was returning to school to study radiology.

Sasha had also developed computational strategies, which might not be efficient like algorithms used in school, but these strategies were accurate and the operations used meaningful in the context. Like Ruby, Sasha recognized that each flower stem was less than $\$ 1$ when thinking about the variation of the Flower Stem problem, but Sasha did not have a unit cost strategy. She attempted to determine the cost per flower by successively halving the composed unit 18 stems to $\$ 15$. When she reached the conclusion that $4 \frac{1}{2}$ stems cost $\$ 3.75$, she then estimated that 6 stems would cost $\$ 5$. In fact, Sasha frequently 
used halving and doubling strategies when reasoning about quantities. At another point in the interview, Sasha computed the product of 80 and 5 by doubling 80 twice and adding 80 to this product. When halving, Sasha could not determine half of 13 minutes exactly (she estimated this value by finding half of 12), but she could easily find half of $\$ 35$ by halving $\$ 30$ and adding to this half of $\$ 5$. Sasha experience at work and managing household finances helped her perform computations with money accurately, whereas she could only estimate half of 13 minutes. Sasha's computational strategies appear more effortless in the contexts that constitute her everyday mathematics.

Computations in her everyday mathematics were reasonable because they are grounded in familiar contexts.

Sasha, like the other participants, did not have a good experience with mathematics in school, especially when she got to middle school:

I would go to a different class, I remember, to go to math. And so, I think at the time, those were the kids that were in the classroom with us were just noisy and just didn't pay attention. And so then I would just get distracted. My instructor would just, 'Here's your lesson.' He really wouldn't explain it to me. My dad actually put me into some tutoring with the same teacher and I just didn't seem to get anywhere with it. So, I just kinda was like [inaudible]. I am never going to get this. So I am just going to leave it alone [Sasha, 22 December 2011]. When completing her high school diploma online, Sasha described taking the mathematics test repeatedly until she passed. She used a GED Preparation text and had some help from a brother, but her only motivation for completing 'the course' was to 
obtain her credential. Like Andrea and Ruby, Sasha was expecting Basic Math to be review, but she seemed a little more anxious about the course than the others:

Sasha: I really want to get to where I can multiply and divide in my head instead of having to write it out, or using a calculator. I want to be able to just do it in my head.

Ann: Okay.

Sasha: I really don't know what to expect in this math level. I am assuming it is just the basics, refreshing your brain.

Ann: It's like fractions, decimals, percents... There is some review of regular multiplication, subtraction addition, division.

Sasha: And fractions is where I really want to... I think I really need help with fractions [Sasha, 22 December 2011].

Sasha was aware that she did not know multiplication facts. As I discuss in Chapters 5 and 6, Sasha did have strategies for computing some products even when she did not have access to a multiplication fact such as $5 \times 8=40$. Sasha, perhaps like other Basic Math students, felt she needed help with fractions.

While working on the mathematical tasks during the interviews, Sasha's fears around doing math on paper came into play: “On paper... it's like you are being graded.” This was different from Sasha's experience with everyday mathematics:

I think... because with problem solving, you are expected to get an actual answer. And when you are in the grocery store and buying something, no matter what it is, you have your set dollar amount, and just estimate and be happy when you have that extra change. Or be upset when you underestimate it and you are 
going to have to put something back... whatever your situation is. But when it's on paper, it's not really asking for an estimate. It is asking you for the exact answer [Sasha, 22 December 2011].

For Sasha, estimates are sufficient when shopping, but the tension between everyday mathematics and school mathematics is that estimates are not acceptable in school - or once a problem is presented on paper. In addition, one's mathematics is exposed when it moves onto paper and can be judged by an external authority. Everyday mathematics at least in Sasha's experience - is more forgiving.

Like JR, Sasha's story touches on all four themes. She perceives herself as someone who used mathematics all the time, in particular, counting and computation. Her computations were typically grounded in the context and made sense; Sasha had ways to check the reasonableness of her computations. Sasha used estimates in her everyday, but believed school math to be more rigid because exact answers are expected and putting math on paper means your thinking will be judged. Because her experience and competence with everyday mathematics is so different from her experience of mathematics in school, Sasha's story illustrates the tension between these two mathematical worlds.

Jesse. Jesse was in his mid-20s. Since high school he had been working as a glass blower, a job he left to move to the city six months prior to the study. Jesse was returning to school to study biology, which he had become interested in through his own reading. In addition, he was the only interview participant frustrated with his placement into Basic Math. Because of this, Jesse had been studying mathematics using an online tutorial since taking the placement test. Although this self-study likely influenced how 
Jesse interacted with the mathematical tasks of the interview, Jesse enjoyed learning on his own. When asked how learning now was different from his high school experience, Jesse reported, that

Well, because, I guess, I am initiating it. When I initiated it, it became a lot easier. Instead of in high school... it was like... it wasn't all that much pressure. I just didn't have an interest in it. I had interest in other things, like skateboarding. I guess when that changed, over the past four years of so, just reading a lot [Jesse, 3 January 2012].

Although Jesse reported using mathematics outside school, it did not seem that Jesse valued these ways of thinking as much as the other participants. When describing the ways he used mathematics outside school, he dismissed much of his experience as, "pretty much nothing on paper," as if he believed that mathematics is working things out on paper. Not only was mathematics about working things out on paper, but school mathematics involved determining the formula that could be used to solve the problem at hand:

Jesse: Because if I were just to know the what the formula was... Then it's just easy...

Ann: So, you're looking for a formula.

Jesse: Yeah. Seeking out a formula, and I can't find it so... This way [solving a problem without a formula]... It takes more patience, but you eventually get to it [Jesse, 3 January 2012].

Like Andrea, it appears that Jesse believes strategies from school mathematics are more efficient. For example, using division to find a unit cost is one formula Jesse 
recalled from school. However, unlike Andrea, these efficient strategies did not always seem to make sense to him. On the Flower Stem problem, Jesse reasoned with a unit cost of $\$ 1.50$ per stem. When he realized his strategy led to an incorrect conclusion, he was unable to reconsider the unit cost he had computed. On the other hand, when Jesse was willing to let go of finding a formula to solve a problem, he had robust ways of reasoning. As will be discussed in the next chapter, Jesse's emerging understanding of speed (a topic that was difficult for most of the interview participants) was based on his ability to reason proportionally.

Jesse reported that he had been successful in mathematics courses in high school, but uninterested. Several times during the course of the interview, he reported that one his failings as a math student was not being patient and skipping steps, obtaining an incorrect result. When asked what he expected from Basic Math during the upcoming term, Jesse reported that he expected to, "Memorize everything... And actually work it all out instead... Be more patient with it... with mathematics. Instead of just get the solution real quick because sometimes there [inaudible, but Jesse mentions 'steps.'] So, that's what I want to get back into. Be patient of actually getting the right solution.” Jesse's expectation that he would memorize everything in Basic Math suggests, again, that Jesse believes that doing school mathematics is about applying an appropriate formula to a problem.

Unlike the other participants, mathematics for Jesse was connected to his experience of doing mathematics in school. Although Jesse described measuring adding ingredients according to particular ratios to make colored glass, he did not perceive this work as mathematical. "Pretty much nothing on paper" was Jesse's response when I 
asked him about mathematics in his everyday life. Jesse described getting the feel for the ratio of amounts of ingredients in colored glass and he admitted to using estimates when shopping, but his focus during the interview was on finding the formula that would allow him to solve the problem.

Lily. Lily was also in her mid-20s. She had worked in the fashion industry, in retail and was working as a bartender at the time of the interview. Lily was returning to school to obtain credentials in a health-related field, but her educational goals were not as established as those of the other interview participants. She also described cooking as mathematical.

Like Jesse, shopping was not part of Lily's everyday mathematics because for her shopping was more about negotiation than about quantities:

Ann: So, for these two problems, your strategy was to find the cost per stem and then multiply by the number of stems. Is that something that is familiar to you from outside of school? Do you ever calculate those costs per item?

Lily: Not really... 'cause it is always like bartering. When you are dealing with... when you throw in the people factor in math... And then it's like people, when you are bartering or something like that, you're like, "Well, I am not getting like half of them, so could it just be \$7?” So you have room to wiggle. Or like things like this [pointing to the flower stem problem variation] where it is going to be like 25 . They might be like, “Well, it's $\$ 30$ for 21 roses," probably rounding up or rounding down.

Ann: So, in the real world there is more room for wiggling. 
Lily: There's way more... math is like super structured and solid. There's a definite... There's lots of different ways you can come up with the answer, but there's a right answer and a wrong answer in the end. The world is so... [Lily, 21 December 2011].

The 'people factor' was a theme that was unique to Lily. Although she described planning her father's wedding as a mathematical activity, she recognized that planning accurately was difficult because people are unpredictable: "There are 100 RSVPs. And even if someone RSVPs, that doesn't mean that they are coming. You have to add for human error in that. So, there's the wiggle room. So, if I am like estimating... well, 100 people are coming and that means maybe $10 \%$, so 10 people, will be late, not eat food, bring somebody else. There are those kind of things to think about, and figuring out the budget, bringing in extra food."

Lily found the mathematics she encountered in high school to be irrelevant and she reported that she is still not served by what she learned in school. School mathematics was rigid as it was for Sasha: “There's a black and white. There's a right and a wrong only answer. There's not like any... no wiggle room.” However, Lily was aware of the tension between what she expected from mathematics in school and the ways of thinking about mathematics that she was developing as an adult:

Lily: I want to understand math better so that I can understand the art behind things and the way flowers grow... It all correlates together, I am finding I want a better understanding of it.

Ann: So, that sounds like you have a different perspective now? 
Lily: Right. So, that is like why I want to go back, kinda immerse myself and have a passion for it even though I...

Ann: So, what are you expecting from your [Basic Math] class?

Lily: Total frustration and bewilderment... [Lily, 21 December 2011].

Lily had a different relationship with her quantitative world than the other participants. Like others, Lily estimated and relied on rules of thumb, especially in bartending (a gin and tonic is "about half and half"), but her everyday also involved negotiating and compensating for the 'people factor.' Lily was also the only participant to indicate that mathematics might help her understand the world even though she was not expecting her Basic Math course to help her on this quest.

Although on her survey Lily listed shopping, planning her father's wedding and cooking as activities that involved mathematics, she did not seem to see mathematics as ubiquitous and as reasonable in everyday life as some of the other participants. Lily had a sense of mathematical structure and the belief that mathematics might be a tool for understanding the world that none of the other participants described. However, the tension between her ideas about mathematics and what she expected from school mathematics was pronounced. From school mathematics she expected nothing but "frustration and bewilderment."

Summary of findings from interview data. The four themes summarized below answer the second part of the first research question, "What are students' experience of mathematics in their lives and in school?" 
Everyday math is ubiquitous and reasonable. As described above, most adult students report that they use math in their everyday lives and within a variety of contexts that can be categorized using the pan-cultural mathematical activities described by Bishop (1988). As Sasha explained, "I think that almost everything I have done uses math at some point." In these contexts, mathematics is reasonable, and the context of a problem is used both to solve a problem and to check the reasonableness of the solution. For example, both Ruby and Sasha used their understanding that the unit cost of a flower was less than one dollar to determine a reasonable solution to the alternative to the Flower Stem problem. When reasoning about the original Flower Stem problem, Andrea, Sasha and Lily all answered the question, "Why divide 15 by three?" by describing the need to determine how many bunches (Andrea), bundles (Lily) or sets (Sasha) of five flowers made up 15. When reasoning about the Percent Discount problem, both Andrea and Sasha understood a 40\% discount as 40 cents off each dollar. Ruby, as she considered another student's computation of the product of 0.40 and $\$ 35$ to compute $40 \%$ off $\$ 35$, she referred to 0.40 as 40 cents. Jesse communicated the understanding that 40 was 40 parts out of 100 and $18 \% 18$ parts out of 100 ; he was certain of this understanding, but it was not as contextual as the understanding of a $40 \%$ discount communicated by Andrea, Sasha and Ruby.

In addition, it appears that several of these adult returning students, in particular, Andrea, Ruby and Sasha, had developed computational strategies that worked for the mathematical tasks they encounter in their everyday lives when the computational strategies they had used in school had been forgotten. All of these strategies were meaningful and could be used as a bridge to topics these women will encounter in 
developmental mathematics. For example, Andrea's strategies for computing percentages were based on her understanding of percentages less than $100 \%$ as fractions; she could compute $40 \%$ of a number by finding a fifth of the number and then doubling it. Equating a percentage to a fraction was a computational tool, not a procedure to memorize. Sasha's strategies for finding the product of 80 and 5 might be used to illustrate the distributive property: $80 \times 5=80(2+2+1)$. Finally, Ruby's strategy for distributing a $\$ 1000$ grant over three months is an illustration of a partitive model for division that might help her makes sense of why the quotient of -100 and 4 is -25 if she considers a family of four sharing a $\$ 100$ debt.

\section{Everyday mathematics involves working with estimates and using rules of}

thumb. Ruby, Andrea, Sasha and Lily all talked about using estimates. When asked about $18 \%$, Ruby commented that, "I'd rather overcharge and estimate, than go under. So, if it's 18\% I just use 20\%." Both Andrea and Sasha discussed making estimates when shopping. Andrea reported that, "A lot of the times I just estimate it in my head. I am not worried about exact numbers." Sasha shared that, "Yeah, I usually estimate. That's ... I just round up or down depending on where I am at, usually up. That way I can be over money." Lily described the "people factor," the necessity of making room for human error or engaging in bartering. For example, Lily expected that the number of people who RSVPed for a wedding would not be the actual number of people attending. She frequently referred to using "wiggle room" to account for this uncertainty.

When Jesse described mixing different types of glass to obtain a particular color, he described moving beyond precision to getting the "feel of it." This highlights another feature of everyday mathematics that other participants described explicitly: Outside 
school - and particularly at work - people frequently reason about quantities using a rule of thumb rather than working with precise quantities. Lily, a bartender, described a gin and tonic as "about half and half," and that, "An ounce is typical for a drink. So, you can gauge what glass you're grabbing." JR used the ratio $2 \frac{1}{2}$ gallons of gasoline to six ounces of oil to obtain the 50 to 1 ratio he needed for his chain saw. The use of estimates and rules of thumb in these students everyday mathematics is in contrast with their perceptions of mathematics in school.

School mathematics is rigid and requires exact answers. Both Lily and Sasha portrayed school mathematics as more rigid than their everyday mathematics.

Ann: So, you see math as very structured?

Lily: Yeah, or like... There's a black and white. There's a right and a wrong only answer. There's not like a ... no wiggle room [Lily, 21 December 2011].

Sasha articulated this tension with respect the everyday mathematics she used:

When I was in school, I always went for the exact answer. Now, with like time, for me it is... because I have been out of an actual math class and being graded on it continuously. I just problem solve as far as estimation. I estimate everything [Sasha, 22 December 2011].

Although the students' interviewed all were enrolling in Basic Math, an arithmetic review course, several of the students described algebra as a mysterious topic again the introductory algebra course, shared that, "[Algebra has] been my nemesis since I was a sophomore in high school. I dropped out of high school over algebra." Both Sasha and Lily reported that the symbols did not make sense to them. Sasha was not 
even sure if she had studied algebra in school: "I think I may have been in a pre-algebra. I remember having to do like $x \mathrm{~s}$, and I was like, 'What is that?"' Although Andrea was ultimately able to make sense of algebra in high school, her first two attempts at freshman math left her confused: "Freshman math was algebra... [I repeated the course] just ‘cause I didn't understand how it worked.” Although Lily found all her school mathematics to be irrelevant, she was particularly distressed by the jargon of mathematics: "I get it, but when it is in a whole sequence of jargon. I am like, 'Oh, nonsense. Great."' In school, mathematics was not always reasonable or sensible and the symbolic representations these students encountered remained mysterious to them. Unlike everyday mathematics, which was reasonable for many of the participants, several participants had experienced school mathematics as something inaccessible to them.

\section{A tension exists between students' experience of mathematics in their lives and}

in school. Perhaps Lily expressed this tension best when she described her wonder about the mathematics of nature and her expectation that she would be bewildered and frustrated in her Basic Math course. Sasha was also aware of this tension. Mathematics in school requires exact answers, but it is also the case that once you put your mathematical thinking on paper as one does in school, it becomes visible to others: "It's like you are being graded." JR who was confident in his practical, everyday knowledge, resorted to strategies for tackling school mathematics problems that appeared very different from how he experienced his quantitative world outside school. However, this tension was not part of every participant's story. For example, Andrea had a positive experience with school mathematics, even though she initially struggled with algebra in 
high school. She attributed this positive experience to a teacher who helped her make sense of algebra. Andrea never described differences between her everyday mathematics and school mathematics. She had computational strategies that were reasonable to her and she expected the mathematics she would encounter in Basic Math to be reasonable as well: "I feel really comfortable going into it, because I am starting with a base that I kinda know." Although not all students experience a tension between their everyday mathematics and what they expect of school mathematics, it is important to understand this tension so that the transition back to school mathematics might be a transformative experience that addresses this tension.

\section{Summary and Discussion}

Summary of findings. The findings described in this chapter address the first research questions, "What are the backgrounds of students who enroll in a Basic Math course and what are their experiences of mathematics in their lives and in school?" This question was posed to make visible characteristics of a population of students that differ from younger students studying similar mathematics to the mathematics these adult students will encounter in their Basic Math course. The purpose of pursing this question was also to learn more about these adult students' experiences of mathematics in order to consider ways the mathematical concepts and strategies Basic Math course might be more closely aligned with these experiences.

Findings from both the survey and interview data inform our understanding of these particular students' background. The survey data reveals that the maturity of many of the students in Basic Math (34\% are 27 or older), the time they have been away from school (38\% had not taken a mathematic class for more than 5 years and $22 \%$ for more 
than 10 years) and the statistic that nearly half of the students reported that they require more than a review of the central topics studied in Basic Math suggest that the expectation that students need to review particular topics and that they are accessing knowledge resources from prior schooling may not be reasonable. The interview participants shared the demographic characteristics of the surveyed students and their stories reveal that their backgrounds were varied, although there were common experiences such as being a parent, living on a tight budget, or working in retail among several of the participants.

The survey data revealed the broad range of activities that adult returning students perceive as mathematical, providing a snapshot of students' experience of mathematics in their lives. These activities were discussed using Bishop's six pancultural mathematical activities to acknowledge the universality of students' experience, as well as a framework to consider the ways these everyday activities might connected to the more formal mathematics that Bishop claims arise from these pan-cultural activities (Bishop, 1988). The survey data also suggests that adult students perceive a wide variety of everyday activities as mathematical, and the interview data allowed me to query further students' experience of mathematics in their lives and in school. Four themes emerged from the analysis of the data: (1) Mathematics in everyday life is ubiquitous and reasonable; (2) Everyday mathematics involves working with estimates and using rules of thumb; (3) School math is rigid and requires exact answers; and (4) There is a tension between everyday mathematics and school mathematics. The first two themes suggest a foundation upon which adult students' mathematical understanding in a Basic Math course might be built. The second two themes suggest that acknowledging 
students' perceptions of school mathematics and making visible the tensions between adults' everyday mathematics and what they can expect in their Basic Math classes might be an important first step in constructing a bridge between the ways of reasoning students use in their everyday lives and more formal ways of reasoning expected in Basic Math.

In this chapter I argued that students perceive a wide variety of their activities as mathematical. It is possible that both the survey respondents and interview participants described everyday activities as mathematical because I asked them to do so. It is possible that under other circumstances, they might not think about these activities as mathematical. However, the survey respondents had no connection to me. Their mathematics instructor administered the survey and informed the students that their responses were being passed on to a researcher and were not part of their work in the course. Yet when primed, nearly half (48\%) of the survey respondents reported that they use mathematics either "All the time" or "Frequently" outside school. The interview participants were asked to not only list activities they perceived to be mathematical, but to explain the mathematics in the activities they listed. Although some explanations were generic, for example, using measurements in cooking, each interview participant was able to describe in detail the mathematics in at least one activity.

Implications for practice. Should Basic Math be an arithmetic review course or might adult returning students be better served by a course that builds on computational strategies developed in everyday activities? The time away from school experienced by many of the students who participated in this study indicate that these adults are likely not drawing upon knowledge resources from previous schooling. In addition, nearly half 
the students who enroll in Basic Math indicate that they need more than to brush up on the concepts and procedures that comprise the Basic Math course. If this is the case, than treating these topics as review does not serve all students. In fact, according to data provided by institutional research at the college where this study took place, only $28 \%$ of the students who enroll in Basic Math persist to complete introductory algebra within two years. What would a course look like that bridges informal ways of reasoning to both the more formal types of reasoning students will encounter in either algebra or in courses that are being developed as an alternative to the introductory and intermediate algebra courses that have traditionally characterized developmental mathematics? The question "What do the students who place into Basic Math need in order to be to be successful in the remainder of the developmental mathematics curriculum?" needs to be addressed.

Implications for research. The findings discussed in this chapter help us understand the background of students who enroll in Basic Math and their experience of mathematics in their lives and in school. We need to better understand the ways adult returning students position themselves with respect to the mathematical topics they encounter in developmental mathematics courses so that practitioners are better able to design these courses. Research questions that might explore this topic include "How do adult returning students perceive their understanding and proficiency with common fractions such as those used in cooking or measurement?" or "How do adult returning students perceive their understanding and proficiency with decimal arithmetic when the numbers are like the familiar numbers used to represent currency?" Another implication for further research that emerges from these findings is inquiry into questions that would 
help researchers better understand the mathematics in adults' everyday experience and provide curriculum developers a framework for developing activities that could bridge adult students' mathematics to the mathematical concepts and strategies that comprise a course like Basic Math. The details of this implication are discussed below.

What is the nature of the mathematics that adults perceive in their everyday mathematical activities and how are these ways of thinking related to the more formal mathematics students encounter in a course in like Basic Math? The findings from the next two chapters provide a partial answer to the question with respect to proportional reasoning. However, the findings discussed in this chapter suggest that adult returning students perceive a wide range of activities as mathematical. Previous research into some of these activities has been undertaken, e.g. Lave's work on shopping (1988) and Milroy's work on carpentry (1992). However, the focus of this work has been to characterize differences between everyday and school mathematics. These studies might be reviewed in light of the findings from this study in order to make conjectures about the relationship between everyday mathematics and the formal mathematics students encounter in a course like Basic Math. For example, examining adults' experience with fractions in everyday contexts might reveal that adults typically reason with a part-whole model of fractions, which would indicate that this model needs to be connected to other models, such as fraction as operator or fraction as ratio. Developmental research methodology (Gravemeijer, 1994) could then be used to develop activities to test these conjectured relationships and the iterative process of developmental research be used to both revise these conjectures and to produce activities that build on adult students' 
everyday mathematics as they explore the mathematical concepts and procedures they need to be successful in future course work.

Conclusion. Resnick (1987) described four discontinuities between learning in school and learning outside school: (i) individual cognition in school versus shared cognition outside, (ii) pure mentation in school versus tool manipulation outside school, (iii) symbol manipulation in school versus contextualized reasoning outside school, and (iv) generalized learning in school versus situation-specific competencies outside. The last two of these discontinuities highlight the tensions these interview participants described between their experience of mathematics in school and in their lives. Sasha, Ruby and Andrea were particularly competent reasoning about contextual problems that resembled problems they encountered in their everyday lives. When reasoning about percentages and unit costs, both Sasha and Ruby used the context to make sense of the problem. In addition, each participant who was a mother described using everyday examples when explaining math to their children. Everyday math was both contextualized and reasonable, a contrast to these women's and others' experience of mathematics in school.

However, many of the competencies these adult students describe may be situation specific. Reflecting on Resnick's work, Schliemann (1995) expresses the concern that bringing everyday mathematics into school is that mathematical problems in which the quantities have concrete referents do not naturally reveal the relationships between quantities that comprises the content of school mathematics. Schliemann gives an example from her work with street vendors, which illustrates the difficulty of constructing the commutative property of multiplication when one is working with a 
repeated addition model of multiplication. For example, to compute the total cost of 100 items at $\$ 6$ each, the vendors would add $1006 \mathrm{~s}$, whereas the easier computation, $6 \times 100$, or 6100 s loses its meaning in this context. Although some of the computation strategies these adult students bring to a Basic Math classroom are inefficient (for example, the strategies Ruby and Sasha used to solve the variation on the Flower Stem problem), these strategies made sense to each women and for Sasha, especially, the operations were meaningful. (More about this tension will be discussed in the next chapter about returning students' proportional reasoning.) It makes sense to start from contexts that adults perceive as mathematical and from their ability to make sense of quantities in these situations on the path to engaging with the structure and generalizations that are an important part of mathematics in school. 


\section{Chapter 5: Proportional Reasoning}

In the previous chapter, I described ways adult returning students experience mathematics in their everyday lives and in school, highlighting the variety of activities perceived as mathematical, as well as the variety of experiences drawn upon as they interact with their quantitative worlds. This chapter addresses the second research question, "What proportional reasoning abilities do students placing into Basic Math demonstrate prior to returning to school mathematic?" In this chapter the theme of variety continues; students enrolling in Basic Math are bringing a variety of ways of reasoning about problems involving proportional situations. Two major findings emerge from my analysis of mathematics problems included on the survey and students' engagement with the mathematical tasks developed for the interview:

(i) Overall, adult students bring to the classroom a variety of ways of reasoning about problems involving proportional situations. In this chapter, I describe these ways of reasoning, which are, for the most part, reasonable and accurate; reasoning with unit rates is the one strategy that was often applied inappropriately.

(ii) When reasoning about percent - a context familiar to many adult returning students - the interview data reveals that adults have flexible ways of thinking about percent and computing percentages.

\section{Methodology}

The findings reported in this chapter are based upon an analysis of the four mathematical tasks chosen for the survey, as well as the additional tasks developed for the interview. My rationale for selecting the tasks used on the survey was described in 
detail in Chapter 3. However, to recap two of the mathematical tasks were adapted from prior research studies, one was a released item from the NAEP exam and the last a problem about percent discount I wrote. The preliminary analysis of students' work on the survey tasks was used to develop tasks for the interview. Some of these tasks were variations of the survey problems, two tasks were adapted from prior research studies and I wrote the remaining tasks.

Data collection. Cluster sampling was used to survey students in their mathematics classrooms during the first week of fall term 2011. Sections of Basic Math throughout the community college district were selected at random by a staff member in the college's institutional research office. The number of sections sampled at each campus was proportional to the total number of sections offered at the campus. The instructors of the selected sections were not required to administer the survey, but the instructors of 13 of 21 sections sampled were willing to administer the survey. (The number of sections sampled was more than necessary for a representative sample since not all instructors were expected to participate.) In all, 340 student surveys were collected in 13 sections of Basic Math, approximately $21 \%$ of the total number of sections offered that term. Table 5 describes the sample in terms of each of the four campuses of the college. 
Table 8

Survey sample

\begin{tabular}{|lcc|}
\hline $\begin{array}{c}\text { Number of } \\
\text { sections }^{\text {a }}\end{array}$ & $\begin{array}{c}\text { Percentage } \\
\text { of total }\end{array}$ & $\begin{array}{c}\text { Number of } \\
\text { sections } \\
\text { surveyed }\end{array}$ \\
Northside 15 & $26 \%$ & 4 \\
Westside 17 & $24 \%$ & 4 \\
Eastside 9 & $0 \%$ & 0 \\
Southside 16 & $25 \%$ & 4 \\
Extended 4 & $25 \%$ & 1 \\
& & \\
Total 50 & & 13 \\
\end{tabular}

The survey included four mathematical tasks (discussed in Chapter 3) and 128 of these 340 surveys (about 38\%) included responses to all four tasks.

Seven interview subjects were selected from among the 600 students who had registered for Basic Math six weeks prior to the start of winter term 2012 and were not repeating Basic Math at the college. These students were contacted by email and asked to complete and return the survey used in the first stage of the study to indicate their willingness to participate in the task-based interviews. The students who responded were eligible to win a $\$ 100$ gift card from the college bookstore. A purposeful sample was to be selected from the students willing to participate in the interviews, but only seven students were willing and able to participate in the interview, creating a self-selected sample. The interview participants' motivation for participating in the interviews was 
varied. Two of the interview participants, Lily and Ruby, made comments that suggested that the opportunity to win the bookstore gift card motivated them to participate. (All interview participants were provided a $\$ 25$ gift card from the college bookstore, except Lily who was selected at random as the winner of the $\$ 100$ gift card.) One participant, JR, was trying to decide whether he should retake Basic Math (he had completed Basic Math at another community college three years prior to the study) or whether he should attempt Introductory Algebra again, a course he had started but never successfully completed. Roo, another participant, was JR's partner, and his interest in the interview may have influenced her decision to participate. The other participants, Andrea, Jesse, and Sasha were all excited to return to school and made comments that suggested that the interview was an opportunity to get a head start on their upcoming mathematics course.

The seven interview participants completed the mathematical tasks from the survey prior to the interview. Each of the seven interview participants attempted all four problems and with a few exceptions, which will be addressed later in this chapter, the interview participants obtained accurate or reasonable solutions to these problems. The interview protocol used for the interview is included in Appendix B.) The interview protocol included nine additional mathematical tasks that were developed after completing a preliminary analysis of the survey data (see Section 5.2.2). The interviews were semi-structured in that the protocol was used as a guide to my conversation with each participant, so not all participants were asked to address all nine of the mathematical tasks. The interviews ranged in length from 65 to 100 minutes, were video-recorded and the recordings transcribed verbatim. 
Data analysis. Students' work on the mathematical tasks on the survey underwent several rounds of analysis. The preliminary analysis included the following steps:

- Separate surveys with no response from surveys with an incorrect (or incomplete $^{27}$ ) response from surveys with a correct (or reasonable ${ }^{28}$ ) response.

- Sort both correct (or reasonable) and incorrect (or incomplete) strategies into categories, recording observations, queries, conjectures and possible interview tasks.

- Merge categories of strategies in terms of similar features for the purposes of the preliminary analysis.

Participants' reasoning on four mathematics problems were analyzed using a priori categories described in the research literature on proportional reasoning ${ }^{29}$ (Miles \& Huberman, 1994), but these data were also mined for ways of thinking not previously described in the research literature, since it was conjectured that adults' strategies would differ from children's strategies for several reasons. First, the literature on adult students' mathematical reasoning is sparser than the literature on children's mathematical reasoning; we simply do not know enough to conclude that adults' strategies would be similar to the strategies used by younger students. Second, we often hear teachers interpret their younger students' abilities in terms of a developmental framework, but presumably adults are cognitively mature. Finally, adult students have

${ }^{27}$ The category of incomplete response was used for the Bread Flour problem.

${ }^{28}$ The category of reasonable response was used for the Percent Discount problem.

${ }^{29}$ The strategies provided in Table 3 were be the starting point for a list of a priori categories used to code both the from students' work on the mathematical problems on the survey. 
experience living independently in a quantitative world and certainly have had more opportunities to engage in proportional reasoning than younger students; these experiences might generate new ways of thinking about proportion.

This preliminary analysis of students' work on the four mathematical tasks from the survey raised questions as well and these questions were used to develop mathematical tasks for the interview. This preliminary analysis was shared with other researchers in order to determine next steps for analysis and the development of tasks for the interviews. (Findings from this preliminary analysis are included in Appendix D.)

Four-strategies framework. A framework adapted from a priori strategies described in previous research on proportional reasoning (Kaput \& West, 1994; Lamon, 1993; Lobato \& Ellis, 2010) was developed to analyze students' written work on the surveys and the interview transcripts. The preliminary analysis of student' written work on the mathematical tasks identified four a priori strategies (discussed fully in Chapter 2) as sufficient for analyzing the data: iterated-composed-unit strategy (ICU), buildingup strategy (BU), scalar strategy, and unit-rate strategy.

The ICU strategy involves identifying a composed unit, such as three flower stems for $\$ 2$, and then iterating this unit. This first step - identifying the composed unit is called unitizing by Lamon (1994) and is foundational for proportional reasoning: "Understanding ratio and proportion depends on one's ability to view a relationship as a single quantity and then to operate on it" (p. 112). Lamon (1993) also observes that iterating a composed unit is a form of counting, linking "earlier learned mathematical structures and processes and the more complex multiplicative field" (p. 59). As Lamon 
notes here, this strategy works for scalars that are whole numbers as is the case with the Flower Stem problem. For example, a student would literally write ' 3 stems for $\$ 2$ ' five times (see Figure 5), keeping track of the 3 stems until she reaches 15 stems and then adding up the five $\$ 2$ s to conclude that 15 stems cost $\$ 10$.

The next strategy involves building up (BU) (or partitioning) a composed unit. For example, three flower stems for $\$ 2$ can be built up to nine flower stems for $\$ 6$, or three stems for $\$ 2$ can be partitioned down one flower stem for $\$ 2 / 3$. In addition, if another florist sells 10 flower stems for $\$ 6$, building up three stems for $\$ 2$ to nine stems for $\$ 6$ allows one to determine which is the better buy. Thompson (1994) describes the building-up strategy as generative and essential for developing an understanding of rate:

If a child is trying to fi nd, say, how m any apples there are in a basket where the ratio of apples to pears is 3:4 and ther e a re 24 pears, and the child thinks " 3 apples to 4 pears, 6 apples to 8 pears, ..., 18 apples to 24 pears" (a succession of ratios), then this provides an occasion for the child to abstract the relationship "3 apples for every 4 pears" (an iterable ratio relating collections of apples and pears as the amounts of either might vary), and eventually 'there will be $3 / 4$ of an apple or part thereof for every pear or $\mathrm{p}$ roportional part thereof' (an accum ulation of apples and pears, which carries the im age that the values of both can vary, but only in constant ratio to the other) (p. 192).

The building-up strategy, unlike the ICU strategy, can be used with scalars that are not integers. For example, a building-up strategy on the Comparing Speeds problem might be used to compare Victor's constant speed of 8 miles in 10 minutes to Sharon's 
constant speed of 20 miles in 25 minutes, by building up the composed unit 8 miles in 10 minutes. If Victor keeps driving at a constant speed, the 8 miles in 10 minutes is the same as 16 miles in 20 minutes, and adding on half of 8 miles in 10 minutes -4 miles in 5 minutes - means that Victor would also travel 20 miles in 25 minutes.

Another strategy is what I refer to as scalar strategy. A student using scalar reasoning would observe that 15 stems is five times three stems, or 6 stems is one-third of 18 stems. Although some researchers view this as merely an abbreviated building-up strategy (Kaput \& West, 1994), I distinguish this strategy from a building-up strategy because it makes one of the multiplicative relationships between two quantities explicit. For example, as the number of flower stems increases or decreases by a factor so does the cost. This distinction is also aligned with the description of proportional reasoning provided by Lamon (2007) that grounds my work; proportional reasoning includes "the ability to discern a multiplicative relationship between two quantities as well as the ability to extend the same relationship to other pairs of quantities" (p. 638).

Finally, the fourth strategy is reasoning with a unit rate, the other multiplicative relationship in a proportion. Vergnaud $(1983,2004)$ described this strategy as one that supports students' understanding of direct variation, a functional understanding of proportional situation. For example, a student might argue that the unit cost of each Flower Stem is $\$ 2 / 3$ per stem, so 15 stems costs $\frac{\$ \frac{2}{3}}{\text { stem }} \times 15$ stems $=\$ 10$. In addition, the unit rate in a formula for computing a percentage that many students recalled, $A=R B^{30}$,

\footnotetext{
${ }^{30}$ In this formula, $A$ represents the amount of the percentage, $B$ the base amount and $R$ the percent rate.
} 
may or may not be a part of students' understanding of percent even though this formula represents a functional relationship between the base of the percent and the amount of the percentage. In addition, in a study to understand proportional reasoning in out-ofschool contexts, Schlieman and Nunes' (1990) observed that fisherman would use a scalar strategy even when a unit-rate strategy involved a simpler mental computations. Examples of solutions using these four strategies are provided in Table 9.

Table 9

Examples each strategy in the four-strategies framework

\begin{tabular}{|c|c|}
\hline Strategy & Example using the Flower Stem problem \\
\hline Iterated-composed-unit & $\begin{array}{c}3--\$ 2 \\
3--\$ 2 \\
3--\$ 2 \\
3--\$ 2 \\
3--\$ 2 \\
15 \text { flowers stems cost } \$ 10 .\end{array}$ \\
\hline Building-up strategy & $\begin{array}{c}3--\$ 2 \\
6--\$ 4 \\
9--\$ 6 \\
12--\$ 8 \\
15--\$ 10 \\
15 \text { flowers stems cost } \$ 10 .\end{array}$ \\
\hline Scalar strategy & $\begin{array}{l}\text { There are five bunches of three stems in } 15 \text { stems, so } 15 \text { stems } \\
\qquad \text { cost } 5 \times \$ 2=\$ 10\end{array}$ \\
\hline Unit-rate strategy & $\begin{array}{l}\text { Each Flower Stem cost } \$ 2 / 3 \text {, so } 15 \text { stems costs } \\
\qquad \frac{\$ \frac{2}{3}}{\text { stem }} \times 15 \text { stems }=\$ 10\end{array}$ \\
\hline
\end{tabular}


The four-strategies framework is an adaptation of descriptions of students' strategies on proportion problems from previous research with younger students. For example, Kaput and West (1994) do not describe the ICU strategy, but do describe the Building-up (partitioning) strategy in detail. In addition, Kaput and West conceive what I describe as the scalar strategy as an abbreviated Building-up strategy (p. 246) that is not significantly different from building up a composed unit. I chose to distinguish these two categories in order to query the distinction between determining the multiplicative relationship between two quantities and recognizing this relationship. For example, multiplication facts may not be as accessible to adult students who have been away from school, but a Building-up strategy might be a tool for determining the factor that relates two quantities in a situation understood as multiplicative. However, with scalar reasoning, one recognizes the factor. For example, since six flour stems are one-third of 18 stems, then the cost of six stems must be one-third the cost of 18 stems. Kaput and West describe both of these strategies as "additive at heart" (p. 248), but I disagree. The description of proportional reasoning that is used in this study (Lamon, 2007) includes "the ability to discern a multiplicative relationship between two quantities as well as the ability to extend the same relationship to other pairs of quantities" (p. 638). For this reason, the four-strategies framework includes both Building-up and Scalar strategies under the umbrella of proportional reasoning. Kaput and West focus on strategies that involve reasoning with rates as strategies that indicate proportional reasoning. Their analysis of strategies that involve reasoning with rates is more nuanced than what is needed for this study. Like Kaput and West, I understand Unit-rate strategies to be a bridge to a functional model of proportional situations, but the preliminary analysis of 
students' written work on the mathematical tasks from the survey suggested that it was not necessary distinguish between different types of unit-rate strategies. Finally, I felt it was important to distinguish the Iterating-composed-unit (ICU) strategy from the Building-up (BU) strategy, because only that latter could be used with non-integer factors. In addition, Lamon (1993) highlights the ICU strategy as a strategy that bridges additive and multiplicative reasoning. The preliminary analysis of students' written work on the mathematical tasks from the survey revealed that some adult returning students were solving problems using the ICU strategy. If this strategy turned out to be prevalent in the data, this might suggest that students who enroll in a Basic Math course might be well served by a focus on the distinction between additive and multiplicative relationships. Finally, in their summary of research on proportional reasoning Lobato and Ellis (2010) do not distinguish between ISU and BU strategies, but note that these types of strategies require a student has recognized the composed unit or ratio in a proportional situation, an essential characteristic of proportional reasoning.

For each problem on the survey, I coded solution attempts for which a student supplied enough reasoning to categorize the solution attempt. These solution attempts were classified as Correct, Valid, or Invalid. A solution was coded as correct is a student obtained a correct solution using valid reasoning. A solution attempt was coded as relying on Valid reasoning if the student's strategy would have resulted in a correct solution if a computational error were not made. Invalid reasoning led to incorrect solutions. In addition, on the Bread Flour problem there was an additional category, Incomplete, which was used when a student provided a solution that varied only one of the two quantities. Next, I coded each survey using the four-strategies framework or 
noted when a student used a strategy not included in the framework. Table 10 provides examples of solutions that would be coded Correct, Valid and Invalid, as well as how each would be coded using the four-strategies framework.

Table 10

Examples of Correct, Valid and Invalid solutions from Flower Stem problem

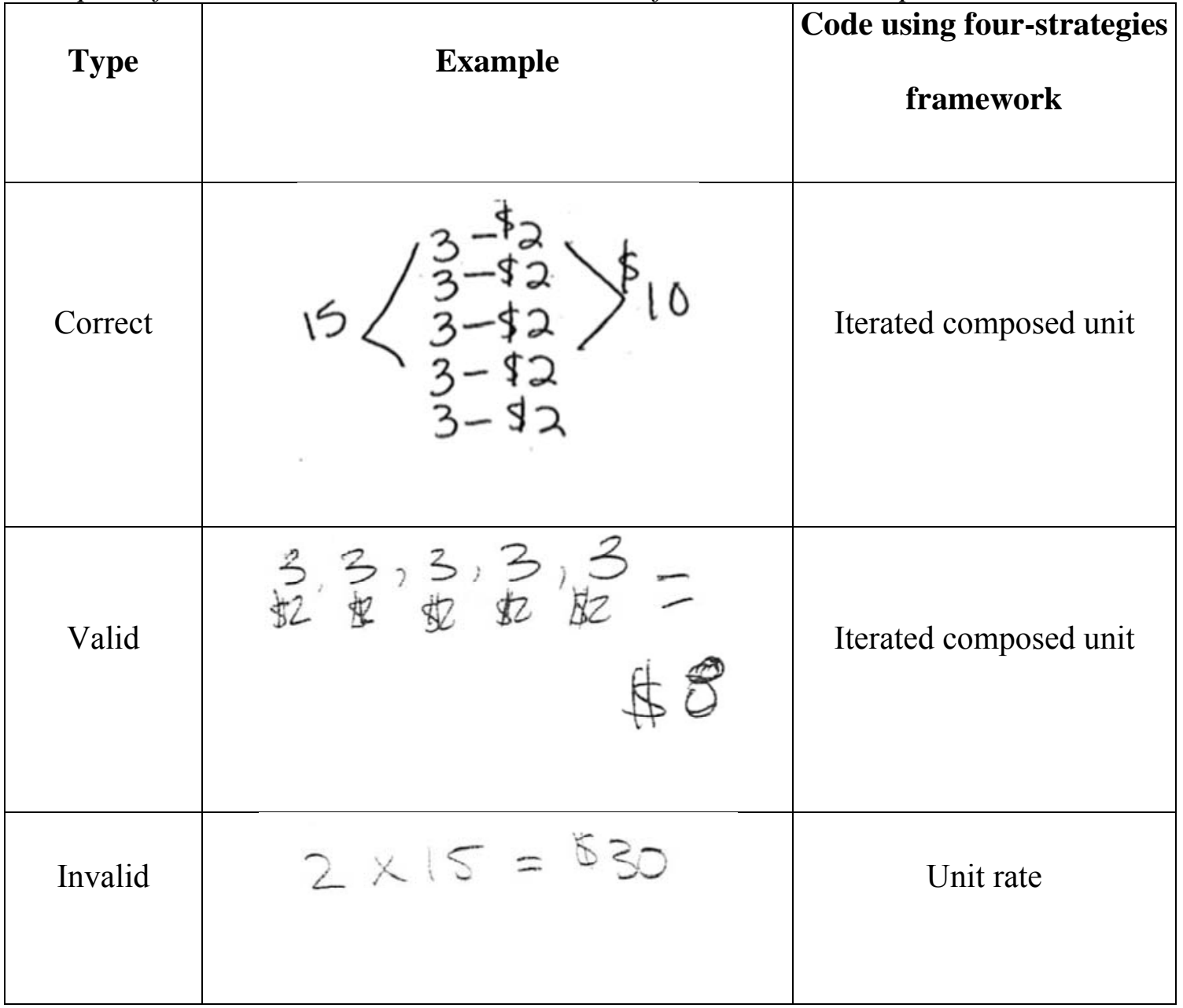

Inter-rater reliability. In order to check the reliability of this coding, $10 \%$ of the analyzed solution attempts for each problem were selected at random and each of these problems were double coded by a colleague and me (about 70 solution attempts in all). The second coder was introduced to the descriptions of the codes, provided examples of 
solution strategies that would be tagged with a particular code and the opportunity to practice coding. I and another coder categorized a problem solution the same way $100 \%$ of the time on the Flower Stem problem, 100\% of the time on the Percent Discount problem, $75 \%$ of the time on the Bread Flour problem and $90 \%$ of the time on the Comparing Speeds problem. The coding differences the Bread Flour were minor. When a student appeared to find the product of the values given in the problem, I coded this as Other, since it was not clear that the student recognized that 50 people is five times 10 people or that 28 days if four times one week. My colleague coded these solutions as scalar. Three of the five solutions to which we assigned these different codes were of this type. Another coding difference was on solution that was difficult to interpret; it appeared the student was iterating a composed unit, but it was unclear how $\mathrm{s} / \mathrm{he}$ determined the solution. The final coding difference was on whether a particular solution should be coded as an iterated-composed-unit or building-up strategy. The primary strategy seemed to be iterating a composed unit, but there were some additional annotations that could be interpreted as reasoning with a building-up strategy.

Not all the solution strategies could be categorized using the four-strategies framework. In Section 5.3 I note strategies that could not be categorized using the framework, such as performing random operations or making estimates. The two coders agreed on these instances and neither categorized solutions coded as Other as representing proportional reasoning strategies not represented in the four-strategies framework. 
Further frameworks. Although the four-strategies framework was a useful tool for understanding proportional reasoning strategies, it did not fully describe students' reasoning about the Percent Discount problem, where students used reasonable strategies that did not rely on proportional reasoning. A framework for students' understanding of percent (Lembke \& Reys, 1994) was adapted and used for further analysis of students' responses to this problem, as well as the interview participants' responses to follow-up questions about percent. This framework is discussed fully in Section 5.4: Variety across and within: The case of percentage.

Finally, students' responses to the Bread Flour and the Comparing Speeds problems, as well as interview participants' responses to the follow-up questions to these problems, were considered in terms of other studies of students' understanding of joint variation (De Bock, Verschaffel, \& Janssens, 1998; Vergnaud, 1994) and speed (Thompson, 1994) as described in Chapter 2 .

\section{Findings}

Strategies adults use to reason about proportional situations. In this section, I start with a summary of students' responses to the four mathematics problems on the survey that addresses both the number of attempts on each problem and the percentage of correct responses. Next, I discuss the strategies used on these problems using the fourstrategies framework described previously. Finally, I look to the interview data to examine in more detail how these particular students reason about problems that elicit proportional reasoning. 
Survey data. Table 11 displays how students performed on each of the four problems from the survey.

Table 11

Surveyed students'a overall performance on the four mathematical tasks on the survey

\begin{tabular}{|l|c|c|}
\hline \multicolumn{1}{|c|}{ Problem } & $\begin{array}{c}\text { Number (\%) of students who } \\
\text { attempted the problem }\end{array}$ & $\begin{array}{c}\text { Number (\%) of } \\
\text { correct solutions }\end{array}$ \\
\hline Flower Stem & $332(98 \%)$ & $212(62 \% / 64 \%)^{\mathrm{b}}$ \\
\hline Percent Discount & $259(76 \%)$ & $108(32 \% / 42 \%)$ \\
\hline Bread Flour & $229(67 \%)$ & $127(37 \% / 55 \%)$ \\
\hline Comparing speeds & $139(41 \%)$ & $40(12 \% / 29 \%)$ \\
\hline
\end{tabular}

${ }^{\mathrm{a}} n=340$

${ }^{\mathrm{b}}$ Percentage of sample/percentage of attempted solutions

The problems were presented on the survey in the same order the problems appear in Table 11. The number of students who attempted each subsequent problem decreased. It might be argued that the problems increase in difficulty, but other factors such as time limitations or fatigue may contribute to the decrease in number of solution attempts. However, the interview data confirm that the problems did seem to increase in difficulty for the students who participated in the interviews. (This topic will be discussed in more detail in Section 5.3.2). Correct solutions indicate accurate responses to the problem, regardless of whether or not a student supplied his reasoning. Subsequent analysis of the data reveals that on some problems students used valid reasoning, but made a computation error that led to an inaccurate response. The Flower Stem problem was solved correctly $64 \%$ by students who attempted the problem. The Comparing Speeds problem was solved correctly by $29 \%$ of the students who attempted the problem and by only $12 \%$ of the students overall, suggesting that reasoning about constant speed was problematic for the students surveyed.

Not all attempted solutions were as Correct, Valid or Invalid, and analyzed using the four-strategies framework. A student's strategy could not be determined if she 
provided a one-word or one-number response to a problem (for example, the response ' $\$ 10$ ' on the Flower Stem problem). Only solutions on which a student provided enough reasoning to classify his or her strategy were categorized using the four-strategies framework: iterated-composed-unit strategy (ICU), building-up strategy (BU), scalar strategy, and unit-rate strategy. Surveys on which a student attempted to write and solve a proportion equation (PE) were also noted. In addition, when other strategies were used (e.g., estimation), these were also recorded. These other strategies depended on reasoning that could not be classified as proportional reasoning. Tables 12-15 show the percentage of students who used the various strategies on each problem. 
Table 12

Students' strategies on the Flower Stem problem

\begin{tabular}{|c|c|c|c|}
\hline \multirow{2}{*}{} & \multicolumn{3}{|c|}{ Flower Stem problem } \\
\cline { 2 - 4 } & Correct Invalid & reasoning Valid & reasoning $^{\mathrm{b}}$ \\
\cline { 2 - 4 } & $23(10 \%)$ & $2(<1 \%)$ & $2(<1 \%)$ \\
\hline ICU & $6(7 \%)$ & $3(1 \%)$ & $2(<1 \%)$ \\
\hline BU 1 & $104(45 \%)$ & $60(26 \%)$ & \\
\hline Scalar & & $8(3 \%)^{\mathrm{c}}$ & \\
\hline \multirow{2}{*}{ Unit rate } & $(<1 \%)$ & \multicolumn{3}{|c|}{} \\
\hline PE 2 & 8 & $(3 \%)$ & \\
\hline Other & \multicolumn{3}{|c|}{} \\
\hline Random operations & \multicolumn{3}{|c|}{} \\
\hline
\end{tabular}

a $n$ represents the number of surveys on which a student's strategy could be categorized

b Includes solutions that contains valid reasoning but were incorrect due to a computational error

c 60 students reasoned with a unit cost of $\$ 2$ per stem and 8 students with a unit cost of $\$ 1.50$ per stem

Table 13

Students' strategies on the Percent Discount problem

\begin{tabular}{|c|c|c|c|}
\hline \multirow{2}{*}{} & \multicolumn{3}{|c|}{ Percent Discount problem } \\
\cline { 2 - 4 } & Correct Invalid & reasoning Valid & reasoning \\
\cline { 2 - 4 } & $(<1 \%)$ & & $2(1 \%)$ \\
\hline ICU 1 & $2(1 \%)$ & $25(14 \%)$ & $7(4 \%)$ \\
\hline Scalar 5 & $(3 \%)$ & $4(2 \%)$ & $1(<1 \%)$ \\
\hline Unit rate & $35(20 \%)$ & & \\
\hline PE & $1(<1 \%)$ & $(9 \%)$ & \\
\hline Other & $4(2 \%)$ & & \\
\hline $\begin{array}{c}50 \% / 10 \% \\
\text { Reasonable } \\
\text { estimate }\end{array}$ & $76(42 \%)$ & & \\
\hline $\begin{array}{c}\text { Random } \\
\text { operations/ } \\
\begin{array}{c}\text { Unreasonable } \\
\text { estimate }\end{array}\end{array}$ & 16 & & \\
\hline
\end{tabular}




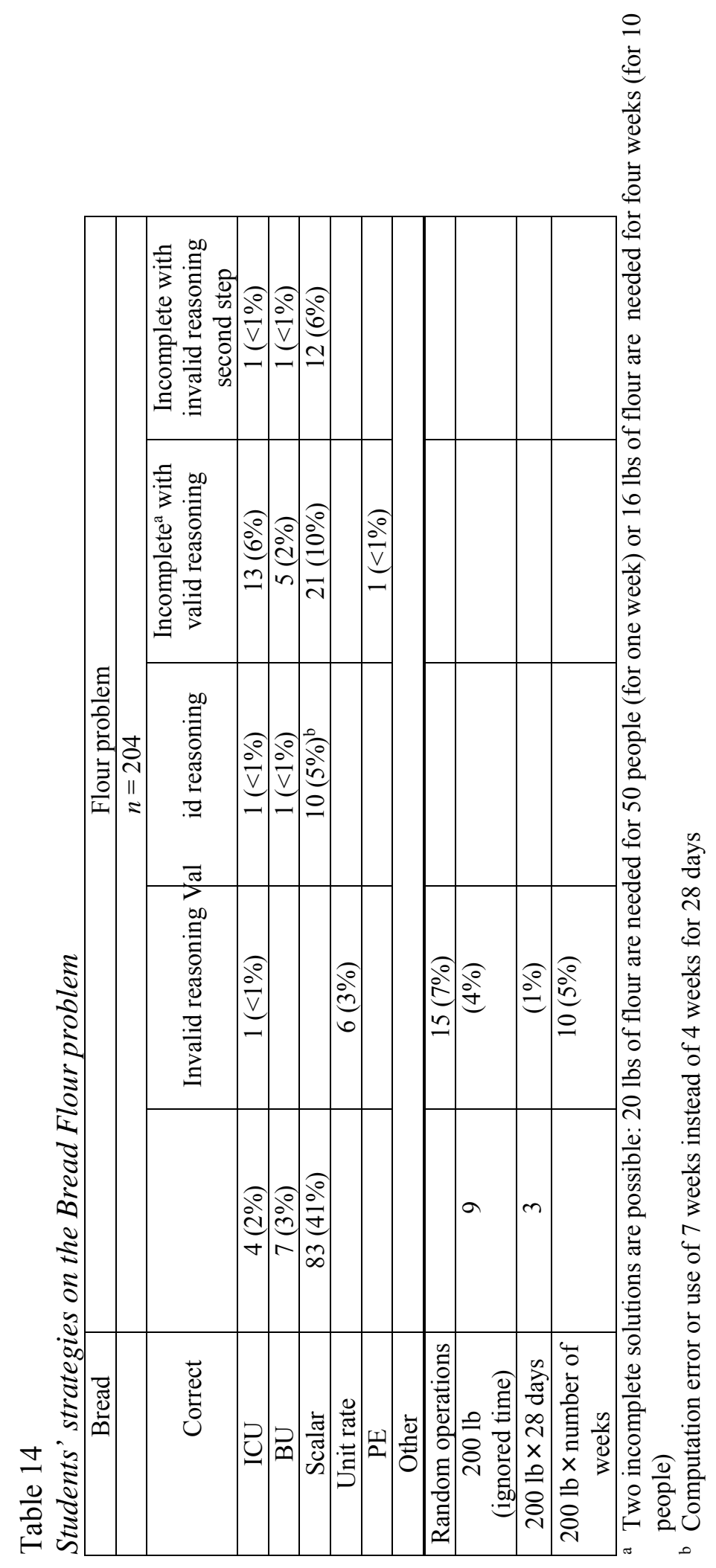


Table 15

Students' strategies on the Comparing Speeds problem

\begin{tabular}{|c|c|c|c|}
\hline & \multicolumn{3}{|c|}{ Comparing Speeds problem } \\
\hline & \multicolumn{3}{|c|}{$n=105$} \\
\hline & Correct Invalid & reasoning Valid & reasoning \\
\hline ICU & & & \\
\hline BU 1 & $1^{\mathrm{a}}(10 \%)$ & $22(20 \%)$ & $3(3 \%)$ \\
\hline Scalar 2 & $(2 \%)$ & & \\
\hline Unit rate & & \multirow{4}{*}{$15^{\mathrm{b}}(14 \%)$} & \\
\hline Correct units & $1(<1 \%)$ & & \\
\hline $\begin{array}{l}\text { No units or } \\
\text { incorrect units }\end{array}$ & $6(6 \%)$ & & \\
\hline $\begin{array}{c}\text { Based on a estimate } \\
\text { of about a mile per } \\
\text { minute }\end{array}$ & $1(<1 \%)$ & & \\
\hline $\mathrm{PE}$ & 1 & $(<1 \%)$ & \\
\hline \multicolumn{4}{|l|}{ Other } \\
\hline $\begin{array}{c}\text { Comparing ratios: } \\
40 / 50 \\
\end{array}$ & $3(3 \%)$ & & \\
\hline Random operations & 11 & $(10 \%)$ & \\
\hline \begin{tabular}{|c|} 
Other poorly \\
recalled procedures
\end{tabular} & 2 & $(2 \%)$ & \\
\hline Additive partitioning & 1 & $(<1 \%)$ & \\
\hline $\begin{array}{c}\text { Invalid for other } \\
\text { reasons }\end{array}$ & 26 & $(25 \%)$ & \\
\hline
\end{tabular}

a One of these solutions involved both partitioning the composed unit related to Sharon's speed and building up again to compare to the composed unit related to Victor's speed.

b Four of these responses included a correct computation, but the student was unable to interpret the meaning of the rates.

c The student's reasoning indicated confusion about the concept of constant speed. Most stated Sharon was faster, perhaps because the numbers in the given composed unit are larger. But nine students stated Victor was faster.

There are several surprising results evident in Tables 12-15, which will be discussed fully below, but are worth pointing to here. First, writing and solving a proportion equation was a strategy rarely used by students at the start of Basic Math and this is the one strategy for solving proportion problems that most of these students will encounter in the course. Next, although there were occasional additive strategies brought to bear on the multiplicative relationships within these four problems, students typically recognized the scalar multiples. As will be discussed later in this chapter, some of the examples of iterated-composed unit and building-up strategies might be a way some students seek the 
scalar multiple if multiplication facts are unknown. Finally, on each problem the unitrate strategy was used inappropriately and on the Flower Stem problem this strategy was never used appropriately. I examine these survey findings more fully by considering each strategy and providing examples of the ways students used the strategy. In the discussion of these findings, I will highlight interesting results for each problem.

Iterated-composed-unit strategy. In general, the iterated-composed-unit (ICU) strategy was used infrequently. It was used most frequently on the Flower Stem problem $\left(11 \%\right.$ of the correct responses $\left.{ }^{31}\right)$. An example of this strategy is shown in Figure 5.

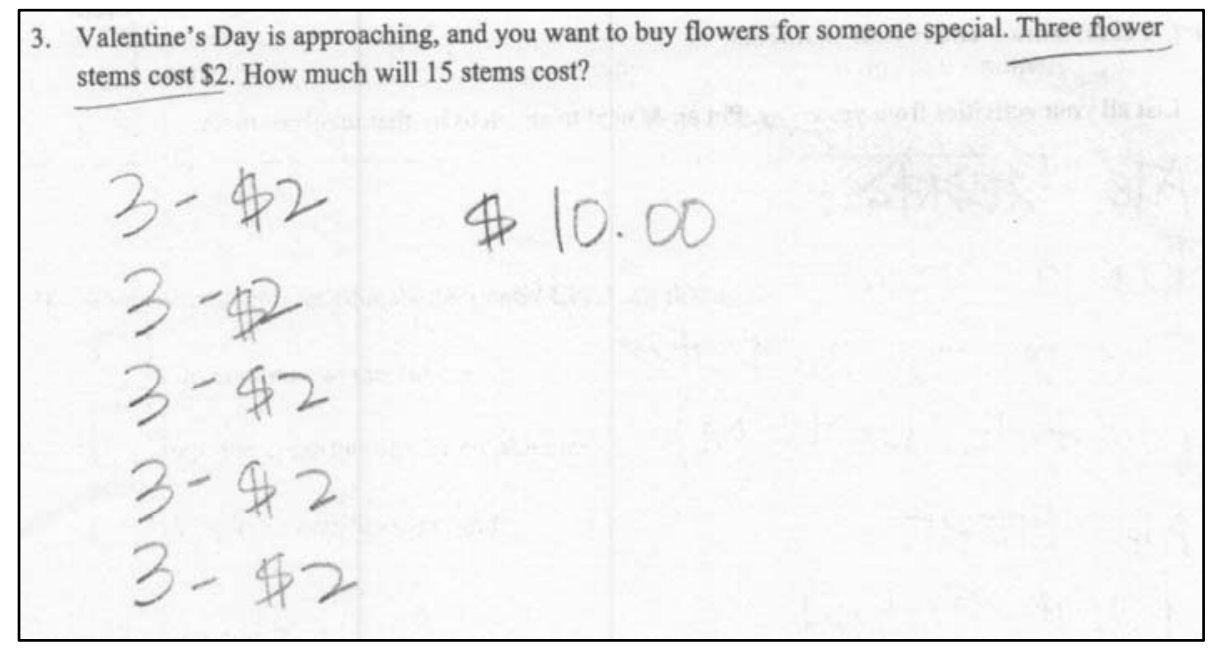

Figure 5. An iterated-composed-unit strategy on the Flower Stem problem

The ICU strategy is a counting strategy. In Figure 5, the student iterated three stems for $\$ 2$ five times, perhaps counting up by threes until reaching 15 stems, and then adding up the five $\$ 2$ s and concluding that the 15 stems cost $\$ 10$. This is certainly an elementary strategy based on counting. It is not clear from this students' written work whether the

\footnotetext{
${ }^{31}$ In this discussion, I am referring to the percentage of the total number of correct solutions, including solutions for which a strategy could not be identified.
} 
strategy was a tool for reasoning or whether s/he used the iterated composed unit to communicate how s/he determined the result.

The ICU strategy was also used on the Bread Flour problem on about $10 \%$ of the analyzed responses, although many of these responses were incomplete. Three percent of the correct responses to the Bread Flour problem used an iterated-composed-unit strategy, but 13 out of $56^{32}$ incomplete solutions also employed this strategy. Figure 6 shows an attempt to iterate a composed unit twice, but the solution is incomplete.

5. A cook is planning for a group of 50 people who will spend 28 days at a summer camp. He needs to buy enough flour for baking bread and the cook knows that the average consumption of flour is 4 pounds per week for 10 persons. How much flour does he need to buy?
per $10 \frac{\text { week } 1}{4 \text { flour }}$
week 2
20 pounds of Nour perweek
Per to 4 flocr
perlo 4 flow $\rightarrow$
per 104 flow
Per 104 flow

Figure 6. An iterated-composed-unit strategy on the Bread Flour problem

The arrow in Figure 6 suggests that the student recognized that the duration of the stay was varying as well, although s/he did not iterate the 20 pounds of flour needed for 50 people per week four times. Although several responses revealed an attempt to iterate the two composed units in this problem, students would typically first determine that either 20 pounds of flour are needed for 50 people for one week or 16 pounds of flour are needed for four weeks for 10 people, and then used scalar reasoning to complete the problem. For example, some students might use a ICU strategy to determine that 20

\footnotetext{
32 There were 56 incomplete solutions to the Bread Flour problem; not all of these solutions included the student's reasoning so this number is larger than the number of incomplete solutions categorized in Table 14.
} 
pounds of flour are needed for 50 people for one week as in Figure 6 and then multiply 20 by four rather than using iteration.

The scalar in the Comparing Speeds problem was not an integer, so it is not surprising that no student used the ICU strategy to solve this problem. On the Percent Discount problem, a solution strategy was categorized as an ICU strategy whenever a student iterated the unit $10 \%$ to $\$ 3.50$; however, only one student recorded this way of thinking. The other students who reasoned with $10 \%$ used scalar reasoning, recognizing that $40 \%$ is four times $10 \%$. The ICU strategy was rarely used on these two problems. Students' use of the ICU strategy is interesting. Research with younger students (Lamon, 1993) indicates that this is an elementary strategy used by students as they transition from the additive reasoning to multiplicative reasoning. As mentioned above, it is not possible to determine from students' written work on the survey whether the ICU strategy was a tool for reasoning about an unfamiliar problem or a computational tool used to determine an unknown scalar factor, such as five sets of 10 people in a group of 50 people. In either case, this strategy does make visible the composed units, or ratios, present in these problems. As will be discussed in Chapter 6, by the end of the term, one student in Basic Math could model a problem with using a proportion equation, but she did not connect this strategy to the concept of ratio introduced in the same unit.

Building-up or partitioning strategy. A building-up or partitioning (BU) strategy was most prevalent on students' reasoning on the Comparing Speeds problem. This strategy led to $27.5 \%$ of the correct solutions (that is, 11 students used a BU strategy to 
obtain a correct solution out of the 40 students who solved this problem correctly).

Figures 7 and 8 provide two examples.

6. Victor's van travels at a rate of 8 miles every 10 minutes. Sharon's sedan travels at a rate of 20 miles every 25 minutes.

If both cars start at the same time, will Sharon's sedan reach point A, 8 miles away, before, at the same time, or after Victor's van? Explain your reasoning.

$$
\begin{array}{cc}
\text { at the } & 1620 \\
\text { tine } & 2 \& 35
\end{array}
$$

Figure 7. A student builds up the unit 8 miles in 10 minutes in order to compare Victor's speed to Sharon's

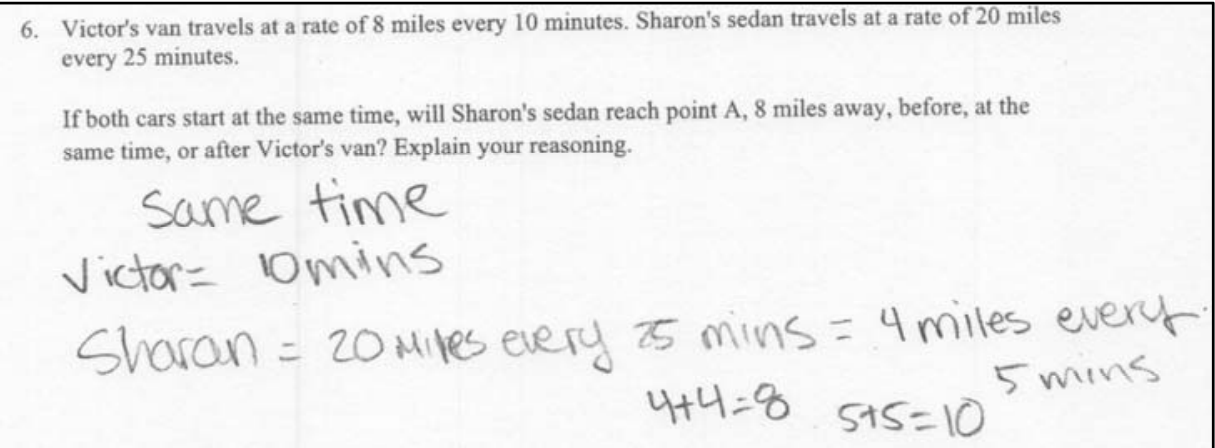

Figure 8. A student partitions the unit representing Sharon's speed and then builds up this new unit to compare Sharon's speed to Victor's

The solution shown in Figure 7 shows that the student doubled the composed unit and then added on a half of the composed unit (four miles in five minutes) in order to compare Victor's constant speed with Sharon's. Figure 8 is an example of a partitioning strategy. The student first partitions the composed unit representing Sharon's constant speed by determine one-fourth of each unit. The student then builds up the new unit four miles every five minutes in order to compare Sharon's speed to Victor's. However, building up was also a strategy used by $24 \%$ (25 of the 105 surveys on which a student's 
reasoning could be classified) of the solutions that led to an incorrect conclusion to the Comparing Speeds problem. Many students either doubled the composed unit related to Victor's speed, observing that he would travel 16 miles in 20 minutes (five surveys), or halved the composed unit related to Sharon's speed, noting she travels 10 miles in 12.5 minutes (eight surveys). Since neither of these quantities could be directly compared to the other composed unit, students either drew no conclusion or an erroneous conclusion. Another frequent error was to conclude that Victor traveled 24 miles in 25 minutes, tripling the number of miles, but not tripling the duration of the trip (three surveys). Several students recognized that they could easily determine Victor's constant speed in miles per hour since 10 minutes is one-sixth of an hour, but were unable to build up Sharon's composed unit in a similar way.

A building-up strategy was used in a similar way to the iterated-composed-unit strategy on both the Flower Stem and Bread Flour problem. That is, it appears that adult students use these strategies to determine an integer scalar. This conjecture might explain why several students either built up the composed unit 8 miles to 10 minutes by doubling, or partitioned the composed unit 20 miles in 25 minutes by halving and stopped there when an integer scalar in the Comparing Speeds problem was not immediately obvious. However, during the interviews, building-up and partitioning strategies were used as both a computational tool and a tool for reasoning. This finding will be discussed in Section 5.3.2.

In summary, the use of building-up and partitioning strategies on the Comparing Speeds problem suggests that this strategy is likely a tool that students use to understand an unfamiliar problem. Although twice as many students used a building-up strategy 
without reaching a valid conclusion, many of these solution strategies - in the context of a classroom where students' strategies were visible within the classroom community might be built upon to develop the reasoning needed to lead to correct conclusion to a problem like the Comparing Speeds problem. The building-up strategy appears to be used as a tool to reason about a problem that was likely difficult ${ }^{33}$ for many students.

Scalar reasoning. Scalar reasoning was the most common strategy leading to a correct solution (on surveys where a strategy could be categorized) on both the Flower Stem problem (45\% of correct solutions) and the Bread Flour problem (41\%). A student's written work on the Flower Stem problem from the survey was classified as a scalar strategy if the student's reasoning included a computation similar to the following:

$$
\begin{aligned}
& 15 \div 3=5 \\
& 5 \times 2=10 \\
& 15 \div 3=5 \\
& 5 \times 2=10
\end{aligned}
$$

Some students were explicit about the meaning of the scalar multiples in these two problems ${ }^{34}$, although this understanding was not frequent in the survey data. Figures 9 and 10 illustrate two examples.

\footnotetext{
${ }^{33}$ I make the claim that this was a difficult problem for students based on the finding that only $41 \%$ of the students surveyed attempted this problem and the fact that the interview participants also struggled with the concept of speed (see Section 5.3).

${ }^{34}$ The interview provided an opportunity to query students' scalar reasoning on this problem in more detail.
} 
3. Valentine's Day is approaching, and you want to buy flowers for someone special. Three flower stems cost \$2. How much will 15 stems cost?

pividua! lowers pundizos

$s^{2} \frac{15}{x^{3}}=5 \quad 5 \times 2=\$ 10$

wingle I will cost $\$ 10$.

Figure 9. A student interprets the factor of five in the Flower Stem problem

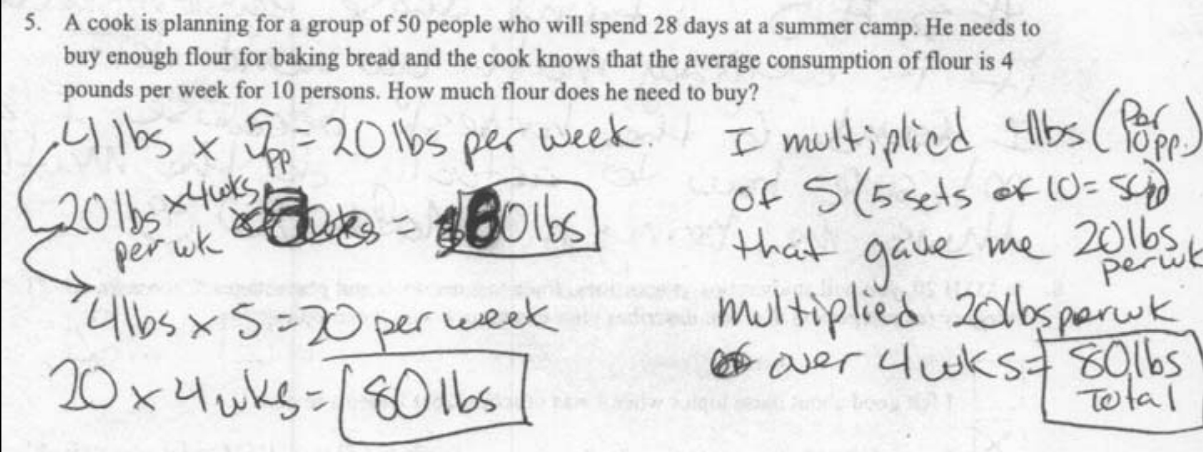

Figure 10. A student interprets the scalars in the Bread Flour problem

In Figure 9, the student interprets the factor of five as meaning that there are five bundles of three flower in 15 stems, justifying the decision to multiply five by two to determine the solution. In Figure 10, the student highlights that the factor of five is needed because there are five sets of 10 people in a group of 50 people and that the unit 20 pounds of flour for 50 people for one week needs to be multiplied by the four weeks in 28 days.

The data in Table 14, which categorizes students' strategies on the Bread Flour problem, also show that students used scalar reasoning even though they made a computational error or arrived at an incomplete solution. Students who concluded that 20 pound of flour are needed for 50 people for one week or 16 pounds is needed for 10 
people for four weeks, reasoned with the factor of five in the first case and four in the second. But these solutions led to an incomplete and therefore incorrect solution since a student did not recognize that two quantities were varying jointly in this problem.

Using a scalar strategy was rare on the Comparing Speeds problem. Only two students made a partially valid argument based on a factor of 2.5 , but it was not clear from the students' written work whether they recognized that Sharon travels 2.5 times the distance Victor travels in 2.5 times his time (see Figure 11).

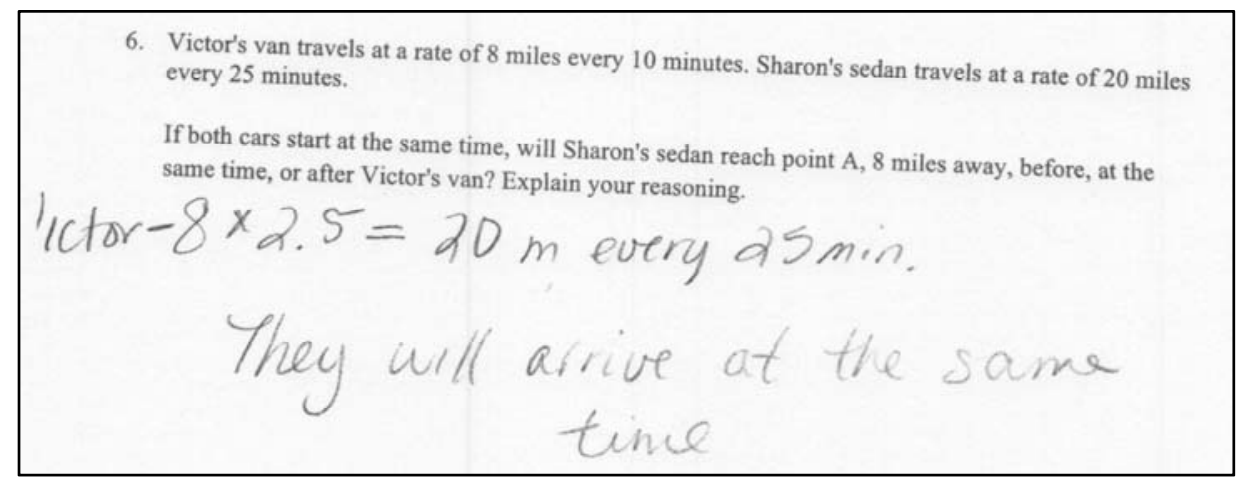

Figure 11. Scalar reasoning on the Comparing Speeds problem

The scalar strategy illustrated by the student's work on the Comparing Speeds problem is an abbreviation of the building-up strategy illustrated in Figure 7. Scalar strategies are also abbreviations for ICU and BU strategies on the Flower Stem and Bread Flour problems. However, the meaning of the scalar 2.5 is different from the meaning of the scalars in the Flower Stem and Bread Flour problems. In this case, the student needs to recognize that both the distance and time of travel that describes Sharon's constant speed is 2.5 times the distance and time of travel that described Victor's speed, indicating one of the ways that constant speed is a complex example of a proportional situations (Thompson, 1994). 
In summary, correctly using a scalar strategy suggests a student is reasoning multiplicatively about a proportional situation, but a scalar strategy might not always be the most efficient way to reason about a particular problem. For example, an efficient solution to both the Percent Discount and Comparing Speeds problems might rely on a unit-rate strategy. The findings in the following section indicate that the unit-rate strategy was the strategy that was most problematic for the surveyed students. However, building on students' scalar strategies that relate quantities of the same type (for example, three flower stems to 15 flower stems or 8 miles to 20 miles) might be used to reveal the other multiplicative relationship between quantities in a proportion (for example, the constant factor between 8 miles and 10 minutes and 20 miles and 25 minutes) that leads to the unit rate.

Unit-rate strategy. No student used a valid unit-cost strategy on the Flower Stem problem, but 68 used an incorrect unit cost. Most of these incorrect unit-cost strategies (see Table 12) involved making the assumption that each stem cost $\$ 2$ and concluding that 15 stems cost $\$ 30$. (The prevalence of this strategy might be attributed to not reading the problem carefully; the word three was used instead of the numeral 3.) Eight students reasoned incorrectly with a unit cost of $\$ 1.50$ per stem - a simpler computation than the correct unit cost computation - concluding that 15 stems cost $\$ 22$.

The unit-rate strategy was prevalent on the Comparing Speeds problem, but only one student $(<1 \%)$ correctly interpreted the constant speeds using correct units and drew a valid conclusion. It was more typical for students who correctly concluded that Victor and Sharon would arrive at their destination at the same time to either not include the units of speeds or use incorrect units (see Table 15). In addition, the number of students 
who used invalid reasoning with a unit rate was almost double the number of students who computed a rate and reached the correct conclusion. (This finding also emerged from the interview data). For example, the response shown in Figure 12 indicates that the student had a divide-to-find speed strategy, but did not account for what quantities the values in the problem represented.

6. Victor's van travels at a rate of 8 miles every 10 minutes. Sharon's sedan travels at a rate of 20 miles every 25 minutes.

If both cars start at the same time, will Sharon's sedan reach point A, 8 miles away, before, at the same time, or after Victor's van? Explain your reasoning.

$V=1.25$ min mile $-\frac{8}{10}$
$\mathrm{S}$
$.8 \mathrm{~min}$ mile $\frac{25}{20}$
Sheron = Before

Figure 12. An example of one student's difficulty with reasoning using unit rates on the Comparing Speeds problem

Here we see that the values the student computed indicate that travels at a speed of 1.25 minutes per mile and that Sharon travels at a speed of 0.8 miles per minute. Not recognizing that the two rates indicate different quantities, the student concluded that Sharon was traveling faster, which would indeed be the case if both quantities represented speed in minutes per mile.

Students' written work on the Bread Flour indicated that a few students (six out of the 204 students who supplied reasoning) attempted to reason using a unit rate by determining how many pounds of flour were needed per day per person. Although this is a viable strategy, it is not as simple as the case of direct variation and no one successfully concluded that $4 / 70$ pound of flour is needed per person per day.

$20 \%$ of the analyzed survey responses on the Percent Discount were categorized as unit-rate strategies if a student's written work indicated that the computation 
$0.40 \times 35$ was used to determine the percent discount. Although the factor 0.40 can be interpreted as a unit rate, students' written work on this problem is insufficient to examine what students do or do not understand about reasoning with a unit rate when computing a percentage. However, the solutions shown in Figures 13 and 14 indicate an emerging understanding of a $40 \%$ discount as a rate and $\$ 4$ off every $\$ 10$. The solution in Figure 13 uses this understanding along with a building-up strategy. The solution is incomplete because only the percent discount is determined and includes a computational error, but the reasoning appears to be grounded in the context of shopping since the student interpreted the discount as $\$ 4$ off every $\$ 10$ spent.

$$
\begin{aligned}
& \text { 4. Fred Meyer is having a sale. A } \$ 35 \text { pair of jeans is marked } 40 \% \text { off. Can you buy the jeans for } \$ 20 \text { or } \\
& \text { less? How do you know? } \\
& \text { Yes, } 40 \%=4^{\text {Sl }} \text { off per } 10^{\text {s/ }} \text { spent }=4+4+4+2=18 \\
& 4
\end{aligned}
$$

Figure 13. A student uses an emerging understanding of percent as rate and a building-up strategy on the Percent Discount problem

4. Fred Meyer is having a sale. A $\$ 35$ pair of jeans is marked $40 \%$ off. Can you buy the jeans for $\$ 20$ or less? How do you know?

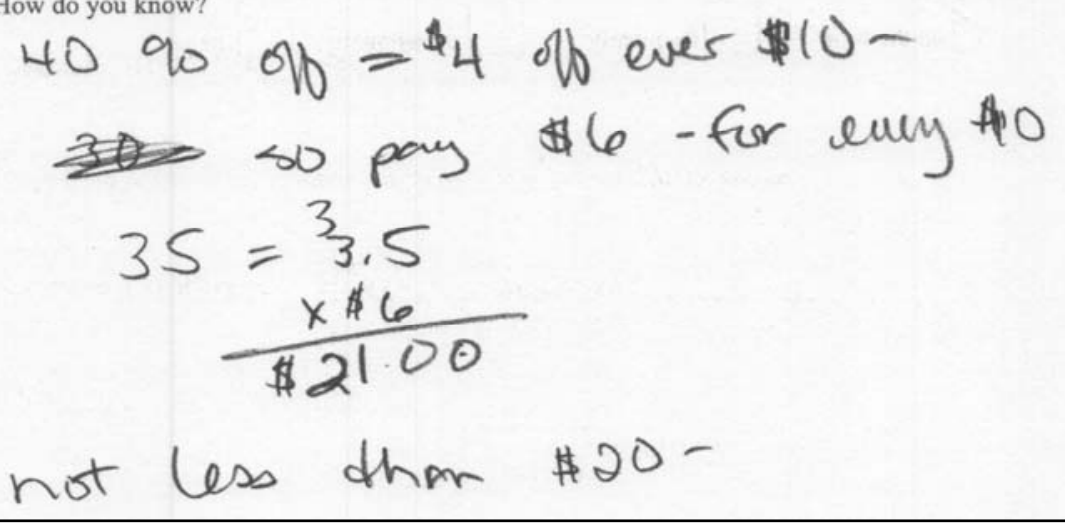

Figure 14. A student uses an emerging understanding of percent as rate along with scalar reasoning 
The solution in Figure 14 illustrates an emerging understanding of percent as rate along with scalar reasoning to conclude that the jeans will cost $\$ 21$. Here, a student uses the understanding that $\$ 4$ off every $\$ 10$ means one pays $\$ 6$ on every $\$ 10$, along with the additional understanding that there are 3.5 sets of $\$ 10$ in $\$ 35$, to solve the problem.

Summary of students' use of these strategies. All four of these strategies, which also emerged from research with younger students, were evident in students' written work on the mathematics problems on the survey. As will be discussed in the next section, it is likely that some strategies (e.g., a scalar strategy) are better suited to some problems rather than others and that students' use of more elementary strategies, such as iteration or building-up strategies, may indicates something about the ways students are reasoning about a particular problem. In addition, the survey data indicated that students used a variety of strategies to solve each problem and that one strategy for solving proportion problems students typically see in a Basic Math class, writing and solving a proportion equation, was used rarely.

Discussion of survey findings. The discussion of the survey findings is organized by problem for two reasons. First, different strategies are likely better suited for different types of problems. In addition, when one strategy appears to be problematic for students on a particular problem, other successfully used strategies might indicate why a particular strategy is problematic. Second, the prevalence of the use of one type of strategy on a given problem may have something to teach us about the ways students approach a particular problem, which would inform instruction.

Flower Stem problem. It is not surprising that most students attempted the flower stem problem and that more than half the students who attempted the problem obtained a 
correct solution. For example, most of the correct responses indicate that students recognize the primary multiplicative relationship in the problem: the cost of 15 stems is five times the cost of three stems. As with the other problems on the survey, students rarely $(<1 \%)$ wrote and solved a proportion equation to answer this question. However, on this problem, the two students who used wrote and solved a proportion equation did correctly conclude that 15 stems cost $\$ 10$, whereas on the other three problems (see Tables 12-14) attempting to write and solve a proportion equation was equally rare, but in these seven instances only one attempt led to a correct solution. This is an important finding for instructors teaching Basic Math since writing and solving a proportion equation is the only strategy for solving problems about proportion featured in the curriculum materials used in the course, but not a strategy most students are using to reason about problems involving proportional reasoning.

It is difficult to compare directly these findings with findings from studies with younger students, but the Flower Stem problem was adapted from a problem used by Lamon (1994) used to explore children's pre-instructional thinking about proportional situations (the Balloon problem ${ }^{35}$ ). Lamon interviewed 24 sixth-grade students, using five problems including the Balloon problem. Ten students (42\%) used scalar reasoning on the Balloon problem, a similar percentage to the one found in the survey data for this study. Only two students (8\%) used a building-up strategy, which is a smaller percentage than the percentage of students who used this strategy on the survey. Lamon observed that students who used a building-up strategy could not predict the cost given any

\footnotetext{
${ }^{35}$ The Balloon problem: Ellen, Jim and Steve bought three helium-filled balloons and paid $\$ 2.00$ for all three. They decided to go back to the store and get enough balloons for everyone in their class. How much did they have to pay for 24 balloons? (Lamon, 1994, p. 100)
} 
number of balloons and suggested that the building-up strategy was merely a computational tool. She writes, "The tables they constructed began as convenient methods to keep track of a double counting process and were expanded as patterns were recognized" (pp. 102-103). (I explore this question further in my analysis of the interview data.) However, in a Basic Math classroom, where it is likely that some students would use a building-up strategy on a problem like the Flower Stem problem, being unable to determine the cost of any number of flower stems could be a teachable moment. There are two possibilities: either students recognize that the cost of the flowers is always two-thirds the number of flowers or they partition down the composed unit three flower stems to $\$ 2$ to one stem for $\$ 2 / 3$ or that $\$ 1$ purchases $1 \frac{1}{2}$ stems.

Lamon (1994) reported that three of the 24 students interviewed for her study determined that the cost per stem is $\$ 0.66$, but she observes, "the strategy sacrificed accuracy [and] although correct, their thinking in terms of single units proved less powerful than thinking in terms of composed units." The unit cost strategy was not a successful strategy for students in this study, but there is no reason why the accurate unit cost of $\$ 2 / 3$ per stem would not emerge from the ways of thinking adult students bring to Basic Math and their familiarity with unit cost. (For further discussion of this possibility, refer to Section 5.3.2 and the discussion of one student's thinking on the Variation of the Flower Stem problem).

Percent Discount problem. The unit rate strategy was prevalent on the Percent Discount problem, but a student's response to this problem was categorized as relying on a unit-rate strategy if $\mathrm{s} / \mathrm{he}$ performed a computation such as $0.40 \times 35$. This strategy was successful on about one-third of the correct responses, but it also accounted for about 
one-third of the incorrect responses. This finding suggests that students might benefit from activities to help them make sense of the formula $A=R B$, in particular, coming to understand percent as rate. As discussed in Section 5.2, the four-strategies framework was insufficient for examining students' thinking about percent. I discuss the Percent Discount problem, as well as follow-up problems about percent used in the interview, in more detail in Section 5.4.

The Bread Flour problem. The Bread Flour problem was selected for the survey for several reasons. One reason involved the need for a replacement of a problem involving joint variation that was used in pilot studies, the Flooring problem.

\section{The Flooring problem}

A florist is building an addition that is 3 meters by 4 meters. When her financing comes through, she considers doubling each dimension of the addition. Will doubling each dimension double the cost of flooring (not including labor)? Why? This problem yielded little data in the pilot study. Most students did not attempt the problem or supplied qualitative reasons such as "more flooring will cost more money." Many of the attempted solutions included the assumption that doubling the dimensions would double the area, a finding consistent with other studies of students' reasoning about similar problems (De Bock et al., 1998). The few students who illustrated the situation accurately were able to conclude that the cost of flooring would more than double, but student, etts did not, on the whole, illustrate the scenario. The Bread Flour problem was chosen as an alternative since it involved one discrete quantity (number of people) and the two continuous quantities (amount of flour and the duration of the stay at camp) were conjectured to be more familiar than length and area. The 
problem was adapted slightly from a problem Vergnaud (2004), which he used to illustrate that joint variation can be expressed schematically rather than formally.

It was surprising that $37 \%$ of the surveyed students and $55 \%$ of the students who attempted the problem determined correctly that 80 pounds of flour are needed for 50 people over four weeks. Joint variation is not an explicit topic in the developmental mathematics curriculum at the college where the study was conducted and the topic is not introduced formally until College Algebra. In addition, although scaling problems like Flooring problem are included in middle school mathematics curricula, such as Connected Mathematics 2 (Lappan, Fey, Fitzgerald, Friel, \& Phillips, 2006), scaling problems are not typically explored in the developmental mathematics curriculum. However, many students in Basic Math were able reason about quantities that vary jointly in the context of the Bread Flour problem. This finding suggests that joint variation might become an explicit topic in developmental mathematics, an experience that makes the symbolic treatment of variation students encounter in later courses more meaningful. Future studies might also query adult returning students' understanding of situations in which one quantity varies inversely with a second quantity. ${ }^{36}$

Comparing Speeds problem. Students' written work on the Comparing Speeds problem suggest that determining an average speed by division is a poorly understood strategy for many students. In Section 5.5, I will discuss in more detail this particular finding from the survey data, as well as findings from an analysis of the interview participants' work on the Comparing Speeds problem and other problems about speed.

\footnotetext{
${ }^{36}$ Anecdotal evidence from my own Basic Math classes indicates that students who learn to reason about proportional situations rather than learn to model the situation with a proportion equation are able to distinguish between direct and inverse variation.
} 
However, although average speed is a difficult concept, it was encouraging that 36 of the 105 students who attempted this problem on the survey (34\%) used a building-up strategy. As was the case with students' work on the Flower Stem problem and some instances of students' reasoning on the Percent Discount problem, a building-up strategy can be a generative in that these strategies might provide the foundation for developing more formal ways of reasoning about proportion problems. A discussion of a student's building-up strategy on the Comparing Speeds problem might lead to a "mature conception of speed as quantified motion" since this strategy works because "we move a given distance in a given amount of time and that any segment of the total distance will require a proportional segment of the total time" (Thompson, 1994, pp. 224-225). It might be argued that students who take Basic Math do not need to develop a "mature conception of speed." In fact, a content analysis of the curriculum materials used in Basic Math uncovered only one problem about average speed. However, an understanding of average speed is necessary for understanding the relationship between distance traveled and the duration of the trip that is used in many of the problems that students will model symbolically with linear equations in Introductory Algebra courses. Reflecting on both the cognitive complexity of understanding average speed and adult returning students' understanding of this concept is an important task for community college instructors working on transforming the developmental mathematics curriculum.

Summary. The findings from the survey data were grounded on students' written work on the mathematics problems from the survey. The strategies students use suggest ways students might be thinking about a problem, but the written work indicates tells us which strategies students were using on a particular problem and suggests questions that 
could be answered by an analysis of the survey data. For example, how are students reasoning about the factor of five in the proportional situation described in the Flower Stem problem? What do students understand about the computation $0.40 \times 35$ many used to solve the Percent Discount problem? More than one-third of the students solved the Bread Flour problem, but what do students understand about variation? To what extent are students using an iterated-composed-unit or building-up strategy as a tool to reason about a problem? Although a discussion of the findings from the interview data cannot answer these questions for the population as a whole, considering these questions with respect to the interview data can provide more insight into some students' proportional reasoning.

Interview data. Like the survey participants, the interview participants used a variety of strategies to reason about the mathematical tasks during the interview and most participants were able to use more than one strategy reason about particular problems. No participant could be categorized as relying on one strategy more than others, although some participants used particular strategies in signature ways. Participants' reasoning on two problems - the Variations of the Flower Stem problem and the Better Buy problem - highlight the variety of ways of thinking adult returning students might bring to a Basic Math class, supporting a finding from the survey data. Participant's difficulties with the Comparing Speeds problems suggest that an understanding the concept of constant speed is not as unproblematic as is typically assumed. 
In this section, I look at the interview data from two perspectives: strategy and problem. The interview data is robust, providing the opportunity to construct a detailed description of the ways students reason about proportional situations.

Iterated-composed-unit (ICU) strategy. Only Ruby used an ICU strategy during the interview on any of the interview tasks. Prior to the interview Ruby used a buildingup (BU) strategy on the Bread Flour problem as illustrated in Figure 15. Ruby's work written work on the survey problem suggests that she built up the composed unit of four pounds per week (for 10 people) four times and concluded that 16 pounds of flour were needed for 10 people for four weeks ${ }^{37}$.

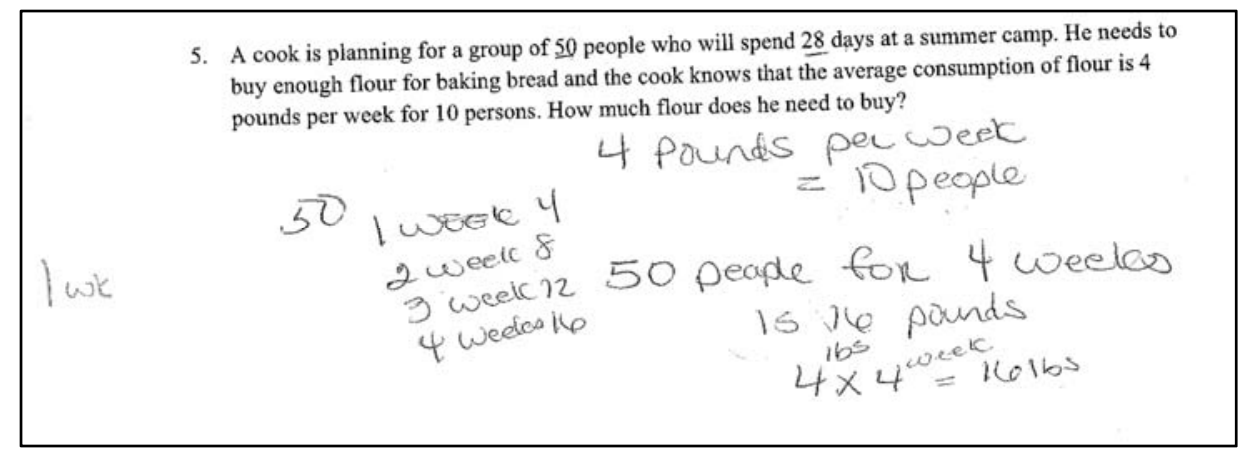

Figure 15. Ruby's written work on the Bread Flour problem prior to the interview

\footnotetext{
${ }^{37}$ Ruby was the only interview participant who submitted an incomplete solution to the Bread Flour problem prior to the interview. All other students reasoned to a complete and accurate solution.
} 
During the interview, Ruby articulated her BU strategy:

For me, I just had to break it down. There were four pound per week for 10 people. [Pointing to what she had written.] Then I say, okay, for one week that would be four pounds, for two weeks eight pounds, three weeks 12 pounds, four weeks 16 pounds. So, for 50 people [sic] it would be 16 pounds. So, I took the four weeks times the four pounds. (Ruby, 20 December 2011)

As we spoke about the problem, Ruby realized that she had not accounted for the increase in the number of people. She then used an ICU strategy to determine that 20 pounds of flour were needed for 50 people for one week (see Figure 15) and quickly completed the problem using scalar reasoning - perhaps based on her previous reasoning grounded on the BU strategy - to conclude correctly that 80 pounds of flour are needed for 50 people attending camp for four weeks.

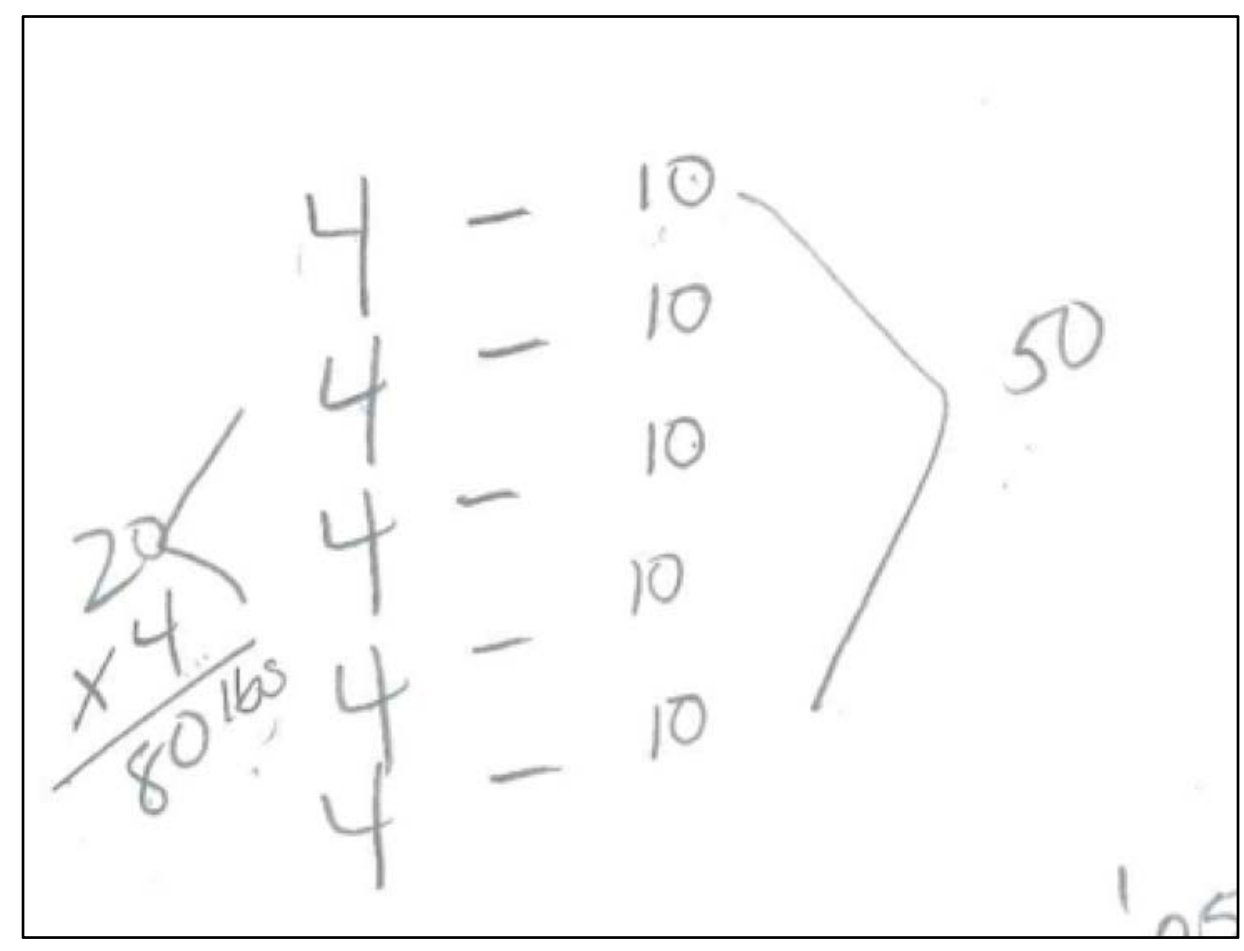

Figure 16. Ruby's ICU and scalar strategies on the Bread Flour problem 
Ruby's reasoning on this problem, in addition to other participants' reports that the Bread flour problem was difficult, suggests that an ICU or BU strategy may be more than a computational tool, but a way of reasoning that adult students may bring to bear on complex problems. For example, on her written work Ruby concluded that 16 pounds of flour were needed for four weeks (for 10 people) by working with the composed unit four pounds per week (for 10 people). When she recognized that she had not accounted for the increase in the number of people, she started from the beginning, now working with the other composed unit, four pounds for 10 people (for one week). The problem for Ruby did not seem to be determining how many sets of 10 people are in a group of 50 , since in in this case she would just need to iterate 10 until she reached 50. Instead, she intentionally reasoned with the composed unit to determine that 20 pounds of flour per week are needed for 50 people. Once she reached this conclusion, she quickly multiplied just the 20 pounds by four to solve the problem. The next section on buildingup strategies explores this idea further.

Building-up strategy. The survey data led me to query whether or not students' written explanations of their reasoning on the Flower Stem problem indicated that they were reasoning using a building-up strategy or whether these annotations were simply a way to communicate scalar reasoning. During the interview I asked the participants to examine building-up strategies used by other survey participants on the Flower Stem. I hoped to uncover whether or not the interview participants might have used a buildingup strategy to reason even though they did not record this way of thinking on their written work. Although the interview data cannot be used to answer this particular question that emerged from the survey data, the interview data did reveal that 
participants were using a building-up strategy both as a computational tool and as a way of reasoning about a proportion problem (as suggested by the previous discussion of Ruby's work on the Bread Flour problem). In this section examples will be provided that suggest Sasha and Lily used building-up strategies as a computational tool. In contrast, another example will suggest that Sasha uses a building-up strategy as a tool for reasoning on the Better Buy problem and that both JR and Ruby attempted to do so as well. In addition, Sasha's reasoning on the first variation of the Flower Stem problem also will provide an example of an attempt to partition a composed unit in order to determine a unit rate, which is not a computational strategy.

Lily's written work on the survey problems did not include any evidence of using building-up strategies. For example, on the Flower Stem problem she wrote, "3 times 5 is 15 stems... 5 times $\$ 2$ is $\$ 10$.” However, as she considered an example of another student's work on this problem that illustrated a building-up strategy (see Figure 17), Lily commented,

So, they're just counting up. So, the first one [an example of an ICU strategy] is a ton of work, and this one is like how I would do it in my head. Two, four six... I know that if I was counting up in money, two, four, six, eight, ten. But then I'd have to go back and count how many groups of three would get me to the ten. The number I am trying to find is five. And that's how I do everything. (Lily, 21 December 2011)

In this excerpt, Lily describes that this way of thinking is how she solve the problem "in my head," and suggests that the building-up strategy is a computational tool she uses to determine products. 


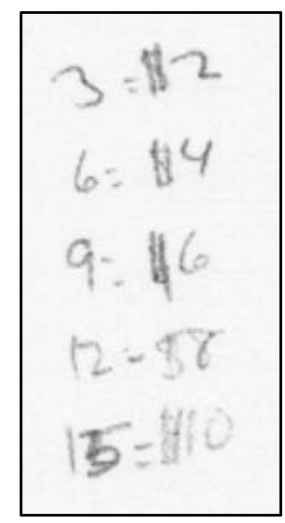

Figure 17. Sample BU strategy considered by interview participants

Sasha also used the building-up strategy as a computation tool. Unlike the other interview participants, Sasha admitted to not knowing multiplication facts and - as I discuss in detail in Chapter 6 - she had developed alternate ways of both computing and estimating products and quotients. Figure 18 shows Sasha's written work on the first variation of the Bread Flour problem. It is unclear whether Sasha recognized that 250 is five times $50^{38}$, but she knew she could decompose 250 into 100,100 and 50, as illustrated in Figure 18.

The cook needs 80 pounds of flour for the 50 people who are coming to the camp for 4 weeks. How much flour will he need if 250 people show up instead?

Figure 18. Sasha's written work on the first variation of the Bread Flour problem

\footnotetext{
${ }^{38}$ Unfortunately, I did not ask Sasha whether she recognized the multiplicative relationship between 50 and 250 .
} 
Unlike Lily who described counting up by twos as the ways she would solve the Flower Stem problem in her head, Sasha is reasoning explicitly with the composed unit, 80 pounds of flour for 50 people:

Well, for every 80 pounds, it's 50 . So, 50,50 , and 80 is 160 . So, 160 and 160 would be [computes mentally]... It would be $220 \ldots$ [Sasha decides to write her computation] So, 160 for 100 people, and then 160 for 100 people, and then 80 for 50 people [Sasha writes the sum $160+160+80$ vertically and tallies] 400 pounds... [Sasha, 22 December 2011].

This excerpt suggests that Sasha recognized that five times a number was its double plus its double plus the number itself, a computation tool. But Sasha was also reasoning with the composed unit and within the context of the problem; she was not using repeated addition to determine the product of 50 and five.

Although one might argue that students enrolled in Basic Math should not compute products using repeated addition, Lily's admission that this strategy is how she would multiply in her head suggests that this is a strategy that may not always be visible to Basic Math instructors. We may assume that students are using known multiplication facts when they do not. However, making these ways of thinking visible in the classroom could serve several purposes. Students who do not know multiplication facts may not feel as deficient with respect to the course content. In addition, Sasha's work might be annotated to show that double plus double plus single can be represented as $2+2+1$ and that the product of 80 and five can be found using the distributive property:

$$
80 \times 5=80 \times(2+2+1)=160+160+80=400 .
$$


JR, Ruby and Sasha's reasoning on the Better Buy problem provide further examples of using a building-up strategy as a tool for reasoning. JR initially reasoned about this problem by articulating his mental computations:

You get nine for 16 [ounces]... No... 16 [ounces] for 9 [dollars] ... 24 [ounces] for 13 [dollars]. For four ounces... divided by 4 is $2 \ldots$ [JR is not writing, just thinking aloud]. So 4 [ounces] for 2 and a quarter [dollars]... So, six ounces would be 3 and a quarter. [Pauses.] About the same price [JR, 19 December 2011].

However, when I asked JR to explain how he concluded that the two sticks of deodorant are about the same price, he abandoned this building-up strategy and computed the unit cost of each and drew his conclusion based on these computation. Similarly, Ruby also started reasoning about the problem using a building-up strategy. Her written work on the problem is shown in Figure 19. 


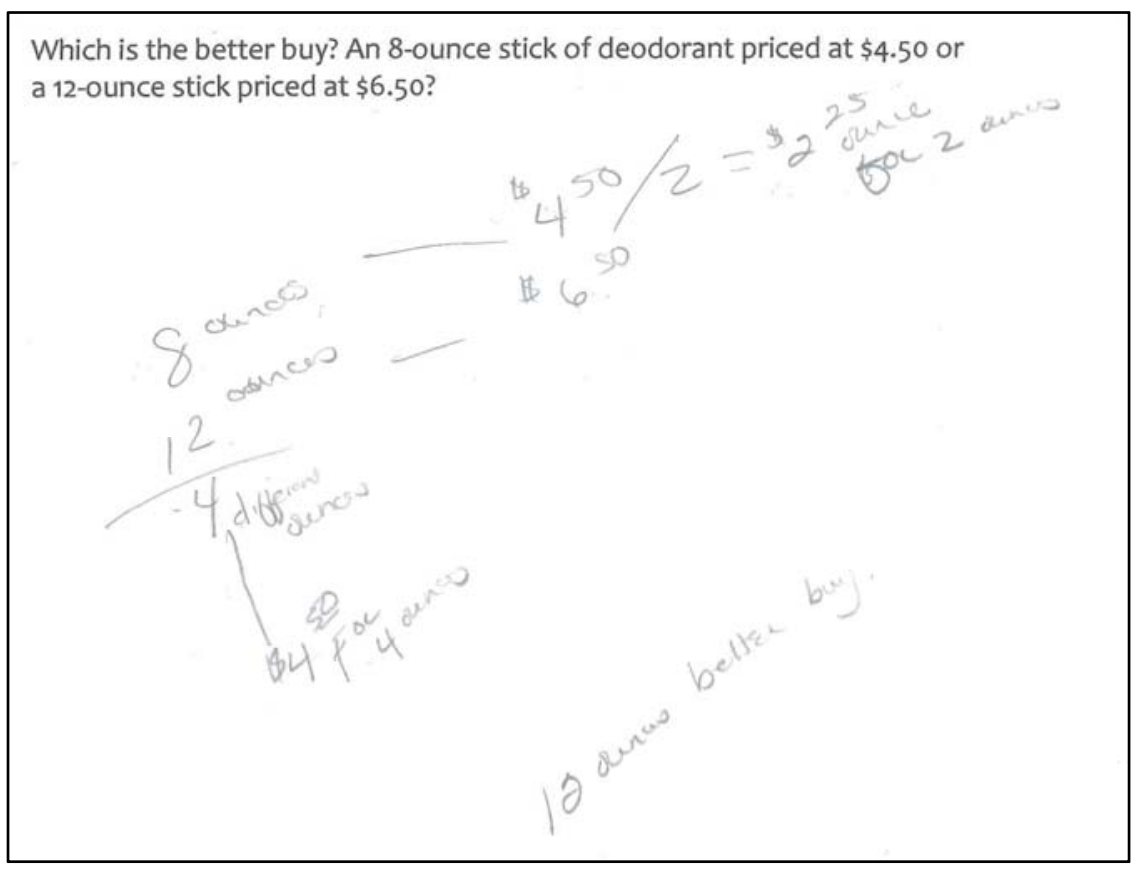

Figure 19. Written record of Ruby's reasoning on the Better Buy problem

Ruby's started with an attempt to build-up the composed unit of eight ounces for $\$ 4.50$ to 12 ounces for an unknown cost. She computed the quotient of $\$ 4.50$ and two, but she did not interpret this amount as the cost of four ounces. If she had, she might have recognized that 12 ounces for the first stick of deodorant would cost $\$ 6.75$, making it more expensive than the second stick. However, the transcript suggests that Ruby was actually attempting a unit-rate strategy:

Four ounces is the difference between the two. Then, go back to the eight ounces and figure out how much are you paying, on average per ounce. For me, I came out with... dividing the two into $\$ 4.50 \ldots \$ 2.25$ an ounce [Ruby, 20 December $2011]$. 
Although Ruby had written that two ounces (rather than four ounces) would cost $\$ 4.50$, she was interpreting the result of this computation as a unit cost. I asked Ruby why she divided $\$ 4.50$ by two, since she had performed this computation after noting the fourounce difference between the two sticks; I expected she intended to compute the cost of four ounces using the composed unit eight ounces for $\$ 4.50$. However, Ruby was not able to articulate why she chose to divide $\$ 4.50$ by two and was confused about what quantity two represented:

Ann: Okay. So, you started with the eight ounces, which was $\$ 4.50$, and divided it by two. Why did you divide by two there?

Ruby: Because the $\$ 4.50 \ldots$ If you go to two, the two ounces, I mean the $\$ 2$, two is $\$ 4.50 \ldots . \$ 2.25$ an ounce based off the eight ounces that you pay $\$ 4.50$ for. It didn't matter how much I was paying on the 12 ounces, because the 12 ounces was only $\$ 2$ cheaper than the eight ounces, which to me is the same thing as... it is basically $\$ 2.25$ per ounce [Ruby, 20 December 2011].

Although this is a weak example of a student using a building-up strategy to reason about a proportion problem, it is interesting that Ruby initially considered the cost of the additional four ounces, suggesting that this how she might reason about a similar problem outside school.

Sasha, on the other hand, read the Better Buy problem and said, "This is what I do all the time." Like JR and Ruby, Sasha initially reasoned about the problem using a building-up strategy, however she was able to use this strategy to conclude that the 12ounce stick was the better buy. She started by explaining her reasoning as follows: 
And the reason I say [the 12-ounce stick is the better buy] is because if you double your 12-ounce, you are going to get 24 ounces for $\$ 13$. So that's 24 ounces. If you go with two 8 ounces, you are going to get 16 ounces for $\$ 9$. So, you are definitely going to get more... even though it seems like it cost more, you're still going to get a better amount [Sasha, 22 December 2011]. At this point, Sasha has built up each composed unit in order to compare the two products, but she is comparing 24 ounces for $\$ 13$ to 16 ounces for $\$ 9$. It was unclear to me how she reached her conclusion.

Sasha: Just because... to me, I would just say, "Okay, for..." [thinks to herself quietly]. For eight more ounces, I only have to pay three more dollars, which would make this one [we cannot see which she is pointing to] still more expensive.

Ann: So, you need eight more ounces to get the 16 to match up with the 24 ?

Sasha: Yeah. If I bought three 8 ounces for $\$ 4.50$, it would still be more than it would be I bought the two for the $\$ 13$ [Sasha, 22 December 2011].

Although Sasha does not compute that three 8-ounce sticks cost $\$ 13.50$ at this point in the interview (she does later), she is convinced that her conclusion is reasonable. These examples suggest that some adults may not first consult or compute the unit cost when comparing which product represents a better buy.

Sasha's way of thinking about the first variation of the Flower Stem problem stood out as an example a building-up - or in this case, a partitioning - strategy. Her written work on this problem is shown in Figure 20. 


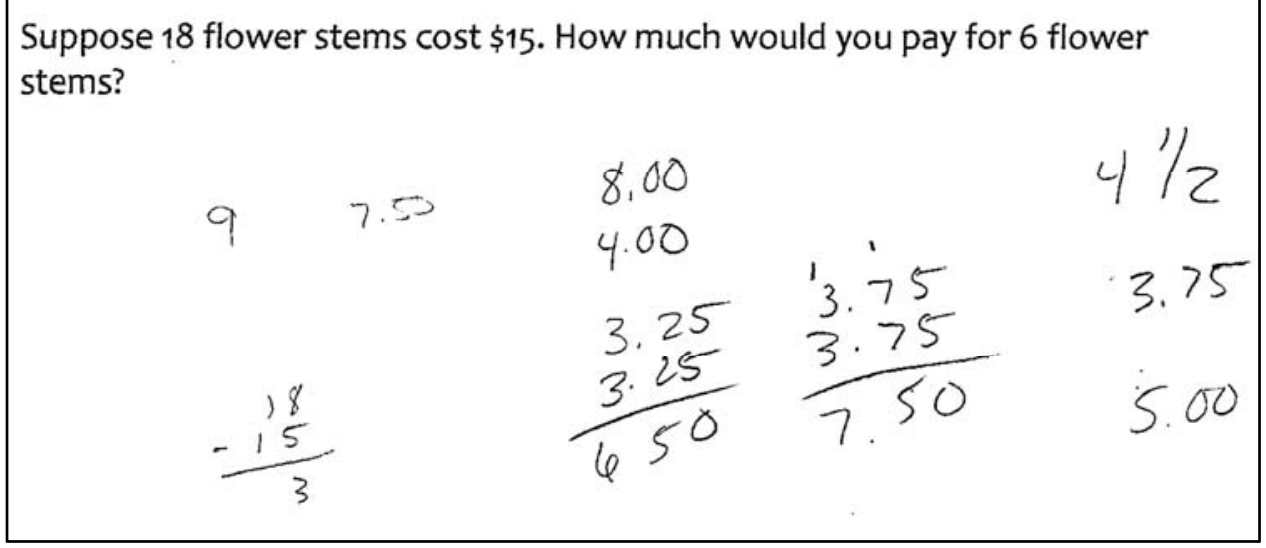

Figure 20. Written record of Sasha's thinking on the first variation of the Flower Stem problem

Sasha started by halving the composed unit, 18 stems for $\$ 15$ obtaining 9 stems for \$7.50, annotated in the upper left corner. When asked, “What are you thinking?” Sasha explained that she knew that each flower stem cost less than a dollar. If she could determine the cost per stem, she would multiply this value by six to answer the question. Continuing with this strategy, Sasha struggled to halve $\$ 7.50$, but by rounding $\$ 7.50$ to $\$ 8$ and revising her estimates she determined that half of $\$ 7.50$ is $\$ 3.75$. She spends a minute thinking about how to halve $\$ 3.75$, but eventually abandons this strategy of partitioning the composed unit to determine the unit cost.

So, four and a half stems is 3.75 , but I need six so, two stems would be half of 3.75, would be a dollar... [thinks for about 30 seconds] So, I would say it is about $\$ 5$ for six stems.

It's going to be about $\$ 5$ as an estimated amount, just because you cannot break them down... an odd amount to get an even amount. So, I am going to say that it is about $\$ 5$. I am estimating higher. I think it is going to be under $\$ 5$. Four and some change [Sasha, 22 December 2011]. 
Sasha's partitioning strategy served a particular purpose - to determine the cost per stem. If the problem had provided the cost for 16 or 8 flower stems, Sasha's halving strategy would have led to the unit cost. In a classroom context, Sasha's partitioning strategy could be used to make sense of the question, "Why divide when computing a unit rate?" Sasha's strategy was not an efficient strategy for determining the unit cost, but her intuition about what that unit cost would be led her to a reasonable solution to the problem.

The last example is another partitioning strategy from Jesse's reasoning on the Speed as Proportional Reasoning problem. This was the last of the mathematical tasks he considered in the interview. Prior to considering this problem, Jesse was fixated on recalling and using the appropriate 'formula' to reason about almost every problem during the interview and he had limited success using this strategy. As described in Chapter 4, Jesse's equated mathematical activity with his experience of school mathematics, believing that finding and applying the appropriate formula could solve any problem. However, he let go of a way of thinking he felt was appropriate to school mathematics and reasoned about constant speed as a proportional relationship between the distance traveled and the duration of travel as he considered the Speed as Proportional Reasoning problem. Jesse's reasoning and gestures indicated that he recognizes the proportional relationship between any distance traveled and the corresponding time of travel:

Jesse: Here's a chunk. 125 miles, $2 \frac{1}{2} 2$ hours, constant speed... So, it's a constant... How far is it she travels in a half hour? A half hour, plug a half into $2^{1 / 2}$ and you get 5 . 
Ann: Okay.

Jesse: So, divide that portion into 125 and you get 25 . So, it's 25 .

Ann: So, here you didn't even look for a formula. Why not?

Jesse: No. I am probably learning a different way of doing it. I have been looking at word problems, like, if this, then that.

Ann: In the course of this interview...

Jesse: If not this, then that. So, 125 miles, a chunk there... [Jesse uses his two hands to indicate the distance.] $2 \frac{1}{2}$ hours [Jesse uses his two hands to illustrate the duration.] And some portion of that constant, and a half into that portion of it is the portion of that constant.

Ann: So, I see that you are doing this with your hands [mimicking Jesse gestures]. 125 miles, $2 \frac{1}{2}$ hours and you just need to figure out what portion.

Jesse: Exactly [Jesse, 3 January 2012].

Jesse was the only participant who reasoned this way. He partitioned 125 miles into five equal parts and $2 \frac{1}{2}$ into five equal parts. Since the person is traveling at a constant speed, each 25 miles corresponds to $1 / 2$ hour, as suggested by Jesse's gestures.

Scalar reasoning. Scalar reasoning was prominent in the interviews. All students used a scalar strategy on the Flower Stem problem, and Andrea, Lily and Sasha also were able to articulate what the scalar factor represented in the context of the problem: 15 stems is five bundles or sets of three stems. Each used this understanding to explain why they multiplied $\$ 2$ by five to determine that 15 stems cost $\$ 10$. However, the scalar 
factor of five did not have the same contextual meaning for all participants. Ruby struggled to answer my question, "Why did you need to figure out that three goes into 15 five times?"

If three of them cost $\$ 2$, and that was just three and you need a total of 15 . Then how many stems can you get out of 15 ? If three cost $\$ 2$, they weren't a dollar a piece or... [pauses] [Ruby, 20 December 2011].

Ruby recognized that the cost per stem is less than $\$ 1$, but she is unable to articulate why she divided 15 by three to solve the problem. When asked the same question, JR focused on his knowledge of multiplication facts:

JR: 'Cause the 15 and the five. It's divisible by five. And it just happens to be divisible by three also, which is the amount of stems you get for $\$ 2$. I call it deductive reasoning. Remember the Pee Chees? We used to have as kids?

Ann: Oh, those Pee Chee notebooks?

JR: It had the little cheater stuff in it. I learned my times tables off that. I memorized it and I memorized it. I memorized it [JR, 19 December 2011].

JR may have known that he was looking for the number of bunches of three flowers in 15 flowers, but he responds to the question, "Why divide 15 by three?" in terms of what he knows about multiplication facts. If JR was reasoning about the scalar contextually, he does not say. 
All participants except Jesse ${ }^{39}$ used scalar reasoning on the Flower Stem problem, but only JR and Roo used scalar reasoning on the first variation of the Flower Stem problem, recognizing that six flowers stems is one-third 18 stems. JR also used scalar reasoning on the second variation:

JR: $\quad 18$ stems costs $15 \ldots$ Three more flower stems to that... Umm... Let's see. [Quietly] Six... [Takes out a piece of candy]. [JR discusses candy; Ann checks the camera.] Yeah, it's three more... See here... [JR picks up a pen to write.] Six stems are five... Oh, \$2.50. [JR reaches this conclusion without writing anything.] \$2.50 more would be... \$2.50 more.

Ann: So, how did you get $\$ 2.50$ ?

JR: Half of five...

Ann: Okay... Where did the five come from?

JR: $\quad$ Six of them cost $\$ 5[\mathrm{JR}, 19$ December 2011].

The variations of the Flower Stem problem were intended to uncover scalar reasoning, since I saw many examples of ICU and BU strategies on the Flower Stem problem survey data and I wanted to query whether or not these strategies were ways of reasoning for the students or just a way to explain their scalar reasoning. For example, student may have recognized that 15 flower stems is five times three flower stems, but explained how he knew this by building up the composed unit three stems for $\$ 2$ to 15 stem for $\$ 10$. However, the remaining participants attempted a unit-cost strategy on this problem,

\footnotetext{
${ }^{39}$ Jesse used an incorrect unit-rate strategy, concluding that 15 stems cost $\$ 22$. When he recognized his error during the interview, he became flustered and I did not ask him to consider the variations of the Flower Stem problem.
} 
which was unexpected since it was assumed that interview participants would recognize the factor of one-third in this first variation.

Scalar reasoning was evident in the participants' reasoning about the Bread Flour problem. Six of the seven participants' written work, completed prior to the interview, included a correct solution to the Bread Flour problem. The seventh participant, Ruby, submitted an incomplete solution, but she was prompted to complete the problem during the interview since the fact that 80 pounds of flour are needed for 50 people for four weeks was necessary for a discussion of the three variations of this problem. As discussed above Ruby used ICU, BU and scalar strategies to reason about this particular problem. The other participants' scalar reasoning became evident as we discussed the three variations of the Bread Flour problem included in the interview to query students' understanding of how the amount of flour needed varied jointly with the duration of the stay at the camp and the number of people in attendance. For example, the participants recognized that half as much flour was needed when the duration of the stay was cut in half, and that five times as much flour is needed if 250 people rather than 50 people showed up. On the third variation of the Bread Flour problem in which both the duration of the stay and the number of people are varied, Roo claimed correctly that $3 / 2$ as much flour was needed to scale up both quantities, but she was unable to articulate how she determined this factor. The other students either tripled the amount of flour (three times as many people) and then halved the result (duration of stay was halved), or halved and then tripled, using a scalar strategy in two steps. Sasha recognized that halving the duration of the stay would provide enough flour for twice as many people and she used this scalar reasoning and a building-up strategy to solve the problem: 
Okay. [Pointing to the quantities in the problem] So, that would take care of... So, the 80 pounds is for four weeks so that would take care of 100 [people for two weeks]. So, you need only 40 more [pounds for two weeks]. So 120 [Andrea, 4 January 2012].

Andrea was fluent with scalar reasoning. She was the only interview participant to use a scalar strategy on the Percent Discount problem by determing the amount of the discount by multiplying $10 \%$ or $\$ 3.50$ by four. Another example of Andrea’s scalar reasoning emerged as she discussed an episode from her everyday mathematics working in retail:

Like, for example, our gallons of milk. Normally they were like $\$ 3.50$ and sometimes they'd go on sale for $\$ 2$. For example, the whole milk, normally I would order 20 gallons. We'd go through - if it was on sale - we'd probably go through about twice that amount. Somewhere between half again and twice that. So we'd go through 30 to 40 gallons. So, I'd generally order 35 , just to be safe. [Andrea, 4 January 2012, emphasis added].

This excerpt illustrates that Andrea was comfortable with non-integer factors such as 1.5. In addition, when reasoning about percent, Andrea reasoned with thirds and fifths easily (see Section 5.4). It is interesting that Andrea did not reason with thirds on the first variation of the Flower Stem problem.

Unit-rate strategy. The interview data, like the survey data, suggest that computing a unit rate is a poorly recalled procedure. Lily, Ruby, and Andrea initially used an incorrect unit cost on the first variation of the Flower Stem problem, dividing 18 stems by $\$ 15$ and interpreting the result as $\$ 1.20$ per stem. (It should be noted that the 
values for the two quantities, number of stems and total cost of the given number of stems, were presented in the problem in the order these participants used to compute the unit cost.) Andrea corrected her work when I pointed out that her articulated strategy, figuring out how many times 18 goes into 15 is represented by $15 \div 18$, not the $18 \div 15$ she computed on the calculator:

Ann: [Summarizing Andrea's strategy] So you divided 18 by 15 . That told you the cost per flower. Why divide 18 by 15 ? How does it give you the cost per flower?

Andrea: 18 flowers cost $\$ 15$, which means you just have to figure out how many times 18 goes into 15 to figure out the cost of the flower [Andrea, 4 January 2012].

Ruby worked with her intuition that each stem cost less than one dollar, using a guess-and-test strategy. She first computed the difference of 18 and 15, then the quotient of 18 and 15, and finally the quotient of 15 and 18. It did not appear that Ruby had a unit-cost strategy, although she eventually stumbled upon a value less than one that happened to be the unit cost. Unlike Sasha who had a viable, although inefficient, strategy for determining the unit $\operatorname{cost}^{40}$, Ruby appeared to be trying to recall which operation. However, all participants, except Sasha, correctly computed the unit costs to solve the Better Buy problem. The unit, dollars per ounce, may have been more familiar than the unit dollars per flower stem. Lily, who determined each flower stem cost $\$ 1.20$ rather than about $\$ 0.83$ per stem, recalled a rule she had learned when I asked her why

\footnotetext{
${ }^{40}$ Sasha also computed the difference of 18 and 15 to see if this would yield a result less than one, but this appeared to be a temporary attempt to find an alternative to the halving strategy that caused her difficulty.
} 
she divided 4.50 by eight when computing a unit cost while solving the Better Buy problem:

Lily: The numbers that are out there... This one is the price and this one is the stick of deodorant. Look, I know when you do it the other way, it doesn't make sense. It would be like [using a calculator] eight divided by $\$ 4.50$ is one point seven (1.7). [Lily pauses and then she says quietly] I don't know.

Ann: So, you are saying that one wouldn't make sense.

Lily: It doesn't make sense.

Ann: Why not?

Lily: I don't know. It doesn't make sense in my head. It's like, how I learned it. You divide the money by the ounce versus the other way [Lily, 21 December 2011].

Lily believed that only one of the two quotients made sense; that is, she would be unable to determine which stick of the deodorant is the better buy if she computed the number of ounces she could purchase for one dollar. But it did not appear that Lily was reasoning contextually, both attending to the units of measure (ounces and dollars) and interpreting the computed rates. Rather, dividing "the money by the ounces" is how she learned it.

A division strategy for computing a constant speed is another poorly recalled strategy. The survey data on the Comparing Speeds reported in Table 15 shows that only one student correctly concluded that Victor and Sharon would arrive at their destination at the same time and was able to interpret the unit rate on which she or he based this 
claim. In addition, some students computed unit rates on this survey, but were either unable to draw a conclusion or drew an incorrect conclusion. The interview participants also struggled with the unit rate representing a constant speed, although most worked with this strategy during the interview.

Jesse knew there was a formula for reasoning about problems involving speed comparison, but he could not recall it when thinking about the Two Joggers problem:

Jesse: The difference between 25 and 39 is 14 . So, 14 and two or 14 and three... I don't know exactly where to put that relationship.

Ann: Why look at the difference between 39 and 25? You were thinking something there, what were you thinking?

Jesse: I was thinking, get the unknown. So part of the unknown is the relationship between those two portions. And two miles and three miles... [pauses]. I just go back to the formula, because I can't quite get it [Jesse, 3 January 2012].

Both Lily and Ruby computed unit rates, but misinterpreted the rate in terms of miles per minute (Ruby) or miles per hour (Lily). Neither participant was able to use her computation of a unit rate to determine the faster jogger. For example, Ruby uses a division strategy, but cannot seem to make any sense of the quotients she computes. I need to figure out the difference. If she runs two miles in 25 minute, my first thought is to break down how many miles is she running per minute. And if he runs three miles in 39 minutes...the same thing. To get the difference in their speed. So [computing using pencil and paper and obtaining inaccurate quotients]... So, hers is 12 point one and his is 16 . [Ruby pauses] So, she runs 
12.1 miles a minute. [Reading] "Her partner runs three miles in 39 minutes. Who is the faster jogger?" [Now Ruby computes the difference between the times.] A 14-mile difference... Is the difference... He covers more area... so he's the faster jogger. He is. [Ruby, 20 December 2011].

Like Jesse, without being able to interpret the quotient she computed, Ruby was unable to use the quotients and took recourse to considering the difference in the time it took each jogger to complete the run.

In contrast, Andrea computed a unit rate to solve the Comparing Speeds problem, correctly concluded that Victor and Sharon were traveling the same speed and would arrive at their destination at the same time. However, she initially explained her reasoning using percent as is evident in her written work completed prior to the interview, shown in Figure 21.

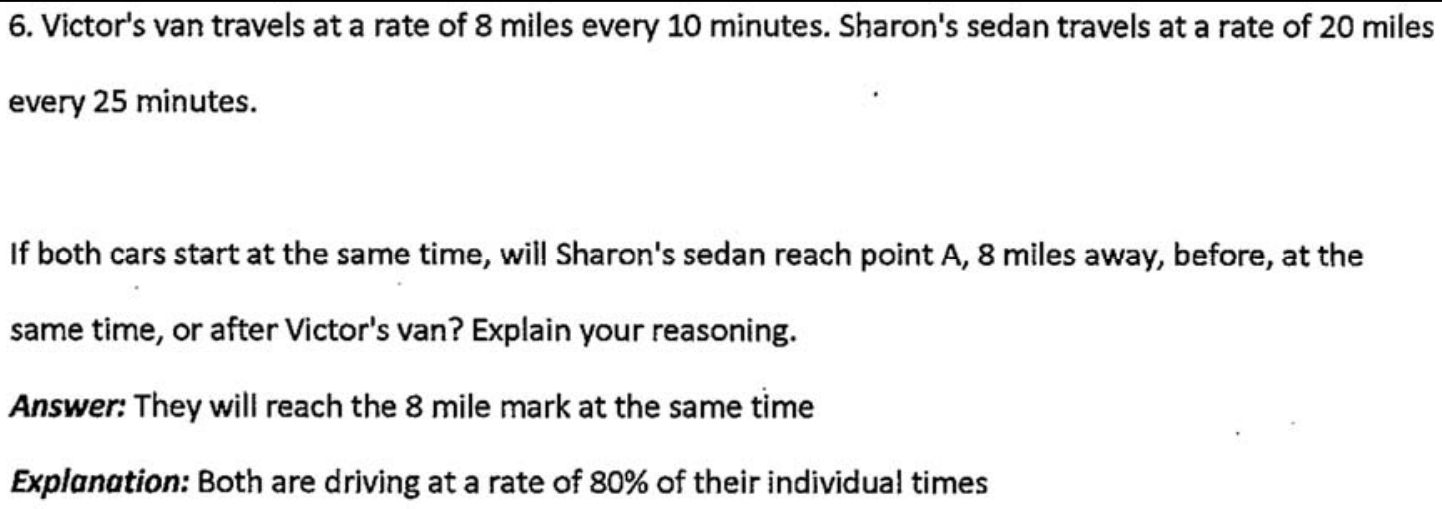

Figure 21. Andrea's written work on the Comparing Speeds problem

Andrea's explanation of her reasoning evolved as we spoke about the problem:

First explanation

Ann: What made you say that they were going about the same?

Andrea: Because 8 by 10 is $80 \%$ and 25 miles in 20 is $80 \%$. 


\section{$\underline{\text { Second explanation }}$}

Ann: $\quad$ What does that point eight (0.8) mean to you?

Andrea: [Hesitates for about 10 seconds] They're covering [pauses for a few seconds] For every minute, they are covering $80 \%$ of a mile.

\section{Third explanation}

Andrea: For every minute it is point eight (0.8) miles.

Ann: $\quad$ What about the other division? [10/8 $=1.2]$

Andrea: That is pretty much just reversing it. They got the same answer for both of them. So instead of point eight (0.8), it's one point two (1.2). So, instead of doing eight by ten, they did ten by eight.

Ann: $\quad$ So, any idea what the one point two [1.2] tells us?

Andrea: So, one point two (1.2) says that for every mile they drive, it takes about a minute and 20 seconds per mile [Andrea, 4 January 2012].

This evolution suggests that Andrea knew that if two rates are equivalent, the speeds are the same, but she needed to work to interpret the meaning of these rates in the context of the problem.

Sasha was the only participant who reasoned about the Two Joggers problem considering the units of measurement for time and distance and correctly interpreting the result of her unit rate computations. Sasha's first computations were incorrect, but when she used a calculator to compute the rates, she was able to solve the problem. However, Sasha first approached the problem using a building-up strategy to compare the speeds, but she abandoned this strategy quickly. 


\section{Sasha's first attempt using a building up strategy}

Sasha: Well, I would say he [the jogger who runs 3 miles in 39 minutes rather than the woman who runs 2 miles in 25 minutes] runs faster.

Ann: Why?

Sasha: The reason why is if I added her to run four miles, it would her take 50 minutes.

Ann: Okay.

Sasha: And he did 3 miles in 39 minutes. So, he still did more, or he still did more mileage in less amount of time that it would have taken her, even if she did four.

$\underline{\text { Sasha's second attempt using a unit rate strategy with estimation }}$

Sasha: [After some thought] It took her about 13 minutes to run one mile.

Ann: Okay. And how did you get that?

Sasha: Because I just divided the 25 into two, so it took her almost 13 minutes to run one mile. And he did his time... I rounded it up to 40 minutes, have would be 20 minutes... It took him about 11 minutes to run a mile.

Ann: Okay. So, your strategy to compare them was to estimate how far they ran... how long it took them to run one mile?

Sasha: One mile, yeah.

Ann: And it took her about 13 from your estimate, and him about $11 \ldots$

Sasha: About 11 minutes... So, he would be faster. 


\section{$\underline{\text { Sasha's third attempt using a calculator to compute the unit rates }}$}

Ann: How? How would you figure it out? Your strategy was to figure out how long it took each of them to run a mile.

Sasha: So, I would just divide the two into 25 and then I would divide the three into 39 .

Ann: Why don't you do that. There's a calculator here.

Sasha: 25 divided by 2 would be twelve fifty (12.5). So, it would take her 12 and a half minutes to do one. 39 divided by three. It takes him 13 minutes.

Ann: So, now you have those exact numbers. So, you knew how to figure them out. So, you know that it takes her 12 and a half minutes to run a mile and it takes him 13 minutes to run a mile. So who’s faster?

Sasha: She's faster [Sasha, 22 December 2011].

In addition to being able to interpret the unit rate she computed, Sasha also reasoning using a rate not computed by dividing the distance traveled by the time of travel, the typical computation for determining speed. Sasha computed how many minutes it took each jogger to cover one mile, a reasonable computation based on the context of the problem.

The participants' reasoning with unit rates in the context of speed comparison problems varied from being unable to reason about these problems (Roo ${ }^{41}$ and Jesse) to computing unit rates but being unable to interpret the rates to solve the problem (Ruby and Lily) to computing the rates to solve the problems with different abilities to interpret these rates (Andrea and Sasha). These data suggest knowing that speed is computed

\footnotetext{
${ }^{41}$ Roo did not have a unit rate strategy and attempted reasoned about the Two Joggers problem additively.
} 
using division is insufficient solving speed comparison problems. In fact, Thompson (1994) is critical of starting instruction with a definition of speed that involves division, because it assumes students have already "conceived of motion as involving two distinct quantities - distance and time" and they have developed a sense of a proportional relationship: "we move a given distance in a given amount of time and that any segment of the total distance will require a proportional segment of the total time," that is, a "mature conception of speed as quantified motion" (pp. 224-225). Only Jesse's partitioning strategy on the Speed as Proportional Reasoning problem indicated a sense of the proportional relationship. He recognized that each 25 miles would be covered in $1 / 2$ hour. $^{42}$

A unit-rate strategy on the speed comparison problems was problematic, but so was a unit-cost strategy on the variations of the Flower Stem problem and the Better Buy problem. Some participants appeared to prefer a building-up strategy to a unit-cost strategy. For example, Sasha's used a building-up strategy to reason about the Better Buy problem and JR and Ruby's initial reasoning about this problem also relied in a building-up strategy. Jesse, Andrea, Ruby and Lily all struggled with computing a unit cost; Jesse did so on the Flower Stem problem and Andrea, Ruby and Lily did so on the first variation of the Flower Stem problem. Having access to a calculator did not seem support viable reasoning; Andrea, Ruby and Lily all used the calculator to incorrectly conclude that each flower stem cost $\$ 1.20$. Sasha did not have a unit-cost strategy, but

\footnotetext{
${ }^{42} \mathrm{~A}$ unit rate strategy to solve the speed comparison problems was problematic. In addition, both the survey and interview data reveal a variety of conceptions about speed - not all viable. An analysis of these data to answer the question, "What do adult students enrolling in Basic Math understand about speed?", is beyond the scope of this paper. But this is an important question to ask since many curricular materials, in particular materials used in introductory algebra and first-year calculus, often assume the concept of constant or average speed is unproblematic.
} 
using her intuition that each flower stem cost less than one dollar, she did attempt to partition the composed unit 18 stems to $\$ 15$ to determine the unit cost. Each of these findings suggests that determining a unit rate, and in particular, a unit cost, may not be as unproblematic as assumed. This is significant since the two texts used in Basic Math at the time of the study define unit rate in terms of a quotient. For example, one text defined a unit rate as a rate that is "rewritten so that the denominator is a 1-unit measurement" and "To write a unit rate given a rate: (1) Do the indicated division and (2) Keep the unlike units" (Van Dyke, Rogers, \& Adams, 2007, p. 438). Participants' challenges and successes with reasoning with unit rates, suggest that the intended curriculum might be better aligned with the ways of thinking adult students bring to the Basic Math classroom.

Discussion of interview findings. The interview data provided an opportunity to look beyond the number of students who used a particular strategy on a problem and examine the different ways students used these strategies. A building-up strategy appeared to be used as a computational tool (on the Flower Stem and Bread Flour problems) to compute a product using repeated addition. However, this strategy also seemed to be way of reasoning about a problem (e.g., Sasha's reasoning on first variation of the Flower Stem problem and the Better Buy problem, and Jesse's reasoning on the Speed as Proportional Reasoning problem.) Partitioning a composed unit is one way to establish 'why divide?' when computing a unit rate. For example, Sasha's halving strategy led her to conclude correctly that $4 \frac{1}{2}$ flower stems would cost $\$ 7.50$. In a teaching situation, when Sasha reasoning stalls at this point, she might be asked, "Why not divide both $4 \frac{1}{2}$ stems and $\$ 7.50$ by $4 \frac{1}{2}$ to determine the cost of one stem?" Sasha, 
who has been dividing each quantity in the composed unit by two, should be able to recognize that this is a reasonable strategy and with access to a calculator be able to determine the cost per stem. Based upon this particular partitioning strategy to determine the unit cost, Sasha's attention might be redirected to the original composed unit, 18 stems for $\$ 15$, and asked if it is possible to divide each quantity by the same factor to determine the cost per stem. Similarly, Jesse did not divide 125 miles by $2 \frac{1}{2}$ hours to compute a unit speed on the Speed as Proportional Reasoning problem. Rather, he partitioned both 125 miles and $2 \frac{1}{2}$ hours into an equal number of parts and reasoned that a person traveling at a constant speed would cover the distance represented by each part in the time represented by the corresponding part. A partitioning strategy like the one Sasha used stands in contraposition to the difficulty other participants struggled had recalling how to compute a unit cost and Jesse's partitioning strategy illustrates what is meant by traveling at a constant speed and why proportional reasoning is essential to this understanding.

One problem that was used in the interview, the first variation of the Flower Stem problem, illustrates the variety of strategies students may bring to a Basic Math classroom. Interview participants attempted to determine the unit cost of a flower stem by division or partitioning on the first variation on the Flower Stem problem. Lily, Ruby and Andrea initially concluded that six flower stems would cost $\$ 7.20$, dividing 18 stems by $\$ 15$ and misinterpreting the rate. Although Lily, Ruby and Andrea revised their thinking, only one participant - Sasha - started with her intuition that each stem cost less than one dollar and attempted to partition the composed unit, 18 stems for $\$ 15$, to determine this unit cost. Sasha was unsuccessful, but her ability to remain grounded in 
the context of the problem allowed her to reasonable conclusion that six stems would cost $\$ 5$. JR and Roo both recognized that 6 flowers stems is one-third 18 flowers stems and used this scalar reasoning to determine that 18 stems would cost one-third of $\$ 15$, that is, $\$ 5$. JR continued to use scalar reasoning to solve the second variation of the Flower Stem problem, although Roo resorted to an estimation strategy on the second variation of the problem. If we imagine a classroom in which these ways of thinking about the first variation of the Flower Stem problem are present, the partitioning strategy Sasha attempted could be leveraged to address the question with which Lily, Andrea and Ruby struggled, "Why divide the total cost by the number of units (flower stems, number or ounces, etc.)?" In addition, JR and Roo's thirding strategy might be leveraged to help Sasha determine the unit cost: 18 stems for $\$ 15$ is equivalent to 6 stems for $\$ 5$, and 6 stems for $\$ 5$ is equivalent to 2 stems for $\$ 5 / 3$ or 1 stem for $\$ 5 / 6$.

A direct comparison with the research on children's proportional reasoning is difficult even though the mathematical tasks selected for the survey and interview were grounded on previous research on proportional reasoning (e.g., Lamon, 1993; Lembke \& Reys, 1994; Thompson, 1994; Vergnaud, 2004). None of these researchers explicitly addressed the role the context of a problem plays in students' reasoning. Younger students have everyday experiences that certainly inform their ways of thinking about mathematical tasks posed in school, but the everyday experiences of adult returning students, in particular the activities they perceive as mathematical, has both depth and variety, as described in Chapter 4. It is not surprising that adult students focus on the context in which a problem is posed (Evans, 2000), but the ways adult learners use context to reason about proportional situations do suggest that adults ways of thinking 
might be leveraged to inform the intended curriculum of developmental mathematics courses. The findings from these interview data suggest that adult students make sense of problems when they remain grounded on the context of the problem, and in particular, when a problem is familiar from their everyday lives. As soon as a student reaches for a poorly understood strategy, such as a unit-rate strategy, the context (that is, the quantities, the relationship between quantities and what these mean) may be abandoned. 'Real-world applications' are an important component of curricula for adult learners, but a careful analysis of the ways adult learners use context to reason or abandon context is an equally important component for adult learners if we want to be able to build on adults' experiences and strategies when developing curricula.

Variety across and within: The case of percentage. In the previous section I described the range of strategies for reasoning about proportional situations that adult students bring to the Basic Math classroom. However, the Four Strategies framework was insufficient to describe the ways adult students reason about percent. Some of these ways involve proportion reasoning, but other viable ways for reasoning about percent emerged as I analyzed students' strategies students on the Percent Discount problem and the additional questions about percent I pursued during the interviews. Percent is an important topic in Basic Math. The following analysis extends the Four Strategies framework in order to examine adult returning students' ways of reasoning about percent.

As I embarked on this study I conjectured that adults' experience with shopping and budgeting, paying taxes and encountering percent as a statistic would reveal informal ways of reasoning about percent that are more robust than the ways of thinking 
about percent children bring to school. On the one hand, prior to learning about percent in school children hear about percent in weather reports, as a statistic reported in the news, and in many states, in the context of sales tax. They are able to reason with a benchmark such as $50 \%$, but have difficulty representing or computing other percentages beyond determining whether the amount is more or less than $50 \%$ (Lembke \& Reys, 1994). On the other hand, it is likely that adults regularly estimate to compute percent discounts, sales tax and tips. In addition, some adults have experience procuring financing. For example, returning students applying for federal financial aid may encounter statements such as, " 15 percent of the difference between your adjusted gross income (AGI) and 150 percent of the poverty line for your family size in the state where you live ${ }^{43}$," as they explore ways to finance their further education. As the findings about students' written work on the Percent Discount problem from the survey indicated, shopping was a familiar context and some adult students were able to reason about a $40 \%$ discount as $\$ 4$ off every $\$ 10$ spent. Unlike children who may be familiar with phrases such as a $70 \%$ chance of rain or a $76 \%$ free throw percentage, adults' encounters with percentage have significance in their everyday lives.

In this section, I describe the variety of strategies adult students used to solve the Percent Discount problem on the survey and the variety of ways of understanding percent that emerged from both the interview data and from the field notes collected in Sasha's Basic Math classroom. Next, using the interview data, I highlight the flexible ways of thinking about percent that each participant brought to bear on his or her solution to Percent Discount problem. The second research question asks, "What

${ }^{43}$ From http://studentaid.ed.gov/glossary\#Financial_Need 
proportional reasoning abilities do students placing into Basic Math demonstrate prior to returning to school mathematic?" As the data on the Percent discount data was analyzed, it became clear that students were reasoning with percent as a ratio, but that students were also using other ways of reasoning about percent to solve this and similar problems. In this section, students thinking about percent is explored in more detail to examine further ways students use proportional reasoning when solving problems about percent, but also to highlight non-proportional ways of thinking about percent since the topic of percent is important in a course like Basic Math and since it is a topic typically taught in tandem with the topic of proportion.

Variety across students. The Percent Discount problem was attempted by 259 of the 340 students surveyed (76\%) and the way the problem was posed led to classifying two responses as correct:

- No, you cannot buy the jeans for $\$ 20$ or less

- The jeans cost $\$ 21$.

Of these attempts $42 \%$ (108 of 259) were correct, but 164 of the 259 responses $(63 \%)$ were either correct, as defined above, or suggested a reasonable estimate, such as $\$ 20$, for the sale price of the jeans.

Lembke and Reys (1994) classified eight strategy types students used on questions about percent: (1) reasoning with benchmarks, (2) transforming a percent to a fraction, (3) reasoning with a ratio, (4) using an equation, (5) computing and checking, (6) using trial and error, (7) reasoning with a picture, and (8) unclassified or no justification. Four these strategies were not evident in students' written work on the Percent Discount problem on the survey: transforming a percent into a fraction, 
computing and checking, trial and error, and reasoning with a picture. For example, the Percent Discount problem involved $40 \%$ or $60 \%$, rather than a percent related to a common fraction such as $50 \%$ or $25 \%$, so it is not surprising that students did not reason using the equivalent fraction representation.

The remaining categories require further clarification, since these ways of thinking do not align with the Four-Strategies framework described in Section 5.2. Reasoning with benchmarks involves reasoning with 50\%, 25\% and/or 10\%; these strategies may lead to an exact computation or be used to make a reasonable estimate; Reasoning with a ratio is described as follows: "Sets up a comparison or a proportion to solve the problem or finds a proportionality constant" (p. 243). This is not necessarily writing and solving a proportion equation. For example, a student may argue that $21 \%$ of 400 is four times $21 \%$ of 100 or four times 21 . Computing and checking involves performing an operation (in the case of reasoning with percent, either multiplication or division) and determining which result is reasonable, whereas using trial and error involves making a guess, checking that value and then revising the guess.

These strategies, originally developed using research with middle school students, were adapted to categorize adult students' written work on the Percent Discount problem. The framework was adapted since some of the strategies observed by Lembke and Reys were not observed in the data that illustrated adult students' reasoning about percent. Table 16 compares Lembke and Reys' framework to the adapted framework I used to analyze the survey data and provides examples of the categories of the categories I used to analyze the data. 
Table 16

Adaptation of the framework from Lembke and Reys

\begin{tabular}{|c|c|}
\hline $\begin{array}{c}\text { Framework from } \\
\text { Lembke and Reys }\end{array}$ & $\begin{array}{c}\text { Framework as adapted } \\
\text { for this study }\end{array}$ \\
\hline \multirow{2}{*}{ Equation } & Using a formula \\
\hline \multirow{2}{*}{ Benchmarks } & Reasoning with $50 \%$ and $10 \%$ \\
\hline \multirow{2}{*}{ Ratio } & Making a reasonable estimate using $50 \%$ \\
\hline Fraction & Reasoning with four times $10 \%$ \\
\hline Compute and check & Reasoning with percent as rate \\
\hline Trial and error & \\
\hline Draw a picture & \\
\hline & \\
\hline & \\
\hline
\end{tabular}

The first distinction between the two frameworks involves separating solving an equation from using a formula. In school, the focus is often on determining whether a problem involves determining an unknown percentage, an unknown percent or an unknown base (Dole, Copper, Baturo, \& Conoplia, 1997). In this study, survey participants were only asked to determine an unknown percentage, which could be solved using the formula $A=R B$ directly without solving for an unknown. The interview participants were asked to solve a base unknown strategy, but no one solved this problem by solving the equation $A=R B$ for the base $B$. The benchmark strategies described by Lembke and Reys involved reasoning with $50 \%$ or $25 \%$. The adapted framework includes two categories that correspond to Lembke and Reys' benchmark strategy: (i) using the benchmarks $50 \%$ and $10 \%$ to obtain an exact solution, and (ii) using the benchmark $50 \%$ to make a reasonable estimate. Three categories correspond to Lembke and Reys' ratio strategy. The first category is reasoning with $10 \%$ and either iterating the composed unit $10 \%$ to $\$ 3.50$ or using scalar reasoning computing four times 
$10 \%$. The second category involves reasoning with an informal understanding of a percent as rate such as 40 cents to the dollar or a $\$ 4$ discount on every $\$ 10$. The third category is writing and solving a proportion equation.

Some of Lembke and Reys' categories were not needed. Although one interview participant admitted to using the compute-and-check strategy on the Percent Discount problem, but her written work on the problem - completed prior to the interview - did not reveal this thinking. This suggests that it is possible that the compute-and-check strategy was more prevalent than the written work on the surveys indicated; further study directed at this question might reveal whether a compute-and-check strategy is prevalent. In addition, there was no evidence of reasoning with a picture in either the survey responses or during the interview. Finally, students whose strategy involved computing $0.40 \times \$ 35$ were classified as using a formula.

Tables 17 and 18 display the number of students surveyed who used a particular strategy as their primary strategy. If a student used more than one strategy, the strategy that appeared to support the student's conclusion was deemed the primary strategy. The Other category indicates strategies that led to an incorrect response, including unreasonable estimates, solutions that indicate that students are using random operations and one case of a response that I was unable to interpret. 
Table 17

Surveyed students' correct primary strategies on the Percent Discount problem

\begin{tabular}{|c|c|c|c|c|c|c|}
\hline $\begin{array}{c}\text { No reasoning } \\
\text { supplied }\end{array} \mid$ & $\begin{array}{l}\text { Using a } \\
\text { formula }\end{array}$ & $\begin{array}{c}\text { Reasoning } \\
\text { with } \\
50 \% \text { and } \\
10 \%\end{array}$ & $\begin{array}{c}\text { Making a } \\
\text { reasonable } \\
\text { estimate }\end{array}$ & $\begin{array}{c}\text { Reasoning } \\
\text { with } \\
10 \%\end{array}$ & \begin{tabular}{|c|}
$\begin{array}{c}\text { Reasoning } \\
\text { with } \\
\text { percentage as } \\
\text { a rate }\end{array}$ \\
\end{tabular} & $\begin{array}{c}\text { Solving a } \\
\text { proportion } \\
\text { equation }\end{array}$ \\
\hline $37(34 \%)$ & $35(32 \%)$ & \multirow[t]{3}{*}{$7(6 \%)$} & \multirow{3}{*}{$\begin{array}{l}\text { Reasonable } \\
\text { estimate: } \\
\text { More than } \\
\$ 20 \\
\mathbf{2 0}(19 \%)\end{array}$} & \multirow{3}{*}{$5(5 \%)$} & \multirow{3}{*}{$3(<3 \%)$} & \multirow{3}{*}{$\mathbf{1}(<1 \%)$} \\
\hline $\begin{array}{c}\text { No, you } \\
\text { cannot buy } \\
\text { the jeans for } \\
\$ 20 \text { or less. } \\
15\end{array}$ & $\begin{array}{c}0.40 \times 35=14 \\
35-14=21 \\
30 \\
0.60 \times 35=21 \\
\mathbf{1}\end{array}$ & & & & & \\
\hline $\begin{array}{c}\text { The jeans cost } \\
\$ 21 . \\
22\end{array}$ & $\begin{array}{c}\frac{35 \times 40}{100}=14 \\
35-14=21 \\
4\end{array}$ & & & & & \\
\hline
\end{tabular}

Table 18

Surveyed students' incorrect primary strategies on the Percent Discount problem $(n=151)$

\begin{tabular}{|c|c|c|c|c|c|c|}
\hline $\begin{array}{c}\text { No reasoning } \\
\text { supplied }\end{array}$ & $\begin{array}{l}\text { Using a } \\
\text { formula }\end{array}$ & Other & $\begin{array}{l}\text { Making a } \\
\text { reasonable } \\
\text { estimate }\end{array}$ & $\begin{array}{c}\text { Reasoning } \\
\text { with } \\
10 \%\end{array}$ & \begin{tabular}{|c|}
$\begin{array}{c}\text { Reasoning } \\
\text { with } \\
\text { percentage as } \\
\text { a rate }\end{array}$ \\
\end{tabular} & $\begin{array}{c}\text { Solving a } \\
\text { proportion } \\
\text { equation }\end{array}$ \\
\hline $39(26 \%)$ & $32(21 \%)$ & $\begin{array}{c}\text { Poor estimate } \\
6(4 \%)\end{array}$ & \multirow{3}{*}{$\begin{array}{l}\text { Reasonable } \\
\text { estimate: } \\
\text { Less than \$20 } \\
\mathbf{5 6}(37 \%)\end{array}$} & \multirow[t]{3}{*}{$1(<1 \%)$} & \multirow[t]{3}{*}{$3(2 \%)$} & \multirow[t]{3}{*}{$4(<3 \%)$} \\
\hline $\begin{array}{c}\text { Yes, you can } \\
\text { buy the jeans } \\
\text { for } \$ 20 \text { or } \\
\text { less. }\end{array}$ & $\begin{array}{c}0.40 \times 35=14 \\
24\end{array}$ & $\begin{array}{c}\text { Random } \\
\text { operations } \\
\mathbf{9}(6 \%)\end{array}$ & & & & \\
\hline $\begin{array}{c}\mathbf{2 4} \\
\text { The jeans cost } \\
\$ 14 . \\
7 \\
\text { Just a number, } \\
\text { but not } 14 . \\
\mathbf{8}\end{array}$ & $\begin{array}{c}\frac{35 \times 40}{100}=14 \\
\mathbf{1} \\
\text { Computation } \\
\text { error } \\
\mathbf{7}\end{array}$ & $\begin{array}{l}\text { Unclear } \\
\mathbf{1}(<1 \%)\end{array}$ & & & & \\
\hline
\end{tabular}


As in this study, Lembke and Rey (1994) were interested in exploring the interaction between informal and school-based ways of reasoning about percent. However, their methodology differed in significant ways from my methodology: they interviewed students in fifth, seventh, ninth and eleventh grade (31 students altogether), using a wide variety of questions about percent - conceptual, contextual and noncontextual questions. Fifth grade students and many of the seventh grade students had no formal instruction on percent; these students might be considered analogous to community college students returning to a mathematics classroom after being away from formal instruction for a significant amount of time. However, there is one significant difference in the results between the younger students and the adults - a much higher percentage of the younger students obtained a correct solution when using a formula (e.g., for the Percent Discount problem, computing $0.40 \cdot \$ 35$ ): from $75 \%$ of the fifth grade students to $96-100 \%$ of the seventh, ninth and eleventh grade students. Using a formula led to only $32 \%$ of the adult students' correct solution only $52 \%$ of the time, whereas a strategy like reasoning with benchmarks led to a correct solution $92 \%$ of the time.

Variety of strategies and understandings across students (interview data). The interview participants submitted their written work on the Percent Discount problem prior to the interview. The interview participants' written work revealed three strategies used to solve the Percent Discount problem: using a formula, reasoning with $10 \%$ and making a reasonable estimate. As I will describe in the section on the variety within each interview participant's strategies and ways of understanding, the snapshot of strategies captured in the interview participants' written work tells only a partial story. 
Prior to discussing the percent problems during the interview, participants were asked to describe their understanding of a $40 \%$ discount and an $18 \%$ tip. Participants' responses to the question, "What does an $18 \%$ tip mean to you?" are summarized in Table 19. The question about the $18 \%$ tip was selected to illustrate each participant's understanding of a percentage, because the interview participants had an understanding of $40 \%$ as almost $50 \%$ or half. For example, when asked, What does $40 \%$ off mean to you? Andrea replied, "Slightly less than half," and Lily replied, "It's almost half off." Table 18 highlights the variety of understandings of $18 \%$ that these students brought to their Basic Math course. For example, Ruby, Andrea and JR all used a nearby benchmark ( $20 \%$ or $25 \%$ ) to describe $18 \%$. Sasha, Jesse and Roo offered an 18-out-of100 perspective although each communicated this understanding in a different way. Jesse and Lily explained that they would compute a percentage using the formula $A=$ $R B$, although they did not reference this formula explicitly. 


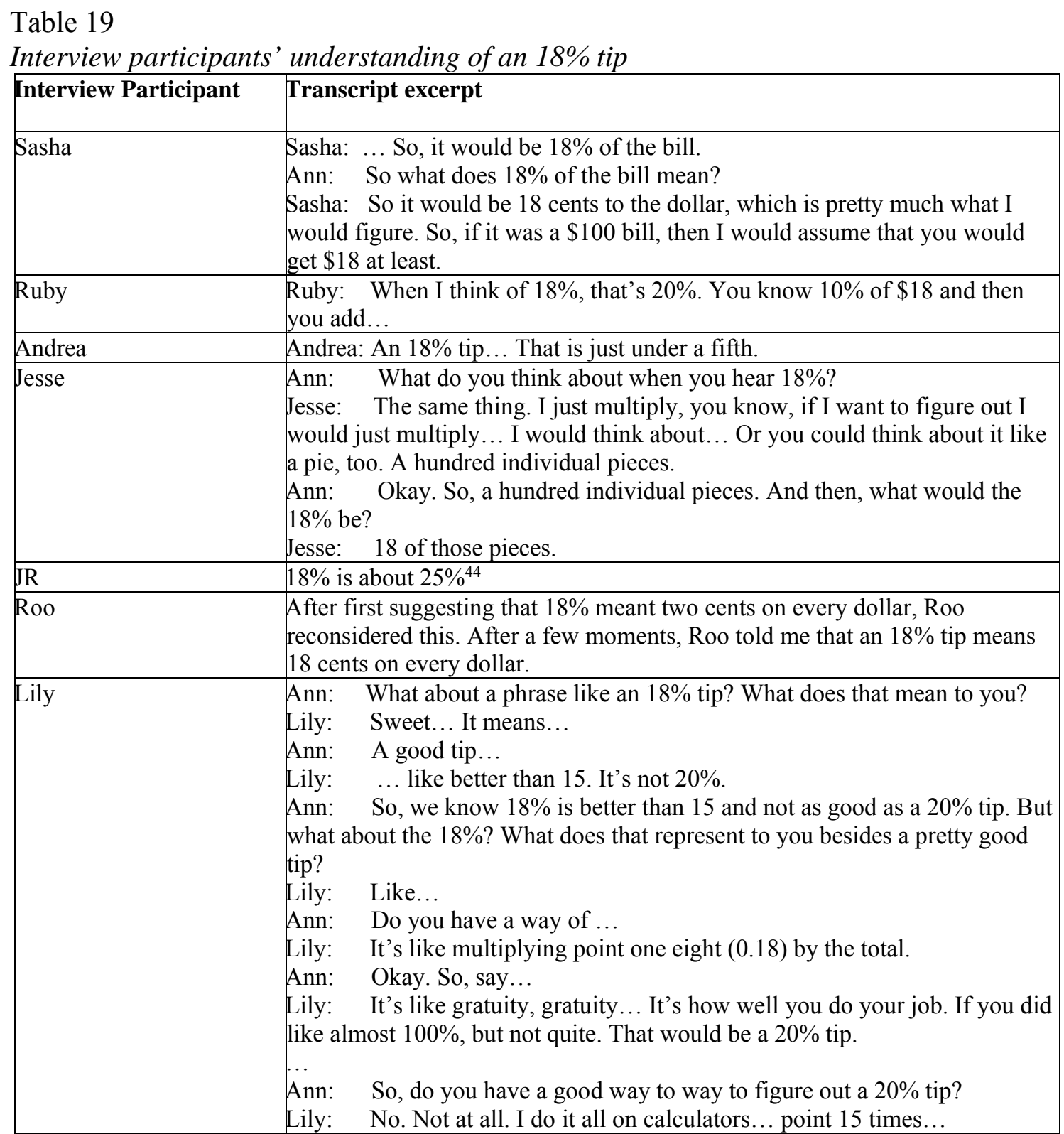

${ }^{44} \mathrm{JR}$ and Roo were interviewed on the same day and the video recording equipment stopped functioning during JR's interview and did not record Roo's interview. I had taken extensive notes and reconstructed as much of JR and Roo responses immediately after the interviews. The ways of thinking recorded in this table are what I recorded in my notes, not a transcript of what these participants said. 
Variety of strategies and understandings across students (classroom data). The data presented in the previous sections highlight the variety of strategies and understandings from the analysis of the survey and interview data, summarized in Tables 16 and 17. Field notes taken in Sasha's classroom ${ }^{45}$ provide evidence that in one particular classroom many of these strategies and understanding were present, such as reasoning with estimates, the benchmarks of $50 \%$ and $10 \%$ and an emerging understanding of percent as a rate exemplified by statements such as a $40 \%$ discount means 40 cents off each dollar.

The topic of percent was introduced the second half of class during the seventh week of a ten-week quarter and continued into the eighth week. (This section of Basic Math met one day per week for four hours). At this point in the term the students were accustomed to sharing ideas and asking questions. Perhaps due to their comfort level with each other and the instructor, Ms. Rose ${ }^{46}$, as well as their familiarity with percent from everyday life, the students shared many of their own ways of thinking and understandings about percent.

Ms. Rose introduced the topic of percent by telling her students that she would be teaching them mental arithmetic strategies for computing percentages. She shared that the strategy was the one she developed as an adult, since as a student she never made sense of the strategies for solving percent problems presented in school. Ms. Rose illustrated her mental computation strategy by creating a table, illustrated in Figure 22.

\footnotetext{
${ }^{45}$ Sasha's classroom was selected by convenience. Each interview participant was asked whether or not they were willing to participate in the third part of the study and all participants were willing, but participation in the third part of the study also required that the Basic Math instructor agreed to participate. Sasha's Basic Math instructor agreed to participate, as did JR and Roo's instructor.

${ }^{46}$ Sasha's Basic Math class was taught by Ms. Rose, a teacher new to community college mathematics teaching, but with nine years experience teaching middle and high school mathematics.
} 


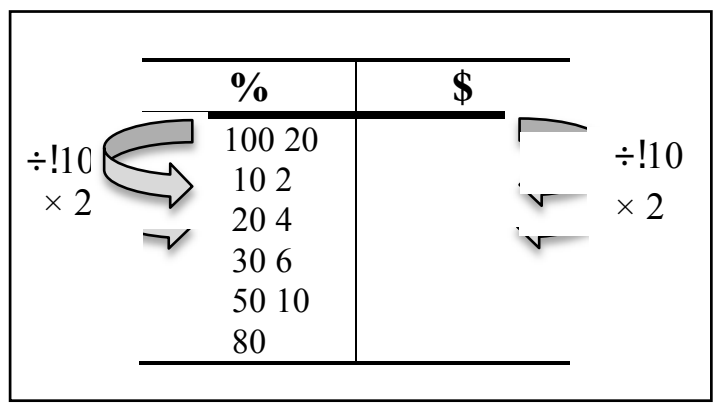

Figure 22. Ms. Rose's first percentage table

Ms. Rose started by labeling the columns and pointing out that they would let $100 \%$ represent \$20 in this first example. Ms. Rose wrote 10\% below the $100 \%$ and asked the class, "What is the relationship between 100 and 10?" She annotated this relationship on the left side of the table with $\div \mathbf{1 0}$ on the left and then annotated the right side of the table in a similar way to compute $10 \%$ of $\$ 20$. Ms. Rose observed that $20 \%$ is two times $10 \%$ and used this way of thinking to record dollar amounts for $20 \%, 30 \%$ and $50 \%$.

As I describe in the next chapter, opportunities to reason proportionally in Sasha's Basic Math class were often serendipitous, since the curriculum materials used in the course did not highlight proportional reasoning. This example provided an opportunity to reason multiplicatively about percent, yet several students struggled with Ms. Rose's strategy, including Sasha. As Ms. Rose worked with the table, a student asked, "How would we use the table to find something like $59 \%$ ?" but this was a question that was unheard.

Ms. Rose also used her table additively, observing that it is possible to compute $50 \%$ by adding $20 \%$ to $30 \%$, or, $\$ 4$ to $\$ 6$. It was at this point a student shared her own way of thinking about percent, using the benchmarks of $50 \%$ and $10 \%$ to figure out 
$40 \% .{ }^{47} \mathrm{Ms}$. Rose celebrated this way of thinking by telling the class, "You guys already have a sense of percents!"

As Ms. Rose worked through examples and presented material from the textbook, students continued to share their ways of thinking. When Ms. Rose asked, “How do you compute 20\%?" one of Sasha's classmates, Mercedes, offered the understanding that $20 \%$ means 20 cents out of every dollar, an understanding similar to Sasha's money perspective on percent. Ms. Rose acknowledged Mercedes' way of thinking and later used it to interpret $0.4 \%$ as four-tenths of a cent to every dollar. During the next class meeting, Ms. Rose returned to the mental computation strategy to illustrate finding percentages of $\$ 36$. When the class determined that $1 \%$ of $\$ 36$ is $\$ 0.36$, Sasha says, "36 cents per dollar" and Ms. Rose recalled Mercedes' similar contribution the prior week. This emerging understanding of a percentage as rate was made public several times during the two lessons on percent.

Students contributed two different understandings of percentage greater than $100 \%$ (an understanding not explored using the surveys or in the interviews). The first understanding is that a percentage over $100 \%$ is a way to compare two quantities multiplicatively. After the class completed an example that yielded $275 \%$ (write $44 / 16$ as a percent) Mateo shared quietly that $275 \%$ is "more than double." Later, as they considered an example that required writing 5 as a percent, Ms. Rose asked, "Why is it $500 \%$ ?" and Mateo replied, "Because it is five wholes." He then explained to the class that the students in his reading class have been discussing the nutritional information on food labels. Mateo shared that when a beverage lists $200 \%$ of the RDA for a particular

\footnotetext{
${ }^{47}$ I indicated in my field notes that the student shared the $50 \%$ and $10 \%$ strategy, but she may have explained how she figured a percentage other than $40 \%$ using benchmarks additively.
} 
nutrient, this is twice the recommended daily allowance. Another understanding that emerged is that a percentage over $100 \%$ adds something onto $100 \%$. This understanding first came up when Ms. Rose used the context of converting a test score into a percentage. The particular test had 20 problems and one bonus problem, and was worth 40 points. Ms. Rose wrote on the board,

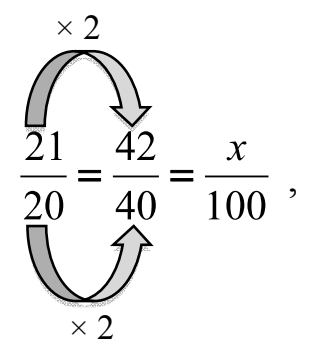

highlighting that 40 is twice 20 , but not using the fact that 100 is $2 \frac{1}{2}$ times 40 or that 100 is five times 20 to reason to a solution. After determining that the maximum percentage is $105 \%$ algebraically, one women shared, "When I do it in my head, I would do it differently," explaining that she would work with the 20 and the one separately, adding $5 \%$ onto $100 \%$. This idea emerged again during the next class meeting. While working on a problem that involved the quantity $162 \%$ of 142,000 , Carl asked, "Couldn't you find $62 \%$ of 142,000 and add that to 142,000 ?" Ms. Rose then used Carl's strategy to solve the problem. Later, when working on a problem involving sales tax, Ms. Rose highlights that there are two ways to solve the problem: (1) determine $8.25 \%$ of the cost of the item and add that amount to the cost, or (2) determine $108.25 \%$ of the cost of the item.

Finally, one women's way of thinking in Sasha's classroom highlighted the difference between operating with a percent as a ratio and understanding a percent as representing a part-whole relationship. A problem posed in the textbook was "Change 
$60.5 \%$ to a fraction." Stacy explained her strategy. Since she needed a whole number in the numerator and $0.5+0.5$ is a whole number, she computed $\frac{60.5}{100}+\frac{60.5}{100}=\frac{121}{200}$.

Although the notation is unconventional, it is true adding 60.5 out of 100 to 60.5 out of 100 is 121 out of 200 . This is perhaps an incidental understanding, but an understanding that highlights the difference between two interpretations of percent (Parker \& Leinhardt, 1995).

Summary. Reasoning with benchmarks and the emerging understanding of a percentage as a rate were ideas shared by students in Sasha's classroom. Ms. Rose introduced a building up/partitioning strategy for computing percent. Ways of thinking that were evident in the survey and interview data and not visible in Sasha's classroom were reasoning with estimates and using the formula $A=R B^{48}$. At one point, Ms. Rose introduces the 'formula strategy' from the textbook and worked one example using the formula, but a student declared, "I don't like that way" and this strategy was not used again by Ms. Rose. No student shared an estimation strategy for solving any of the problems involving percent, which is surprising due of the prevalence of this strategy in the survey and interview data, but perhaps not so surprising due to the expectation for exact answers in the mathematics classroom.

\footnotetext{
${ }^{48}$ It is possible that this way of thinking was not recorded in the field notes, since my focus was on alternate ways of thinking about percent.
} 


\section{Variety of strategies and understandings within a student's repertoire. An}

analysis of the interview data using the framework adapted by Lembke and Reys, revealed not only variety across students, but also that each participant could think about percent in a variety of ways. Table 19 indicates the strategies used by the seven interview participants on the Percent Discount problem and ways of understanding percent that emerged during the interviews. The entries in bold indicate the strategy used by each participant on his or her written work. In addition, each student described at least two ways of thinking about problems involving percent during the interview. In several instances, the strategy a participant described to compute a percent discount during the interview was not the strategy they used in their written work. For example, all students except $\mathrm{JR}^{49}$ described working with estimates while shopping, but on their written work on the Percent Discount problem only Lily and Sasha presented an estimate. Also, the strategy Ruby used on her written work was not the strategy she uses while shopping. Lily knew how to compute an $18 \%$ tip or a $40 \%$ discount exactly, but she either worked with estimates or used a rule of thumb in her everyday life. Andrea had the most flexible way of thinking about percent; she reasoned with $10 \%$ as a benchmark, used fractions to represent $20 \%$ and $80 \%$, reported using an estimation strategy for many of her everyday activities, had an informal understanding of percent as rate, and when reminded of the strategy for computing a percentage using a formula, she readily identified this as an efficient strategy that she had once learned in school. Next each participant's unique way of reasoning about percent to highlight both the

\footnotetext{
${ }^{49} \mathrm{JR}$ was able to estimate, but reported he did not do so while shopping.
} 
proportional reasoning these students brought to their Basic Math class and to illustrate each student's flexible ways of reasoning about percent.

Table 20

The variety of interview participants' strategies and understandings of percent

\begin{tabular}{|c|c|c|c|c|c|c|c|}
\hline $\begin{array}{c}\text { No } \\
\text { reasoning } \\
\text { supplied }\end{array}$ & $\begin{array}{c}\text { Compute } \\
\text { and check }\end{array}$ & $\begin{array}{l}\text { Using a } \\
\text { formula }\end{array}$ & $\begin{array}{l}\text { Reasoning } \\
\text { with an } \\
\text { equivalent } \\
\text { fraction }\end{array}$ & $\begin{array}{c}\text { Reasoning } \\
\text { with } 50 \% \\
\text { and } 10 \%\end{array}$ & $\begin{array}{c}\text { Making a } \\
\text { reasonable } \\
\text { estimate }\end{array}$ & $\begin{array}{l}\text { Reasoning } \\
\text { with } 10 \%\end{array}$ & \begin{tabular}{|c|}
$\begin{array}{c}\text { Emerging } \\
\text { understanding } \\
\text { of percent as } \\
\text { rate }\end{array}$ \\
\end{tabular} \\
\hline Roo & Roo & $\begin{array}{c}\text { JR } \\
\text { Ruby } \\
\text { (Incorrect) } \\
\text { Jesse } \\
\text { (Incorrect) } \\
\text { Andrea } \\
\text { Lily }\end{array}$ & $\begin{array}{c}\text { Jesse (only } \\
1 / 2) \\
\text { Andrea }\end{array}$ & $\begin{array}{l}\text { Ruby } \\
\text { Sasha }\end{array}$ & $\begin{array}{c}\text { Lily } \\
\text { Sasha } \\
\text { Roo } \\
\text { Ruby } \\
\text { Jesse } \\
\text { Andrea } \\
\text { JR }\end{array}$ & Andrea & $\begin{array}{l}\text { Roo } \\
\text { Ruby } \\
\text { Sasha } \\
\text { Andrea }\end{array}$ \\
\hline
\end{tabular}

Ruby. In her written work on the survey, Ruby computed $0.40 \times \$ 35$ and concluded the jeans cost $\$ 14$ on sale. However, during the interview and prior to reviewing her written work, Ruby reasoned with the benchmarks of $50 \%$ and $10 \%$ to solve the percent discount problem to arrive at a reasonable solution:

Ruby: I always go straight to $50 \%$. I know that $50 \%$ off is ha lf of 35 . So, then I usually say that if it is $40 \%$ off a nd it's $\$ 35$, then half of $\$ 35$ is $\$ 17.50$. So, then I say, so that's at $50 \%$ so I got to add a couple m ore dollars on there because of the $10 \%$. So, I know $10 \%$ of the $\$ 35$ is like, I think, $\$ 3.50$. So, I just add that to the $\$ 17$ and come up with $\$ 20$.

Ann: That's interesting, because that is not how you did it on the survey. So, it's a different strategy that you just used there.

Ruby: Well, that's probably what I th ink out loud, but if I a m writing it down I have to break it down [Ruby, 20 December 2011]. 
Although Ruby rounded and ended up with an estimate, adding the $10 \%$, $\$ 3.50$, to the $50 \%, \$ 17.50$, would result in the exact solution to the problem. When asked why she wrote something different on the survey than the way she would solve the problem in a store, Ruby responded. "I think that I started it one day and finished it... But if I look back at it, I would ask myself the same thing, 'Why did I do that?"” Reasoning with benchmarks was a computation Ruby did in her head, but not the strategy she recorded as a solution to a problem.

Reasoning with benchmarks appeared to be Ruby's go-to strategy, but it was also a strategy that grounded her reasoning within the particular context of the problem. While reasoning about the Ticket Sales problem, which required computing last year's ticket sales given that sales decreased $40 \%$ and this year's sales were 1200 tickets, Ruby first considered the case of a 50\% discount, and she was appropriately confused by how to work with $10 \%$ :

Ruby: Does that mean they normally have 2400 season tickets? 'Cause it decreased by $40 \%$ last time [pauses]. So $50 \%$ times 2400 [pauses]. So $10 \%$ would be $1.2,120$. [She writes 2400 and 1200 underneath.] So, now I need to use a calculator.

Ann: So, first of all, it seems you figured out what it would be if it was a $50 \%$ decrease.

Ruby: And then the $10 \%$ off the 2400 , which would be the season ticket. That's where I am stuck at. I know that $10 \%$ of 2400 should be... that's where I am stuck at. [Ruby picks up the calculator and seems puzzled by what's she gets.] I keep coming up with the same thing. 
Ann: So, what's making you think...

Ruby: 'Cause it's half. $50 \%$ of $1200 \ldots$ I mean $2400 \ldots$ If you go half, and half was 1200 this year. So, $50 \%$ would be half. But it says $40 \%$. So, $40 \%$ of 1200 is not 2400. That's half. So, I am trying to figure out why I did something not right. [Ruby tries to decide between using the pencil or using the calculator. She uses the calculator to compute $40 \%$ of 1200 .] Point 40 times 1200. 480... That's better. So [writing 480 under 1200 and adding].

Ann: So, what did you do there?

Ruby: Just do the 40\% times the 1200. [Laughs] [Ruby, 20 December 2011].

It is striking that Ruby started by trying to make sense of the problem. She attempted the benchmark strategy she used on the Percent Discount problem and made a reasonable claim about what last year's sales would be if they decreased by $50 \%$. But Ruby discovered that determining the $10 \%$ was problematic. When unable to resolve this problem, she did what other interview participants did and computed $40 \%$ of 1200 and added that on to the 1200 tickets. Ruby had access to the formula for computing a percentage; in this case, she was unable to reason to a solution and she used the formula to draw an incorrect conclusion, similar to what her written work on the Percent Discount problem indicated. Ruby had more then one way to approach the problem, but only one of these ways was grounded in meaning.

Sasha. On the survey Sasha estimated that the jeans were about $\$ 20$, but did not provide her reasoning. During the interview she described a strategy similar to the 
strategy that Ruby used, but unlike Ruby, Sasha did not have a quick way to determine $10 \%$ exactly:

Sasha: So, what I do is... this is w hat I do. When I'm at the store, for exam ple, and I have this situation. I would go $50 \%$ off. So if it was half of 35 , I would be looking at... so if it was 40 , it would be 20 . So, it would be like $\$ 22.50$, if it was half off. So, that tells m e already... No, wait, that's wrong. If it was half off, it would be... 30 would be $15.2 \ldots 16,17$, 17.50. So it would be $\$ 17.50$, if it was half off. So, that's under $\$ 20$. So, then I would still have to put into consideration that it is not half off.

Ann: Okay, so half off would be $\$ 17.50$. It 's not half off. So, then what do you do?

Sasha: So, then I would estim ate higher. They would cost more, so I would add about \$3. Why? I don’t know. I just do.

Ann: Okay.

Sasha: So, $17,18,19,20 \ldots$ So it's still $\$ 20.50$. So, it wouldn't be less than $\$ 20$ for the pair of jeans [Sasha, 22 December 2011].

This excerpt provides an example of a computational strategy used by Sasha frequently during the interview; halving even numbers rather than odd numbers and reasoning from there. However, from her experience working with money, Sasha knew that half of $\$ 5$ is $\$ 2.50^{50}$ and she used this understanding to determine the $50 \%$ discount. Sasha did not have a procedure for determining $10 \%$. For example, while considering a strategy using

\footnotetext{
${ }^{50}$ When asked, "So, where did that $\$ 2.50$ come from?" Sasha quickly replied, "Half the five."
} 
$10 \%$ as a benchmark, Sasha said, "So, I am thinking that it sounds right, but I couldn't honestly tell you how they figured $\$ 3.50$ came from the $10 \%$." Here she used an estimate of $\$ 3$ for $10 \%$ to add back onto the $50 \%$ discounted price ${ }^{51}$.

Later in the interview, Sasha considered the strategy of using a formula to determine the discount on the jeans, but reported that this was a strategy she did not use. However, she did share that this was the strategy her oldest daughter used when they were shopping: "She does this exactly. She times that and then she subtracts the dollar amount." It was a strategy that never made sense to Sasha, but by the time of the interview she was starting to make sense of this method:

Sasha: I am always like, “What?" So I don’t use that method, 'cause it doesn't... It seem s too com plicated. Though I have started to realiz e, like the last month or so, I am starting to understand where they're doing that. The 35, like this, so they're tim esing thei $r$ am ount... On the calculator, for example, they just put the point fo ur oh. That's where it always caught me. Why did they put a point? I don't understand why you put the point.

Ann: Well, you told me that $40 \%$ meant 40 cents...

Sasha: ... to the dollar. So it makes sense to me now, but then it didn't. I didn't understand why they put that point th ere. But it would count as a cent method. So, now it $\mathrm{m}$ akes more sense to $\mathrm{m} e$, but I don't use it because I am still not comfortable enough to be like, "Oh..." [Ann assents] And I don't often carry a calculator on me to do it, so I do it the other way [Sasha, 22 December 2011].

\footnotetext{
${ }^{51}$ Similarly, Sasha used an estimate of 300 for $10 \%$ of 2400 while solving the Ticket Sales problem, but was unable to explain how she made this choice.
} 
Unlike other participants who used this strategy without fully understanding it, Sasha would not use a strategy that did not make sense to her. However, as she talked about computing a percentage using her daughter's strategy, Sasha started making sense of this 'cent method,' but reported she would not use this method because she did not use calculator when she shopped.$^{52}$ Sasha was - at the time of the interview - one of the least flexible thinkers in terms of reasoning with percent, but perhaps because she was committed to meaningful ways of computing.

Andrea. On her written work, Andrea reasoned with $10 \%$ to solve the Percent Discount problem, multiplying $10 \%$ of $\$ 35$ by 4 to determine the $\$ 14$ discount. She reported that this is a strategy she frequently used. For example, she would estimate $18 \%$ using two times $10 \%$. She recognized $10 \%$ as one-tenth, $20 \%$ as one-fifth, and rather than using three times $10 \%$ to compute $30 \%$, she estimated $30 \%$ by one-third. As she described these fractional equivalents (or estimates), Andrea realized that $40 \%$ is also two-fifths and that she could have reasoned this way to solve the Percent Discount problem. (Later, when interpreting the value 0.80 in the context of the Comparing Speeds problem ${ }^{53}$, she interpreted this value both as $80 \%$ and four-fifths.) Andrea's response to the work of the student who used the formula $A=R B$ was quite different from Sasha's response:

\footnotetext{
${ }^{52}$ Over the course of the term Sasha and I discussed the formula method and her emerging understanding of the 'cent' method. Eventually she was able to articulate that 35 was multiplied by 0.40 because the 0.40 represented 40 cents off each dollar and each of the 35 dollars needed to be taken into account when computing the percent discount. Unfortunately, this was not an understanding Sasha was able to contribute in class because her teacher, Ms. Rose, only used the proportion equation method for solving percentage problems.

${ }^{53}$ Victor's van travels at a rate of 8 miles every 10 minutes. Sharon's sedan travels at a rate of 20 miles every 25 minutes. If both cars start at the same time, will Sharon's sedan reach point A, 8 miles away, before, at the same time, or after Victor's van?
} 
Andrea: That $\mathrm{m}$ akes sense, $\mathrm{b}$ ecause when $\mathrm{y}$ ou're $\mathrm{b}$ reaking som ething down to a percentage and you' re dividing it. You get a decimal. And the first one is tenths, so point four oh (.40) times 35 is 14. Essentially, just utilizing 40\% directly instead of breaking it down.

Ann: $\quad$ Okay, so why multiply the 35 by the point four oh $(0.40)$ ?

Andrea: Um, 40 cents per dollar.

Ann: $\quad$ Okay, 40 cents per dollar, and then you are $m$ ultiplying it by $35 \ldots$

Andrea: Yeah. Which is $14 \ldots$

Ann: Okay. Okay. I don't want to put words...

Andrea: Which is a lot more simple than what I did!

Ann: $\quad$ Why do you say it is simpler?

Andrea: I just... it's a bit more straightforward, whereas I first divid ed 35 by 10 and then... [Andrea, 4 January 2012].

It is not clear from this excerpt whether Andrea could articulate, "Why multiply?" and I was careful - perhaps too much so - to not push too far, because I did not want to lead Andrea to an understanding when I was interested in her current understanding. However, Andrea immediately latched onto this strategy as a more efficient strategy and it is the strategy she chose on another problem involving percent. Andrea recognized this as a strategy she had used in school but had forgotten. Yet she had developed an effective strategy for reasoning about percent in her everyday life that had been serving her well. 
Lily. Lily used estimates and rules of thumb when reasoning about percent in her everyday life even though she had access to a computational strategy (see Table 19). When describing how she thought about the Percent Discount problem, Lily described a strategy based upon figuring a $50 \%$ discount on a $\$ 40$ pair of jeans:

So, I know that $20 \ldots$ two times 20 is going to be $\$ 40$. So, these numbers are kinda close. And then, almost half off $\$ 40$ is 20 bucks. So I assumed since it is less than 40,35 is less than 40 , that it is going to be less that $\$ 20$. 'Cause ... like the percentage is less. Like 40 is less than $50 \ldots$ Yes, but 35 is less than 40 . And half of 40 is 20 . So it is all less. So it should equal out [Lily, 21 December 2011]. Lily was certain that the jeans would cost about $\$ 20$, a reasonable estimate although her reasoning about percent was flawed; she expected the sale price with a $40 \%$ discount to be less than a $50 \%$ discount since $40 \%$ is less than $50 \%$. As we discussed her estimate, Lily indicated that she could find the exact price using the computation that was "super familiar," but she was not at all concerned about precision in this context: "It would be much more a problem for me to do all the math than it would be like, 'Hey, does somebody have a dollar? I need to catch the bus." Lily used a rule of thumb when describing how she determined whether or not she received a good tip from a customer. The excerpt included in Table 18 indicates that Lily believed 20\% to be a good tip, but her rules of thumb underestimate that amount:

Ann: What would you expect on a $\$ 20$ tab?

Lily: A dollar or two. But more than that is cool.

Ann: Okay. That is kinda what I was getting at... $\mathrm{H}$ ow do you gauge what a good tip... 
Lily: And, I don't know, on a $\$ 50$ tab, like 10 bucks would be cool. Like five or 10 bucks... Som ewhere in between th ere is a nor mal gratuitous range [Lily, 21 December 2011].

In the previous chapter, I described Lily as a returning student who previously found school mathematics to be irrelevant. She also distinguished the rough estimates she made in her everyday life from the exact answers expected in school. Although Lily had access to a computational strategy that would lead to an exact result, she felt no need to use it for the Percent Discount problem.

$J R$, Roo and Jesse. JR, Roo and Jesse all expressed their preference for using a formula to compute a percent. JR and Roo are partners; both expressed they wanted exact values when shopping since they lived on a tight budget. Roo admitted to using a compute-and-check strategy on the Percent Discount problem because she could bot recall whether to multiply or divide $\$ 35$ by 0.40 . However, both JR and Roo were able to estimate a percentage. As described in Chapter 4, Jesse tended to look for the formula that could be used to solve a given problem; he was comfortable computing percentage using one formula that was familiar to him. When pressed, Jesse did reveal he used benchmarks to estimate and - like others - had an emerging understanding of percent as rate, but during the interview he was unwilling to draw upon this repertoire of strategies and understanding when reasoning about problems involving percent.

Emerging understanding of percent as rate. Two formulas that students typically encounter in developmental mathematics classes are $A=R B$ and $d=r t$. The literal symbol $R$ (or $r$ ) stands for 'rate,' as in the statement, "distance equals rate times time." The understanding of percentage as rate or speed as a rate is central to developing 
a functional perspective on proportional situations in which one quantity varies directly with a second quantity. However, as Thompson's work revealed (1994) understanding speed and developing an understanding of speed as a rate is a complex process; simply dividing the distance traveled by the duration of a trip does not support the conceptual development of the concept of speed or rate. The previous discussion about students' use of a unit rate strategy supported Thompson's finding that being told to divide does not support the development of the concept of rate, since this strategy assumes students have already "conceived of motion as involving two distinct quantities - distance and time" (p. 224). In addition, in a later discussion I highlight some of the challenges that students had with the Comparing Speed problems.

In familiar contexts such as computing a $40 \%$ discount or an $18 \%$ tip, four of the participants - Roo, Ruby, Sasha, Andrea - revealed an emerging understanding of percent as rate. Jesse and JR also had an out-of-100 perspective on percent, but this understanding was not as contextual as the understanding the four women offered. Sasha reported that a $40 \%$ discount means that one is saving $\$ 0.40$ on the dollar and an $18 \%$ tip means an $\$ 18$ gratuity on a $\$ 100$ bill. Andrea recognized immediately that the 0.40 in the computation $0.40 \times \$ 35$ that 0.40 represents 40 cents per dollar. Roo also offered that a $40 \%$ discount meant 40 cents off a dollar, but when asked about $18 \%$ she did not initially explain that this means 18 cents to the dollar although this understanding eventually emerged. When Ruby was asked how she knew $\$ 3.50$ is $10 \%$ of $\$ 35$, she replied: Well, everything is like... If you go to th e store and they always say $10 \% \ldots$ So, $10 \%$ is just something that has been embedded. Knowing that $10 \%$ of som ething is just a dollar or som ething... If you say $10 \%$ of a dollar, you know that is only 
10 cents. $10 \%$ is just so common that it is alm ost like... [Ruby, 20 Decem ber 2011].

Ruby's emerging understanding was perhaps the most fragile. While discussing the computation $0.40 \times \$ 35$ Ruby referred to 0.40 as 40 cents, suggesting that she had an understanding that, if pursued in a teaching situation, might be related to the idea of 40 cents off each dollar. However, Ruby reported that her use of 0.40 is computational:

Ruby: $\$ 35$ and then 40 cents. So, I times it and said that's $\$ 14$. But what I didn’t write down, in my mind, is that I al ready figured the half, and then went backwards. So, by this point I was pr obably getting burned out. I just did the 35 times the 40 to come up with the $\$ 14$. And then...

Ann: How did you know to do the 35 times to point 40 ?

Ruby: Point $40 \ldots$ The $40 \%$... 'Cause th e calculator... I don' t know how to do $40 \%$. I just do point 40 . Because I don't know how to do pe rcents, so... I know how on a computer, how to do it... [Ruby, 20 December 2011]. Although Ruby was able to reason to a solution of the Percent Discount problem using benchmarks, she did not understand why she multiplied by 0.40 and claimed she did not know how to "do percents." Ruby was familiar with the formula, but unable to explain how it worked. As reported earlier, Sasha was unwilling to use a computational strategy that she did not understand and Lily was unwilling to use a strategy she had no need for. Jesse, JR and Roo reported they use this particular computational strategy in their daily lives, but were unable to explain how the computation yielded the result they wanted. And, as evident in the excerpt from Ruby's interview and Sasha unwillingness to use a procedure she did not understand, using this computational strategy was not meaningful 
to these students. However, both Andrea and Sasha, with their emerging understanding of a percentage as rate in this context, appeared to be close to explaining "Why multiply?". I chose not to push Andrea when she described her understanding of this computational strategy, because I did not want to interfere with the knowledge she brought to the interview. However, I did have the opportunity to continue my discussion with Sasha about her understanding of the cents method she was beginning to understand at the time of the interview; the understanding that $\$ 35$ was multiplied by 0.40 dollars of each dollar because the discount on each 35 dollars is needed did not emerge until many weeks later.

This emerging understanding of percentage as rate could serve as the link between students' informal ways of reasoning about percent and understanding the formula that many - perhaps all of them - will encounter in their developmental mathematics courses, $A=R B$.

Discussion. Lembke and Reys (1994) report the percentage of correct responses for each of four grade levels: $5^{\text {th }}, 7^{\text {th }}, 9^{\text {th }}$ and $11^{\text {th }}$ and for students in the upper and middle quintile for their grade level (based on a standard assessment). Although Lembke and Reys' study queried students' strategies on a variety of percent problems, a few comparisons can be made. Of the students who attempted the Percent Discount problem $(n=259), 42 \%$ obtained an accurate answer. However, if estimates around $\$ 20$ are included, $63 \%$ of the students obtained a reasonable response. These numbers are similar to the percentage of correct responses of the $7^{\text {th }}$ grade students in Lembke and Reys study, $44 \%$ without reasonable estimates and $63 \%$ with these estimates included. However, these percentages are considerably lower than the percentage of correct 
(reasonable) solutions for $9^{\text {th }}$ and $11^{\text {th }}$ grade students, $87 \%(93 \%)$ and $90 \%(94 \%)$ respectively. As mentioned previously, a higher percentage of the students in Lembke and Reys study obtained a correct solution using a formula: from $75 \%$ of the fifth grade students to $96-100 \%$ of the seventh, ninth and eleventh grade students. However, using a formula led to only $32 \%$ of the adult students' correct solution $52 \%$ of the time, whereas a strategy like reasoning with benchmarks - used infrequently - led to a correct solution $92 \%$ of the time.

In another study of school age students (Dole et al., 1997), $8^{\text {th }}, 9^{\text {th }}$ and $10^{\text {th }}$ grade students were interviewed about their strategies for solving a variety percent problems. Based on the interview participants' work on a survey administered prior to the interviews, participants were categorized as proficient, semi-proficient or non-proficient. In this study, it was the proficient students who reasoned flexibly with benchmarks, and were more able to use a variety of strategies than non-proficient students. Although the participants in this study (surveyed students, interview participants and members of Sasha's classroom community) were not proficient with percent problems, they demonstrated flexible ways of thinking about percent that might be a stepping-stone to proficiency. In addition, Dole and her colleagues found that non-proficient students did not check the reasonableness of their answers, not a finding from the interview data. In fact, adult students typically discussed the reasonableness of their solutions.

One study of adults' understanding of percent involved adult learners with between six and12 years of formal schooling (Ginsburg, Gal, \& Schuh, 1995). About 70 students were interviewed using a small number of tasks. Adults were able to describe the meaning of the benchmarks $25 \%$ and $50 \%$ when presented in the context of 
shopping, however they were not as familiar with visual representations of $50 \%$ and $25 \%$. One of the tasks asked participants to find $25 \%$ of $\$ 80$, a problem similar in structure to the Percent Discount problem. One difference between the data collected by Ginsburg and her colleagues and the data presented in this study is the low percentage of students who used a formula: $3 \%$ of the participants used a formula to obtain an accurate result and $5 \%$ of the participants used a poorly recalled procedure to obtain an inaccurate response. In addition to using a formula, halving $\$ 80$ twice was used accurately by $31 \%$ of the participants, converting $25 \%$ to a fraction and dividing $\$ 80$ by four was used accurately by $20 \%$ of the participants, and an informal understanding of percent as rate ( $\$ 0.25$ to $\$ 1)$ was used accurately by one participant.

Finally, it was striking how few students in this study solved a proportion equation to solve a percent problem. In Sasha's classroom, Ms. Rose relied exclusively on this method to solve percent problems. The other technique for solving percent problems presented in the Basic Math curriculum materials, working with a formula, was the only technique used to solve percent problems in JR and Roo's Basic Math class. Although many of the surveyed students and the interview participants used this strategy, it did not lead to an accurate solution as often as some of the more informal ways of reasoning students used.

\section{Summary and discussion}

Summary of findings. The findings described in this chapter address the second research question, "What proportional reasoning abilities do students placing into Basic Math demonstrate prior to returning to school mathematics?" The survey and interview data were the two primary sources of data discussed in this chapter. Each data source 
served a different purpose. The survey data was used to describe the frequency of a particular proportional reasoning strategies on a given problem. These data led to several conjectures that were explored in the interviews. The interview data - although not able to prove or disprove conjectures from the survey data - did provide a more nuanced perspective on adult students' strategies for reasoning about ratio, rates and proportions. In addition, some survey data led to findings that could be compared with research literature on the proportional reasoning abilities of middle-school-age children, and the interview data provided the opportunity to interrogate whether or not adult students' proportional reasoning was similar to or different from the proportional reasoning of younger students.

The primary finding discussed in this chapter is that adults' ways of thinking about ratio, rates and proportion can be described using a framework developed from research on younger students' proportional reasoning. In response to the question, "What proportional reasoning abilities do students placing into Basic Math demonstrate prior to returning to school mathematic?", we discovered that adult students rely on strategies such as iterating, building up or partitioning a composed unit. The interview data also reveals that adult students bring their everyday experience of mathematics to bear when reasoning about problems. Both of these findings might be leveraged to inform the development of curriculum that is aligned with the ways of thinking about proportional situations that adult students bring to the classroom. For example, from a mathematical perspective, building-up and partitioning strategies, which were evident in both the survey and interview data, highlight the significance of a composed unit to proportional reasoning, as well as the ability to extend the same relationship to other pairs of 
quantities" (Lamon, 2007, p. 638). Students' struggles invoking unit-rate strategies suggest that more attention might be focused on the multiplicative relationship between the two quantities in the composed unit. JR and Roo both recognized that if 18 stems cost $\$ 15$, the six stems cost $\$ 5$, but making explicit that the cost of a given number of stems is $\frac{15}{18}$ times the number of stems (see Figure 23) is essential for developing a functional interpretation of a proportion, but also uncovers the unit cost.

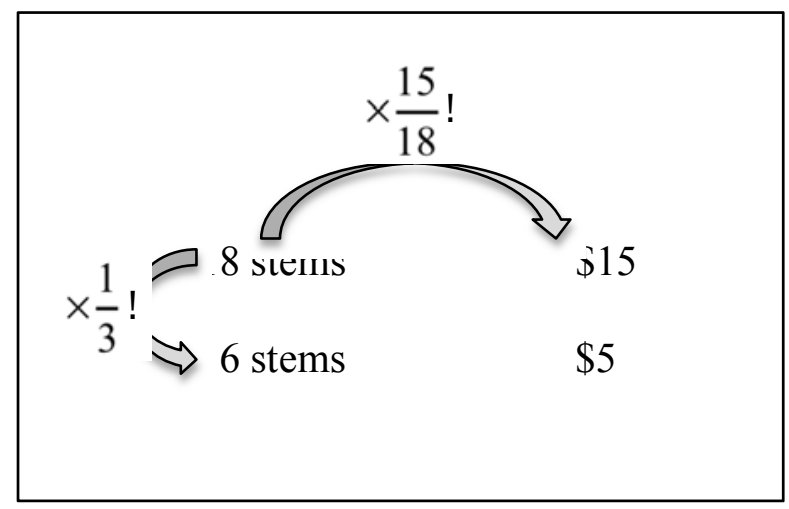

Figure 23. Two types of multiplicative relationships between quantities in a proportion

The understanding of unit rate is implicit in any statement of direct variation: $y=k x$. Although students in Basic Math are not representing direct variation symbolically, they are familiar with the formula $A=R B$. The informal understanding of percent as rate that was observed in the survey data, the interview data and in the field note data suggests that some adult students are bringing to the classroom the understanding that a $40 \%$ discount means 40 cents of each dollar or $\$ 4$ off every $\$ 10$. As with the unit cost example, these ways of thinking might be made explicit in a way similar to making the unit cost explicit in the Flower Stem problems: 


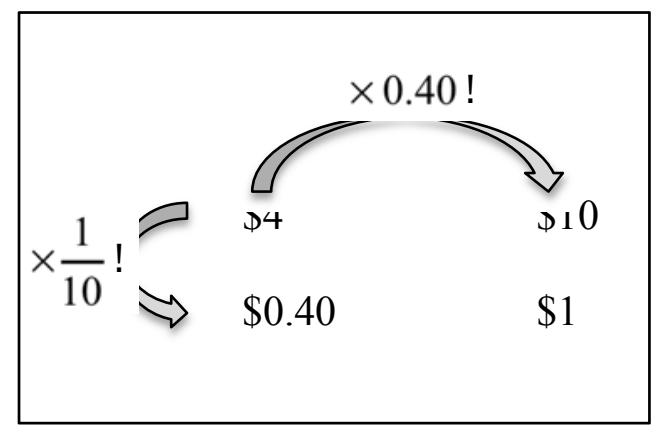

Figure 24. Unpacking the formula $A=R B$ by building on students' understanding

Students' work on the Bread Flour problem suggests that students are able to reason about joint variation in particular contexts. During the interviews, the participants recognized the difference between varying one of the two quantities (duration of stay or number of people) and varying both quantities. The interview participants were not asked how much flour would be needed of both the duration of stay and the number of people were doubled, but it is reasonable to assume that Basic Math students would be able to recognize that four times as much flour would be needed. Introducing joint variation in a context similar to the Bread Flour problem would make explicit the joint variation implicit in the familiar formula for the area of a rectangle. Research has shown that in this context students struggle with the effect of doubling, for example, the dimensions of the rectangle on the rectangle's area (e.g., De Bock et al., 1998). Exploring similar figures is a common application of proportions in many Basic Math classrooms, but students' ability to reason about joint variation in a particular context might be built upon to examine the affect of scaling up the dimensions of a figure on the figure's area. In fact, this topic is an explicit topic in some middle school curricula that build upon the research on how younger students learn (e.g., Lappan et al., 2006). 
The data from students' reasoning on percent problems reveal that students frequently use estimates and benchmarks when computing percentages outside school. On the other hand, findings from interview data discussed in Chapter 4 also revealed that students bring to our classrooms the belief that school math is about finding exact answers and that the mathematics in their everyday lives is somehow different that what is expected in school. Indeed, school mathematics is about developing efficient and accurate ways to solve problems and model relationships between quantities, but these efficient and accurate strategies might be built upon students' estimation strategies, number sense and the informal ways of reasoning of adult students.

Finally, the four-strategies framework was robust enough to capture the strategies and ways of thinking that adult students bring to bear on proportion problems. This framework was adapted from frameworks developed using research with younger students, but remains aligned to these previous frameworks. This particular finding suggests that studies of adult students' mathematical strategies and ways of thinking in domains other than proportional reasoning might be informed by previous research with younger students. However, adult students' experiences are more extensive than younger students and the finding that adult students' reasoning often remained grounded in the context of a posed problem suggests one significant difference between adult and younger students' proportional reasoning.

Implications for practice. The proportional reasoning abilities that adult students bring to Basic Math straddle the trajectory of ways of thinking about proportional relationships. In particular, data from Sasha's Basic Math class suggest that the variety of ways of thinking about percent that was evident in the survey and 
interview data were also present in Sasha's classroom. This is an exciting finding because it uncovers the potential for building on the variety of ways of thinking about proportional relationships that are likely present in a Basic Math classroom. Curricula that has been developed for younger students based on proportional reasoning research (e.g., Lappan et al., 2006) might be adapted for adult students. However, the practice of making public students' ways of thinking and using these ways of thinking to develop further mathematical understanding may not be in the repertoire of community college mathematics faculty (Grubb \& Worthen, 1999). The question, "What tools do faculty need to build on the mathematics and experience that students bring to the classroom?" is an important question for faculty members teaching developmental mathematics to address.

Implications for research. Understanding the role of context in adult students' reasoning about proportional situations is an important area of further inquiry, particularly if we want to move forward with the research agenda in community college mathematics education (Mesa et al., 2014) and understand the ways previous mathematics education research can inform research in community college mathematics education and the ways previous research is insufficient to address questions that emerge from this domain. The variety and extent of everyday activities adult returning students perceive as mathematical (see Chapter 4) and that way several of the interview participants kept the context of a problem they were solving in the foreground suggests that this may be one distinction between adult learners and younger students. Further research should query the contextual reasoning that adult students bring to bear on solving problems involving proportion and previous research with younger students 
could be reviewed for evidence that these students use contextual reasoning in a way similar to adult students. Using context as a tool for reasoning is a possible dimension that distinguishes children's proportional reasoning from adults. The strategies and ways of thinking about proportion that adults brought to bear on the mathematical tasks used in this study resembled those of younger students, but their experiences in the world are more extensive and it is likely the adults and children invoke and use contexts in a different way.

In addition, unit-rate strategies were, in general, problematic for the research participants. An understanding of unit rate is essential for developing the concept of direct variation and a functional model for representing proportional situations. Another area of further inquiry could build on previous research with younger students to develop a conjectured learning trajectory (Gravemeijer, 1994) from the informal proportional reasoning that adult students bring to Basic Math towards the functional understanding of proportion that these students will encounter in future mathematics courses. Developmental research methodology could then be used to develop activities to test these conjectured relationships and the iterative process of developmental research be used to both revise these conjectures and to produce activities that build on adult students' informal proportional reasoning.

Conclusion. Schliemann and Carraher (1993) observed that, "If people with little or no schooling really understand proportional relations in these [everyday] contexts, or if highly schooled individuals who have difficulty understanding proportionality in school-type settings fail to exhibit such difficulty in informal learning contexts, then there is something important to be understood" (p. 49). Many of the research participants 
were able to reason informally about proportional relations prior to the term. In addition, they were not using the school strategy of writing and solving a proportion equation to solve proportion problems, which is likely the only strategy they will use in Basic Math. If we want students enrolled in developmental mathematics at community colleges to develop quantitative reasoning abilities, then it is imperative that we first focus on the strategies and ways of thinking the adult returning students who enroll in developmental mathematics courses bring to these courses. 


\section{Chapter 6: Sasha's Story}

This chapter addresses the final research question: "How do a student's proportional reasoning abilities interact with the mathematics she encounters in a Basic Math class?" The student whose experience I share is Sasha. Two episodes exemplify the ways her proportional reasoning interacted with the mathematics in her Basic Math class: Sasha's thinking about the first variation of the Flower Stem problem both prior to the terms and at the end of the term; and our discussion about a proportion problem Sasha's Basic Math instructor, Ms. Rose, posed in class.

The chapter begins with a brief introduction to Sasha, followed by a discussion of how I conceive interaction. The next section discusses the methodology I used to address the research question. Findings are reported in four parts: (1) a description of Sasha's mathematics prior to enrolling in Basic Math, focusing on Sasha's ways of reasoning about proportional situations, (2) a description of Sasha's Basic Math class, (3) a description of the way ratio and proportion is presented in the curriculum materials used in the course, and (4) and Sasha's story as it unfolded over the term, addressing how her ways of reasoning about proportional situations interacted with the mathematics she encountered in Basic Math.

My prior experience as a Basic Math instructor helped frame this study (see Chapter 1), but it also led to particular assumptions - and even biases - that I brought with me as I embarked on this part of the study with Sasha. My experience as an instructor in a Basic Math classroom led me to suspect that the ways of thinking students were bringing to the Basic Math classrooms had a different character than the expectations for mathematical activity that arise as the curriculum was enacted in the 
classroom, a potential bias. In addition, I wondered whether students would abandon their everyday mathematics in the classroom or whether the interaction between their ways of thinking and expectations for what constitutes expert practice in classroom would manifest as either public or private conflict. I expected that one of these possibilities was likely, which was an assumption I brought to this part of the study.

Indeed, Sasha had an interesting relationship with her quantitative world and accurate, if sometimes inefficient, strategies for solving proportion problems prior to the term. She might seem to be the ideal candidate to exemplify my assumptions and biases about the course, but prior to engaging in this part of the study I did not know Sasha at all. I had interviewed her once about two weeks prior to her first Basic Math class and I wrote a brief summary of the interview the same day. However, prior to any analysis of the interview data, each participant's prior experience were interesting to me and many of their ways of thinking were still a mystery. Sasha became my ethnographic informant because she was willing (as were the other interview participants and her instructor was willing to allow a researcher in her classroom. She was not selected purposefully.

However, some of my assumptions changed over the course of the term that I came to know Sasha. As I tell her story, it will become clear that although Sasha let go of some of her everyday mathematics, something was also gained. Learning this from Sasha changed my assumptions about the relationship between students, their mathematics and the Basic Math course. 


\section{An introduction to Sasha}

"I am a mom of five; yeah, I have five kids. And I am really - right now focused on trying to go back to school and get a career going so that I can give them a better future. That's really my main focus right now." [Sasha, 22 December 2011].

Sasha is an adult student. At the time of the study, she was 29 years old; her oldest daughter was 14 and her youngest son one. Sasha moved to the metropolitan area when she was 21 years old; prior to this she lived in an agricultural town in a neighboring state. Sasha left high school after $9^{\text {th }}$ grade to raise her oldest child, but education is very important to her. When Sasha was 20 years old she realized that she needed to finish high school by the time she was 21 if she wanted to graduate from the high school in her community, an accomplishment that was important to her. But two credits away from graduation, circumstances dictated Sasha work full time and she was unable to graduate. Three years prior to starting at the community college, Sasha earned an adult high school diploma. To complete the mathematics requirement for the online degree, Sasha used published GED prep materials and took the mathematics exam several times before passing the requirement.

Sasha enrolled in Basic Math during her first term at the college. Although she originally planned to take only two courses that term- mathematics and writing - she also enrolled in a computer course. Sasha was successful in all three courses, and enrolled in three courses again for her second term, including a course offered by the Women's Resource Center intended for single parents and designed to "to assist students 
in making a career choice and developing skills that will lead to financial independence."

Sasha's primary reason for returning to school was to provide a better future for her children. Sasha wants a career that is both fulfilling and will allow her provide for her family; she wants to be able to support her children academically as they attend school; and she wants to set an example about the importance of education, in particular for her oldest daughter: “And I don’t want her to ever say, 'Well, you didn’t finish school, so why should I have to finish?" I want her to say, no matter what the situation was, I still able to do it... no matter how old you are" (Sasha, 22 December 2011).

Sasha began supporting her children when she was a teenager and she has had a variety of work experience. She has worked a restaurant manager and as a photographer. Both of these jobs influenced the quantitative reasoning she developed outside school. Sasha was adept at performing computations when the context involved money (a skill she developed managing both a restaurant and a household) and her experience sizing and resizing photographs informed her understanding of measurements. Sasha's most recent job was as a teacher's aid in a Head Start program, a job she left when she became pregnant with her youngest child. Although Sasha left high school at 15, she shared that her professional work had been more fulfilling than jobs held by her friends who graduated from high school. When I met Sasha prior to her first term at the college, she told me she was interested in studying pediatrics or becoming trained to work as an ultrasound technician, interests that emerged from her own experience with her last pregnancy, which was difficult. Currently, she is exploring transferring to a four-year public university to become an ultrasound technician. 


\section{Interaction}

I conceive of interaction in terms of Sasha's participation in several communities of practice (Wenger, 1998). Her Basic Math classroom - the students, Sasha's instructor, the physical layout of the space and the curriculum materials - constitute one community of practice where mathematics learning occurred. At home with her children, and even within her bowling league, were other communities of practice where mathematics learning took place.

As I consider Sasha's story with respect to my research question, I focus primarily on what Wenger describes as peripheral participation ${ }^{54}$ and ask whether Sasha's participation in the Basic Math community provided her opportunities for "mutual engagement with other members, to their actions and their negotiation of expertise, and to the repertoire in use" (Wenger, 1998, p. 100). In the context of one particular classroom, I explore opportunities for mutual engagement by considering the members of the classroom community, the way these members participated in classroom activities and how they interacted with each other as they engaged in these activities. The members of the classroom community also negotiate the activities and forms of participation that are normative. In any community, the members negotiate what it means to be an expert participant, but in a mathematics classroom these negotiations might occur on different levels. For example, students may accept that the teacher and the textbook represent expertise in Basic Math, but they may also negotiate what it means to be a good student in a particular classroom community. For example, expert practice may be judged by where a student sits in the classroom or the questions she

\footnotetext{
${ }^{54}$ When I describe the classroom community of practice, I make the case that Sasha was "granted enough legitimacy to be treated as a potential member" (Wenger, 1998, p. 101).
} 
asks. Finally, the participants adapt the intended curriculum, the curriculum materials and ways of thinking that emerge within the community to develop a repertoire of tools for participation.

In order to describe the ways Sasha's ways of reasoning about proportional situations interacted with the mathematics she encountered in Basic Math, in the Findings section of the chapter, I describe these ways of reasoning in detail, the practice of learning mathematics in Sasha's mathematics classroom and her participation in these practices.

\section{Methodology}

Data sources and analysis. Four sources of data were used to address the research question:

1. the interview conducted with Sasha prior to the term (also analyzed for Questions 1 and 2).

2. six interviews with Sasha conducted during the term,

3. field notes from Sasha's Basic Math class, and

4. a final interview with Sasha conducted after she completed Basic Math.

The analysis of these data started with a review of the prior analyses of Sasha's first interview in order to develop a robust sketch of Sasha, her mathematics prior to taking Basic Math and her expectations for the course. Next, my field notes were used to describe Sasha's Basic Math class, characterizing the classroom, students, teacher, curriculum materials and practices as a community of practice. 
My initial review of the six interviews with Sasha focused primarily on my role in the interviews (see Section 6.2.2), because I felt the need to understand myself as a practitioner engaged in research, and in particular, ethnographic research. Subsequent analysis of each interview (including the final interview) started with a review of my field notes from Sasha's class the day of the interview (we met after her Basic Math class) to review what had transpired on a particular day and to orient myself prior to analyzing these interviews. I listened to the recording enough times to create analytic notes that captured areas of potential mathematics learning and participation in the classroom community. In the previous section I described what I mean by participation in the classroom community. For these notes, I considered learning broadly. The questions Sasha asked in class and during our interviews highlighted features of the mathematics she encountered in Basic Math that were - at least initially - inaccessible. Other questions and conversations indicated concepts Sasha was curious about, suggesting she was interested in developing further understanding. There were also mathematical ideas Sasha returned to several times over the course of the term, such as understanding her daughter's strategy for computing a percent discount and understanding how her bowling average changed as a result of the scores she obtained in a weekly bowling league. These conversations suggested an emerging understanding. As I analyzed my interviews with Sasha, I wanted to understand what constituted potential areas of learning from her perspective.

As I conducted this analysis, I first focused on themes that emerged from my analysis of my first interview with Sasha held prior to the term (see Section 6.3.1 below). In addition, analytic notes developed during this analysis of these interviews 
focused on the interaction between the ways of thinking about proportional situations that Sasha brought to her Basic Math class and the description I had developed previously of the resources members of Sasha's classroom community used to solve problems involving proportions (see Section 6.3.2). Since proportional reasoning was a form of reasoning only implicit in the resources used by members of Sasha's classroom community, only three episodes - described in these analytic memos - addressed the interaction between Sasha's proportional reasoning and the mathematics she encountered in the classroom. Two of these episodes were combined to tell a story of Sasha's work on the first variation of the Flower Stem problem before the term and after the term ended. The last of these episodes tells the story of how Sasha's experiences prior to enrolling in Basic Math interfered with her ability to consider a routine problem involving proportion that was introduced in her classroom.

My role in Sasha's Basic Math classroom. I attended most of the meetings of Sasha's Basic Math class Winter Term 2012. My primary objective as an ethnographer was to understand the course from a student's perspective. The ethnographic informant, Sasha, was intended as to be my guide. However, I was not a participant in the classroom community in the same way as my informant and it was important to me to be honest with the other students about my role in the classroom. My primary role was as a researcher, querying students' experience, but I also shared with students that I was a mathematics instructor at the college. Revealing myself as a mathematics instructor was an ethical decision based on the fact that any of the students in Sasha's class might end up in my classroom in the future; concealing my role as an instructor at the college felt 
dishonest. In addition, as the term progressed, I also took on the role of student ${ }^{55}$, completing assignments and discussing this work with classmates, participating in small group discussions, and taking quizzes and exams with students. Hence, my role in the classroom was complex; at times I was as a researcher, at other times a colleague of the students' mathematics instructor, or at other times I was a fellow student.

The complexity of my role in the classroom community influenced what students shared with me. When I was a classmate - the most artificial of the roles I played - I would commiserate with students about the length of a particular assignment or the challenge of a particular exam question. At other times, a student would turn to me rather than to his or her instructor - for clarification of what was going on. Some students appeared to perceive me as an ally, but one with access to both mathematics and teaching mathematics. During partner or small group discussions, I recognized that I both queried and validated students' thinking. I queried as a researcher, but I validated as a teacher/researcher who recognized that students' ways of thinking were being overlooked (although not intentionally) by both the curriculum and the instructor. I could not, in good conscience, also overlook these students' ways of thinking. I would share with a student, "That is how I would think about the problem, too." However, I recognize that my privileged position with respect to mathematics provided more weight to my validation of students' thinking and likely influenced what students were willing to share with me. Finally, neither Sasha's instructor nor her fellow students knew about

55 I played a more active role as a student several weeks into the term in response to two influences: (i) reading $M$. Cyrene Wells' ethnography describing $8^{\text {th }}$ grade students transition to high school (Wells, M.C., 1996), and (ii) assimilating an observation made by a student. This student encountered me outside class and asked whether I had finished the homework assignment. When I responded, "Not yet," he responded, as if he uncovered my ruse, "You are part of class, but not really." From this point forward, I completed all assignments with the students. 
Sasha's participation in the study. For this reason, I did not focus all of my attention on Sasha during class.

My role during the interviews with Sasha. I am not an ethnographer by training, but rather a mathematics teacher. However, I am a teacher motivated to understand students' experience of the Basic Math course, an experience I expected to find to be much different from my own experience as a student. On the other hand, the context of Sasha's Basic Math class was familiar to me since I have taught this course many times over 15 years. It is not the course itself, but the adult students' experience of the Basic Math class that is unfamiliar. At times, my familiarity with the context made it challenging for me to step outside my role as a teacher and I know that I sometimes failed in my role of a participant-observer in both the classroom and in my conversations with Sasha. The following describes some of these digressions from my role as an ethnographer.

During our conversations, I often reviewed with Sasha her work on homework, quizzes and exams. My goal was to query both her experience of these assessments and her thinking, but I sometimes reverted to my role as a teacher by helping Sasha understand the problem or its solution. Additionally, Sasha used me as a resource, and it seemed to me unethical to not be a resource when she asked this of me. For example, during one of our conversations I asked whether Sasha had been convinced by a discussion in class about the statement $(-4)^{2}=16$. Sasha replied, "No," and shared that she intended to ask me about this when we met after class. She described me as her "go- 
to person" and that I helped her "use my brain more." In this sense, I was a resource for Sasha and it was important for me to honor this role.

Occasionally I was Sasha's virtual collaborator on activities students engaged with during class. Our collaboration was virtual because it was during conversations outside class that I allowed Sasha to share her thinking about an activity she worked on during class. If we were in the classroom I would be acting as a participant in these activities, listening to others ideas and sharing my own thinking with Sasha or others (and I did so whenever the opportunity presented itself). But in my conversations with Sasha outside class we were not acting as participants in the classroom community in a true sense, but if Sasha did not have the opportunity to collaborate with others during class I became her collaborator outside class.

Finally, my experience with the course and mathematics at the college allowed me to be a guide for Sasha both with respect to the ideas she encountered in her mathematics class and with respect to mathematics at the college as a whole. For example, I would support Sasha's thinking when I recognized her thinking was viable even if it looked different from the mathematics in the classroom. Also, when Sasha shared her perception that some students seemed to be mastering the material quickly, I pointed out that it is typical in a course like Basic Math to encounter some students who are reviewing the mathematics and others who are learning the mathematics for the first time.

Why Sasha? It was not possible to select an ethnographic participant purposely. Sasha was my informant because she was willing, her instructor was willing to have a 
researcher in the classroom and she persisted through the term. Sasha's story is remarkable to me and I learned so much from her. Her story is also unique, but it has much to offer those of us who teach adult students and those of us interested in adults learning mathematics. I expect that any adult returning student's story would be as powerful and as thought provoking as Sasha's story.

\section{Findings}

Sasha before Basic Math. Sasha perceived herself as a woman who uses mathematics in her everyday world: "I think almost everything I have done uses math at some point." At the same time, Sasha positioned herself as deficient with respect to what she perceived school mathematics to be: "I am not super strong with multiplication." However, Sasha's computational strategies and the ways she used the context of a mathematical tasks to reason about problems prior to the term suggest Sasha brought particular competencies to her Basic Math class.

Almost everything I have done uses math at some point. This was a theme that emerged from my analyses of the data used to address the first research question about students' experience of mathematics in their lives and in school. Here, I focus on two examples of Sasha's everyday mathematics, cooking and comparison-shopping. Sasha described these activities in my interview with her prior to the term. I discuss these activities in order to introduce Sasha's proportional reasoning.

Sasha, like many of the students who participated in the study, perceived cooking as a mathematical activity. During the first interview with Sasha, I asked her whether she ever adapted recipes when cooking in order to learn whether Sasha used proportional reasoning when cooking: 
I have a big family, so we usually end up with - I would say -an average four-person meal - and I have to make that into a seven-person meal or a six-person meal. So trying to... Okay, that takes three cups, but I need to make a bigger batch so I would add and sometimes subtract certain things to make it ... to make sure it turns out the way it is supposed to [Sasha, 22 December 2011, emphasis added].

Sasha does not observe here that the amount of ingredients in a recipe for six people is $1 \frac{1}{2}$ times the amounts in a recipe for four, nor that the amount of ingredients for seven people would be nearly twice what is needed for four. Sasha's language in this excerpt is additive not multiplicative. This is not too surprising; in a study of out of school mathematical practices that included professional cooks (Schliemann \& Carraher, 1993), the researchers found that cooks often worked with estimates rather than scaling up recipes proportionally. However, I was still curious whether or not Sasha recognized the multiplicative comparisons that might be made when scaling up a recipe. I followed up Sasha's response with a particular question:

Ann: So if you... you can just throw out an answer here. We don't have to spend a long time on this. So if a recipe for four takes three cups and you were scaling it up to your family, how would you go about it?

Sasha: So, usually, let's say, for example, it is like pancakes and I need I need to make seven and it's three cups of mix, then I would add it, keep adding. So if I need 14 of them I would add another three cups of the mix. So I would double [Sasha, 22 December 2011]. 
Sasha did not answer my question directly. Instead she invoked the context of using three cups of mix for seven pancakes, the usual number of people she cooked for. She then scaled up the recipe to make 14 pancakes. Again, Sasha focuses on adding another three cups of mix, recognizing that she has doubled the recipe. It remains not entirely clear that she understands that the amounts of ingredients in a recipe for seven are nearly double the amounts for a recipe for four.

Sasha did not have a unit-cost strategy prior to the term to use when comparisonshopping. That is, she did not divide the total cost of a product by the amount purchased (e.g., number of items or number of ounces) to determine the unit cost as other participants did during the interview (even though for some of the other participants, this strategy was a poorly recalled procedure applied incorrectly during the interview). However, Sasha solved the Better Buy problem using a building-up strategy and shared that she uses this particular type of reasoning "all the time":

I do this all the time. For example, one of our biggest things that we buy is orange juice. Orange juice is so expensive. It doesn't matter where you go, even the cheapest brand is expensive. So, they always tell you, "We have a 64 -ounce for $\$ 5.99$ ” or you have a 96 -ounce for seven something. So, I always think, if I had two 64s, is it going to come out... Which one is going to have more? [Sasha, 22 December 2011]

Sasha's strategy was to build up one or both quantities of orange juice so that she could compare two "containers' of the same size: "If I had two 64s." During the first interview, Sasha quickly responded that the 12-ounce stick of deodorant was the better buy. She explained her reasoning as follows: 
And the reason I say [the 12-ounce stick is the better buy] is because if you double your 12 -ounce, you are going to get 24 ounces for $\$ 13$. So that's 24 ounces. If you go with two 8 ounces, you are going to get 16 ounces for $\$ 9$. So, you are definitely going to get more... even though it seems like it cost more, you're still going to get a better amount [Sasha, 22 December 2011].

At this point, Sasha has built up each composed unit in order to compare the two products, but she is comparing 24 ounces for $\$ 13$ to 16 ounces for $\$ 9$. It was still unclear to me how she reached her conclusion, so I asked her to help me understand how she determined the 12-ounce stick was the better buy.

Sasha: Just because... to me, I would just say, “Okay, for..." [thinks to herself quietly]. For eight more ounces, I only have to pay three more dollars, which would make this one [we cannot see which she is pointing to] still more expensive.

Ann: So, you need eight more ounces to get the 16 to match up with the 24 ?

Sasha: Yeah. If I bought three 8 ounces for $\$ 4.50$, it would still be more than it would be I bought the two for the $\$ 13$ [Sasha, 22 December 2011].

Although Sasha does not compute that three 8-ounce sticks cost $\$ 13.50$ at this point in the interview (she does later), she is convinced that her conclusion is reasonable and it is. In Sasha's Basic Math classroom, computing a unit cost was assumed to be both unproblematic and part of each participant's repertoire for comparison-shopping. It is clear from Sasha's description of comparisonshopping that a unit-cost strategy was not a strategy she brought to Basic Math. 
I am not super strong with multiplication. At the end of my first interview with Sasha, I asked her what she expected from Basic Math. She replied, "I really want to get to where I can multiply and divide in my head instead of having to write it out, or using a calculator. I want to be able to just do it in my head." Mental computation strategies are not part of the intended curriculum for the course and I know, anecdotally, that most instructors expect students to come to Basic Math knowing multiplication facts, which struck me because this was never important to me. Yet, learning multiplication facts was important to Sasha. Although she was able to compute products and quotients using a combination of doubling/halving strategies with building-up/partitioning strategies while reasoning about problems involving proportional reasoning, Sasha positioned herself as a women who was not "super strong with multiplication."

The following examples illustrate that Sasha had developed flexible doubling and halving strategies, which she used both to compute products and quotients accurately and to arrive at reasonable estimates. The first example illustrates how Sasha computed $50 \%$ of $\$ 35$. The second set of example illustrates Sasha's workarounds for having no "thirding" strategy. The final example illustrates the way Sasha used both a doubling and building-up strategy to accurately compute a product while working on the first variation of the flower stem problem.

Sasha was more comfortable halving even numbers rather than odd numbers with one exception; Sasha knew that half of $\$ 5.00$ is $\$ 2.50$, a fact she used to compute $50 \%$ of 
\$35. Sasha made two attempts at this computation while reasoning about Percent Discount problem. She started by rounding up $\$ 35$ to $\$ 40$, then reasoned by rounding down $\$ 35$ to $\$ 30$, and finally used half of $\$ 5$ to complete the computation:

So if it was half of 35 , I would be looking at... So if it was 40 , it would be 20 . So, it would be like $\$ 22.50$, if it was half off. So, that tells me already... No, wait, that's wrong. If it was half off, it would be... 30 would be $15.2 \ldots 16,17,17.50$. So it would be $\$ 17.50$, if it was half off. [Sasha, 22 December 2011]

Not only did Sasha compute $50 \%$ of $\$ 35$ accurately, if not efficiently, but she also recognized that her original conclusion, \$22.50, was incorrect. Although she did not articulate how she knew $\$ 22.50$ was incorrect, the next few examples illustrate that Sasha typically used the context of the problem (in this case, the familiar context of shopping) to make sense of the reasonableness of her computations.

Sasha's inability to third prior to the term is illustrated by two examples. The first is an example described in detail in Chapter 5, recounting Sasha's reasoning about the first variation of the Flower Stem problem. The second is Sasha's attempt to divide 39 minutes by 3 miles as she reasoned about the Two Joggers problem. The two contexts, and Sasha's strategies for each problem, are different.

Sasha did not recognize that six flower stems is one-third of 18 flower stems when she worked on the first variation of the Flower Stem problem. Sasha knew that the unit cost per stem was under one dollar, but not having a unit-cost strategy, she attempted to partition the composed unit 18 stems for $\$ 15$ by halving in order to determine the unit cost. Being unable to identify the factor of three in this problem, 
which could lead to an efficient and accurate solution, led Sasha to a less efficient workaround for being unable to third ${ }^{56}$ prior to the term. Later in the interview, Sasha needed to compute the quotient of 39 minutes and three miles in order to compare two joggers' speeds. In this case, Sasha recognized that she needed to third, but she did not know that the product of 13 and three is 39 . She obtained a rough estimate of the jogger's speed by halving 40 minutes twice and adding a little onto one-fourth to compensate:

Because I just divided the 25 into two, so it took her almost 13 minutes to run one mile. And he did his time... I rounded it up to 40 minutes, have would be 20 minutes... It took him about 11 minutes to run a mile [Sasha, 22 December 2011].

This particular workaround for thirding led Sasha to estimates for the joggers' speeds (which were numerically close) and to conclude incorrectly that the male jogger was faster. However, when Sasha used a calculator to compute the two rates she interpreted the results accurately, concluding that the female jogger ran faster at 12.5 minutes per mile than her partner who speed was 13 minutes per miles. Sasha was not "super strong at multiplication," but she was able to reason about problems involving ratio.

The last example illustrates the Sasha combined a doubling strategy with a building-up strategy to reason about the first variation of the Bread Flour problem:

\footnotetext{
56 In Chapter 5 I note that Sasha's workaround strategy was inefficient, but partitioning the composed unit might have led Sasha to a more efficient unit-rate strategy in a way that addresses the question, "Why divide?"
} 
Well, for every 80 pounds, it's 50 . So, 50,50 , and 80 is 160 . So, 160 and 160 would be [computes mentally]... It would be $220 \ldots$ [Sasha decides to write her computation] So, 160 for 100 people, and then 160 for 100 people, and then 80 for 50 people [Sasha writes the sum $160+160+80$ vertically and tallies] 400 pounds... [Sasha, 22 December 2011].

Sasha first iterates the composed unit 80 pounds for 50 people in order to double the unit, determining that 160 pounds of flour are needed for 100 people. At this point, she abandons mental computation and on paper builds up the unit 160 pounds for 100 people in order to conclude correctly that 400 pounds of flour will be needed to 250 people. It is not clear from this excerpt whether Sasha recognizes that 250 people is five times 50 people, but she easily built up 50 to 250 in this context.

Sasha perceived herself as someone who was not "strong with multiplication," but despite the fact that she did not know multiplication facts, she was able to reason about ratio and proportion. Sasha also perceived herself as someone who was never good at doing "math on paper," which was the way Sasha characterized her expectations for mathematics in school (discussed in Chapter 4). In this final example, I contrast the advice Sasha gives one of her children about how to approach 'story problems' with Sasha's ability to reason using the context of a problem about a multiplicative situation.

I tell her to group the numbers together and kinda forget about the words. And just worry about the numbers. Then go back to the words and see if your answer makes sense to the story line [Sasha, 22 December 2011]. 
During our first interview, Sasha never took her own advice and removed the numbers from their context. Her reasoning on the third variation of the Bread Flour problem illustrates the importance of the context of the problem for Sasha's reasoning about the problem. The variations of the Bread Flour problem were written to tease out the extent to which joint variation was salient to the interview participants. The first two variations involved varying one of the two quantities; the third varied both. Starting with the condition that 80 pounds of flour are needed for 50 people for four weeks, the third variation queried how may pounds of flour are needed for 150 people for two weeks. After posing the problem to Sasha, she replies:

Okay. [Pointing to the quantities in the problem] So, that would take care of... So, the 80 pounds is for four weeks so that would take care of 100 [people for two weeks]. So, you need only 40 more [pounds for two weeks]. So 120 [Sasha, 22 December 2011]. The statement that 40 pounds of flour is needed to 50 people for two weeks was Sasha's conclusion to the previous problem. She used this fact after she reasoned that halving the duration of the stay would stretch out 80 pounds of flour for twice as many people. The context was perceived as one that involved doubling ${ }^{57}$ the number of people and halving the duration of the stay. Sasha's reliance on doubling and halving strategies gave her insight into the problem, an insight that could lay the foundation for exploring joint variation in more detail in a mathematics classroom.

Summary. Prior to the term, Sasha perceived herself as a woman who uses mathematics in her everyday life, but she also saw herself as deficient with respect to

\footnotetext{
${ }^{57}$ The context actually involved tripling the number of people and halving the duration of the stay, but it is not surprising that Sasha worked with doubling rather than tripling.
} 
school mathematics. Sasha's experiences with everyday mathematics led to mostly accurate, if not efficient, computational strategies and an ability to use the context of a problem to help her both reason and to establish the reasonableness of her solution. Although Sasha told me that she advised her daughter to ignore the context of the "story problems' she encountered in school, this was not a strategy Sasha herself used when reasoning about the mathematical tasks in the interview, which were examples of the types of 'story problems' she might encounter in her Basic Math class. Sasha did admit during the first interview that she was experiencing the mathematical tasks as school mathematics problems, examples of "math on paper" that she perceived as different from her everyday mathematics. However, Sasha reasoned to a reasonable solution to each problem even without access to multiplication facts.

A community of practice: Sasha's Basic Math classroom. In this section I describe Sasha's Basic Math class, focusing on the geography of the classroom, the participants, what was regarded as expert practice and the resources within the community to which the participants had access.

Geography. Sasha's Basic Math class met for four hours each Friday of the 10week term. Sasha and other adult students frequently select a one-day-per-week class because it makes scheduling childcare and work around school less challenging. The classroom is configured with three rows of tables, each of which seats two students (see Figure 25). The long edges of the tables are parallel to the board in the front of the room, so students sit facing the instructor. There is one whiteboard in the front of the classroom and another along the right side of the classroom. A podium is placed to the left of the whiteboard in the front of the classroom, allowing the teacher to project images from a 
computer or a document camera. There are two doors to the classroom at the back of the room and the doors open to the outdoors rather than a hallway. The configuration of the classroom is typical for the college. On the first day of class eight students sat in the last row of the classroom (six make students and two female students including Sasha), seven students sat in the middle row and six students in the front row. As the term progressed, the students who participated most openly in the classroom activities populated the middle row; the first and last row became less populated.

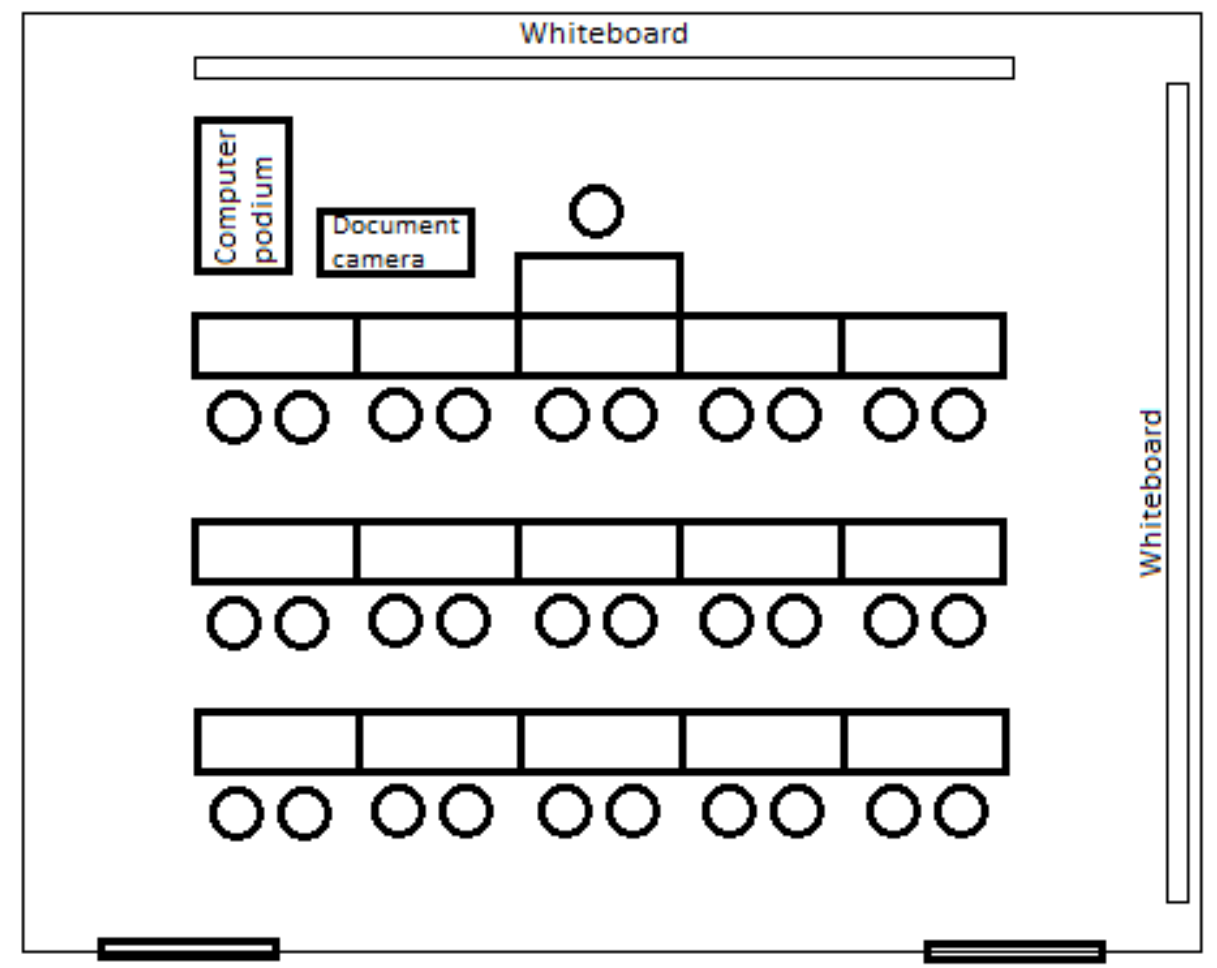

Figure 25. Configuration of Sasha's classroom

The members of the classroom community. The term started with 10 male and 11 female students, but toward the end of the term only six male and 9 female students were attending class regularly. Although two young male students sat in the front row, 
the other male students took over the back row. Older female students, all of whom actively participated in classroom activities, dominated the middle row. Over the first few weeks of the term Sasha moved from the middle of the back row, where she positioned herself the first day, towards the center of the middle row with the other mature female students.

Sasha's Basic Math instructor was a part-time instructor at the college, Ms. Rose. Ms. Rose was new to community college mathematics teaching (this was her second term at the college), but she had taught middle and high school mathematics for nine years previously. She had experience teaching the content of Basic Math, but little experience with the pace that is typical of developmental mathematics courses. Her previous teaching experience presented occasionally as a conflict between Ms. Rose's desire to help the students make meaning of the mathematics and her understanding that she had to cover a significant amount of material in the 10 -week course.

Ms. Rose made an effort to connect with students by admitting her own strengths and weaknesses as a student and by empathizing with students' initial difficulty with some tasks (for example, rounding or long division). Throughout the term Ms. Rose focused on strategies for being successful in mathematics class. Her assessment of students' work and the ways she revisited questions from earlier assessments on subsequent assessments provided Sasha and other students the opportunity to "figure out where we went wrong." In addition, it was obvious that Ms. Rose wanted her mathematics classroom to be a comfortable place for students; in fact, Sasha shared that she felt more comfortable in this mathematics class than in any class she has taken in the past. 
Ms. Rose was enthusiastic about teaching mathematics. The students, including Sasha, appreciated her enthusiasm. She often invoked contexts beyond the mathematics classroom in an attempt to connect what students are learning in the class to their lives outside school. Students listened actively to Ms. Rose and, as the term progressed, students became more active participants in the discussion, not only by asking questions, but also by drawing upon their own experiences and sharing strategies (see Section 5.4).

Participation and activities. Early in the term, Ms. Rose asked the students to engage in several activities that supported making meaning of a particular mathematics concept or strategy. Students enjoyed these activities and Sasha recalled particular activities when we spoke at the end of the term. However, as the term progressed there were fewer opportunities for students to engage with one another and with mathematical ideas as Ms. Rose came to realize that the institution's expectation for material to be covered in the course did not allow the time she needed for these types of activities. ${ }^{58}$ Class time was used in a similar way each week. Class started with Ms. Rose's answers to student questions about the homework. This was followed by either a quiz or an exam. After the assessment, new material was presented and students were expected to take notes, ask questions and participate when Ms. Rose asked questions.

Occasionally, students worked on an activity or on problems from the textbook with a neighbor, but Ms. Rose focused on covering the material, which often meant lecturing on the topics in one chapter of an eight-chapter text. Sasha appreciated opportunities to work with classmates during class; doing mathematics with others helped her develop

\footnotetext{
${ }^{58}$ Part-time faculty members at community colleges are a part of a contingent work force. Many feel that their primary professional obligation is to cover the course content and if they fail at this obligation, they risk being not hired to teach future courses (Thompson, 2003).
} 
understanding. Sasha told me that Ms. Rose's preparation of 'notes' for class as her opportunity to make sense of the mathematics. Sasha wanted this experience as well and found that working with others in class served this purpose. Wenger (1998) described legitimate participation as being "granted enough legitimacy to be treated as a potential member" (Wenger, 1998, p. 101). Ms. Rose construed Sasha and her classmates as legitimate participants in the classroom community.

Repertoire. At the time of the study the college used two texts for Basic Math. Text A was used at three of the campuses, including the campus where Sasha enrolled in Basic Math, and Text B was used at the Southside campus. In general, textbooks for a course like Basic Math include the following topics: operations with whole numbers, fractions, decimals and integers; powers; order of operations; ratio and proportion; percent; measurement and geometry; graphical representations of data (e.g., bar graphs and circle graphs); and measures of center. The order in which these topics are presented varies slightly between texts, but the presentation of the topics in the Ratio and Proportion chapter and the next chapter of Text A, Percent, is very similar in many of these texts.

The chapter on Ratio and Proportion starts with definitions of ratio and rate. A ratio is defined as a comparison of two measurements by division. The multiplicative relationship between the two quantities is not highlighted in the definition, but the text includes one example to illustrate that ratio represents a multiplicative relationship between two quantities. The interpretation of a ratio as a multiplicative comparison is not the focus of the exercises. The emphasis in the text is on writing ratios in simplified form. Rates are defined as a comparison by division of two unlike quantities. Unit rates 
are defined as a rate with a denominator of one unit and the focus is on dividing one value by another (for example, to determine which container of orange juice is the better buy, one finds the cost per ounce by dividing the cost of a container of juice by its capacity measured in ounces).

In the next section of the text, proportions are defined as a statement that two ratios are equal. Students are introduced to solving missing-value problems in noncontextual situations (the proportion is given) by setting the cross products equal to one another and solving for the unknown. The text notes that setting the cross products equal to one another is a shortcut for comparing ratios using the same denominator, however this observation is not connected to the strategy of building up one ratio to compare it to another ratio (see Chapter 5 and Section 6.3). Solutions to all contextual problems in the examples involve writing a proportion equation and solving the algebraic equation that results from setting the cross products equal. The text scaffolds this process by suggesting students complete a table and write the proportion using the table. For example, a solution to the Flower Stem problem would start with constructing a table like the table shown in Figure 26, leading to the proportion equation $\frac{3}{2}=\frac{15}{x}$.

\begin{tabular}{|r|c|c|}
\hline & Case 1 & Case 2 \\
\hline Number of flower stems & 3 & 15 \\
\hline Cost (in \$) & 2 & $x$ \\
\hline
\end{tabular}

Figure 26. Table used to write a proportion equation

The chapter on percent begins with two pages illustrating percentages both as a number of parts out of 100 using a 10-by-10 grid and as a fraction (25\% is one-fourth of 
the figure). Benchmarks values such as $50 \%, 25 \%$ and multiples of $12.5 \%$ are presented but not used in any of the examples. There is a focus on conversions, conversions between fractions and percentages and between decimals and percentages. Strategies for solving non-contextual problems about percent (for example, What percent of 65 is 15?) are presented next. The text focuses on two strategies for problem solving with percentages: writing and solving a proportion equation, $\frac{\text { amount }}{\text { base }}=\frac{p}{100}$, or using the formula percent rate $\times$ base $=$ amount. In addition, the text used in Sasha's classroom scaffolds using the formula with a model to help students determine whether to multiply or divide in order to solve a particular problem.

After one section of examples illustrating how to solve non-contextual problems, the text feature selected applications of reasoning with percentages; each type of problem (general percentages, taxes and interest, and percent increase and decrease) is presented in a separate section. The two strategies (proportion equation and formula) are used to solve these contextual problems.

However, Ms. Rose extended the repertoire of ways of reasoning about problems involving ratio and proportions by highlighting the multiplicative relationships between quantities in a proportion. For example, while working on an example that involved solving the proportion equation $\frac{0.3}{0.5}=\frac{3}{x}$, Ms. Rose first solved the proportion by setting the cross products equal and solving for $x$, but then she observed that three is 10 times 0.3 , so $x$ must be 10 times 0.5 . (Sasha had another way to reason about this problem.) However, based on the students' questions and their written work that I observed in 
small-group problem solving or when students offered to show their work on the board, few students used ways of reasoning not privileged by the curriculum materials as part of their repertoire. There were occasional exceptions that I observed. One day, students in Sasha's classroom were considering the example, $\frac{2}{\$ 4.99}=\frac{5}{x}$. Ms. Rose first solved the proportion by setting the cross products equal and determining the value of $x$. She then observed that five was not an obvious multiple of two, making the case for having access to a strategy that always worked, yet at the same time highlighting the multiplicative relationships between quantities. Mercedes, a member of the community, was sitting next to me as Ms. Rose presented this example, quickly observed that 5 is $2 \frac{1}{2}$ times two. This quiet observation both acknowledged the focus on multiplicative comparisons Ms. Rose highlighted as an extension of the textbook strategy to solving a proportion and Mercedes' understanding of the multiplicative relationship between quantities in a proportion.

Expert practice. As mentioned above, students in Sasha's classroom were provided the opportunity to solve the proportion $\frac{2}{\$ 4.99}=\frac{5}{x}$. However, it was the intended curriculum as established by the college and curriculum materials rather than the instructor or students, who might have observed that since five is $2 \frac{1}{2}$ times two, $x$ must be $2 \frac{1}{2}$ times $\$ 4.99$, that dictated expert practice. With respect to this problem, students were expected to rewrite the proportion equation as a linear equation and solve for $x$ even though Basic Math was not an algebra course. Occasionally, students negotiated forms of expertise more in alignment with their own ways of knowing, as was the case during the first class discussion of percent when students offered their own 
ways of computing and understanding percent (see Section 5.4).

Ms. Rose described characteristics of good students, such as reading the parts of the text that would be discussed in class prior to coming to class, asking questions, doing the assigned homework exercises throughout the week and not only the night before class, and going over mistakes made on quizzes and exams in order to learn from these mistakes. In Sasha's classroom, the students who sat in the center of the classroom came across as the 'good' students. They came to class with their homework assignments done and prepared with questions for Ms. Rose. They also asked questions during lecture and volunteered to write problem solutions on the board. The students in the front row asked few questions and participated less actively, but they all listed attentively and most too notes during class. The young men in the back row did not appear as engaged during the lecture and few took any notes, but when Ms. Rose asked the students a question the students in the back row frequently responded, although their responses were sometimes too quiet to be heard by Ms. Rose.

There were occasional opportunities for negotiating expert practice within the community. For example, the mathematics faculty at the college had established guidelines for presenting written work on mathematics problems. These guidelines included rewriting each exercise to be completed or problem to be solved, showing all work and stating conclusions to applied problems using complete sentences. These guidelines were not discussed during the first class meeting, but were included at the top of the document that included all the textbook exercises students were expected to complete during the term. Ms. Rose had been given this document by a full-time colleague. Sasha followed these guidelines as she completed the first week's assignment, 
which included 124 exercises and problems. During a break at the second class meeting, Sasha asked Ms. Rose whether or not it was really necessary to rewrite the statement of each exercise and problem, and Ms. Rose conceded that it was not really necessary. In fact, Ms. Rose also had to negotiate around these guidelines when they became part of the department chair's assessment of her teaching.

Sasha as a member of the classroom community. Sasha sat in the middle of the back row at the first class meeting. She told me she chose this seat so that she could leave if she felt overwhelmed, but the doors were at each end of the back row. The second week she moved to a seat at the end of the second row and by the third week she had moved to the middle of the second row, where she remained for the rest of the term. During our first interview Sasha used language that suggested an antagonistic relationship with school mathematics. For example, when discussing a problem that required her to find the perimeter of a rectangle illustrated with the two dimensions labeled with their lengths, Sasha said, "It's tricking you," (13 January, 2012) because not all four sides were labeled. Sasha also "kinda felt cheated" (13 January, 2012) by not having enough time to complete a first-day assessment designed to help students determine whether they were prepared for Basic Math. As Sasha became more comfortable in the classroom, she no longer used this kind of language. Sasha quickly became comfortable asking questions, answering Ms. Rose's questions, and going to the board to show her work. If Sasha did not complete an assignment by class time, she would go back and finish her work. She asked questions of her daughter at home and Ms. Rose in the classroom when she could not perform a computation or solve a problem on an assignment. One day Sasha was running late to class and she decided to 
drive rather than take the bus, "I didn't want to miss [Ms. Rose] explaining the homework" [10 February 2012].

One the one hand, Sasha expected Ms. Rose to make sense of the course content for her. She would review her notes from class rather than use the textbook when working on assignments outside class. This caused problems when Ms. Rose did not get to a particular topic in a chapter, as was the case with subtracting mixed numbers. Sasha would look to the text outside class, but she told me several times over the course of the term that she could not make sense of the explanations in the text. On the other hand, Sasha was capable of making sense of mathematics without Ms. Rose interpretations when the she could contextualize the mathematics. For example, before starting Basic Math Sasha told me that her oldest daughter would compute a percent discount by multiplying the rate, which Sasha was able to interpret as a number of cents off each dollar, by the amount of the item. But Sasha told me she did not use this computation because she did not understand it. In Sasha's classroom Ms. Rose either used mental computation strategies or a proportion equation when solving problems involving percent in class; she never used the product of the percent as rate and the base amount.

On her last exam, there was a bonus problem on which students were asked to explain to someone how to compute a $20 \%$ tip on a $\$ 36$ restaurant bill. After class, Sasha told me that she explained, "You can take the 20 cents per dollar and multiply that by the 36 dollars" [9 March, 2012].

The interaction between Sasha's mathematics and Basic Math. Sasha's story begins with two episodes. The first episode focuses on a problem that Sasha encountered twice, the first time during our interview prior to the term and the second time during our 
interview after the term ended. The second episode occurred in the middle of the term, when Sasha and her classmates were solving problems involving proportions. The first episode illustrates that Sasha was, in some sense, enculturated into the expert practices valued in her classroom community. As the episode will illustrate, Sasha had taken on some of the efficient strategies she learned in Basic Math, but sacrificed the contextual way of reasoning about proportional situations she brought into the Basic Math classroom. However, the second episode illustrates that Sasha's out-of-school experience still shaped her experiences within the classroom community. This particular episode, and what I learned from Sasha about the particular context suggests potential opportunities to mathematize students' experience in the classroom.

Each flower stem is less than one dollar. In the previous chapter, Sasha's reasoning on the first variation of the Flower Stem problem was described, which I briefly summarize here. The problem stated that 18 flower stems cost $\$ 15$ and queried how much 6 stems would cost. Sasha did not recognize that six is one-third of 18, but she did recognize that each stem cost less than one dollar. She told me that if she knew the cost per flower, she could multiple the cost per flower by six to determine the cost of six stems. At the time, Sasha did not have a unit cost strategy. She attempted to determine the unit cost by halving the composed unit 18 stems to $\$ 15$. It took her several minutes to determined that $4 \frac{1}{2}$ stems cost $\$ 3.75$ and, at this point, she abandoned her strategy and estimated that six stem would cost $\$ 5$.

Sasha reconsidered this problem after the term ended. At this time, she used a strategy she had learned in Basic Math. She wrote the proportion 'equation' 


$$
\frac{18}{15} \frac{6}{x}
$$

which she solved using equivalent equation $18 x=90$. Sasha explained that the 'amounts' (number of flower stems) were related in the numerators and the costs in the denominators. In response to the question, "How did you know to write a proportion equation for this problem?" Sasha explained that all the word problems she had solved in Basic Math could be solved using this strategy.

I asked whether Sasha would use this strategy while shopping. She laughed and told me she would use her phone and divide 18 by 15 to determine the cost per stem and then multiply by 6 . She performed this computation during the interview, obtaining $\$ 7.20$ for the cost of six stems, a result she knew was incorrect, since she felt confident in her solution of $\$ 5$ obtained by writing and solving a proportion equation. Sasha then divided 15 by 18 and confirmed that the six stems cost $\$ 5$.

After completing Basic Math, Sasha had two strategies for approaching this variation of the Flower Stem problem: writing and solving a proportion equation and a unit-cost strategy. Earlier in the interview, I asked Sasha what was the most important thing she learned in Basic Math. She replied, "The proportions made a lot of sense, like how to figure things out. So I think I did pretty well on that" (2 April, 2012). I was curious about what made sense to her about proportions:

I think trying to figure out what the letter represented, $x$ over whatever. That was probably like my biggest fear of all times. I'd be like, 'Argh! What are all these letters for?" [2 April 2012]. 
Sasha had struggled with proportion equations during the term. Her first difficulty was interpreting $x$ as something other than a symbol representing multiplication. Her second difficulty involved not understanding that an expression such as $0.3 \mathrm{x}$ represented a product. However, she was convinced that in any proportion the cross products were equal. The day proportions were introduced in Sasha's classroom, the students were asked to work on four proportions (see Figure 27).

$$
\frac{7}{20}=\frac{35}{x} \quad \frac{0.3}{0.5}=\frac{3}{x} \quad \frac{4}{6}=\frac{x}{21} \quad \frac{0.12}{x}=\frac{0.03}{1.5}
$$

Figure 27. Four proportion equations

The students worked on finding the solutions to these proportions individually or with a neighboring student. After a few minutes, Ms. Rose asked for volunteers to write their solutions to these proportions on the board. Sasha volunteered to write her solution to the second proportion $\frac{0.3}{0.5}=\frac{3}{x}$. Her solution is represented in Figure 28. Unlike the other solutions on the board, Sasha's solution did not include the equivalent equation $0.3 x=0.5(3)$. Sasha was highlighted the equivalence of the cross products, but I did not know why she had not written an equivalent equation.

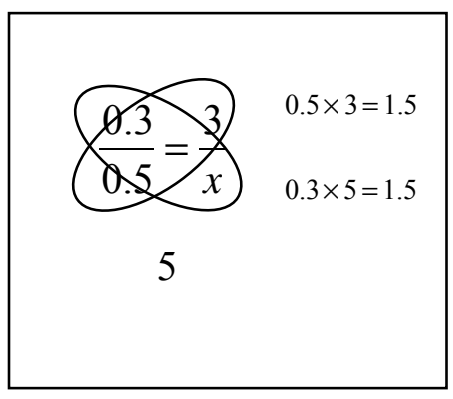

Figure 28. Sasha's solution 
When Ms. Rose went over the volunteers' solutions with the whole class, she erased Sasha's work, writing and solving the equation $0.3 x=0.5(3)$.

When Sasha and I spoke about this after class, I wanted to know what she had been thinking. I rewrote her annotations on the problem, which I had recorded in my field notes and asked her about her thinking:

Sasha: I just figured, well, three times five is 15 . So, then three times something $x$ has to equal... So, three times... yeah, it had to equal 15 and the only way that that was going to happening was if it was a five. And so, this bottom part that she does, like to me, it's like. It confuses me more, ‘cause she's writing out her steps. But like when you... I don't know. That's why I didn't even do it, 'cause it's just confusing. Like to me it was just simpler to say...

Ann: So when you wrote this [pointing to $0.5 \times 3=1.5$ ] were you looking at this product [pointing to a cross product] when you wrote five-tenths times three is one point five? Is that from here?

Sasha: Yeah.

Ann: So, you were looking at these cross products?

Sasha: Yeah. That's how I did it.

Ann: So, did you just know that point three times five is also one point five?

Sasha: Yeah, because I had to move the decimal over. It would have been 15, but since it is point three... Since it had a decimal, I knew I had to move it over one spot to the tenths place. But, the way I did it, she erased it. She said I missed... Well, I didn't miss it, but I didn't write out zero point 
three $x$ equals zero point five times three. To me, that confuses me. I am like, "Why are you doing that?" Like, every time she does that, it threw me completely off what she was doing [17 February, 2012].

Sasha focused on the fact the cross products are equal. Perhaps this was a pattern she had seen in class, since Ms. Rose had been annotating the equivalence of cross products by circling each. However, Sasha was not writing the equivalent equation that Ms. Rose expected her to write, because it was confusing to her. When asked what it was about the remaining steps Sasha found confusing, she replied, "I guess the $x$. I think times. I see five $x$ and I think five times whatever the next number that follows" [17 February, 2012]. Later in class, Sasha asked Ms. Rose about the meaning of the expressions, such as $0.3 x$, that Ms. Rose had been using. By the time we met after class, Sasha had a sense what the $x$ represented and that the expression $0.3 x$ represented a product with implied multiplication. Sasha was unfamiliar with algebra prior to Basic Math (see Chapter 4), but by the end of the term, she felt comfortable with the algebra of proportion equations. At the end of the term, Sasha had a unit-cost strategy, but like other participants in this study, she divided before thinking about which quantity was divided by which. When she obtained a unit cost of $\$ 1.20$ per stem, she did not ask herself whether this was reasonable given that 18 stems cost $\$ 15$ as she did prior to the term. She knew the six stems did not cost $\$ 7.20$ based on the solution she obtained using the proportion equation, so she then tried the other quotient and determined that six stems cost $\$ 5$. She observed that she would have paid too much for six stems if she had used her first computation of the unit cost. In this particular case, an efficient unit cost strategy replaced the inefficient, but accurate, strategy Sasha used prior to the term. Finally, if the 
multiplicative relationships that Ms. Rose referenced but did not use to solve proportion problems were used as an alternative to writing and solving a proportion equation when solving a proportion problem, Sasha might have recognized that six stems is one-third of 18 stems and used this multiplicative relationship to solve the problem, which for this problem would lead to an accurate and efficient strategy.

This problem doesn't make any sense. The first example of a contextual proportion problem Ms. Rose presented in class involved increasing a three-inch by fiveinch photograph proportionally, so that the short side of the photograph is five inches. Ms. Rose notes the multiplicative relationship between the quantities in the problem, telling the students, "Whatever I multiply one side by I need to multiply the other side by" (field notes, 17 February 2012). Ms. Rose also noted that the increase in length was not additive, which was the only time she made a distinction between additive and multiplicative relationships. However, Ms. Rose wrote the equation $\frac{3}{5}=\frac{5}{x}$ rather than noting that five inches is five-thirds of three inches and using this factor to determine the length of the large size of the enlarged photograph would be $8 \frac{1}{3}$ inches.

At this point, Sasha objects that the problem doesn't make any sense. She tells Ms. Rose that no one would print a photograph that was 5 inches by $8 \frac{1}{3}$ inches and shares with us common sizes of photographs: $3 \times 5,4 \times 6,5 \times 7,8 \times 10$ and $11 \times 13$. I learn something I did not know previously; photographs of different sizes are not proportional. Ms. Rose suggests that the photograph is likely cropped. Sasha agrees and tries to explain to us how cropping occurs when photographs are enlarged. I am confused 
and Ms. Rose must seem confused as well because another student jokes that Ms. Rose is going to have nightmares. A young man in the back row remarks that we are in "a math world." Sasha later tells me she found this comment offensive because she perceived her work as a photographer as being all about mathematics: "We deal with measurements all day long” [17 February, 2012]. The members of the community decided to accept the problem as written even if it was not realistic to Sasha and the class moves on. However, Ms. Rose attempts to alleviate the situation by noting that, "there is more then one way to solve these problems" [field notes, 17 February 2012], but following the textbook's emphasis on creating tables to organize the information in a problem prior to writing a proportion equation.

When Sasha and I met that day after class, we discussed this episode. I remained confused by Sasha's explanations of the way photographs are cropped when enlarged. Her experience was contextual and as I have no experience enlarging prints, I needed to mathematize the situation. Sasha and I were talking about enlarging a $4 \times 6$ print to $5 \times 7$ print. I decided to draw a $4 \times 6$ rectangle, the $5 \times 7.25$ rectangle that was similar and the $5 \times 7$ enlargement. It was immediately clear to me why the top of the photograph would be cropped, as Sasha had been trying to explain to her class and to me (see Figure 29). I learned two important lessons. The first was that the photo enlargement problems we pose to our students have no analogue in the world of photography. The second is that this conflict between a school problem and the actual sizes of photographs could be resolved by reposing the problem. For example, students might be asked, "Why is the top of a photo cropped when a $4 \times 6$ print is enlarged to $5 \times 7$ print?” It was I rather than Sasha who mathematized this problem in order to understand it, but this problem might 
have been a vehicle for Sasha to mathematize her everyday understanding of photography if a similar problem had been posed in her classroom.

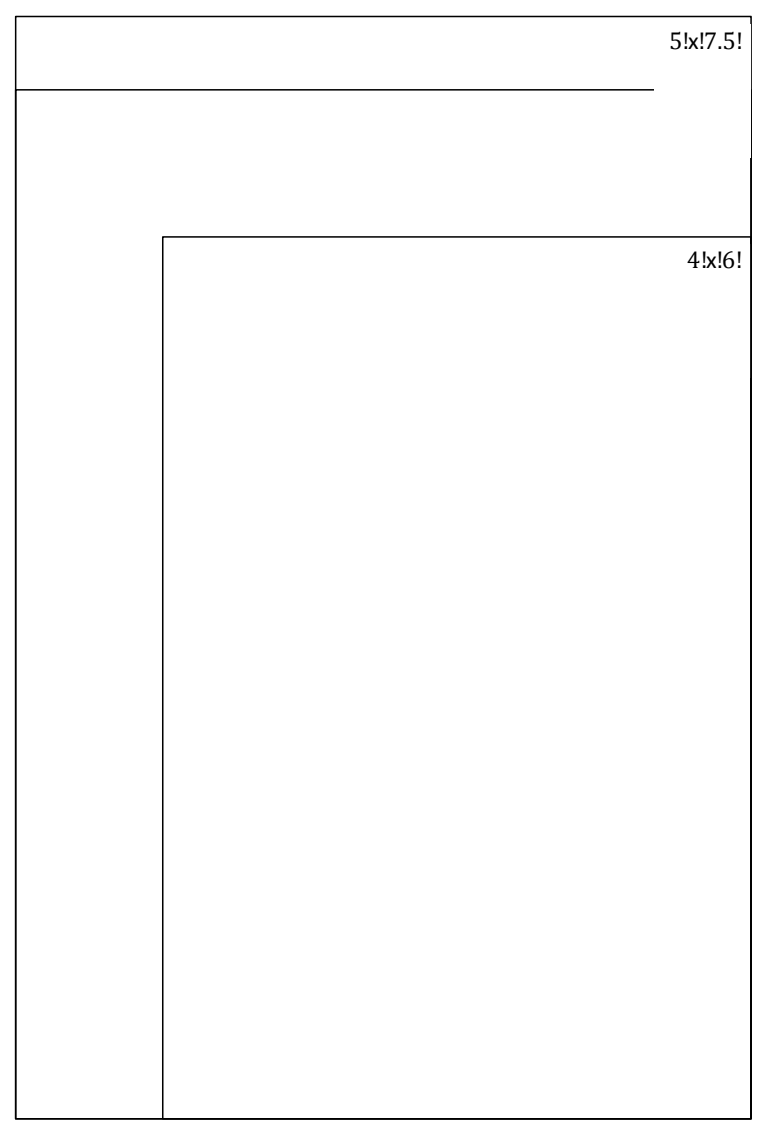

Figure 29. My mathematization of a problem from photography posed by Sasha

\section{Summary and Discussion}

Summary of findings. The role of context in Sasha's reasoning prior to taking Basic Math and the lack of affordances for contextual reasoning in Sasha's Basic Math classroom is the primary finding discussed in this chapter. The absence of opportunities to describe ratio and proportions within the context of the Basic Math curriculum likely contributed to the procedural understanding of proportion Sasha developed over the course of the term, another finding discussed in this chapter. Finally, as discussed in 
Chapter 5, unit rate strategies were problematic for many participants prior to enrolling in Basic Math, and Sasha's story confirms this previous finding, but also suggests how a student's experience with rate in a course like Basic Math may not be sufficient to address students' difficulties with rate. These are significant findings, in particular for practitioners focusing their efforts on reforms to developmental mathematics curricula. In addition, Sasha's story suggests that there is far more to learn about community college students' experience in the classroom, a particular aspect of community college mathematics education overlooked by previous research (Mesa et al., 2014).

Lack of affordances for contextual reasoning. The first episode describing the interaction between Sasha's way of reasoning about proportional situations and the mathematics she encountered in Basic Math suggests that Sasha's experience in Basic Math led her to take the advice she gave her daughter:

I tell her to group the numbers together and kinda forget about the words. And just worry about the numbers. Then go back to the words and see if your answer makes sense to the story line [Sasha, 22 December 2011].

Prior to the term, Sasha used her intuition that each flower stem is less than one dollar as she solved the first variation of the Flower Stem problem. When she approached this problem after she completed Basic Math, she first solved the problem correctly using a proportion equation, which was the strategy Ms. Rose emphasized in class. Sasha then proposed an incorrect unit cost strategy when I asked how she might solve this problem while shopping. She now had a unit cost strategy, which she did not prior to the term, but when she incorrectly concluded that each flower stem cost $\$ 1.20$, she did not 
recognize that this was not reasonable. The intuition about this problem that Sasha invoked prior to taking Basic Math was gone.

Neither contextualizing mathematics nor using everyday contexts to explore mathematical structure was emphasized in Sasha's Basic Math classroom. Ms. Rose often drew upon contexts from her students' and her own everyday experience, but these references seemed to be Ms. Rose's way acknowledging students' experience rather than as a context for problem posing or problem solving. The curriculum materials used in the course did not ask students to interpret the ratios they were asked to simplify and did not highlight the multiplicative relationships between quantities in contextual situations involving proportion. Over the course of the term, the examples considered in class and the assignments students completed outside class had as a primary focus on developing procedural fluency. Contextual problems were included in almost every section of the text, but these problems were assigned less often than procedural exercises. Sasha was assigned 996 exercises and problems over the course of the term; $21 \%$ of these might be classified as contextual. The percentage of contextual problems assigned from each chapter varied from $0 \%$ (Primes and Multiples) to $48 \%$ (Percent). It is not surprising that Sasha abandoned reasoning using the context of a problem over the course of the term and took the advice she had given her daughter to ignore the words and group the numbers together.

The second episode illustrated that when Ms. Rose invoked a context that was familiar to Sasha, she did draw upon her everyday experience, but Sasha's observation that a no one enlarges a 3 " $\times 5$ " photograph to 5 " $\times 81 / 3$ " was not taken up 
mathematically. In the previous chapter, I described the day that Ms. Rose introduced the concept of percent. When Ms. Rose asked the students how they understood 20\%, Sasha (and others) replied 20 cents on a dollar (see Section 5.4). During our conversations outside class, Sasha told me how she used the 'money perspective' to reason about some computations with decimals. However, this money perspective and Sasha and others' emerging understanding of a percent as rate was not taken up in the classroom as a context in which mathematical understanding might be grounded.

Focus on procedural understanding of ratio and proportion. In our last interview, Sasha told me that, "The proportions made a lot of sense, like how to figure things out. So I think I did pretty well on that" [2 April, 2012] and Sasha did solve the variation of the Flower Stem problem successfully by writing and solving a proportion equation. It is important that Sasha was confident using this strategy. Prior to the term Sasha was confident that each flower stem cost less than one dollar, but she was not as confident that the strategy she was using would result in the unit cost she sought. There was something lost over the term, but also something gained. The second time Sasha solved this variation of the Flower Stem problem, she did not rely on an intuition about how much each flower stem cost. But Sasha had confidence: she had been successful in Basic Math, she was starting a new term in Introductory Algebra, and she had mastered many of the procedures she learned in Basic Math.

I argue that was gained was procedural knowledge. Procedures are useful tools for mathematical reasoning and problem solving. But prior to the term Sasha was able to solve almost every mathematical problem posed to her during our first interview without 
having access to procedures, although this sometimes led to inefficient strategies such as the halving strategy Sasha used to find the unit cost of flower stems. After Basic Math, Sasha would have likely been able to solve the problems from the first interview, but there were few - if any - opportunities for Sasha to build on the ways of thinking she brought to class in order to develop a conceptual understanding of ratio as a multiplicative comparison between quantities and the two types of multiplicative relationships within a proportion. At the end of the term, what Sasha understood about proportion was divorced from an understanding of ratio. Before Sasha reconsidered the variation of the Flower Stem problem in our last interview and after Sasha told me she had mastered proportions, Sasha and I had discussed a few problems from her final exam. One of these was the following: "Write a ratio to compare 17 feet to 13 feet." I intended to ask Sasha how she interpreted this ratio, but learned instead that Sasha had “totally blanked on doing ratios. Ratios. I know the word, but I don't know what I am supposed to do" [2 April, 2012]. However, when solving the First Variation of the Flower Stem problem prior to the term, Sasha operated with the composed unit - or ratio -18 stems for $\$ 15$. If Sasha had the opportunity to develop a conceptual understanding of proportion, a ratio might be understood as one of the two multiplicative relationships in a proportion rather than a procedure Sasha had forgotten by the time she sat for her final exam. The emphasis in Sasha's classroom community was on writing and solving proportion equations as the students worked on the chapters on ratio, proportion and percent. Although Ms. Rose highlighted the multiplicative relationships, these relationships were never used to reason to a solution. One might ask why students spend time on this strategy in Basic Math when it was a strategy rarely used by students on the 
survey and during the task-based interviews. For Sasha, writing and solving a proportion equation became an accurate procedure she could to solve problems and it mitigated her fear of algebra, but this procedure was a barrier to further opportunities to engage the experience and ways of thinking Sasha brought to Basic Math.

The difficulty with unit rate. As discussed in Chapter 5, unit-cost and unit-rate strategies were problematic for both the students surveyed and the interview participants. These strategies became problematic for Sasha as well. After the term ended, Sasha used an incorrect unit-cost strategy on the first variation of the Flower Stem problem. Since Sasha did not have a unit-cost strategy at the start of the term, it could only have been Sasha's experience in Basic Math that led her to use a unit-cost procedure rather than rely on her intuition about the unit cost of the flower stems when solving the problem. Sasha and her classmates spent one four-hour class period on the chapter about ratio and proportion. The first section of the text introduced ratio, rate, simplifying ratios, which was procedurally similar to reducing fractions even though the quantities had units of measurement attached, and writing unit rates by dividing the numerator by the denominator. In class, Ms. Rose selected a price comparison problem to illustrate unit rate, building on students' experience with unit cost. The students practiced writing and simplifying ratios and rates, but they were not asked to interpret ratios and rates. Yet during the same class period, the students also learned to solve proportion equations and how to write proportion equations to solve proportion problems. After Ms. Rose defined a proportion as a statement that two ratios are equivalent, ratios and rates were never again an explicit topic of discussion. The phrase 'at the same rate' was used in the statement of several of the contextual problems students were asked to solve in the 
textbook, but the meaning of this phrase was not discussed. There were few - if any opportunities for Sasha to make sense of unit-rate strategies for solving proportion problems in her Basic Math class.

The findings from this study indicate that unit-rate strategies are one example of a poorly recalled procedure that students use without understanding. Although students in Sasha's classroom did not explicitly use the percent formula, $A=R B$, Sasha and many her classmates would be seeing this formula, the formula $d=r t$ and studying functions of the form $y=k x$ in their next mathematics course. Understanding percent as a rate, constant speed as a rate and direct variation underlie the use of each of these formulas. Many students, including Sasha, came to Basic Math able to recognize multiplicative relationships between quantities of the same type such as three flower stems to 15 flower stems. Students' time in Basic Math might be better spent building on their ability to recognize one of the multiplicative relationships in a proportion to develop an understanding of unit rate that addresses both why we divide when computing a unit rate and why we multiply one of the two quantities by the appropriate rate to obtain a value of the second quantity.

Implications for practice. Several questions for practitioners emerge from the findings discussed in this chapter. The first two involve the role of proportional reasoning in developmental mathematics: Should proportional reasoning be a feature of the developmental mathematics curriculum? If the answer to this question is yes, then to what extent is proportional reasoning an outcome of courses in the developmental mathematics sequence? The first question has been answered. The extensive and 
continuing research on proportional reasoning indicates its importance within the mathematics curriculum: "proportional reasoning is both the capstone of elementary arithmetic and the cornerstone of all that is to follow" (Lesh et al., 1988, p. 95). Those of us who teach mathematics at a community college need to query our own understanding of what constitutes proportional reasoning and about the role of proportional reasoning within the developmental mathematics curriculum. The conception of proportional reasoning upon which this study was grounded was not a feature of what Sasha learned in her Basic Math classroom. The intended curriculum for Sasha's Basic Math course included the following references to proportion: Vocabulary, Proportion; Computation, Solve proportion problems for missing value; and Application, Identify and solve problems that involve reasoning about proportions. ${ }^{59}$ Yet the curriculum materials used in the course did not support reasoning about proportions (see Section 6.3.2) and the enactment of the curriculum in Sasha's Basic Math class was highly influenced by the text. Sasha, who arrived to Basic Math wanting to improve her knowledge of multiplication facts, may have been better served by a curriculum that emphasized the multiplicative relationships between quantities within a problem that could be modeled using proportions. Instead, Sasha learned a procedure to solve proportion problems, which she used to solve a problem that could have been quickly solved - without pencil and paper - using one of the multiplicative relationships between the quantities. For this reason, a final question emerges for those of us who teach these courses: Is writing and solving proportion equations a skill that needs to be taught in a course like Basic Math or within the developmental mathematics curriculum at all?

${ }^{59} \mathrm{http}: / /$ www.pcc.edu/ccog/default.cfm?fa $=$ ccog\&subject=MTH\&course $=20$ 
There are several ways that a more formal understanding of proportion might be developed from reasoning like that which Sasha brought to Basic Math. One conjectured trajectory might build upon understanding a composed unit as a ratio and developing an understanding of the relationship between ratio and proportion. For example, prior to the term Sasha operated on ratios as composed units. Even if she did not know that 400 was five times 80 , she was able to build up the ratio 80 pounds of flour for fifty people for four works to 400 pounds for 250 people for four weeks. Sasha's goal was to build up one ratio to an equivalent ratio that related an amount of flour with 250 people; the understanding that a proportion is a statement of the equivalence of ratios was implicit in her strategy. Next, Sasha could be supported in recognizing the particular multiplicative relationship between. In a classroom community that includes ways of thinking proportion that were evident in the survey, it is likely that some of Sasha's classmates recognize the value of the multiplicative factor between quantities in a proportion. Making the multiplicative relationship explicit between quantities of the same type, for example, the number of people attending the camp, is an important facet of proportional reasoning: "[Proportional reasoning] would consist of the ability to discern a multiplicative relationship between two quantities as well as the ability to extend the same relationship to other pairs of quantities" (Lamon, 2007, p. 638). Using this particular form of reasoning could be the primary strategy for solving problems involving proportion in a course like Basic Math. When the factor that relates quantities are not integers, students like Sasha will have the opportunity both to identify and to operate with non-integer factors, another important skill to develop in a course like Basic Math. 
Finally, students need to consider an alternate strategy for solving proportion problems based on computing the unit rate. In the case of the Bread Flour problem, students might consider the following: If the duration of the campers stay (four weeks) remains fixed, how would we compute the amount of flour needed for any number of people? Sasha - when solving the first variation of the Flower Stem problem understood she could solve the problem if she could compute the cost per stem. Similarly, the Bread Flour problem could be solved if we knew the number of pounds of flour needed for one person. Determining the unit rate by halving the composed unit of 80 pounds for 50 people may not be the most efficient way to determine the unit rate, but it would be a reasonable way to start. Sasha might observe that 40 pounds is needed for 25 people, but would perhaps she might stop here because halving again would yield 20 pounds for 12.5 people. Another student might observe that both quantities are divisible by five, so 40 pounds for 25 people is equivalent to eight pounds for five people. Dividing by five again yields $8 / 5$ pound or 1.6 pounds for one person. The observation that the unit rate, in the case of the Bread Flour problem, could be found directly by diving the number of pounds of flour by the number of people in the given composed unit or ratio, should come from the students' understanding rather than as a procedure to compute unit rates. It is important that students have many opportunities to engage with this form of reasoning, that is, determining the unit rate and using this to relate two quantities of different types, prior to representing this relationship algebraically. However, representing each quantity with a variable and relating the two quantities by multiplying one with the appropriate rate, would be a more appropriate way to introduce the algebraic representation of a proportional that the proportion equation strategy Sasha 
learned in her Basic Math course, because the product of the unit rate and one of the two variable quantities represents the other variable quantity; the algebraic expression has meaning. When students set the cross products equal when solving a proportion equation, the products have no contextual meaning. For example, the expression $50 x$ would represent the product of 50 pounds by $x$ people, which is not a meaningful expression. In order for students to appreciate algebra as a problem-solving tool, the first expressions and equations they encounter should represent meaning quantities and relationships between quantities.

Implications for further research. In order to better understand the extent to which is proportional reasoning an outcome developmental mathematics courses, researchers could conduct a content analysis of intended curricula and curricular materials, using a model such as that used by Stylianides to examine middle school mathematics curricula for reasoning and proving (Stylianides, 2009). Stylianides developed an analytic framework in four stages. The first stage involved a review research literature on reasoning and proof. This review led to a preliminary analytic framework that was tested on both reform and traditional middle school textbooks. In this stage, Stylianides compared the definitions of the existing framework categories to determine whether the features of a task indicated differences that would lead new categories or adjustment of existing categories to include those features. The revised framework that emerged from this stage was reviewed by other mathematics education researchers and mathematicians in order to determine whether framework was sufficient to capture affordances for reasoning and proving in textbook tasks. The final stage involved making minor refinements by using the framework to analyze more tasks from 
both reform and traditional texts. The four-strategies framework (discussed in Chapter 5) adapted from previously constructed frameworks of proportional reasoning was robust enough to cover the different strategies and ways of thinking that adult students brought to bear on problems involving proportional reasoning. An analytic framework such as the four-strategies framework could be used to analyze affordances for proportional reasoning in developmental mathematical texts, in order to better understand the character of problem solving with proportions in developmental mathematics curricula. Currently, developmental mathematics curricula are evolving and a variety of curriculum projects are underway. One of these projects, Mathematics Literacy for College Students, calls out proportional reasoning one of its outcomes. The particular learning outcome is stated as follows: "Students will represent proportional relationships and solve problems that require an understanding of ratios, rates, proportions and scaling." However, one of the three particular outcomes stated under this general outcome states, "use symbolic methods with proportions to solve arbitrary as well as applied problems," suggesting that there may be more emphasis on procedure than on developing a conceptual understanding of ratio, rate and proportion. It is an opportune time to take a critical look at the students' opportunities to engage in the particular forms of reasoning that are the intended outcomes for emerging curricula.

Sasha's story is just one student's story. How typical is her experience? For example, to what extent do adult returning students suppress their everyday mathematics in the developmental mathematics classrooms and what happens when they offer their everyday knowledge when it interferes with problems presented in class, such as the

\footnotetext{
${ }^{60} \mathrm{http}: / / \mathrm{dm}$-live.wikispaces.com/Mathematical+Literacy+for+College+Students
} 
photograph enlargement problem presented in Sasha's classroom? Developing an observation protocol that could be used in a variety of development mathematics classrooms and over a large scale might be one way to address these questions. For example, trained observers could note occasions when context is invoked in class. Is the context invoked by the teacher or by a student? How is context invoked? For example, context may be invoked in a problem worked as an example by the teacher or in a problem posed to students. A student might introduce a context. For example, when ratio is introduced a student might offer that he uses a particular ratio of gasoline to motor oil in his chain saw, or a student may object to a proposed context for a problem in the way Sasha objected to the photograph enlargement problem posed by Ms. Rose. Another dimension of the role of context that could be observed is the extent to which problems and problem solutions are grounded in context. For example, the photograph enlargement problem was a superficial application of proportional reasoning because no one prints 5 inch by $81 / 3$ inch photographs. However, posing the question, "How would a three inch by five inch photograph be cropped if it is enlarged to a five inch by eight inch print?" uses context in a different way. In addition, to what extent to students or the teacher test the reasonableness of a proposed solution in the context of the problem. An observation protocol that would captured the various dimensions of the role of context in developmental mathematics classrooms would provide a large-scale data set that could be analyzed to learn the extent to which adults' everyday mathematics is visible in their classrooms.

In addition, as the interchange around the photograph problem in Sasha's classroom revealed, it is difficult work to mathematize adult students' everyday 
experience when these experiences emerge in the classroom. What tools do faculty need to build on the mathematics and experience that students bring to the classroom? A first step might be to collect data of mathematics teaching in a large number of community college mathematics classrooms and to find examples of teachers who are developing tools that allow them to build on students' experiences in mathematically significant ways. These examples could then be used to write case studies that describe this form of practice. This is an important question because we want students to understand mathematics as relevant and useful, but if teachers cannot build on students' experiences and ways of thinking, then we risk losing students to mathematics.

Conclusion. The short answer to the research question, "How did Sasha's ways of reasoning about proportion interact with the mathematics in her classroom?", is that there was no interaction; Sasha's ways of reasoning did not become part of the repertoire of tools members of the classroom community used to solve proportion problems. Instead, Sasha became enculturated into the expert practices valued in her classroom community and this is not a bad thing if Sasha is to be successful in developmental mathematics. For example, at the start of the term, Sasha told me she wanted to be able to perform mental computations, and in particular, using multiplication. Although mental computational strategies was not an explicit topic in her Basic Math course, she did learn multiplication facts, such as the one that led her to determine that $0.5 \times 3=1.5$, that we discussed the day she solved a proportional equation on the board. Sasha was introduced to more efficient strategies, such as the unit-cost strategy she used the second time she approached the variation of the Flower Stem problem; the strategy she used prior to the term on this same problem involved halving the composed unit 18 stems to $\$ 15$ to 
determine the unit cost, which Sasha knew had to be under $\$ 1$ per stem. However, Sasha remained grounded in the context of the problem when the context mattered to her, as was the case with the photograph enlargement problem she reacted to in class.

It was the missed opportunities for learning that resonated with me as I came to know Sasha over the term and as I started to understand her experience in the Basic Math class. For example, when I mathematized the photograph enlargement problem, which for Sasha became a problem about the ways a picture was being cropped as it is enlarged or reduced, I learned something about the mathematics of Sasha's problem. Sasha's problem had the potential to become a better application of proportional reasoning than the problem posed in class, a problem like problems I know I myself have posed as a teacher. Listening to our students' experiences and ways of reasoning is a first step to building on what they bring to the classroom. 


\section{Chapter 7: Discussion and Conclusion}

This study is grounded on a conceptual framework that connects three areas of previous research: research on proportional reasoning, research on adults' everyday mathematical practices, and research on the differences between mathematics learning outside and within school. These areas of research, as well as my own practice as a community college mathematics instructor, suggested the three questions I explored in this study:

(i) What are the backgrounds of students who enroll in a Basic Math course and what are their experiences of mathematics in their lives and in school?

(ii) What proportional reasoning abilities do students placing into Basic Math demonstrate prior to returning to school mathematics? and

(iii) How does a student's proportional reasoning abilities interact with the mathematics he or she encounters in a Basic Math class?

This final chapter begins with a summary of the findings that emerged from each question and continues with a brief review of the implications for practice and research discussed in the previous three chapters. The subsequent discussion focuses on the ways this study and similar studies might advance a research agenda that focuses on community college mathematics education. Limitations of the study are addressed and the chapter concludes with claims about the significance of this work. 


\section{Summary of findings}

Question 1. The maturity of Basic Math students, the time they have been away from school and the statistic that nearly half of the students reported that they require more than a review of the central topics studied in Basic Math suggest that the expectation that students need to review particular topics and that they are accessing knowledge resources from prior schooling may not be reasonable. Instead, further inquiry into students' mathematical ways of thinking about the everyday activities they perceive as mathematical could support the development of curricular materials that draw upon the knowledge resources that Basic Math students are accessing.

Adult returning students perceive a variety of activities from their everyday lives as mathematical. These activities were in alignment with Bishop's six pan-cultural mathematical practices (Bishop, 1988), which he claims are the foundation of formal mathematics. Everyday activities that involve counting (or computing) and measuring could be leveraged to connect informal ways of reasoning students bring to Basic Math to the formal mathematics they encounter in the course. In addition, the interview data revealed that some students' experience with everyday mathematics conflicted with their expectations - based on prior experience - for mathematics in school. Everyday math was contextualized and reasonable for some research participants, in particular JR, Lily and Sasha, and for many school mathematics is rigid; exact answers are expected and context does not matter. These findings confirm findings from previous research on the differences between mathematics learning outside school and within school. In particular, that symbol manipulation is a focus of school mathematics, whereas contextualized reasoning is used outside school (Resnick, 1987). 
Question 2. Whereas adult students' everyday experience was extensive and adults had experience reasoning within a variety of quantitative situations, the survey and interview data suggest that adult students come to a course like Basic Math positioned at some point along the trajectory of proportional reasoning described in the research literature and developed from studies with younger students. Informal strategies, such as iterating or building up a composed unit, were used to reason about problems where the multiplicative relationship between quantities was not immediately evident, such as was the case with the Bread Flour and Comparing Speeds problems. Scalar reasoning was used when students recognized a multiplicative relationship between quantities, such as the relationship between three and 15 flower stems or four pounds of flour for one week and 16 pounds of flour for four weeks. When the multiplicative factor was not an integer, as was the case in the Comparing Speeds problem, explicitly reasoning with a non-integer factor was rare. However the factor of 2.5 was implicit in the building-up strategies students used to reason about the problem. However, on a given problem, students used a variety of strategies, an important finding because these adult students brought multiple ways of approaching proportional reasoning problems and were reasoning in ways that would likely differ from the strategies they will encounter in Basic Math. This finding is exciting because in any Basic Math class we should find the variety of ways of reasoning along this developmental trajectory. Teachers might leverage these ways of thinking in the classroom: strategies involving a composed unit make the ratios in a proportion explicit; recognizing the scalar that represents the multiplicative relationship between quantities of the same type; and finally, making visible the scalar that represents the multiplicative 
relationship between quantities of different types, the unit rate. However, unit-rate strategies were problematic for students. For example, unit-rate strategies were used on $29 \%$ of the solutions to the Flower Stem problem, but none of these solutions attempts used the correct unit rate. On the Comparing Speeds problem twice as many unit-rate strategies used an incorrect rate rather than a correct rate. This is significant because of the importance of the concept of rate in both developmental and college mathematics curricula.

The four-strategies framework was robust enough to capture the strategies and ways of thinking that adult students bring to bear on proportion problems. This framework was adapted from frameworks developed using research with younger students, but remains aligned to these previous frameworks. This particular finding suggests that studies of adult students' mathematical strategies and ways of thinking in domains other than proportional reasoning might be informed by previous research with younger students. However, adult students' experiences are more extensive than younger students and the finding that adult students' reasoning often remained grounded in the context of a posed problem suggests one significant difference between adult and younger students' proportional reasoning.

Question 3. Sasha's story illustrates instances of the findings from the first two research questions. She was 29 years old when she enrolled in Basic Math and was a mother of five. She had a variety of work experience and had been managing a household for many years prior to returning to school. Sasha used building-up and scaling strategies when reasoning about the mathematics tasks on the survey and during the interview, and she did not have a unit rate strategy prior to enrolling in Basic Math. 
But Sasha's story also teaches us that the relationship between adult students' contextual reasoning and school mathematics is complex. Sasha perceived many of her everyday activities as mathematical. For example, managing a restaurant and taking care of her family contributed to her facility with mental operations when she used the 'money perspective,' For example, knowing that there are 20 nickels in one dollar was the basis of her knowledge of the product of five and 20 and although Sasha had difficulty halving odd numbers, she knew that half of $\$ 5$ is $\$ 2.50$. Sasha also worked with reasonable estimates. As Sasha progressed through Basic Math, she held onto this 'money perspective' to make sense of operations with decimals and her emerging understanding of percent as a rate.

Sasha used building-up and partitioning strategies when reasoning about problems during the task-based interview conducted prior to the term. These strategies were grounded on her facility with doubling and halving strategies and the contextual reasoning she brought to bear on problem solving. However, Sasha's building-up and partitioning strategies did not become part of the repertoire of tools used within the Basic Math classroom community and she was not provided opportunities to connect her informal ways of reasoning about proportions to an understanding of proportions based on multiplicative relationships between quantities.

Sasha's experience in Basic Math also interacted with the ways she used context to reason. In the classroom community, mastering procedures for operating with numbers and becoming proficient with one procedure for solving proportion problems writing and solving a proportion equation - dictated expert performance. Students' everyday mathematics was not a resource that framed expert performance. Although 
connections were made between adult students' everyday experience and the topics they explored in Basic Math in Sasha's classroom, leveraging these experiences and informal ways of reasoning did not become part of the repertoire of tools members of the classroom community used in practice. These experiences and ways of reasoning were not recognized in terms of what it meant to be an expert practitioner in Sasha's Basic Math course. This may explain Sasha's lack of conceptual understanding about proportion at the end of the term. For example, she never made the connection between ratio and proportion even though she was reasoning with equivalent ratios prior to the term.

Summary. The variety of strategies and ways of thinking about proportions that adult students bring to Basic Math parallel what is known about the development of proportional reasoning with younger students. Different students in a Basic Math classroom could potentially be thinking about a problem at different places along a developmental trajectory. For example, students using an iterated-composed-unit strategy or a building-up strategy are making explicit one of the two multiplicative relationships in a proportion. Also, reasoning with a composed unit highlights the role of the ratio within a proportion. As students become comfortable recognizing one of the multiplicative relationships in a proportion, they can start to explore the second multiplicative relationship and the role of the unit rate in determining how one quantity varies with respect to the other quantity.

Students in developmental mathematics courses such as Basic Math and beginning algebra are expected to model situations involving direct variation, using relationships such as $A=R B, d=r t$ and $y=k x$; they are expected to develop a functional 
understanding of proportional situations. Although there was an emerging understanding of percent as a rate among some of the research participants, students typically used unit rates procedurally and without understanding, suggesting that this is a topic that should be emphasized more in the developmental mathematics curriculum. In a course like Basic Math students could explore models of direct variation, focusing on the relationship between two quantities rather than on the symbolic representation of the relationship, which is a topic better suited for an algebra course. In addition, students' reasoning about the Bread Flour problem suggests that models of joint variation might be explored informally prior to college-level mathematics courses.

\section{Implications for practice and research}

Implications for practice. The findings of this research suggest the following implications for practice:

- A course like Basic Math might be transformed from an arithmetic review course to a course that serves as a bridge between adult returning students' mathematics and the skills and understanding necessary for success in developmental mathematics.

- Findings from proportional reasoning research conducted with younger students might be leveraged in courses like Basic Math, since adult students use similar strategies to reason about proportion problems.

- Computing unit rates, such as unit cost or average speeds, needs to be problematized within the developmental mathematics curriculum. That is, defining a unit rate as a ratio with a denominator of one seems to be insufficient for using unit rates as a tool for problem solving. 
- Practitioners should interrogate the importance of proportional reasoning within courses that prepare students for college-level mathematics, and if this is found to be an important understanding, take a critical look at course design and curricular materials for affordances for students to engage in proportional reasoning.

- Adults use the context of a problem as a tool for reasoning. One implication of this finding is that curriculum materials and classroom instruction might move beyond using everyday contexts to connect mathematics to students' lives. Problems situated in everyday contexts might be used to reveal mathematical structure and bridge informal ways of thinking to the more formal ways of thinking expected in school. Developmental research conducted under the framework of Realistic Mathematics Education (Gravemeijer, 1998) and undertaken in collaboration with practitioners could be used to develop activities that bridge informal and more formal mathematics. For example, the scalar reasoning used by many adult students prior to Basic Math was used to reason about the relationship between quantities of the same type. Building on this was of reasoning, students could be encouraged to explore the multiplicative relationship between the two quantities of different types in order to uncover the unit rate that relates these two quantities.

Implications for research. The findings of this research suggest the following implications for research: 
- We need to better understand the ways adult returning students position themselves with respect to the mathematical topics they encounter in developmental mathematics courses so that practitioners are better able to design these courses. Research questions that might explore this topic include "How do adult returning students perceive their understanding and proficiency with common fractions such as those used in cooking or measurement?" or "How do adult returning students perceive their understanding and proficiency with decimal arithmetic when the numbers are like the familiar numbers used to represent currency?"

- We need to better understand the nature of the mathematics that adults perceive in their everyday mathematical activities and how are these ways of thinking related to the more formal mathematics students encounter in a course in like Basic Math. Research questions that might explore this topic include "What aspects of gaming [or shopping or budgeting] do adults students perceive as mathematical?"

- We need to better understand the role of context in adult students' mathematical reasoning and query whether this is a dimension along which adults' mathematics differs from children's, since the strategies and ways of thinking about proportion that adults brought to bear on the mathematical tasks used in this study resembled those of younger students. Research questions that might explore this topic include, "In what ways do adult students reference everyday mathematical contexts in a developmental mathematics classroom?", "To what extent is the context of a posed problem used by adult students as a tool for 
reasoning about the problem?" or "Do younger students use the context of a posed problem as a tool for reasoning and if so, how is this similar to or different from the ways adults use context to reason?"

- The four-strategies framework adapted from previously constructed frameworks of proportional reasoning was robust enough to cover the different strategies and ways of thinking that adult students brought to bear on problems involving proportional reasoning. The four-strategies framework could be used to develop survey questions for collecting data on adult students' proportional reasoning or as a framework for conducting a content analyses of new curricula for developmental mathematics courses should be undertaken in order to determine whether affordances for fundamental ways of reasoning, such as proportional reasoning, are present.

- It is important to understand how typical Sasha's experience is. Research questions that might explore this topic include "To what extent do adult returning students suppress their everyday mathematics in the developmental mathematics classrooms and what happens when they offer their everyday knowledge when it interferes with problems presented in class, such as the photograph enlargement problem presented in Sasha's classroom?"

\section{Advancing a research agenda in community college mathematics education}

Answers to two fundamental questions are necessary for advancing a research agenda in community college mathematics education: (1) In what ways are adult students' mathematical reasoning similar to or different from younger students' reasoning about particular concepts, such as proportional reasoning, and (2) How can 
community college mathematic instructors and curriculum developers accommodate students who are 'relearning' content in a course like Basic Math? (Mesa et al., 2014). Each of these questions interrogates whether a research agenda in community education is necessary, and I claim that the findings from this study asserts that this research agenda is a priority.

The 'problem' of developmental mathematics education is under scrutiny, but this scrutiny overlooks the experiences and ways of knowing of students who enroll in developmental mathematics courses. This study examined each of these areas. Adult students perceive many of their everyday activities as mathematical, and many have developed computational strategies that serve them well. I would conjecture that adults' experiences and the necessity to perform computations in their everyday activities distinguish adults' reasoning about 'elementary' mathematics from younger students' reasoning. One apparent difference appears to be adults' ability to use the context of a problem to reason and to check the reasonableness of the solution. A critical look at the role of context for adult learners and younger learners encountering the same mathematical concepts is necessary.

The relearning issue is subtler. About one half of the students who enroll in Basic Math assert that course topics are review. However, remaining half of students tell us that many of the topics taught in Basic Math are topics with which they struggled in school. If topics are review, what do students understand about these topics? Lamon (2007) posed the following question as an outstanding one for further research on rational number and proportional reasoning: "Do algorithms preclude reasoning, or can 
older students develop useful knowledge about the central multiplicative structures?" Indeed, prior research has found that learning procedures prior to development of conceptual understanding interferes with this development (Pesek \& Kirshner, 2000). Sasha's story muddies these waters further. Although Sasha could solve proportion problems prior to the enrolling in Basic Math, she did not have access to school strategies for solving these problems. However, Sasha did keep the context of the problem in the forefront as she solved problems and the procedures she used were meaningful in the context of these problems. At the end of the term Sasha had learned new procedures, but these procedures were no longer meaningful within the context of the problem; it is unlikely that Sasha would pull out pencil and paper and write and solve a proportion equation to determine the cost of six flower stems. Sasha's story is not so much about relearning, but about superseding her ways of thinking with other ways of thinking without providing her the opportunity to make connections, which interfered with the development of conceptual understanding about ratio, rate and proportion. Adult returning students in community college developmental mathematics classrooms have much to teach us about questions around relearning mathematics topics.

\section{Limitations of the study}

The decision was made to use numerical values within the mathematical tasks that made the multiplicative relationships between quantities visible. For the most part, the scalars chosen were whole numbers. Exceptions were familiar non-integer factors such as 1.5 (the Better Buy problem) and 2.5 (the Comparing Speeds problem). It might be argued that if someone understands proportional relationships, they should be able to reason multiplicatively regardless of the nature of the scalars, and this is a valid 
argument. However, in our everyday mathematics, we typically reason with integers and common fractions, or round the numbers we encounter so that they are simpler to reason with. I wanted to access the reasoning adults use outside of school.

A second limitation of the study was not having enough students willing to participate in the interview in order to purposefully selected a sample as was originally intended in the design of the study. The students who participated in the interviews had a variety of motivations: Two of the interview participants appeared motivated by the opportunity to win the bookstore gift card. Another participant was trying to decide whether he should retake Basic Math (he had completed Basic Math at another community college three years prior to the study) or whether he should attempt Introductory Algebra again, a course he had started but never successfully completed. Other participants were excited to return to school and made comments that suggested that the interview was an opportunity to get a head start on their upcoming mathematics course. There is a self-selection bias to the data, but this bias seems to be mitigated by the fact that the interview finding mirrored findings from the survey.

The survey instrument and interview protocol could be improved. For example, Question 8 was written to determine whether students enrolled in Basic Math were reviewing topics explored in the course or needed to learn particular topics for the first time. Many students selected the first two options, suggesting that some of the listed topics were familiar, but other topics a student had struggled with previously. It would have been helpful to know which topic a student needed to review and which topic a student struggled with in school. Also, the option "Attending School" in the question 
that asked what the student had doing prior to enrolling in Basic Math was too vague to interpret the data. The Bread Flour problem had too many fours, which made analyzing some students' strategies on this problem difficult when their written did not indicate which four on which they were operating. One of the interview tasks was adapted by a problem written by Carlson and Oehrtman (2009) in order to query students understanding that traveling at a constant speed means that "we move a given distance in a given amount of time and that any segment of the total distance will require a proportional segment of the total time" (Thompson, 1994, p. 224). The original problem involved a person traveling 300 miles in 51/2 hours. The adapted problem used in the interview included two values that were divisible by five, 125 miles and $2^{1 / 2}$ hours, a decision made because the original task involved elevenths and during pilots of the original task no student reasoned with elevenths. Only Jesse reasoned with fifths as he reasoned about the adapted tasks, arguing that since $1 / 2$ hour is one-fifth of $2 \frac{1}{2}$, the person would travel one-fifth of 125 miles or 25 miles in $1 / 2$ hour. The other participants divided 125 miles by $2 \frac{1}{2}$ hours to determine that the person traveled 50 miles per hour and then halved this rate to answer the question. A better adaption of the problem might be, "A person travels 125 miles in $2 \frac{1}{2}$ hours at a constant speed, how far does she travel in $1 \frac{1}{2}$ hours?" In this case, a student might, for example, recognize the $1 \frac{1 / 2}{2}$ hours is three-fifths of $2^{1 / 2}$ and reason from this observation.

Finally, findings from the interview data could be used refine the survey instrument, developing items that could be tested for content validity. The survey could then be used to assess adult students' proportional reasoning on a larger scale. Such an assessment would be helpful if curriculum materials are developed to support the 
development of adults' proportional reasoning. Survey items could be used to measure whether or not students are learning what the curriculum developers intend the students learn.

\section{Conclusion}

If a goal of developmental mathematics at community colleges is to support the development of quantitative reasoning, then it is imperative that we build on students' ways of thinking prior to introducing them to the strategies and procedures. Students' ways of thinking must be validated, but - more importantly - connected to places along a developmental trajectory of proportional reasoning. Proportional reasoning constitutes one feature of quantitative reasoning. Formal proportional reasoning, as I conceived it, involves recognizing and modeling a particular type of relationship between quantities -

direct variation. Whether a student in developmental mathematics pursues a quantitative, statistical or algebraic reasoning pathway, understanding this representation of a proportion relationship is essential. The findings from this study suggest that the multiplicative relationship between quantities evident to students prior to the term, but not necessarily privileged in Basic Math classroom, could be the foundation for a more conceptual understanding of proportional relationships. 


\section{References}

Abreu, G. d. (2002). Mathematics learning in out-of-school contexts: A cultural psychology perspective. In L. D. English (Ed.), Handbook of International Research in Mathematics Education (pp. 323-353). Mahwah, NJ: Lawrence Erlbaum Associates.

American Association of Community Colleges. (2013). Community College Fact Sheet, from http://www.aacc.nche.edu/AboutCC/Pages/fastfactsfactsheet.aspx

Auerbach, C. F., \& Silverstein, L. B. (2003). Qualitative Data: An Introduction to Coding and Analysis. New York: New York University Press.

Bailey, T., \& Cho, S.-W. (2010). Developmental education in community colleges: Community College Research Center.

Behr, M., Harel, G., Post, T., \& Lesh, R. (1992). Rational number, ratio and proportion. In D. A. Grouws (Ed.), Handbook of research on mathematics teaching and learning (pp. 296-333). New York: Macmillan.

Benn, R. (1997). Adults Count Too: Mathematics for Empowerment. Leicester: NIACE.

Bishop, A. J. (1988). Mathematics education in its cultural context. Educational studies in mathematics, 19, 179-191.

Boaler, J. (1993). Enouraging the transfer of 'school' mathematics to the 'real world' through the integration of process and content, context and culture Educational studies in mathematics, 25(4), 341-373.

Capon, N., \& Kuhn, D. (1979). Logical reasoning in the supermarket: Adult females' use of a proportional reasoning strategy in an everyday context. Developmental psychology, 15(4), 450-452.

Carlson, M. P., \& Oehrtman, M. (2009). Pathways to Calculus: A Problem Solving Approach: Rational Reasoning.

Carraher, T. N. (1986). From drawings to buildings; Working with mathematical scales. International Journal of Behavioral Development, 9, 527-544.

Carraher, T. N., Carraher, D. W., \& Schliemann, A. D. (2004). Mathematics in the streets and in schools. In T. P. Carpenter, J. A. Dossey \& J. L. Koehler (Eds.), Classics in mathematics education research (pp. 187-193). Reston, VA: NCTM.

Coben, D., FitzSimons, G. E., \& O'Donoghue, J. (2000). Perspectives on Adults Learning Mathematics: Research and Practice. Hingham, MA: Kluwer Academic Publishers.

Confrey, J. (1994). Splitting, similarity and rate of change. In G. Harel \& J. Confrey (Eds.), The development of multiplicative reasoning in the learning of mathematics (pp. 291-330). Albany: State University of New York Press.

Cox, R. D. (2009). The College Fear Factor: How Students and Professors Misunderstand One Another. Cambridge, MA: Harvard University Press.

De Bock, D., Verschaffel, L., \& Janssens, D. (1998). The predominance of the linear model in secondary school students' solutions of word problems involving length and area of similar plane figures. Educational Studies in Mathematics, 35(1), $65-$ 83.

Dole, S., Copper, T. J., Baturo, A. R., \& Conoplia, Z. (1997). Year 8, 9 and 10 students' understanding and access of percent knowledge. In F. Biddulph \& K. Carr (Eds.), 
People in mathematics education (Proceedings of the 20th annual conference of the Mathematics Education Research Group of Australasia) (pp. 147-154). Rotorua, New Zealand: Mathematics Education Research Group of Australasia.

Donovan, M. S., Bransford, J. D., \& Pellegrino, J. W. (1999). How People Learn: Bridging Research and Practice. Washington, D.C.: National Research Council.

Duranczyk, I. M., Staats, S., Moore, R., Hatch, J., Jensen, M., \& Somdhal, C. (2004). Introductory-Level College Mathematics Explored Through a Sociocultural Lens. In I. M. Duranczyk, J. L. Higbee \& D. B. Lundell (Eds.), Best Practices for Access and Retention in Higher Education (pp. 43-53). Minneapolis, MN: Center for Research on Developmental Education and Urban Literacy, General College, University of Minnesota.

Eisenhart, M. A. (1988). The ethnographic research tradition and mathematics education research. Journal for Research in Mathematics Education, 19(2), 99-114.

Evans, J. (2000). Adults' Mathematical Thinking and Emotions: A Study of Numerate Practices. New York: RoutledgeFalmer.

Firestone, W. A. (1987). Meaning in method: The rhetoric of quantitative and qualitative research. Educational researcher, 16(7), 16-21.

Ginsburg, L., Gal, I., \& Schuh, A. (1995). What does "100\% juice" mean: Exploring adult learners' informal knowledge of percent. Philadelphia: National Center on Adult Literacy.

Goldin, G. A. (1998). Observing mathematical problem solving through task-based interviews. In A. R. Teppo (Ed.), Qualitative Research Methods in Mathematics Education (pp. 40-62). Reston, VA: National Council of Teachers of Mathematics.

Goldin, G. A. (2000). A scientific perspective on structured, task-based interviews in mathematics education research. In A. E. Kelly \& R. A. Lesh (Eds.), Handbook of research design in mathematics and science education (pp. 517-545).

Mahwah, NJ: Lawrence Erlbaum Associates.

Gravemeijer, K. (1994). Educational development and developmental research in mathematics education. Journal for Research in Mathematics Education, 25(5), 443-471.

Gravemeijer, K. (1998). Developmental research as a research method. In A. Sierpinska \& J. Kilpatrick (Eds.), Mathematics education as a research domain: A search for identity (pp. 277-295). London: Kluwer Academic Publisher.

Grubb, W. N., \& Worthen, H. (1999). Remedial/developmental education: The best and worst. In W. N. Grubb (Ed.), Honored but Invisible: An Inside Look at Teaching in Community Colleges (pp. 171-209). New York: Routledge.

Hoyles, C., Noss, R., \& Pozzi, S. (2001). Proportional reasoning in nursing practice. Journal for Research in Mathematics Education, 32(1), 4-27.

Hutchins, E. (1995). Cognition in the Wild Cambridge, MA: MIT Press.

Illeris, K. (2002). The three dimensions of learning. Malabar, FL: Krieger.

Inhelder, B., \& Piaget, J. (1958). The Growth of Logical Reasoning from Childhood to Adolescence (A. Parsons \& S. Milgram, Trans.): Basic Books.

Kaput, J. J., \& West, M. M. (1994). Missing value proportional reasoning problems In G. Harel \& J. Confrey (Eds.), The development of multiplicative reasoning in the 
learning of mathematics (pp. 235-287). Albany: State University of New York Press.

Lamon, S. J. (1993). Ratio and Proportion: Connecting Content and Children's Thinking. Journal for Research in Mathematics Education, 24(1), 41-61.

Lamon, S. J. (1994). Ratio and proportion: Cognitive foundations in unitizing and norming. In G. Harel \& J. Confrey (Eds.), The development of multiplicative reasoning in the learning of mathematics (pp. 89-120). Albany: State University of New York Press.

Lamon, S. J. (2007). Rational numbers and proportional reasoning. In F. K. Lester, Jr. (Ed.), Second Handbook of Research on Mathematics Teaching and Learning (pp. 629-666). Charlotte, NC: IAP.

Lappan, G., Fey, J. T., Fitzgerald, W. M., Friel, S. N., \& Phillips, E. D. (2006). Connected Mathematics 2. Boston: Pearson Prentice Hall.

Lave, J. (1988). Cognition in Practice: Mind, Mathematics and Culture in Everyday Life. New York: Cambridge University Press.

Lembke, L. O., \& Reys, B. J. (1994). The development of, and the interaction between intuitive and school-taught ideas about percent. Journal for Research in Mathematics Education, 25(3), 237-259.

Lesh, R. A., Post, T., \& Behr, M. (1988). Proportional reasoning. In J. Hiebert \& M. Behr (Eds.), Number concepts and operations in the middle grades (pp. 93-118). Reston, VA: National Council of the Teachers of Mathematics.

Lester, F. K., Jr. (2010). On the theoretical, conceptual, and philosophical foundations for research in mathematics education. In B. Sriraman \& L. D. English (Eds.), Theories of Mathematics Education (pp. 67-85). Berlin: Springer-Verlag.

Lobato, J., \& Ellis, A. B. (2010). Developing Essential Understanding of Ratios, Proportions, and Proportional Reasoning for Teaching Mathematics in Grades 6-8. Reston, VA: National Council of Teachers of Mathematics.

Lobato, J., \& Thanheiser, E. (2002). Developing understanding of ratio-as-measure as a foundation for slope In B. Litwiller (Ed.), Making Sense of Fractions, Ratios and Proportions. Reston, VA: National Council of Teachers of Mathematics.

Mack, N. K. (1990). Learning fractions with understanding: Building on informal knowledge. Journal for Research in Mathematics Education, 21(1), 16-32.

Masingila, J. O. (1993). Learning from mathematics in out-of-school situations. For the learning of mathematics, 13(2), 18-22.

Masingila, J. O., Davidenko, S., \& Prus-Wisniowska, E. (1996). Mathematics learning and practice in and out of school: A framework for constructing these experiences Educational studies in mathematics, 31, 175-200.

Mesa, V. (2010). Student participation in mathematics lessons taught by seven successful community college instructors. Adults learning mathematics, 5(1), 6488.

Mesa, V., Wladis, C., \& Watkins, L. (2014). Research problems in community college mathematics education: Testing the boundaries of K-12 research. Journal for Research in Mathematics Education, 45(2), 173-192.

Mezirow, J. (1991). Transformative dimensions of adult learning. San Francisco, CA: Jossey-Bass. 
Miles, M. B., \& Huberman, A. M. (1994). Qualitative Data Analysis: An Expanded Sourcebook (Second ed.). Thousand Oaks, CA: Sage Publications.

Millroy, W. L. (1992). An ethnographic study of the mathematical ideas of a group of carpenters. Reston, VA: National Council of Teachers of Mathematics.

Noelting, G. (1980a). The development of proportional reasoning and the ratio concept Part I: Differentiation of stages. Educational studies in mathematics, 11(2), 217253.

Noelting, G. (1980b). The development of proportional reasoning and the ratio concept Part II: Problem-structure at successive stages; Problem-solving strategies and the mechanism of adaptive restructuring. Educational studies in mathematics, 11(3), 331-363.

Noss, R., Hoyles, C., \& Pozzi, S. (2000). Working knowledge: Mathematics in use. In A. Bessot \& J. Ridgway (Eds.), Education of rmathematics in the workplace (pp. 17-35). Dordrecht: Kluwer

Parker, M., \& Leinhardt, G. (1995). Percent: A privileged proportion. Review of Educational Research, 65(4), 421-481.

Pesek, D. D., \& Kirshner, D. (2000). Interference of instrumental instruction in subsequent relational learning. Journal for Research in Mathematics Education, 31(5), 524-540.

Resnick, L. B. (1987). Learning in school and out. Educational Researcher, 16(9), 1320.

Schliemann, A. D. (1995). Some concerns about bringing everyday mathematics to mathematics education. In L. Meira \& D. W. Carraher (Eds.), Proceedings of the XIX International Conference for the Psychology of Mathematics Education, Vol. 1 (Vol. 1, pp. 45-60). Recife, Brazil.

Schliemann, A. D., \& Acioly, N. M. (1989). Mathematical knowledge developed at work: The contribution of practice versus the contribution on schooling. Cognition and instruction, 6(3), 185-221.

Schliemann, A. D., \& Carraher, D. W. (1993). Proportional reasoning in and out of school. In P. Light \& G. Butterworth (Eds.), Context and cognition: Ways of learning and knowing (pp. 47-73). Hillsdale, NJ: Lawrence Erlbaum Associates.

Schliemann, A. D., \& Nunes, T. (1990). A situated schema of proportionality. British Journal of Developmental Psychology, 8, 259-268.

Schoenfeld, A. H. (1985). Mathematical Problem Solving. Orlando, FL: Academic Press, Inc.

Scribner, S. (1984). Studying working intelligence. In B. Rogoff \& J. Lave (Eds.), Everyday Cognition: Its Development in Social Context (pp. 9-40). Cambridge, MA: Harvard University Press.

Sitomer, A., Ström, A., Mesa, V., Duranczyk, I. M., Nabb, K., Smith, J., \& Yannotta, M. (2012). Moving from Anecdote to Evidence: A Proposed Research Agenda in Community College Mathematics Education. The MathAMATYC Educator, 4(1), 35-39.

Spradley, J. P. (1979). The Ethnographic Interview. Belmont, CA: Wadsworth. 
Stigler, J. W., Givvin, K. B., \& Thompson, B. J. (2010). What community college developmental mathematics students understand about mathematics. MathAMATYC Educator, 1(3), 4-16.

Strauss, A., \& Corbin, J. (1998). Basics of Qualitative Research (2 ed.). Thousand Oaks, CA: Sage Publications.

Stylianides, G. J. (2009). Reasoning-and-proving in school mathematics textbooks. Mathematical Thinking and Learning, 11(4), 258-288.

Suarez, A. (1977). Formales Denken und Funktionsbegriff bei Jugendlichen. Bern: Verlag Hans Huber.

Thompson, K. (2003). Contingent faculty and student learning: Welcome to the strativersity. New Directions for Higher Education(123), 41-47.

Thompson, P. W. (1994). The development of the concept of speed and its relationship to concepts of rate. In G. Harel \& J. Confrey (Eds.), The development of multiplicative reasoning in the learning of mathematics (pp. 179-234). Albany: State University of New York Press.

Treisman, U. (2011). New Pathways to Success: Lessons Learned from Statway and Quantway. Paper presented at the American Mathematical Association of TwoYear Colleges, Austin, TX.

Valencia, R. R. (2010). Dismantling contemporary deficit thinking : educational thought and practice. New Youk: Routledge.

Van Dyke, J., Rogers, J., \& Adams, H. (2007). Fundamentals of mathematics. Belmont, CA: Thomson Higher Education.

Vergnaud, G. (1983). Multiplicative structures. In R. A. Lesh \& M. Landau (Eds.), Acquisition of Mathematical Concepts and Processes (pp. 127-174). New York: Academic Press.

Vergnaud, G. (1994). Multiplicative conceptual field: What and why? The Development of Multiplicative Reasoning in the Learning of Mathematics (pp. 41-59). Albany: State University of New York Press.

Vergnaud, G. (2004). Multiplicative structures. In T. P. Carpenter, J. A. Dossey \& J. L. Koehler (Eds.), Classics in mathematics education research (pp. 85-96). Reston, VA: NCTM.

Wedege, T. (1999). To know or not to know -- mathematics, that is the question of context. Educational studies in mathematics, 39, 205-227.

Wedege, T. (2000). Epistemological questions about research and practice in ALM. Paper presented at the Adults Learning Mathematics: A Research Forum, Medford, MA.

Wedege, T., \& Evans, J. (2006). Adults' resistance to learning in school versus competencies in work: The case of mathematics. Adults learning mathematics, 1(2), 28-43.

Wells, M. C. (1996). Literacies Lost: When Students Move from a Progressive Middle School to a Traditional High School. New York: Teachers College Press.

Wenger, E. (1998). Communities of Practice: Learning, Meaning and Identity. New York: Cambridge University Press.

Wolcott, H. F. (1994). Transforming Qualitative Data: Description, Analysis, and Interpretation. Thousand Oaks, CA: Sage Publications. 


\section{Appendix A: Survey instrument}

IF YOU ARE UNCOMFORTABLE ANSWERING ANY QUESTION ON THIS SURVEY, IT IS OKAY TO LEAVE THE QUESTION BLANK.

\section{Part 1: Information about your mathematics}

1. List all your activities from yesterday. Put an $M$ next to any activity that involved math.

2. I use math outside school

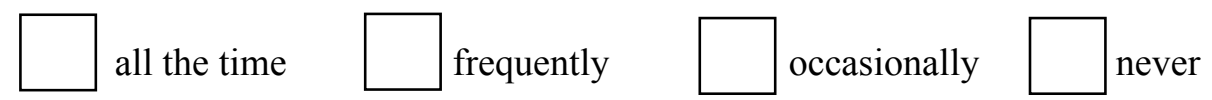

\section{Explain your reasoning on Questions 3-6. It is helpful to know how you determined the}

answer.

3. Valentine's Day is approaching, and you want to buy flowers for someone special. Three flower stems cost $\$ 2$. How much will 15 stems cost?

4. Fred Meyer is having a sale. A $\$ 35$ pair of jeans is marked $40 \%$ off. Can you buy the jeans for $\$ 20$ or less? How do you know?

5. A cook is planning for a group of 50 people who will spend 28 days at a summer camp. $\mathrm{He}$ needs to buy enough flour for baking bread and the cook knows that the average consumption of flour is 4 pounds per week for 10 persons. How much flour does he need to buy? 
6. Victor's van travels at a rate of 8 miles every 10 minutes. Sharon's sedan travels at a rate of 20 miles every 25 minutes.

If both cars start at the same time, will Sharon's sedan reach point A, 8 miles away, before, at the same time, or after Victor's van? Explain your reasoning.

If both cars start at the same time, will Sharon's sedan reach point B (at a distance further down the road) before, at the same time, or after Victor's van? Explain your reasoning.

7. Which of Problems 3-6 were easy for you? Which were difficult? Why?

8. In MTH 20, you will study ratios, proportions, fractions, decimals and percentages. Choose the category (or categories) that best describes your experience with these topics.

I felt good about these topics when I was in school, but I need a review.

I struggled with these topics in school.

I feel my math skills are good, but I am still learning English.

I am still learning English, but I also struggle with these topics.

None of the above

If none of the above, please explain.

\section{Part 2: Biographical information}

9. I am

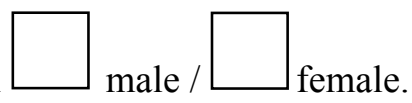

10. How old are you?

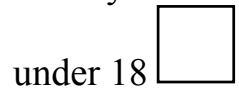

$18-21$

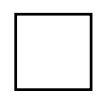

$22-26$

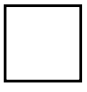

27-30

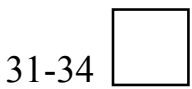

35-39

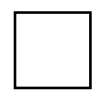

over 40

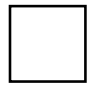


11. Is this your first term in college?
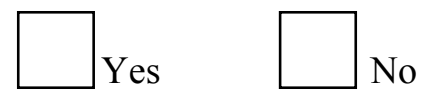

If not, how many terms or semesters have you been in college?

12. Has anyone in your family earned a certificate, an associate's degree, or a higher degree in college?

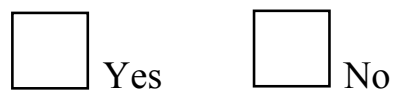

If yes, who?

13. Do your friends and family support your decision to attend college?

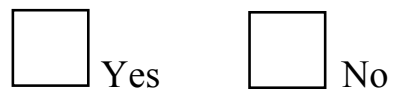

14. Have you taken MTH 20 at PCC before?

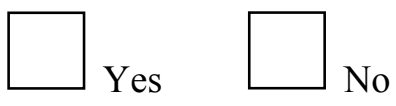

15. Have you taken another mathematics course at PCC or another college before?

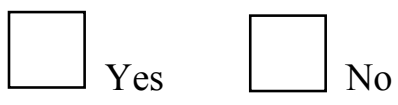

If so, what was the course and when did you take it? 
16. Before MTH 20, the last time you took a math class in school (high school/GED, college, job training) was

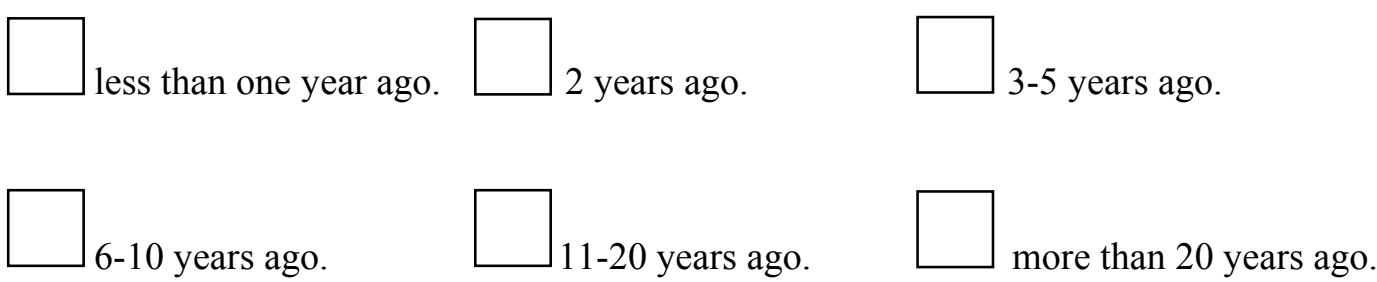

17. Before enrolling at PCC, what have you been doing? (Select as many choices as apply.)

\begin{tabular}{|lll}
\hline & attending school & \\
unemployed & working full-time & working part-time \\
raising a family & \\
other
\end{tabular}

18. What are your current educational goals? Check all that apply.

$\square$ I do not know at this time

Improve opportunities for employment

Complete a certificate program

Which program?

Complete an associate's degree

What degree?

Transfer to a four-year college or university to complete BA/BS degree What college and what degree?

Other 


\section{Appendix B: Interview protocol}

$\underline{\text { Introductory script }}$

Thank participant

Goal of the study

Outline of interview

Questions about your background and experience

Questions about your mathematical thinking

Questions about your experience with mathematics in school

Informed consent

General questions (Perceived role of mathematics in the participant's life)

- Would you tell me a little about yourself, highlighting whatever is most important to you?

- What about your work history? Would you tell me a little about your work experience - both paid and unpaid work?

- Do you now, or have you in the past, used math in any of your work? In what ways?

- On your survey you wrote that you used math to [...]. Would you tell me a bit more about how you use math in these activities.

- Do you use math in any other parts of your life? In what way?

- What brings you to PCC at this point in your life?

- What classes - if any -- did you taking this past term? What classes do you plan to take Winter term? 
Questions about survey responses (Proportional reasoning abilities)

"I'd like to start asking you about the math problems you completed on the survey. I will also ask you to solve some similar problems. It's important to verbalize anything you are thinking as you approach the problem even if you think it is not important. Also, I am going to ask questions about your responses. My questions do not indicate that you are thinking incorrectly; I am just trying to understand how you are thinking about the problem.

After we finish discussing each problem, I am going to ask you to rate the difficulty of the problem on a scale of 1 to 5 with 5 being the most difficult."

Flower-stem problem follow-up questions

- When showing their reasoning, many students wrote something like:

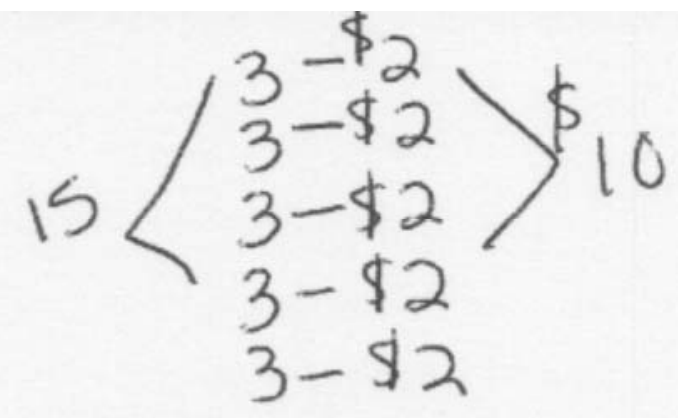

Can you explain what this person did to solve the problem? What do you think of their solution? 
- Other students used a similar strategy:

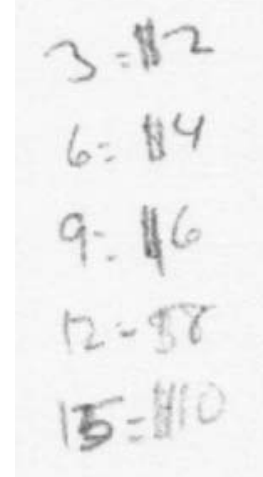

Can you explain what this person did to solve the problem? What do you think of their solution?

- When showing their reasoning, many students wrote something like $15 \div 3=5,5 \times 2=10$.

Can you explain this reasoning? Why divide? Why multiply?

- Rate the difficulty of this problem on a scale of 1 to 5 . Why was this problem easy [difficult] for you?

- Suppose 18 flower stems cost $\$ 15$. How much would you pay for 6 flower stems?

- Suppose 18 flower stems cost $\$ 15$. How much would you pay for 21 flower stems?

- Rate the difficulty of these related problems on a scale of 1 to 5 . Why were these problem easy [difficult] for you?

- Which is the better buy? An 8-ounce stick of deodorant priced at $\$ 4.50$ or a 12-ounce stick priced at $\$ 6.50$ ?

- Rate the difficulty of this problem on a scale of 1 to 5. Why was this problem easy [difficult] for you? 


\section{Percent discount problem follow-up questions}

- Next, we are going to talk about the problem that involved the $40 \%$ off sale. How do you understand the phrase ' $40 \%$ off'?

Possible follow-up question (if a student says something like $40 \%$ is about half off):

"How about the phrase 'an 18\% tax tip? How do you understand"

- Many students solved the problem about the sale price of the jeans showing computations like $0.40 \times 35=14,35-14=21$ and concluding the jeans cost $\$ 21$.

What do you think about this strategy? OR

Would you explain this strategy to me?

Possible follow-up: "Is this a strategy you would use while shopping?"

Possible follow-up (for a student who says that she used a formula): "Could you answer this question another way?"

- Some students solve the jeans problem by reasoning that $10 \%$ of $\$ 35$ is $\$ 3.50$, so $40 \%$ off is $4 \times \$ 3.50=\$ 14$. What's going on here? Have you ever used this strategy? Possible follow-up: "Could you use this strategy to figure out 30\% off a $\$ 150$ coat?"

- Many people estimated that the jeans would cost about $\$ 20$, since $50 \%$ off would be $\$ 17.50$. Do you ever make estimates like this? 
Follow-up: In what situations is an estimate good enough? Can you think of a realistic situation in which an exact answer is necessary?

Possible follow-up: "Suppose you are shopping with a friend's child and you have given him $\$ 20$ to buy a new pair of jeans. How would you help him determine if he has enough money to buy the $\$ 35$ pair of jeans marked $40 \%$ off?"

- Rate the difficulty of this problem on a scale of 1 to 5. Why was this problem easy [difficult] for you?

- "Here's another question that involves percentages. How would you go about answering the question?"

The number of people buying season tickets for Blazer games decreased $40 \%$ from last year's numbers, leaving only 1200 season ticket holders this year. How many season ticket holders were there last year?

- Rate the difficulty of this problem on a scale of 1 to 5. Why was this problem easy [difficult] for you?

\section{Bread flour problem follow-up questions}

- "The next problem we are going to talk about is the bread flour problem. First tell me about how you thought about the problem."

- Rate the difficulty of this problem on a scale of 1 to 5. Why was this problem easy [difficult] for you? 
- What other situations outside school would lead to computations like the ones you performed [or perhaps another student performed] on the bread flour problem?

- We are going to consider some variations of the Bread Flour problem:

The cook needs 80 pounds of flour for the 50 people who are coming to the camp for 4 weeks. How much flour will he need if 250 people show up instead?

The cook needs 80 pounds of flour for the 50 people who are coming to the camp for 4 weeks. How much flour will he need if 50 people come to the camp for only 2 weeks?

\section{The cook needs 80 pounds of flour for the 50 people who are coming to the} camp for $\mathbf{4}$ weeks. How much flour will he need if $\mathbf{1 5 0}$ people show up for $\mathbf{2}$ weeks?

- Rate the difficulty of these related problems on a scale of 1 to 5 . Why were these problem easy [difficult] for you?

Comparing speeds problem follow-up questions

"Before we talk about the problem involving Victor and Sharon, I'd like to ask a similar question:"

- Who is the faster jogger? A women who runs 2 miles in 25 minutes or her partner who runs 3 miles in 39 minutes?

- Some students concluded that Victor and Sharon arrived at the same time using one of two arguments that involve division.

Argument 1: $8 / 10=0.8$ and $20 / 25=0.8$

Argument 2: $10 / 8=1.2$ and $25 / 20=1.2$

What do you think of these arguments? 
Possible follow-up: What do these numbers mean?

- Rate the difficulty of this problem on a scale of 1 to 5. Why was this problem easy [difficult] for you?

- Here's another problem about moving vehicles: A person travels 125 miles in $2 \frac{1}{2}$ hours at a constant speed, how far does she travel in $1 / 2$ hour?

- Rate the difficulty of this problem on a scale of 1 to 5. Why was this problem easy [difficult] for you?

Follow-up questions (Interaction of the participant's mathematics with school mathematics)

- Tell me a little bit about your previous experience with math in school.

- Do you remember the first problem you saw on the mathematics placement exam? Do you remember how it made you feel? What else do you recall about the placement exam?

- What are you expecting from MTH 20 this term? 


\section{Appendix C: Mathematical tasks from the survey and interview}

\section{Survey tasks}

The Flower Stem problem

Valentine's Day is approaching, and you want to buy flowers for someone special. Three flower stems cost \$2. How much will 15 stems cost?

The Percent Discount problem

Fred Meyer is having a sale. A \$35 pair of jeans is marked $40 \%$ off. Can you buy the jeans for $\$ 20$ or less? How do you know?

The Bread Flour problem

A cook is planning for a group of 50 people who will spend 28 days at a summer camp. He needs to buy enough flour for baking bread and the cook knows that the average consumption of flour is 4 pounds per week for 10 persons. How much flour does he need to buy?

The Comparing Speed problem

Victor's van travels at a rate of 8 miles every 10 minutes. Sharon's sedan travels at a rate of 20 miles every 25 minutes. If both cars start at the same time, will Sharon's sedan reach point A, 8 miles away, before, at the same time, or after Victor's van? Explain your reasoning.

\section{Interview tasks}

The first variation of the Flower Stem problem

Suppose 18 flower stems cost \$15. How much would you pay for 6 flower stems?

The second variation of the Flower Stem problem

Suppose 18 flower stems cost \$15. How much would you pay for 21 flower stems?

The Better Buy problem

Which is the better buy? An 8-ounce stick of deodorant priced at \$4.50 or a 12-ounce stick priced at $\$ 6.50$ ?

The Ticket Sales problem

The number of people buying season tickets for Blazer games decreased $40 \%$ from last year's numbers, leaving only 1200 season ticket holders this year. How many season ticket holders were there last year?

The first variation of the Bread Flour problem

The cook needs 80 pounds of flour for the 50 people who are coming to the camp for 4 weeks. How much flour will he need if $\mathbf{2 5 0}$ people show up instead? 
The second variation of the Bread Flour problem

The cook needs 80 pounds of flour for the 50 people who are coming to the camp for 4 weeks. How much flour will he need if 50 people come to the camp for only 2 weeks?

The third variation of the Bread Flour problem

The cook needs 80 pounds of flour for the 50 people who are coming to the camp for 4 weeks. How much flour will he need if $\mathbf{1 5 0}$ people show up for $\mathbf{2}$ weeks?

The Two Joggers problem

Who is the faster jogger? A women who runs 2 miles in 25 minutes or her partner who runs 3 miles in 39 minutes?

The Speed as Proportional Reasoning problem

A person travels 125 miles in $2 \frac{1}{2}$ hours at a constant speed, how far does she travel in $1 / 2$ hour? 


\section{Appendix D: Preliminary findings from the survey data}

\section{General comments/observations}

- 340 surveys were collected in 13 sections of Basic Math across the PCC district ( $21 \%$ of the sections offered); 128 of these 340 surveys (about $38 \%$ ) included responses to all four mathematics problems.

- The large sample provides an opportunity to conjecture ways of reasoning that lead to a particular result, since it is usually the case that at least one student provided enough written work to suggest what the student was thinking. However I recognize that it does not follow that all students who arrived at a particular response were reasoning the same way about the problem. For example, three students responded that 15 flower stems (at $\$ 2$ for three stems) would cost $\$ 6$. Examining these three students' work showed that each student arrived at $\$ 6$ in a different way.

- There are frequent computation errors that may mask viable thinking about the problem. In cases where students provided their reasoning on a problem, incorrect answers due to computation errors were separated from strategies that did not lead to a reasonable result.

- The number of students who attempted to set up a proportion, cross multiply and divide on a given problem was small: flower stem problem, 2; percent discount problem, 7; bread flour problem, 0 ; and comparing speeds problem, 0 .

\section{Flower stem problem}

Valentine's Day is approaching, and you want to buy flowers for someone special. Three

flower stems cost \$2. How much will 15 stems cost?

Steps in on-going analysis

1. Separate surveys with no response to this problem from surveys with an incorrect response from surveys with a correct response.

Blank: $8(2 \%) \quad$ Incorrect: $119(35 \%)$ Correct: $213(63 \%)$

2. Sort incorrect responses into categories, recording observations, queries, conjectures and possible interview questions as I sorted.

3. Sort correct responses into categories, recording observations, queries, conjectures and possible interview questions as I sorted.

4. Merge categories of correct and incorrect strategies in terms of similar features for the purposes of this summary. 


\section{Preliminary findings}

- Unit price strategy: Eight students used an incorrect unit price strategy, computing a unit price of $\$ 1.50$ per stem. Two more students used a unit cost of $\$ 6$ per stem. No student used an estimate of $\$ 0.67$ per stem or an exact unit price of $\$ 2 / 3$ per stem. However, about 80 students multiplied 15 stems by $\$ 2$ (per stem?), perhaps misreading the problem (see Using only two of the three quantities).

- No reasoning provided: No reasoning was provided for 61 of the correct solutions ( $29 \%$ of the correct responses).

- Set up a proportion, cross-multiply and divide: Only 2 students used this strategy to determine that the cost of 15 stems would be $\$ 10$.

- Building up strategies: 36 students (17\% of correct responses) justified $\$ 10$ for 15 stems using one of three representations:

\begin{tabular}{|c|c|}
\hline Example of representation & Number of cases \\
\hline $\begin{array}{l}\text { Iterated composed unit (ratio) } \\
\begin{array}{ccccc}3 & 3 & 3 & 3 & 3 \\
2 & 2 & 2 & 2 & 2\end{array}\end{array}$ & 24 \\
\hline $\begin{array}{l}\text { Building up from a composed unit } \\
\qquad \begin{array}{cccccc}3 & 6 & 9 & 12 & 15 \\
2 & 4 & 6 & 8 & 10\end{array}\end{array}$ & 7 \\
\hline \begin{tabular}{rrrrr}
\multicolumn{6}{|c}{ Hybrid } \\
3 & 6 & 9 & 12 & 15 \\
2 & 2 & 2 & 2 & 2
\end{tabular} & 5 \\
\hline
\end{tabular}

It is unclear to me whether students are reasoning using these representations or whether these representations are an attempt to communicate thinking (for example, demonstrating how they know there are five groups of three in 15). It is not possible to know from these responses whether the students are reasoning multiplicatively, that is, if I purchase five times as many flower stems, the cost increases by a factor of 5 as well. Some of the proposed interview questions attempt to uncover these distinctions.

- Strategies that may be based on scalar reasoning: An example of reasoning multiplicatively might be suggested by a response such as, "if I purchase five times as many flower stems, the cost increases by a factor of 5 as well." However, no 
students provided such an explanation (not surprisingly). Several representations included multiplication:

\begin{tabular}{|c|c|l|}
\hline $\begin{array}{c}\text { Example of } \\
\text { representation }\end{array}$ & $\begin{array}{c}\text { Number } \\
\text { of cases }\end{array}$ & \multicolumn{1}{|c|}{ Comment/questions } \\
\hline $15 \div 3=5,5 \times 2=10$ & 64 & $\begin{array}{l}\text { This is a computation that leads to a } \\
\text { correct response, but does it indicate } \\
\text { proportional reasoning. For example, } \\
\text { is the covariation between the number } \\
\text { of flower stems and the cost evident? }\end{array}$ \\
\hline $3 \times 5=15,2 \times 5=10$ & 35 & $\begin{array}{l}\text { Is this any different from the } \\
\text { representation above? Both quantities } \\
\text { are increased by a factor of 5. }\end{array}$ \\
\hline $5 \times 2=10$ & 5 & $\begin{array}{l}\text { An abbreviation of the previous } \\
\text { representations? }\end{array}$ \\
\hline "multiply them both by 5" & 4 & $\begin{array}{l}\text { I guess a follow-up question might be, } \\
\text { "why?" }\end{array}$ \\
\hline
\end{tabular}

- Using only two of the three quantities: 84 students (25\%) used only two of the three quantities (the 15 stems and the two quantities in the rate $\$ 2$ for 3 stems).

Most of these (81) concluded the cost of 15 stems would be $\$ 30$. There are two possible interpretations: (i) the students assumed that the flowers cost $\$ 2$ per stem, and (ii) the student just multiplied the two numerals in the problem (three was written out), but this interpretation begs the question, "Why multiply?" One student divided 15 by 2 and concluded the cost would be $\$ 7.50$. Two students multiplied 15 by 3 .

- Possible computation error: The written solutions of 14 students (about $12 \%$ of the incorrect responses) suggest that a student may have been reasoning towards a reasonable solution but made a computational error along the way. However, there was not enough evidence to conclude a reasonable strategy was undertaken.

\section{$\underline{\text { Potential flower stem problem follow-up questions for interview }}$}

- Show an iterated composed unit representation and ask, "What do you think is going on here?"

Rationale: Query whether the student recognizes that the quantities in each set (flower stems, money) covary.

Possible follow-up: Is there another way you might think about this problem? Possible follow up: Safeway sells one dozen roses for $\$ 10$. How much would a partyplanner pay for four dozen roses? 
Rationale: Do students who reason by iterating a composed unit recognize that 15 is 5 times 3 flower stems, so the cost must be 5 times \$2? (Is the factor of four more evident in the roses question?)

- Show the $15 \div 3=5,5 \times 2=10$ representation to someone who used an iterated unit representation and ask, "What do you think is going on here? Why divide? Why multiply?"

- "Suppose 18 flower stems cost $\$ 15$. How much would you pay for 6 flower stems?"

Rationale: It is possible that students who showed what appeared to be an iterated composed unit strategy may not have been reasoning using the composed unit, 3 flowers stems for $\$ 2$, but rather trying to communicate how they know that there are five groups of three in 15. This question attempts to tease out this distinction. A response such as, “The flowers would cost a third of $\$ 15$ or $\$ 5$ ?" suggests that this student may be reasoning multiplicatively.

Possible follow-up: "Suppose 18 flower stems cost $\$ 15$. How much would you pay for 21 flower stems?"

Rationale: On the survey, 15 is a multiple of 5 . In this case, 21 is not a multiple of 18. In addition, 3 flower stems cost $\$ 2.50$. I expect this may lead to computational errors, but I am interested in how students reason through this situation.

\section{Percent discount problem}

Fred Meyer is having a sale. A $\$ 35$ pair of jeans is marked $40 \%$ off. Can you buy the jeans for $\$ 20$ or less? How do you know?

$\underline{\text { Steps in on-going analysis }}$

1. I was unable to separate surveys with no response to this problem from surveys with an incorrect response from surveys with a correct response as I did with the flower stem problem. A 'correct' response to this question is, "No, because the jeans cost $\$ 21$." However, many students made a reasonable estimate for $40 \%$ off and concluded that they either had enough to buy the jeans or not. Instead, I first separated the surveys into three categories:

Not completed ${ }^{61}: 80(24 \%)$

Include claim that jeans cost $\$ 21: 80(24 \%)$

Other: $181(52 \%)^{62}$

2. Sort responses that included the claim that the jeans cost $\$ 21$ into categories, recording observations, queries, conjectures and possible interview questions as I sorted.

\footnotetext{
${ }^{61}$ I include in this category "I don't know" responses, "I don't remember the formula" and responses that showed a student had only rewritten information from the original problem (e.g., $\$ 35-40 \%$ ).

${ }^{62}$ There is a miscount here. The total here is 341 .
} 
3. Sort the other responses into categories, recording observations, queries, conjectures and possible interview questions as I sorted.

4. Merge categories in terms of similar features for the purposes of this summary.

$\underline{\text { Preliminary findings }}$

- Determining the jeans cost \$21 exactly: 80 students computed that the jeans cost $\$ 21$ exactly (24\% of sample); 36 of these solutions (45\%) were accompanied by an explanation that showed the student had computed $0.40 \times 35$. No student referenced a formula here, but these solutions do suggest that people know how to compute the amount of a percent discount in this way. These 80 solutions are categorized by how the student represented his or her reasoning:

\begin{tabular}{|c|c|}
\hline Example of representation & Number of cases \\
\hline $\begin{array}{c}\text { No reasoning given } \\
\text { off with no record of how this was } \\
\text { determined }\end{array}$ & 5 \\
\hline $\begin{array}{c}\text { \$14 off } \\
0.40 \times 35=14,35-14=21\end{array}$ & 36 \\
\hline $0.60 \times 35=21$ & 1 \\
\hline Some evidence of setting up a proportion & 4 \\
\hline Alternate strategies (see below) & 18 \\
\hline
\end{tabular}

There were three types of alternate strategies:

\begin{tabular}{|c|c|}
\hline Example of strategy & Number of cases \\
\hline $\begin{array}{c}\text { Reasoning with } 10 \%: 10 \% \text { off } \$ 35 \text { is } \$ 3.50 \text { and } 40 \% \text { off is } \\
\$ 3.50 \times 4=\$ 14\end{array}$ & 7 \\
\hline Reasoning with $50 \%$ and $10 \%$ & 8 \\
\hline $\begin{array}{c}\text { Reasoning with a rate: } \\
\$ 0.40 \text { off every dollar or } \$ 4 \text { off every } \$ 10 .\end{array}$ & 3 \\
\hline
\end{tabular}

The number of alternate strategies is small $(5 \%$ of the sample, but $23 \%$ of the solutions that indicated that the jeans cost $\$ 21)$. The second strategy shows a student understands percent, but there is no evidence of proportional reasoning.

Multiplicative reasoning appears to be emphasized in the first strategy and covariational reasoning in the third strategy. There seems to be value in asking students to reflect in the first strategy, but I am not sure about the third (at least in this context).

- Estimate based on 50\% off: 82 students (24\% of the sample) provided a reasonable estimate that the jeans cost about $\$ 20$, which is true. I find this an interesting finding and I propose below several follow-up questions from this finding for the interview. The just say "no" and just say "yes" categories below may be grounded on estimates as well.

${ }^{63}$ Two of these cases are questionable; there is not a complete record of the student's thinking. 
- Just say "no": 15 students responded "no."

- Just say "yes": 32 students responded "yes"

- Random procedures: There was more evidence of throwing procedures at the percent discount problem than at the flower stem problem. 10 responses were easily categorized this way (although I would not claim that some partial or mysterious responses do not belong here). Examples of random procedures are setting up a proportion of some sort, cross-multiplying and dividing; dividing 35 by 0.40 ; multiplying 35 by 0.040 ; or subtracting 0.40 from 35 .

- Reasoning with a rate like $\mathbf{\$ 0 . 4 0}$ off every dollar: It was noted above that three students used a rate to determine the jeans cost $\$ 21$. However, 3 more students attempted the problem using a rate. This is a small number, but I wonder how many students have this understanding of $40 \%$ off. (I should have asked; I can ask in the interview, but I do not know what I could claim from students' responses.)

Potential percent discount problem follow-up questions for interview

- "How do you understand the phrase " $40 \%$ off"?

Rationale: Do people understand ' $40 \%$ off' as $\$ 0.40$ off every dollar, as $\$ 4$ off every $10 \%$, or as $\$ 40$ off every $\$ 100$ ?

Possible follow-up question (if a student says $40 \%$ is about half off): "How about the phrase $15 \%$ off?"

- "Many students solved the problem about the sale price of the jeans showing computations like $0.40 \times 35=14,35-14=21$ and concluding the jeans cost $\$ 21$. What do you think about this strategy?"

Rationale: No students who performed this computation referenced a formula. However, several students claimed, "I do not recall the formula." If students are using a formula, what does this formula mean to them? Do any students have a functional understanding of the covariation (Vergnaud) here, which is what the formula $A=R B$ assumes? (I do not expect this is the case.) Will students tell me that this is the way they'd solve the problem in school, but that they would use another strategy while shopping?

Possible follow-up (for a student who says that she used a formula): "Could you answer this question another way?"

- "Some students solve the jeans problem by reasoning that $10 \%$ of $\$ 35$ is $\$ 3.50$, so $40 \%$ off is $4 \times \$ 3.50=\$ 14$. What's going on here? What do you think of this strategy?" 
Rationale: Is this an informal strategy that makes sense to people? Would someone use this informal strategy outside school?

Possible follow-up: "Could you use this strategy to figure out 30\% off a \$150 coat?"

Rationale: Teasing out a possible distinction between understanding a strategy and using it...

- "You estimated that the jeans would cost about \$20. Do you often make estimates like this? In what situations is an estimate good enough? Can you think of a realistic situation in which an exact answer is necessary?"

Rationale: These questions attempt to uncover when people rely on estimate and why. The next follow-up question attempt to uncover whether a student who relies on reasonable estimates can indeed determine that the jeans cost $\$ 21$ exactly (it is here that proportional reasoning may reside).

Possible follow-up: "Suppose you are shopping with a nephew and you have given him $\$ 20$ to buy a new pair of jeans. How would you help him determine if he has enough money to buy the $\$ 35$ pair of jeans marked $40 \%$ off?"

- "Here's another question that involves percentages. How would you go about answering the question?"

The number of people buying season tickets for Blazer games decreased $40 \%$ from last year's numbers, leaving only 1200 season ticket holders this year. How many season ticket holders were there last year?

Rationale: This problem could be solved informally using an understanding of percentages and a scalar strategy: $60 \%$ of the number of ticket holders last year is 1200 season ticket holders, so $10 \%$ is 200 and $100 \%$ (last year's numbers) is 2000 season ticket holders. However, I expect that students who rely on a formula may be confused about whether to "multiply or divide" here. Would this question only be appropriate for a student who used a $10 \%$ strategy on the percent discount problem?

\section{Bread flour problem}

A cook is planning for a group of 50 people who will spend 28 days at a summer camp. He needs to buy enough flour for baking bread and the cook knows that the average consumption of flour is 4 pounds per week for 10 persons. How much flour does he need to buy? 


\section{Steps in on-going analysis}

1. Separate surveys with no response to this problem from surveys with an incomplete response ( $20 \mathrm{lb}$ for 50 people for one week or $16 \mathrm{lb}$ for 10 people for 4 weeks) from surveys with a correct response from other responses.

[I do not have a record of the subtotals for each category. However, I did compute that $37 \%$ of the students in the sample arrived at a correct solution.]

2. Sort incomplete responses into categories, recording observations, queries, conjectures and possible interview questions as I sorted.

3. Sort correct responses into categories, recording observations, queries, conjectures and possible interview questions as I sorted.

4. Examine the other responses. Many responses fell into one of the categories above upon further examination (due to arithmetic errors largely).

5. Merge categories of incomplete, correct and incorrect strategies in terms of similar features for the purposes of this summary.

\section{$\underline{\text { Preliminary findings }}$}

- Arithmetic errors: There were many arithmetic errors on this problem, errors that concealed good reasoning (difficulties with $16 \times 5$ and even $20 \times 4$ ). Also, some students reasoned with three or five weeks in 28 days rather than 4 weeks.

- Iterating a composed unit (ratio): Several students represented their thinking by iterating a composed unit although I did not record the number of solutions that included this representation. I made this choice because of my previous conjecture that this representation might be more about communication than how a student reasons. Also, this problem requires a double iterated composed unit and only one student attempted to illustrate this.

- Incomplete strategies: There were two incomplete strategies. This first led to the conclusion that the cook needs $20 \mathrm{lbs}$ of flour; the second to the conclusion the cook needs $16 \mathrm{lbs}$ of flour. In both cases, the student only varied one of the quantities: 20 lbs of flour are needed for one week for 50 people an $16 \mathrm{lbs}$ of flour are required for 10 people for 4 weeks.

$$
\begin{array}{|l|l}
\hline \text { Strategy leading to } 20 \mathrm{lb}: 41 & \text { Strategy leading to } 16 \mathrm{lb}: 16
\end{array}
$$




\begin{tabular}{|c|c|}
\hline Variations of $20 \mathrm{lb}$ solution & Variations of $16 \mathrm{lb}$ solution \\
\hline $20 \mathrm{lb}$ per person $\times 28$ days $=560 \mathrm{lb}: 5$ & $\begin{aligned} 160 \mathrm{lb}: & 3 \\
& (\text { Sample: } 4 \mathrm{lb} \times 4 \text { weeks }=16 \mathrm{lb} 16 \\
& \mathrm{lb} \times 10 \text { people }=180 \mathrm{lb})\end{aligned}$ \\
\hline \begin{tabular}{|l}
200 lb: 14 \\
(It is difficult to interpret these \\
solutions)
\end{tabular} & $\begin{aligned} 16 \times 4= & 64 \text { lb: } 4 \\
& (\text { Too many fours in the problem?) }\end{aligned}$ \\
\hline $200 \mathrm{lb} \times \times 28$ days $=5600 \mathrm{lb}: 4$ & $\begin{aligned} 800 \mathrm{lb}: & 10 \\
& \text { (It is possible that the student } \\
& \text { understood that } 4 \mathrm{lb} \text { per week per } \\
& \text { person are needed. One of these } \\
& \text { responses included the following } \\
& \text { computations: } \\
& 4 \times 4=16,16 \times 10=160 \\
& 160 \times 5=800 .)\end{aligned}$ \\
\hline & \begin{tabular}{|c} 
Other responses build on $16 \mathrm{lb}: 5$ \\
$\begin{array}{c}\text { (These are difficult to } \\
\text { summarize.) }\end{array}$
\end{tabular} \\
\hline
\end{tabular}

- Correct conclusions: These 127 responses were sorted into the following categories:

No reasoning provided: 12

Difficult to decipher reasoning: 3

$20 \mathrm{lb}$ per week for 50 people $\times 4$ weeks: 100

$16 \mathrm{lb}$ for 10 people for 4 weeks $\times 5$ groups of 10 people: 12

I am not certain why the $20 \times 4$ strategy is more prevalent than the $16 \times 5$ strategy, although the sequence of computations for the $20 \times 4$ strategy may be more aligned with the order quantities were presented in the problem statement.

I am impressed that more than one-third of the students in the sample were able to reason to a solution to this problem. Although multiple proportions (Vergnaud's language) is not an explicit topic in the curriculum of the Basic Math course, a significant fraction of students were able to reason through this problem in this context. This problem may present a segue into the topic of joint variation; however, do students understand that the amount of flour required varies jointly with the number of people at the camp and the duration of their stay. I also wonder the extent to which an understanding of joint variation depends on moving from scalar to functional reasoning about proportional situations. Schliemann and Carraher claim that outside of school people rarely reason with unit rates (a functional approach) and there is little evidence of this reasoning on the survey (however, the problems did not 
lend themselves to this strategy). These musings lead to several questions/ideas I might consider when thinking about potential follow-up questions:

a. How far do I want to pursue multiple proportions or joint variation in this study? What would be gained?

b. Exploring the extent of students' ability to reason functionally (using a unit rate) is better done in the context of a simple proportion.

c. On pilots of the survey, I had a problem that queried students' understanding of how the area of a rectangle varied with its dimensions. Far fewer students were successful with this problem. No particular numbers were given in area problem and although an amount of flour is a continuous quantity, we often think about flour in discrete units like 2 cups. Is it worth teasing out the differences between students' abilities to reason with discrete versus continuous quantities like length? There is a tendency to take recourse to additive reasoning when reasoning about a photo enlargement problem, for example. Are there stretching and shrinking problems that involve discrete quantities? (For example, querying which of two cities "grew more" if the populations increase by the same number of people, but started with different number of people.)

- Unit rate strategies: A small number of responses (4) appeared to be attempts to find the amount of flour required for 1 person and then multiplying this result by 50 .

- Random strategies: Random strategies consisted of multiplying pairs (or triples) of quantities in the problem, adding and subtracting quantities. A few strategies that were difficult to interpret seemed to indicate that a student may have confused the role of the two quantities of 4 . About 21 responses fell into this category.

\section{$\underline{\text { Potential bread flour problem follow-up questions for interview }}$}

- [Question for a student who provided one of two incomplete strategies, based on asking the student to compare her solution to an example of an incomplete solution of the other type.]

"Here is your solution to the bread flour problem and here is another solution that someone came up with. What do you notice?"

Rationale: The tendency to vary only one of the quantities may be an oversight or it may be due to the students' lack of experience with situations that involve joint variation. Asking a student to consider the other incomplete strategy may be one way to uncover this difference.

- "What other situations outside school would lead to computations like the ones you performed [or perhaps another student performed] on the bread flour problem? 
Rationale: This question queries whether the student will make explicit that the amount of flour the cook needs to purchase depends both on the number of people coming to the camp and the duration of their stay. However, the phrase other situations may be too ambiguous to generate much data.

- [Provide the student with a copy of a variation of bread flour and a problem that queries how the square footage of a building with a rectangular footprint varies when each dimension is doubled.]

Variation of bread flour problem: The cook needs 80 pounds of flour for the 50 people who are coming to the camp for 4 weeks. How much flour will he need if 100 people show up and stay for 8 weeks?

Building problem: A manufacturing firm was having difficulty obtaining a permit for the building with a rectangular footprint. The manufacturer settled on a building that was smaller than originally planned. However, the permit came through and the manufacturer is able to double each dimension of the building. How will the square footage of the building change?

"How is the building problem the same and different from the new bread flour problem?"

Rationale: The rationale for this problem is similar to the rationale provided about, although this questions also queries whether or not the non-specified continuous quantities in the building are problematic as they were on a pilot version of the survey that also included the bread flour problem. However, I may be attempting a "teaching experiment" here rather than trying to uncover what the student understands about joint variation when I suggest a structural similarity between the two problems.

Possible follow-up: "Would you like to try to solve one or both of these problems?"

\section{Comparing speed problem}

Victor's van travels at a rate of 8 miles every 10 minutes. Sharon's sedan travels at a rate of 20 miles every 25 minutes.

If both cars start at the same time, will Sharon's sedan reach point A, 8 miles away, before, at the same time, or after Victor's van? Explain your reasoning.

If both cars start at the same time, will Sharon's sedan reach point B (at a distance further down the road) before, at the same time, or after Victor's van? Explain your reasoning.

This problem is a released item from the NAEP exam. The item was used with students in $8^{\text {th }}$ grade. However, I did not know until after the survey was piloted that released 
NAEP items are frequently items have been discarded for some reason. In addition, it was not until survey data were being collected that it was pointed out to me that it is not entirely clear that the cars started at the same place; there was an illustration that accompanied the NAEP item that I chose not to include, which may have suggested to students taking the NAEP exam that the cars started at the same place. For these reasons, the current analysis is limited.

$\underline{\text { Steps in on-going analysis }}$

1. Sort solutions according to the categories used to report the results of this problem from the NAEP exam. A partially correct solution is a correct conclusion on both questions with no explanation or a correct explanation on one question with an explanation.

NAEP results

Blank: $8 \%$

Incorrect: $65 \%$

Partial: $11 \%$

Correct: $14 \%$

Off task: $2 \%$

$\underline{\text { Survey results }}$

Blank: 53\%

Incorrect: $36 \%$

Partial: 6\%

Correct: $5 \%$

2. Sort correct responses into categories, recording observations, queries, conjectures and possible interview questions as I sorted.

3. Sort partially correct responses into categories, recording observations, queries, conjectures and possible interview questions as I sorted.

4. Sort incorrect responses into categories, recording observations, queries, conjectures and possible interview questions as I sorted.

[I chose to sort responses in this order because I thought that by examining strategies used by students who reasoned to a correct or partially correct response I might see more examples of viable reasoning in some of the incorrect responses.]

5. Merge categories of correct and incorrect strategies in terms of similar features for the purposes of this summary.

Preliminary findings

- Comparison to NAEP findings: PCC students did not fare as well as $8^{\text {th }}$ grade students on this problem. I am not sure what this tells us. It is possible that students experienced this problem as more 'school-like' than the other problems (the alliteration of both Sharon's sedan and Victor's van may have indicated that this is a school problem). Also, there appeared to be more strategies that relied on poorly recalled school strategies (e.g., attempting to use $D=R T$, setting up linear functions that represent each car). A colleague suggested that problems about traveling cars and trains freak people out. A best buy problem might get at similar ways of 
reasoning. Also, I would not report the NAEP categories above unless I resorted the surveys (perhaps with someone else).

- Robust ways of reasoning: The number of surveys that included students' thinking about this problem is small. However, there are a variety of ways of reasoning about the problem, which suggest several possible ways of thinking to explore but perhaps in a different context. (Only $9 \%$ of the students in the sample reasoned by comparing ratios.)

- Building up Victor's ratio: One category of response indicated that a student built up Victor's ratio (8 miles in 10 minutes) in order to compare it to Sharon's ratio (20 miles in 25 minutes).

11 of the 17 correct responses suggest this way of thinking 2 of the 20 partially correct responses suggest this way of thinking

- Breaking down Sharon's ratio: A smaller category of responses indicated that a student broke down Sharon's ratio into 4 miles every 5 minutes and then built this back up to conclude that Sharon also traveled 8 miles in 10 minutes.

1 of the 17 correct responses suggest this way of thinking

2 of the 20 partially correct responses suggest this way of thinking ${ }^{64}$

- Building up or breaking down: 13 of 25 of the incorrect strategies that I classified as incomplete suggest this way of thinking [I have not sorted these by building up or breaking down, but I may still do so].

- Comparing ratios: A common strategy is to compare ratios either as unit rates (although the rates were frequently not interpreted or misinterpreted) or by building up both ratios to show they are equivalent to 40/50 or broken down to show both were equivalent to $8 / 10$. These strategies were typically decontextualized. However, four students' responses indicated that the two vehicles arrived at the same time because both were traveling at $48 \mathrm{mph}$. One of these was classified as correct because this was the reason provided for why the two cars arrive at the same time; however, the student did not indicate how s/he determined this rate. The other three occurrences occurred in responses that were classified as incomplete because this viable strategy was not taken to a point where the student might make a reasonable claim.

5 of the 17 correct solutions used a comparing ratio strategy 6 of the 20 partially correct solutions used a comparing ratio strategy 9 of the 25 incomplete strategies were attempts to compare the two ratios

${ }^{64}$ There are conflicting annotations in my notebook about two of the partially correct solutions. One claims these students used a building up; the other claims a breaking down strategy. I'll check which is the case. 
- Incomplete strategies: When I attempted to categorize the 123 incorrect solutions, I identified 25 as incomplete because each of these showed some evidence of one of the strategies that would lead to a reasonable conclusion about the two vehicles.

Potential comparing speeds problem follow-up questions for interview

- "Some students concluded that Victor and Sharon arrived at the same time using one of two arguments that involve division.

Argument 1: $8 / 10=0.8$ and $20 / 25=0.8$

Argument 2: $10 / 8=1.2$ and $25 / 20=1.2$

What do you think of these arguments?"

Possible follow-up: What do these numbers mean?

Rationale: Some students used these arguments but either misinterpreted or did not interpret the meanings of these ratios in the context. This question queries whether these ratios have meaning for the students, as well as whether these particular unit rates have meanings that are challenging to construct.

Possible follow-up for students unsure of the meaning: "Some students noticed that Sharon travels 4 miles in 5 minutes. What do you think about this?

[If a student recognizing breaking down the ratio] "How might you figure out how far Sharon travels in one minute?"

Rationale: Is the meaning of a unit rate more visible if a student has unpacked a breaking down strategy? (Too teaching experiment?)

- "Who is the faster jogger? A women who runs 2 miles in 25 minutes or her partner who runs 3 miles in 39 minutes?"

Rationale: This is a similar context to the NAEP problem, but there are no moving vehicles in this problem. 